Information Strategies for Communicators 


\section{Information Strategies for Communicators}

Kathleen A. Hansen and Nora Paul 


\section{(c) (i)}

Information Strategies for Communicators by Kathleen A. Hansen and Nora Paul is licensed under a Creative Commons Attribution 4.0 International License, except where otherwise noted.

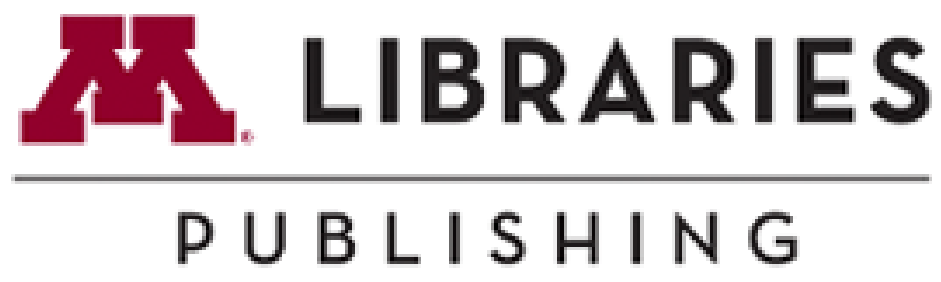

This book was produced using Pressbooks.com, and PDF rendering was done by PrinceXML. 



\section{Contents}

Publisher Information

Lesson 1. Personal / Professional Skills of Successful Communicators

$1.1 \mathrm{EQ}$ vs IQ

1.2 Attributes Employers Desire $\quad 3$

1.3 Team Membership Skills $\quad 4$

$\begin{array}{ll}1.4 \text { Values for Success } & 6\end{array}$

$\begin{array}{lr}1.5 \text { Resources } & 7\end{array}$

Lesson 2. Information Strategy Process and the Needs of Communicators

2.1 Information for Messages $r$

$\begin{array}{ll}2.2 \text { The Information Strategy Process } & 11\end{array}$

$\begin{array}{lr}2.3 \text { Information Tasks of Communication Professionals } & 13\end{array}$

$\begin{array}{lr}2.4 \text { News Messages } & 14\end{array}$

$\begin{array}{lr}2.5 \text { Advertising Messages } & 17\end{array}$

$\begin{array}{ll}2.6 \text { Public Relations Messages } & 20\end{array}$

$\begin{array}{ll}2.7 \text { Storytelling and the Information Strategy } & 24\end{array}$

$\begin{array}{lr}2.8 \text { Resources } & 26\end{array}$

Lesson 3. Question Analysis: From Assignment to Message

3.1 Understanding the Gatekeeper Audience $\quad 29$

$\begin{array}{ll}3.2 \text { Assignment Clarification } & 31\end{array}$

$\begin{array}{ll}3.3 \text { Message Purpose } & 32\end{array}$

$\begin{array}{ll}3.4 \text { Time / Space } & 33\end{array}$

$\begin{array}{lr}3.5 \text { Formats / Channels } & 34\end{array}$

$\begin{array}{ll}3.6 \text { Resources } & 35\end{array}$

Lesson 4. Question Analysis: Who's the Audience?

$\begin{array}{ll}4.1 \text { Types of Audiences } & 37\end{array}$

$\begin{array}{lr}4.2 \text { Gatekeepers } & 39\end{array}$

$\begin{array}{lr}4.3 \text { Colleagues and Professionals } & 40\end{array}$

$\begin{array}{ll}4.4 \text { Target Audience } & 41\end{array}$

4.5 Audience Segments: Demographics $\quad 42$

4.6 Audience Segments: Geographics 43 
4.7 Audience Segments: Psychographics

4.8 Combining Segment Data $\quad 47$

$\begin{array}{lr}4.9 \text { News } & 48\end{array}$

4.10 Advertising $\quad 49$

$\begin{array}{lr}4.11 \text { Public Relations } & 50\end{array}$

$\begin{array}{ll}\text { 4.12 Who's the Audience for News? } & 51\end{array}$

4.13 Who's the Audience for Advertising?

4.14 Who's the Audience for Public Relations?

4.15 Summary / Resources $\quad 54$

Lesson 5. Question Analysis: What's the Topic?

5.1 What's the Angle? $\quad 57$

$\begin{array}{lr}5.2 \text { News Angle } & 58\end{array}$

$\begin{array}{lr}5.3 \text { Strategic Communication Angle } & 59\end{array}$

$\begin{array}{ll}5.4 \text { Key Questions to Answer } & 60\end{array}$

5.5 Idea Generation $\quad 62$

$\begin{array}{ll}5.6 \text { Observation for Idea Generation } & 64\end{array}$

5.7 Types of Observation: Routine $\quad 65$

$\begin{array}{ll}5.8 \text { Types of Observation: Participant } & 66\end{array}$

5.9 Types of Observation: Unobtrusive $\quad 67$

$\begin{array}{ll}5.10 \text { Types of Observation: Social Listening } & 68\end{array}$

$\begin{array}{ll}5.11 \text { Narrowing the Focus } & 69\end{array}$

$\begin{array}{ll}5.12 \text { Conventional Wisdom } & 71\end{array}$

5.13 Conclusion/Endnotes $\quad 72$

Lesson 6. Question Analysis: Who Contributes Information?

6.1 Institutional Sources $\quad 75$

6.2 Public Sector Institutions $\quad 76$

$\begin{array}{ll}6.3 \text { Private Sector Institutions } & 77\end{array}$

$\begin{array}{lr}6.4 \text { Scholarly Sources } & 80\end{array}$

$\begin{array}{lr}6.5 \text { Journalistic Sources } & 84\end{array}$

$\begin{array}{lr}6.6 \text { Informal Sources } & 86\end{array}$

$\begin{array}{lr}\text { 6.7 Disciplines of Knowledge } & 87\end{array}$

6.8 The Library as Contributor $\quad 89$

$\begin{array}{lr}\text { 6.9 Types of Libraries: Public } & 91\end{array}$

6.10 Types of Libraries: Academic $\quad 92$

$\begin{array}{lr}\text { 6.11 Types of Libraries: Special } & 93\end{array}$

6.12 Types of Libraries: Archives $\quad 94$

6.13 Types of Libraries: Media 95

$\begin{array}{lr}\text { 6.14 The Library in the Process } & 96\end{array}$ 
Lesson 7. Question Analysis: What are the Ethical and Legal Considerations?

7.1 Social Responsibility

7.2 Analyzing Ethical and Legal Considerations - Overview

7.3 Obligations in News

7.4 Obligations in Advertising

103

7.5 Obligations in Public Relations

105

7.6 Levels of Social Responsibility

107

7.7 The Societal Perspective

108

7.8 Professional and Organizational Perspective - Journalism 111

7.9 Professional and Organizational Perspective - Advertising 112

7.10 Professional and Organizational Perspective - Public Relations 114

$\begin{array}{ll}7.11 \text { Individual Perspective } & 115\end{array}$

$\begin{array}{ll}7.12 \text { Legal Considerations - Journalism } & 116\end{array}$

$\begin{array}{ll}7.13 \text { Legal Considerations - Advertising } & 117\end{array}$

$\begin{array}{lr}\text { 7.14 Legal Considerations - Public Relations } & 118\end{array}$

7.15 Social Responsibility and the Information Strategy 119

$\begin{array}{lr}7.16 \text { Endnotes / Resources } & 120\end{array}$

Lesson 8. Research Skill: Searching

8.1 Getting Started on Your Information Strategy 122

8.2 One-step / Two-step Research 125

$\begin{array}{ll}\text { 8.3 One-step Research Tools } & 126\end{array}$

$\begin{array}{lr}\text { 8.4 Two-step Research Tools } & 128\end{array}$

$\begin{array}{lr}\text { 8.5 Basics of Searching on the Web } & 129\end{array}$

$\begin{array}{ll}\text { 8.6 The Deep Web } & 131\end{array}$

8.7 The "Disappeared" Web 132

$\begin{array}{ll}\text { 8.8 Key Words and Subject Headings } & 133\end{array}$

8.9 Search Logic and Boolean Connectors $\quad 135$

$\begin{array}{ll}\text { 8.10 Searching Fields } & 137\end{array}$

8.11 Contributors of Information and Database Searching 139

$\begin{array}{ll}\text { 8.12 Tracking Your Search } & 141\end{array}$

$\begin{array}{lr}8.13 \text { Resources/Endnotes } & 142\end{array}$

Lesson 9. Research Skill: Interviewing

$\begin{array}{ll}9.1 \text { Interviewing as a Research Skill } & 144\end{array}$

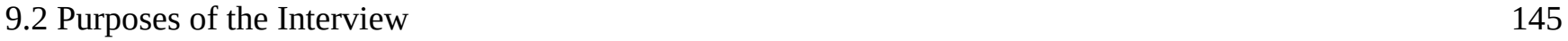

$\begin{array}{ll}9.3 \text { Purposes / Information Gathering } & 146\end{array}$

$\begin{array}{ll}9.4 \text { Human Interest } & 147\end{array}$

$\begin{array}{lr}9.5 \text { Corroborative } & 148\end{array}$ 
$\begin{array}{lr}9.7 \text { Opinion Seeking } & 150\end{array}$

$\begin{array}{lr}\text { 9.8 Methods: Face-to-Face } & 151\end{array}$

9.9 Methods: Telephone 152

9.10 Methods: Digital 153

$\begin{array}{ll}\text { 9.11 Methods: Focus Group } & 154\end{array}$

9.12 Methods: News Conference 156

$\begin{array}{ll}9.13 \text { Preparing for an Interview } & 157\end{array}$

9.14 Information Contributors as Interviewees 159

9.15 Public Sector Contributors $\quad 160$

9.16 Private Sector Contributors 164

$\begin{array}{lr}9.17 \text { Scholarly Contributors } & 166\end{array}$

9.18 Journalist Contributors 172

9.19 Informal Contributors 173

$\begin{array}{lr}9.20 \text { Evaluating Interviewees } & 176\end{array}$

9.21 Planning Interviews $\quad 177$

\begin{tabular}{lr}
9.22 & Interview Questions \\
\hline
\end{tabular}

9.23 Contract with the Interviewee $\quad 181$

$\begin{array}{ll}9.24 \text { Recording the Interview } & 184\end{array}$

9.25 Some Interviewing Cautions 185

Lesson 10. Research Skill: Evaluating Information

10.1 Thinking Critically about Information 188

$\begin{array}{ll}10.2 \text { Tests of Evidence } & 190\end{array}$

10.3 Evaluating Observations 194

10.4 Evaluating Visual Information 196

$\begin{array}{lr}10.5 \text { Evaluating Websites } & 200\end{array}$

10.6 Stop that Rumor $\quad 202$

10.7 Evaluating Information Subsidies 203

$\begin{array}{lr}10.8 \text { Endnotes/Resources } & 205\end{array}$

Lesson 11. Research Skill: Managing and Synthesizing Information

11.1 Synthesizing the Information 208

11.2 What Have You Found? 209

$\begin{array}{ll}11.3 \text { Finding the Focus } & 210\end{array}$

11.4 Fitting Things Together $\quad 213$

$\begin{array}{ll}\text { 11.5 What Synthesis Helps You Do } & 215\end{array}$

$\begin{array}{ll}11.6 \text { Examples of Synthesis } & 216\end{array}$

$\begin{array}{ll}\text { 11.7 Plagiarism } & 218\end{array}$

$\begin{array}{ll}11.8 \text { Endnotes / Resources } & 219\end{array}$ 
Lesson 12. Information Resources: Publications

12.1 Publications from Contributors $\quad 221$

12.2 Public-Sector Institutions $\quad 222$

12.3 Private-Sector Institutions 225

$\begin{array}{ll}\text { 12.4 Scholarly Sources } & 227\end{array}$

$\begin{array}{lr}12.5 \text { Journalistic Sources } & 229\end{array}$

$\begin{array}{lr}\text { 12.6 Informal Sources } & 230\end{array}$

12.7 Popular, Scholarly, Trade Periodicals 231

12.8 Popular Periodicals (aka "magazines") 232

12.9 Scholarly Periodicals (aka "Journals") 233

12.10 Trade Periodicals $\quad 235$

$\begin{array}{ll}12.11 \text { Grey Areas } & 236\end{array}$

Lesson 13. Information Resources: Public Records

13.1 Public Records and Information Contributors 239

$\begin{array}{ll}\text { 13.2 Nature of Public Record Information } & 240\end{array}$

$\begin{array}{ll}13.3 \text { Types of Public Records } & 241\end{array}$

13.4 Public Records about Individuals $\quad 243$

$\begin{array}{ll}13.5 \text { Public Records Laws } & 245\end{array}$

$\begin{array}{ll}\text { 13.6 What You Can Request } & 246\end{array}$

$\begin{array}{ll}13.7 \text { Open Meetings } & 247\end{array}$

$\begin{array}{ll}13.8 \text { Privacy and Public Records } & 248\end{array}$

13.9 Court Records and Legal Information $\quad 249$

$\begin{array}{ll}\text { 13.10 Locating Public Records Information } & 251\end{array}$

13.11 Evaluating Public Record Information 252

Lesson 14. Information Resources: Data and Statistics

14.1 Big Data $\quad 255$

$\begin{array}{ll}14.2 \text { Public-Sector Institutions' Data } & 256\end{array}$

$\begin{array}{ll}14.3 \text { Private-Sector Institutions' Data } & 259\end{array}$

$\begin{array}{lr}\text { 14.4 Sources of Audience Data } & 260\end{array}$

14.5 Broadcast Audience Data 263

$\begin{array}{ll}\text { 14.6 Media Analysis Data } & 264\end{array}$

$\begin{array}{lr}14.7 \text { Audience Analytics Data } & 265\end{array}$

$\begin{array}{ll}\text { 14.8 Data from Media Kits } & 267\end{array}$

$\begin{array}{ll}14.9 \text { Consumer Data from Private-Sector Sources } & 269\end{array}$

$\begin{array}{ll}\text { 14.10 Data from Scholarly Sources } & 272\end{array}$

$\begin{array}{ll}\text { 14.11 Data from Journalistic Sources } & 274\end{array}$

14.12 Data about Journalistic Audience 276 
14.13 Data from Informal Sources

14.14 Numeracy Skills

14.15 Applied Statistics

Lesson 15. Information Resources: Polls and Surveys

15.1 Surveys and Information Contributors

15.2 Survey Definition

15.3 How are Surveys Used?

15.4 Searching for Survey Data

15.5 Survey Sample Types: Non-Probability

15.6 Survey Sample Types: Probability

15.7 Sample Size

15.8 Wording of Survey Questions

298

15.9 Question Order in Surveys

300

15.10 Survey Interview Types

15.11 Face-to-Face

15.12 Telephone

303

15.13 Self-Administered 304

15.14 Interpreting Survey Data 305

15.15 Cautions for Careful Communicators 307

15.16 Endnotes

Lesson 16. Message Tasks: Applying What You've Learned

16.1 Putting It All Together

16.2 Freelance Magazine Scenario

16.3 Journalism: Clarify Message Task

16.4 Journalism: Identify Audience

16.5 Journalism: Narrow Focus / Brainstorm Ideas

16.6 Journalism: Locate Information from Sources

16.7 Crisis Communications Scenario

16.11 PR: Locate Information from Sources 324

16.12 PR: Synthesize the Information 326

16.13 New Advertising Pitch Scenario 327

16.14 Advertising: Locate Information from Sources 328 
16.15 Advertising: Synthesize the Information

16.16 So What and Who Cares? 


\section{Publisher Information}

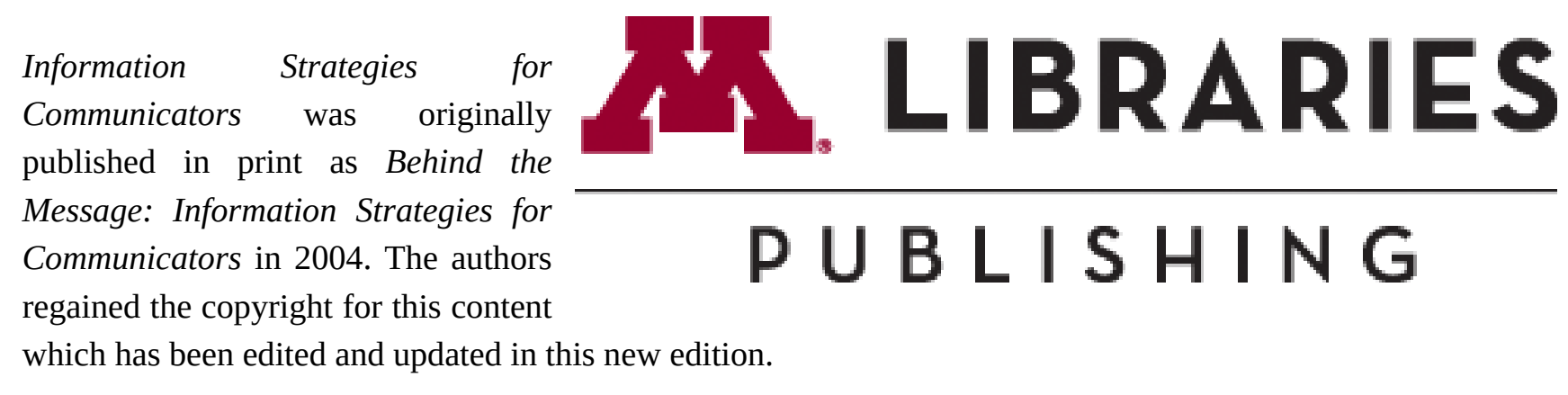

This edition is produced by the University of Minnesota Libraries Publishing through the eLearning Support Initiative.

Authors retain ownership of their content, which is made available under the terms of a Creative Commons Attribution license (CC BY 4). 


\section{Lesson 1. Personal / Professional Skills of Successful Communicators}

\section{KEY CONCEPTS}

- Media message creators work within a set of social, legal and ethical expectations and responsibilities.

- These skills, attitudes and standards of practice will help communicators be successful in their work.

- Some of these are standards, like ethics, that can be learned. Others are modes of conduct, like punctuality, which can be practiced. Others are personality traits, like curiosity or enthusiasm, that can be cultivated.

- Media message creators work in a team environment and each person's individual set of competencies and efforts on specific information tasks contributes to the overall message creation process and the success of the organization.

- These skills, attitudes and standards will also help students be successful in their academic careers.

\section{LEARNING OUTCOMES}

After completing this lesson you will be able to:

- understand the kinds of personal and professional characteristics that employers look for.

- understand how your individual efforts as a team member contribute to overall organizational success.

Our goal in this course is to help you hone your ability to ask good questions and efficiently find appropriate answers related to whatever communications task set before you.

Your goal is to learn the skills that will help you excel as a student and eventually secure and be successful in a job as a journalist or strategic communicator.

Before we get into developing the skills to manage the information tasks required to fulfill the communications assignment given to you, we need to discuss the personal and professional skills that employers look for and that will help ensure your success both on the job and in the classroom.

Whether you are interested in working in news, advertising, or public relations there are personality traits and professional standards of practice that you should be aware of and work to develop. 


\subsection{EQ vs IQ}

It is not just intelligence, as measured by IQ tests, that predicts a student's or professional's success. Emotional intelligence and personal resilience are becoming as important a measure as test scores. The Knowledge is Power Program (KIPP) developed a "character growth chart” to help measure students' personal characteristics that auger well for success in higher education.

Among the attributes it lists and the indicators that a student has those attributes are:

- GRIT: Sticks with a project for more than a few weeks, tries hard even after experiencing failure, keeps working even when s/he felt like quitting

- ZEST: Actively participates, shows enthusiasm, approaches new situations with excitement and energy

- SELF CONTROL (school work): Comes to class prepared, remembers and follows directions, pays attention and is able to resist distractions

- SELF CONTROL (interpersonal): Remains calm even when criticized or otherwise provoked, allows others to speak without interrupting, is polite

- OPTIMISM: Believes that effort would improve his/her future, stays motivated even when things don't go well

- GRATITUDE: Recognizes what other people do for them, shows appreciation by saying thank you or doing something nice for someone else

- SOCIAL INTELLIGENCE: Finds solutions during conflicts with others, shows they care about the feelings of others

- CURIOSITY: Eager to explore new things, asks questions, takes an active interest in learning

You can see why this list of attributes would be attractive to employers as well.

These are not "skills" per se, but personality traits that will help you succeed in both your academic and professional work environments. We encourage you to develop these approaches and attitudes. 


\subsection{Attributes Employers Desire}

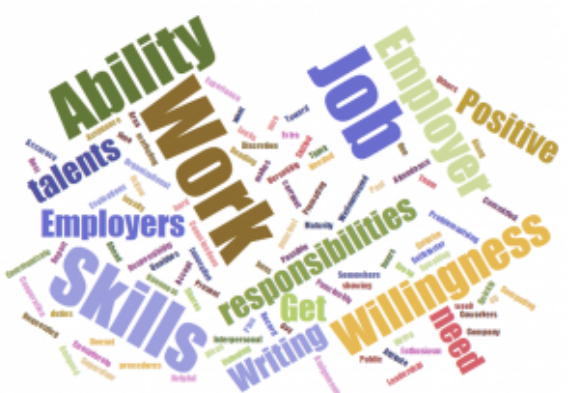

The Wisconsin Job Center surveyed employers in their state to get a sense of what they are looking for when hiring or promoting employees. Take a look at the list below and see how much the personality traits and behaviors identified by KIPP are mirrored in employers’ wish list.

- Attendance

- Punctuality

- Enthusiasm

- Cooperation

- Maturity

- Accuracy

- Problem-solving Skills

- Organizational Skills

- Interpersonal Skills

- Openness — Shares Experience and Ideas

- Discretion and Loyalty to Employer — Doesn’t Criticize Past or Present Employers

- Versatility — Skilled in More Than One Area

- Conscientious - Committed to Doing the Best Job Possible

Identify those skills or personality traits on this list that you currently possess, and those that you might want to develop. As emotional intelligence becomes more widely appreciated, it is your ability to demonstrate these skills that will be the strongest predictor of your success. 


\subsection{Team Membership Skills}

Mass communication professionals almost always work in teams. Different members of the group bring their particular skill sets and competencies to the overall task. Employers expect that each individual understands the role s/he plays and understands how to work collaboratively to accomplish the goals set by supervisors and clients.

You will almost certainly begin your career as one member of a larger team and as someone who is responsible for working with a variety of colleagues who have different expertise and different responsibilities. You will be successful if you understand how your contributions to the overall effort fits with others contributions. Your ability to both "manage laterally" and "manage up" will help your colleagues and superiors understand and acknowledge the role you are playing in the team effort.

Author Dan Collins has outlined characteristics of a good team member:

- Works for consensus on decisions

- Shares openly and authentically with others regarding personal feelings, opinions, thoughts, and perceptions about problems and conditions

- Involves others in the decision-making process

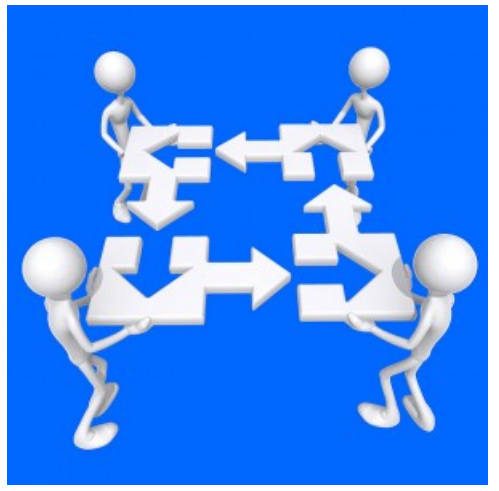

- Trusts, supports, and has genuine concern for other team members

Scott Maxwell - CC BY-SA 2.0

- “Owns" problems rather than blaming them on others

- When listening, attempts to hear and interpret communication from other's points of view

- Influences others by involving them in the issue(s)

- Encourages the development of other team members

- Respects and is tolerant of individual differences

- Acknowledges and works through conflict openly

- Considers and uses new ideas and suggestions from others

- Encourages feedback on own behavior

- Understands and is committed to team objectives

- Does not engage in win/lose activities with other team members 
- Has skills in understanding what's going on in the group

Again, you can see how this list overlaps with the KIPP traits and the employers' wish list. These are some of the key skills and characteristics that successful students, professionals and team members share.

A short video from Study.com on being a good team member 


\subsection{Values for Success}

Another list of what employers look for comes from About.com's article on internships. This is oriented a bit differently from the previous lists in that it identifies "values" that employees possess that are of importance to employers. It includes:

- Strong work ethic

- Dependability and responsibility

- Possessing a positive attitude

- Adaptability

- Self motivation

- Self confidence

Two other personal attributes are vital to maintaining the ethical and legal standards in your communications work. They are:

- Honesty and integrity

- Professionalism

In Lesson 7 we will be discussing how to evaluate the ethical and legal considerations you must keep in mind as you begin your information strategy work.

As for the personality traits and attitudes discussed in this lesson, it is important for you to do an honest selfassessment of where your own strengths lie, and where there might be the need for an attitude adjustment. Learning now which personality skills you have and which you need to work on will help ensure your success both in the classroom and on the job.

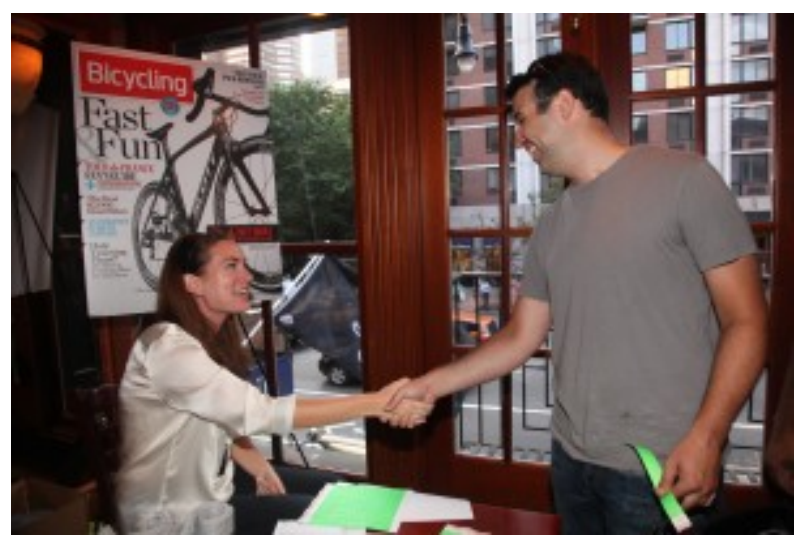

J1986boston24 - CMS Student Internship - CC BY-SA 3.0 


\subsection{Resources}

\section{Links to Resources in the Lesson}

- Characteristics of a Good Team and Team Member: www.innovativeteambuilding.co.uk/pages/articles/ characteristics.htm

- Top 10 Work Values Employers Look For: internships.about.com/od/internshipsuccess/a/workvalues.htm

\section{Additional Resources about Work Values}

- 7 Traits of a Solid PR Professional: www.prdaily.com/Main/Articles/ 7_traits_of_a_solid_PR_professional_14347.aspx

- 9 Traits of Uber-Effective PR Pro in 2015: www.cision.com/us/2014/10/9-traits-of-an-uber-effective-prpro-in-2015/

- Advertising Manager Careers: www.mymajors.com/career/advertising-manager/skills/

- Top 10 Qualities of a Great Advertising Team: advertisingschools.com/resources/top-10-qualities-of-agreat-advertising-team

- What are the Qualities to Become a Good Journalist?: www.buzzle.com/articles/what-are-the-qualitiesrequired-to-become-a-good-journalist.html

- Trust Me, I’m a Journalist: how-to-become-a-journalist.blogspot.com/2013/05/personal-skills-needed-tobe-journalist.html 


\section{Lesson 2. Information Strategy Process and the Needs of Communicators}

\section{KEY CONCEPTS}

- Communicators can apply a consistent and comprehensive information strategy to their work no matter what type of message will be created.

- A media message (news story, advertisement, press release) is only as effective as the information strategy process that was used to inform and create it.

- Messages have many different forms, purposes and characteristics.

- A variety of storytelling techniques are used. They are selected to best match the message context and content decisions made at the start of the information strategy process.

\section{LEARNING OUTCOMES}

\section{After completing this lesson, you will be able to:}

- identify the elements and sequence of steps in the information strategy process.

- identify the five types of information contributors.

- understand the differences between types of media messages.

- recognize the various purposes of media messages.

- understand the characteristics of good storytelling and elements important in crafting media messages.

- understand that an information strategy is needed at each stage in the creation of messages. 


\subsection{Information for Messages}

Communicators perform two basic tasks: they gather and evaluate information, and they create messages. This course focuses on the information strategy skills communicators must hone to find the information they need to form effective messages.

Media messages take myriad forms and serve different functions. In this lesson we will discuss the variety of media message types.

To get started, answer this - which of the following is not a media message?

- Editorial about mass transit needs

- Branded content (advertorial) about nursing home services

- News release announcing a company’s merger with another company

- TV commercial for dog food

- Breaking news story about a tornado

- Profile of a performance artist

- Billboard for a mobile phone company

- Five-part series on climate change

- Pop-up ad on your mobile device for cheap car insurance

- Reporter’s Twitter post linking to a new investigative report

The answer, of course, is that they all are media messages.

The differences in these messages, though, are readily apparent. Where you find them, what purpose they serve, and what the message creator hopes you will do with the information contained in the message are all different. So are the information requirements in creating these different messages. The pop-up ad just needs the facts about the insurance company and a link, whereas the series on global warming needs extensive information from reports and experts to effectively create the message.

Whether you are a reporter, a public relations specialist, or someone who works in advertising, the main output of your work will be a media message. 
According to Wikipedia,

"A message in its most general meaning is an object of communication. It is a vessel which provides information.”

Just as it takes clay to make pottery, it takes information to craft a

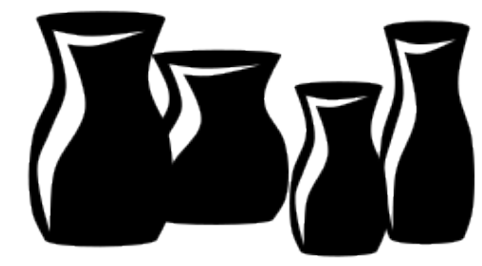
message. At all stages in the process of crafting a message, information is the essential material. Just as pottery can come in many shapes and Pottery - CCO forms and serve various purposes, so, too, do the information "vessels" communicators create. 


\subsection{The Information Strategy Process}

\section{THE INFORMATION STRATEGY MODEL}

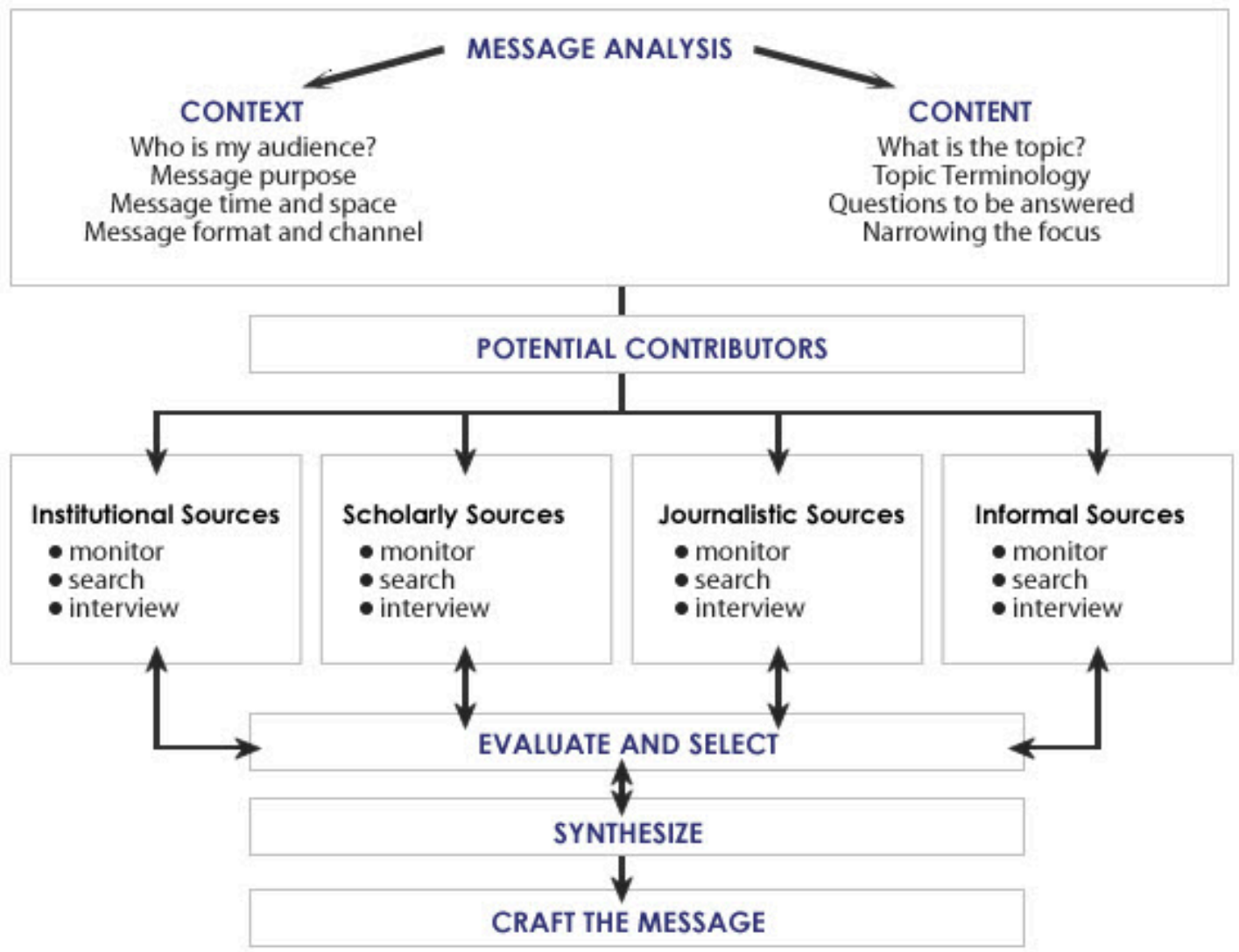

Models can be useful ways to illustrate often complicated processes. The Information Strategy Process model below recognizes that in an information-rich environment, it is impossible to remember thousands of specific information-finding tools and resources for answering specific questions. Instead, the model suggests a systematic course to follow when developing a strategy for determining, and seeking, the information needed for any message type or topic.

The model identifies the steps in the information strategy process and indicates the paths between the steps. As the two-way arrows indicate, the process may include some backtracking in the course of verifying information or raising additional questions. As a graphic representation of both the steps to take in the process and the sources that might meet a particular information need, the model serves as the outline of your entire information-gathering process.

The model also identifies the contributors to an information strategy. Information is created by many different 
types of sources and is intended to meet a wide variety of needs for both the information creator and for anyone who might gather and use that information. The model points out the major contributors or sources of information: institutional sources (which includes both public-sector and private- sector institutions), scholarly sources, journalistic sources and informal sources. We will discuss each of these in more detail in Lesson 6 and in other Lessons where appropriate.

The information strategy model for mass communicators applies to any type of message task and any topic that you may be working on. The process applies to an information search for news, advertising, public relations or even for an academic paper. The information strategy process can facilitate the search for information on any topic and for any audience.

For mass communicators, the information strategy process will help you:

- think through the message's purpose, context, audience and key topics

- identify and select a manageable portion of the topic which needs to be examined

- develop a method for in-depth examination of a segment of the topic selected

- identify appropriate potential sources of information

- select effective techniques for researching the topic

- determine a vocabulary for discussing your message analysis, information gathering and selection process with others (colleagues, supervisors, critics, audience members. etc.)

- save time by helping you avoid wading through masses of information that may be interesting, but in the end, not very useful for the message task

We will use this conceptual map as a way to think about how to accomplish each of the information tasks that communication professionals might face. 


\subsection{Information Tasks of Communication Professionals}

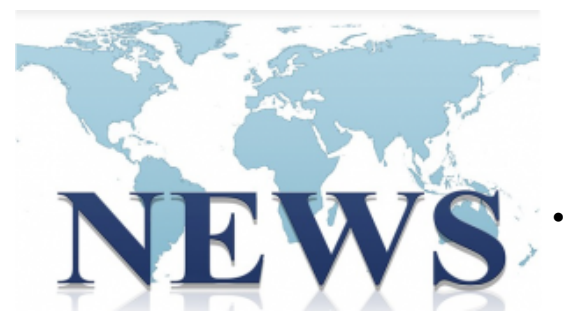

News - CCO
Each of the mass communication professions - journalism, advertising, public relations - serve different information objectives for their organizations.

- Journalistic organizations want to inform and engage the readers / viewers / listeners of their messages through publishing stories about current events, people, ideas, or useful tips. By providing compelling and interesting information they hope to draw an audience to the publications in which their messages appear.

- Advertising firms create messages for their clients that inform or persuade potential customers to purchase a product or service or adopt an idea or perspective. Ads generally include a "call to action" that identifies the intended outcome of the message.

- Public relations firms help their clients influence

Advertising vs. Public Relations legislators, stakeholders (ie: regulators, business partners, media organizations and the general public) to think positively about the company or organization and manage the organization's information environment.

They serve these key objectives using a variety of message types. Let's look at the different forms of media messages in news organizations, advertising agencies, and public relations firms and the information tasks of the professionals creating those messages.

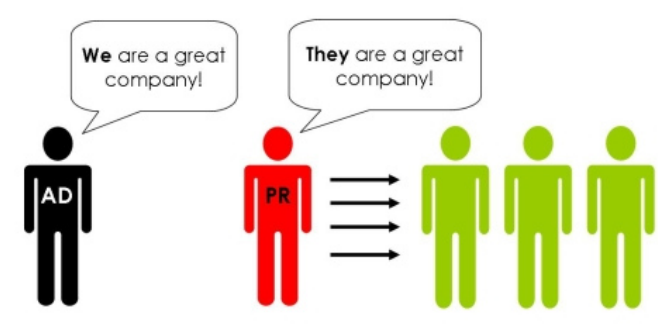

Source: John Moore, Brond Autopsy

O Mark Smiciklas IntersectionConsulting.com/Blog

Advertising vs PR - CC BY-NC 2.0 - Mark Smiciklas 


\subsection{News Messages}

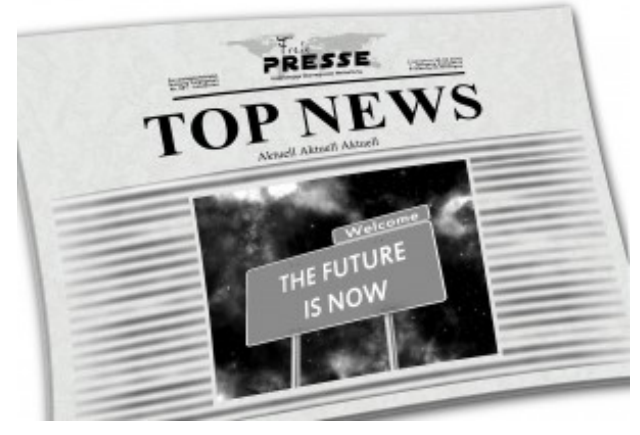

News - CCO
News messages are often broken into three categories: "hard" news, "soft" news or features, and opinion. "Hard" news comprises reports of important issues, current events, and other topics that inform citizens about what is going on in the world and their communities while "soft" news covers those things that are not necessarily important and are handled with a lighter approach. Opinion pieces, unlike the other two which value “objectivity,” are subjective and will have a specific point of view.

\section{Hard News}

- Breaking news - Sometimes referred to as "the first take on history" breaking news stories provide as clear and accurate an accounting of some kind of event as possible while it is happening. In reporting about wildfires raging in the west, the breaking news story requires a timely accounting of what's happening, with a tight focus on the "who, what, when, where, why" and it requires well-honed observation and interviewing skills. For the breaking news story, the information tasks for the reporters are to show up, assess the situation, use their senses to cover the event, and learn more information through first-person interviews. Breaking news provides the "need to know" information as an event unfolds. EXAMPLE

- Depth report - The depth report is the story after the breaking news report. The goals for journalists preparing a depth report are to try to help people understand how the event happened, who was affected, what is being done about it, how people are reacting. For instance, in the aftermath of a story about wildfires in the West, the reporter's information tasks would include gathering background information about the firefighting efforts, the economic impact of the fires, the reactions of home and business owners, the potential impact that the weather might have on future similar events. As with the breaking news story, the journalist is transmitting information, not opinion and they must be able to identify the most knowledgeable sources. EXAMPLE

- Analysis or interpretive report - The focus here is on an issue, problem or controversy. The substance of the report is still verifiable fact, not opinion. But instead of presenting facts as with breaking news or a depth report and hoping the facts speak for themselves, the reporter writing an interpretive piece clarifies, explains, analyzes. The report usually focuses on WHY something has (or has not) happened. The information tasks are greater for this type of report, due to the need to clarify and explain rather than simply narrate. An analysis of the wildfires might look into how environmental policy or urban sprawl factored into the event. Analyses generally require learning about different perspectives or ranges of opinion from a variety of experts and more "digging” into causes. EXAMPLE

- Investigative report - Unlike the analysis which follows up on a news event, the information tasks for an investigative report require journalists to uncover information that will not be handed to them, 
these stories are reported by opening closed doors and closed mouths. These are the stories that expose problems or controversies authorities may not want to see covered. This requires unearthing hidden or previously unorganized information in order to clarify, explain and analyze something. A key technique used in investigative reports is data analysis. In the aftermath of the wildfires a news organization might investigate the insurance claims process or how a charitable organization that received relief funds for fire victims actually allocated the money. The investigative report requires the communicator to have a high level of information sophistication, and the ability to convey complex information in a straightforward way for the audience. EXAMPLE

\section{Soft News}

- Feature - The feature differs from the other types of news reports in intent. The previous examples seek to inform the audience about something of importance or concern. Features, on the other hand, are designed to capture audience interest and are more about providing entertainment than critical information. The feature story depends on style, great writing, and humor as much as on the information it contains. There are several types of features:

News - A story about a man who used cardiopulmonary resuscitation (CPR) to revive a pet dog rescued from the bottom of a pool might be reported as a news feature. It is based on an event, but covered as a feature, but the information tasks require gathering material to put more emphasis on the drama of the event than on the information about how to do CPR on a dog. EXAMPLE

Personality sketch or profile - A story about the accomplishments, attitudes and characteristics of an individual seeks to capture the essence of a person. This requires both thorough backgrounding of the subject and skills in interviewing as information tasks. The communicator has to have a well-honed ability for noticing details that bring to life what is interesting or unique about the person. EXAMPLE

Informative - A sidebar to accompany a main news story might be written as an informative feature. For example, an informative feature that describes the various methods firefighters use to combat wildfires might accompany a breaking news story. The information tasks for the reporter include a good command of sometimes-technical information to convey the story to the audience. EXAMPLE

Historical - Holidays are often the inspiration for this type of piece, with focus on the history of the Christmas tree, the first Thanksgiving dinner, etc. The curious communicator could also create features about the anniversary of the founding of an important local business or the celebration of statehood using background archival documents. The information tasks for these types of reports obviously require locating and interpreting extensive historical information. EXAMPLE

Descriptive - Many features are about places people can visit, or events they can attend. Tourist spots, historical sites, recreational areas, and festivals all generate reams of feature story copy, pictures and video. Public relations specialists often have a significant hand in generating much of the background information in these types of features and promoting these events or places to the news media. The information tasks include finding a fresh and engaging angle for the content. EXAMPLE

How-to - Some features are created to provide information about how to improve your golf game, become a power-shopper, install your own shower tile. The communicator has to have a solid grasp of the subject matter to do a respectable job with this type of piece. The information tasks for how-to features include the need for material that is descriptive, specific, and very clearly communicated. EXAMPLE 


\section{Opinion:}

- These types of reports include editorials, columns, and reviews. They are characterized by the presentation of facts and opinion to entertain and influence the audience. Nonetheless, they still require correlation and analysis of information. Because their purpose is persuasion, they must contain clear, detailed information and make logical and understandable arguments in support of the point of view being presented.

Editorials - The editorial is a reflection of management's attitude rather than a reporter's or editor's personal view. Most are unsigned and run on a specific page of the newspaper or website or during a particular time of the broadcast. Editorials usually seek to do one of three things: commend or condemn some action; persuade the audience to some point of view; or entertain and amuse the audience. The information tasks for an editorial include locating and using credible information as evidence for whatever position is being taken.
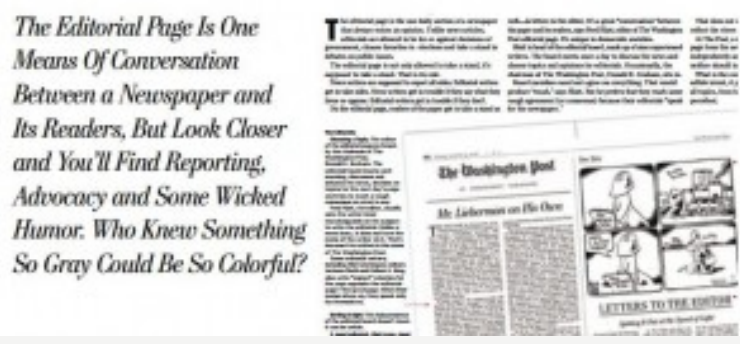

Image from Washington Post Newspapers in Education

Columns - A column includes the personal opinions of the writer on the state of the community and the world. Many columns are written by syndicated, national writers, but local commentators and columnists also have a following in their communities. Columnists use information selectively, based on their point of view and the argument they are making. Columnists' information tasks include maintaining a consistent "voice" and approach to each topic. EXAMPLE

Reviews - Reviewers make informed judgments about the content and quality of something presented to the public-books, films, theater, television programs, concerts, recorded music, art exhibits, restaurants. The responsibility of reviewers is to report and evaluate on behalf of the audience. The information must be descriptive as well as evaluative. The reviewer describes the concert and then makes an evaluation of the quality of the performance. Reviewers' information tasks require them to be deeply knowledgeable about the type of content or activity they are reviewing, as well as having an opinion about it. EXAMPLE 


\subsection{Advertising Messages}

Advertising is defined as a paid form of communication from an identified sponsor using mass media to persuade or influence an audience. Because there are so many diverse advertisers attempting to reach so many different types of audiences with persuasive messages, many forms of advertising have developed. We will discuss nine types of advertising and the information tasks they require of the communicator.

1) Brand or national consumer advertising - This type of advertising emphasizes brand identity and image. Advertising campaigns for Coca-Cola, Nike, or American Express are examples. Brand advertising seeks to generate demand for a product or service, and then convince the audience that a specific brand is the one they want. For example, Nike ads seek to generate demand for expensive athletic shoes and to convince purchasers that they want Nikes rather than Reeboks. The information tasks for these types of campaigns are extensive but much of the information that is gathered usually does not actually appear in the content of the ads themselves. Rather, the information informs the development of the advertising campaign strategy and the choice of media in which to place the ads.

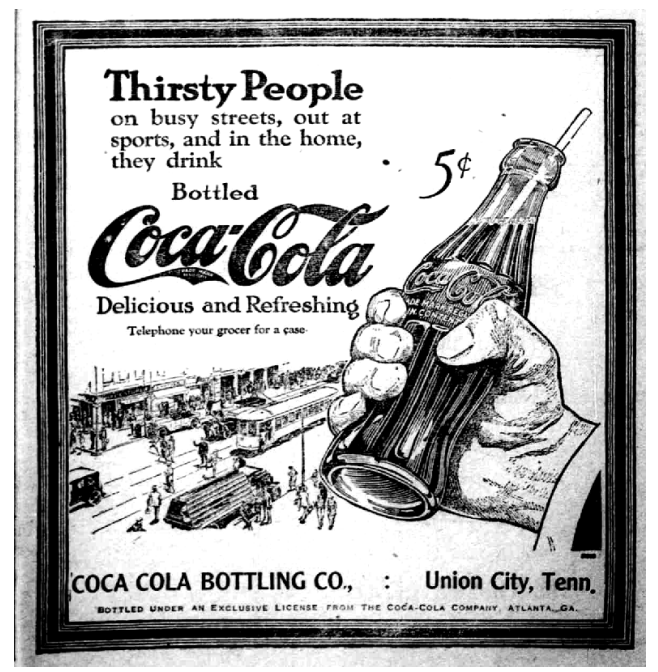

1922 Coca-Cola ad - CCO

2) Retail - Advertising that is local and that focuses on the store where products and services can be purchased is called retail advertising. The message emphasizes price, availability, location and hours of operation. Nike, for example, might generate a brand ad about their shoes, but the local department store would generate a retail ad telling about the great sale they are having on Nikes and other shoes. The department store managers don't care which brand of shoe you buy as long as you shop in their store rather than their competitor's store. The information tasks for these types of ads include gathering a lot of highly specific information about the retailer, given the purpose of the advertisements.

3) Directory - Ads that help you learn where to buy a product or service are directory ads. The telephone yellow pages are the most common form of directory ads, but many other directories perform the same function. The ads that appear as "sponsored links" next to your results from a search in a search engine are a form of directory ads. They are classified and served to you according to the terms in your search. These types of ads are almost purely information-based and meet an already-expressed need for information on the part of the audience member. The information tasks connected to directory ads include analysis of vast data sets of information about consumers, much of which is done by computer algorithms. But the ad creators need to understand how and why a particular consumer was targeted for a particular ad in order to be effective. 


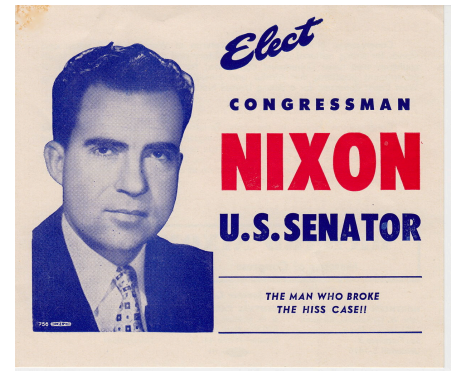

Nixon ad - CCO
4) Political - Ads designed to persuade people to vote for a politician are familiar fixtures on

the media landscape every political season. We can all recall candidate ads we've seen during each election cycle. Information tasks for this type of ad include gathering background research about the opposition candidate as well as material about the candidate sponsoring the ad, the latest polls of likely voters, public attitudes about the issues, and other facts that inform the strategy for the copy and placement of the ad. Communicators also must know the relevant legal and regulatory restrictions for political advertising in each market where they ads may run.

5) Direct-response - These types of ads can appear in any medium. A direct-response ad tries to stimulate a sale directly. The consumer can respond by phone, mail, or electronically, and the product is delivered directly to the consumer by mail or to a mobile device (a coupon for the pizza parlor you just passed on the street). On television, the infomercials for hair-care products, exercise equipment, or kitchen gear are examples of direct-response ads. Flyers you get in the mail to "Buy this Product" are also examples. These ads have a high information component and the communicators' information tasks reflect the need to be well-informed. The message-makers assume the audience is already interested in or curious about the goods or services, since they are watching the infomercial, reading the catalog, or have gone to the website. The direct-response piece includes lots of information about the products, and the goal is to make the sale. Mobile versions of direct response ads have to have a good "hook" to get the receiver to pay attention and act. EXAMPLES AND EXPLANATION

6) Business-to-business - Messages directed at retailers, wholesalers, distributors, industrial purchasers, and professionals such as lawyers and physicians comprise business-to-business advertising. These ads are concentrated in business and professional publications. For example, banks advertise to small business owners; or equipment manufacturers advertise to factory managers, hospital administrators, restaurant owners, and others who might purchase their equipment. Unless you do the type of work that makes you an audience member for these kinds of messages, you aren't likely to see very many business-to-business ads. Because these types of ads require that they be directed toward a specialist audience with specific needs for products or services tailored for a particular industry, the information tasks required to produce these ads are highly detailed. EXAMPLES OF AWARD-WINNING B2B ADVERTISING

7) Institutional - This form of advertising is sometimes called corporate advertising. The focus of the message is on establishing a corporate identity or winning the public over to the organization's point of view. Rather than outlining the product or service offered by the institution, the ad attempts to create an image or reinforce an attitude about the company as a whole. Also, the ad may attempt to influence policymaking by advocating a particular position on some national issue that affects the interests of the sponsoring institution. The information component of this type of ad usually consists of extensive background research about the attitudes and psychologies of the intended audience, and the information tasks include gathering in-depth knowledge about the sponsoring institution and its goals for the message. 


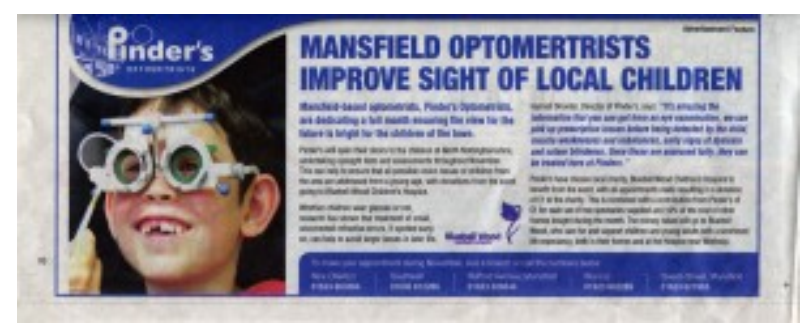

Nigel Lamb - Pinder's Optometrists Advertorial - CC BY 2.0

know how to write like a journalist. Hence, the information tasks for this type of content include both content and stylistic aspects.

9) Public service - This type of ad communicates a message on behalf of some good cause, such as stopping drunk driving or preventing AIDS. Unlike the other types of advertising, media professionals create these ads for free, and time or space to run the ads are donated by media outlets. The ads typically include some information that emphasizes the nature of the problem or the cause so as to induce the audience to take the problem seriously. Information tasks for public service ads or PSAs usually include identifying an emotional or psychological "hook" for the audience to get engaged with the ad content. UNEP World Environment Day PSA

Much of the information that is used in the creation of advertising never actually appears in the copy of the ad or in the visuals that are produced. Instead, extensive information is uncovered to help the advertising professionals understand the background about the audience and message. For instance, communicators need to understand the product or service they will be pitching, the interests and needs of the intended audience, the competitors' products advantages and disadvantages, all of which helps them decide how much money should be spent on the campaign and where the ads should appear.
8) Advertising features - Also referred to as an advertorial, branded content or native ads, this form is becoming more common. Many magazines carry inserts that look like a feature piece but are actually generated by an advertiser or a public relations firm, not by a journalist. For example, you might find an insert in a newsweekly magazine about living a healthy lifestyle, with articles and photographs that is sponsored by a pharmaceutical company. The communicator must have solid background information about the product, service or topic AND must 


\subsection{Public Relations Messages}

Public relations messages are sometimes referred to as "earned media" (as opposed to "paid media" like advertising.) This means that the PR professional has "earned" the attention of the journalist who decides to use the information the PR professional supplied as the germ of a news story. The messages created by public relations professionals get a major portion of their exposure through journalism organizations - output from public relations professionals is a major source of news. A significant routine for news professionals is the monitoring and use of news releases generated by public relations specialists, attendance at news conferences organized by PR professionals, coverage of events sponsored by PR strategists, and use of material from the media kits that PR firms create for their clients.

Generally speaking, the policy of news organizations is that PR-generated messages are checked, edited, and supplemented by information independently generated by news professionals before running. In fact, much PR appears in mass media, but most of it is produced for specialized media such as trade, association, and employee publications. Public relations messages are also a part of what is referred to as "strategic communications" along with advertising in that there is a strategic objective in the crafting of the message to influence people's opinions or purchasing decisions.

Just as there are various forms of news and advertising messages, there are a number of forms of public relations messages, and a set of information tasks for communicators.

1) Internal PR - These include corporate newsletters, crisis management plans, corporate intelligence reports, and other forms of communication that are intended for the internal audience of employees and officers of a company. Also included here are the annual reports prepared for stockholders in publicly-held firms. These types of public relations media are information-rich and the information tasks include having an extensive understanding of the company, the issues and problems the company faces, the finances of the firm and any other factors that employees and stockholders would have an interest in knowing about. EXAMPLE 
2) News releases - News releases are sent to media outlets by PR specialists who want to generate interest for their client or company. A news release might be prepared:

- as a simple announcement story (IBM's 3rd quarter profits rose)

- as an advance story (The circus will be unloading animals for the 3-day stay in town at such-and-such a place and time)

- as a follow-up after an event (Ground was broken for a new nursing home)

- in response to a trend, current event or unfolding crisis (Interest rates are at an alltime low, so ABC Mortgage is offering the following tips to consumers about refinancing).

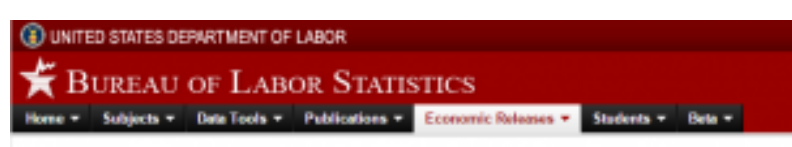

Economic News Release

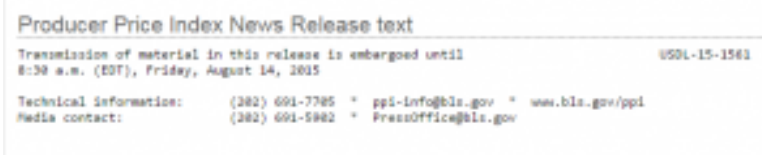

mencea mats robss - suir aeas

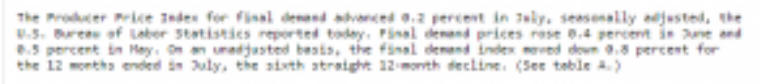

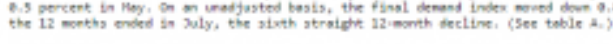

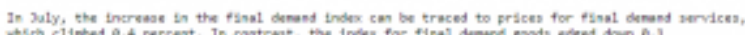
mercent.

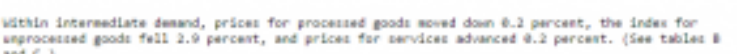
mac.) Fiest beses

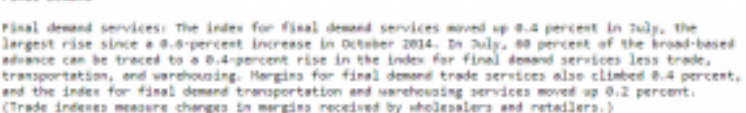
Bureau of Labor Statistics

The best news releases are produced to have the look and feel of a news story that might have been produced by news professionals. They therefore share many of the same information characteristics as news reports. The one big difference, as we have already stated, is that PR specialists are not obligated to tell all sides of the story. The information tasks for news release producers are very similar to those for feature story journalists.

3) Broadcast (video) news releases - A video news release (VNR) is simply a news release in the form of a broadcast news story. The video and voice-over are designed to look like a piece that you would see on any television news program. B-roll footage, or video images sent to the media, is closely related to a VNR. The difference is that b-roll does not include a narrated voice-over, and is not edited as a ready-to-go news package. Reporters use b-roll footage from companies to enhance their own stories. For example, for a new movie release the promotion company might send out b-roll footage of the filming to be used in a story or review. EXAMPLE

An audio news release (ANR) is designed to be played on the radio. The audio clip might be a "voicer," a news story recorded by a PR professional in the style of a radio announcer; or the clip might be an "actuality," the actual voice of a newsmaker or news source speaking. These types of messages are usually accompanied by a print news release or an announcement to alert news professionals that the VNR or ANR is available. ANRs EXPLAINED

Once again, these announcements are produced to have the look and sound of reports produced by news professionals, but with a different standard for completeness of information. PR news releases rarely include information representing all sides of the issue. For that reason, it is generally considered an ethical breach to use information from a VNR or ANR without attributing it to the source so the news audience isn't confused about where the information originated. But the information tasks are again similar to those for feature journalists.

4) Media kits - Media kits consist of a fact sheet about the client or event, biographic sketches of major people involved, a straight news story, news-column material, a news feature, a brochure, photographs, and for those kits delivered digitally, audio and video segments. Often, media professionals package these materials in a folder or other unique format that is professionally designed and printed, or post the materials on a website specifically created for the distribution of the media kit content. Public relations organizations create media kits with the 
intent of providing story ideas for news professionals, as well as to generate interest and attention for the client. For example, the Salvation Army might update its "Kettle Bell Ringing” media kit before the holiday season each year. Magazine publishers create media kits to attract advertisers by highlighting the size and quality of their audiences, the effectiveness of their editorial content and the prices for placing an ad. With all the different components that go into a media kit, you can understand that the information tasks for communicators producing these types of messages are large in number and detailed in requirements. EXAMPLE

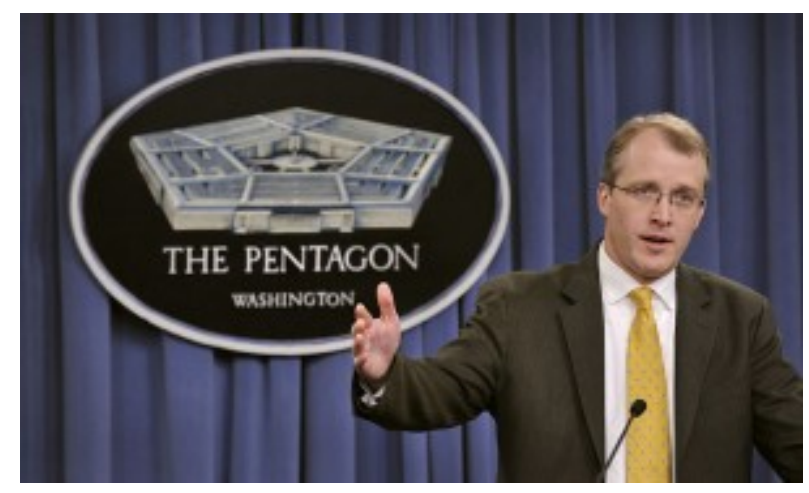

Glenn Fawcett - Pentagon Press Secretary George E. Little briefs the media in the Pentagon Press Briefing Room Public domain.
5) Backgrounder or briefing session - PR specialists provide in-depth information about an issue or event for reporters in backgrounders or briefing sessions. The PR people offer handouts (information sheets or reports) and the principal news source about the issue or event makes a presentation. Unlike news conferences, there is little give and take between reporters and the moderator of these sessions. They are used to explain a policy or situation rather than to announce something. The National Transportation and Safety Board (NTSB), for example, might hold a briefing session following an airplane crash. The handouts prepared for these sessions are sometimes quite extensive, requiring solid information preparation among the PR specialists working on the handouts. The information tasks for the PR specialists include the need to anticipate the types of questions journalists will ask and the depth of follow-up material they need to provide.

6) News conferences - There are two categories of news conferences: information or personality. The information news conference usually has a single motive - someone wants media attention for an announcement, for an update on a breaking event, for follow-up about an investigation, or some other specific item of interest to news professionals. There is give and take as reporters ask questions of the person the podium. EXAMPLE

The personality news conference is designed to provide news professionals with access to someone famous, about-to-be-famous, or otherwise in the public spotlight. Whenever a professional sports team signs a major college star, for example, there is usually a personality news conference where the individual

Information tasks for a news conference include preparing an opening statement, a briefing paper for the person which anticipates reporters' questions, and social media content that can be shared during and after the news conference. There may also be a handout outlining the major points made in the announcement. Again, PR

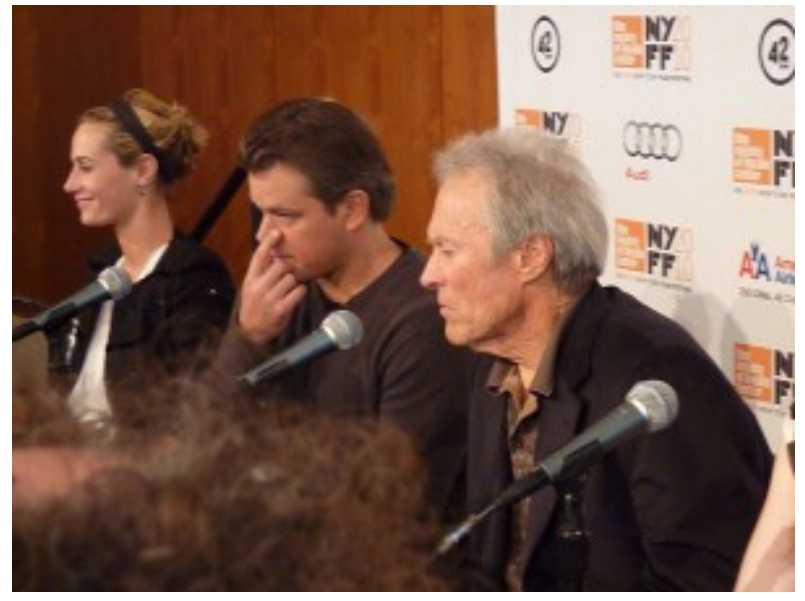

aphrodite-in-nyc - Hereafter - CC BY 2.0 specialists must understand what makes news and prepare their news conference information to meet those requirements. 


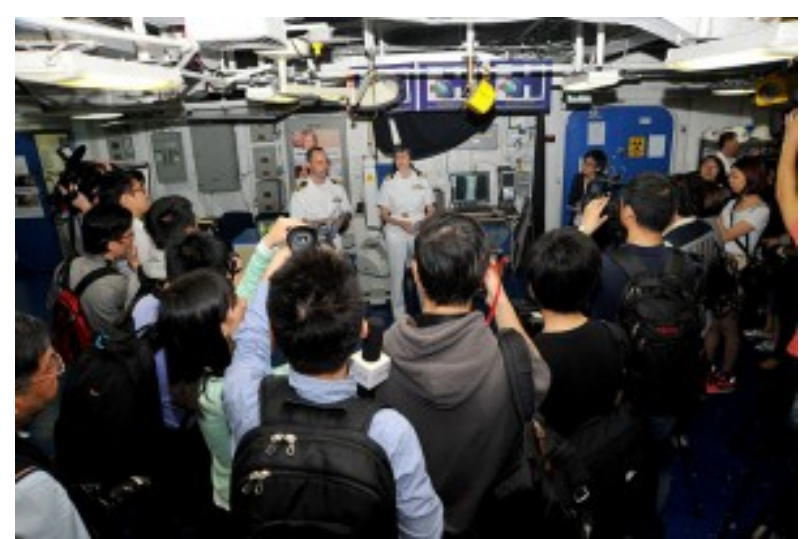

Public domain
7) Media tour - Like a briefing or background session, the purpose of a media tour is to provide in-depth information to reporters. However, the format of the meetings that take place on the media tour is often highly interactive, with one-on-one between a reporter and company official (and public relations specialist). The nature of the information provided as part of a media tour is generally slightly less timely than what would be discussed as part of a news backgrounder or briefing. A media tour might be arranged so that reporters can "demo" a new high-tech product while a company representative walks them through the features. PR specialists' information tasks include knowing what will be most interesting to the journalists on the tour and what can and can't be shared as part of the event.

8) Special events - PR specialists may plan special events (sometimes disparagingly-labeled "pseudo-events”) for clients who want media attention for a cause or issue. There may be a jump-rope-a-thon for cancer research, or a grain company may sponsor a food lift for famine victims. These events must be planned to have news value, and the information that is generated to announce and entice coverage by news professionals must have all of the same characteristics that we have already mentioned. Coverage of these types of events is usually framed as a feature, with similar information tasks for PR practitioners.

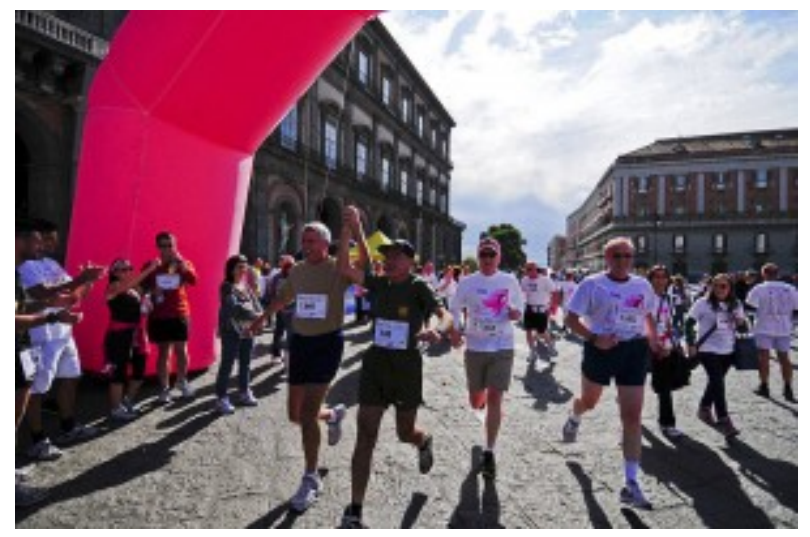

Public domain.

9) Responses to media inquiries - There are cases when a company may not proactively send out a news release or hold a press conference, but may receive requests from the media for comment. Public relations employees are there to respond to reporters' requests for quotes, examples or explanations. In these cases, the public relations practitioner needs to act quickly to help meet the journalist's deadline, and the information tasks involve gathering additional background information about the situation and arranging a meeting or conference call with company management to discuss how best to respond. Getting back to a reporter in a timely manner is key to maintaining good relationships with the media, even if the response is that your company will not be able to provide the requested statement or information at that particular time. Keeping the reporter informed is always a better approach than "stonewalling."

10) PR features - As is the case for advertising message types, many $P R$ firms and corporate communications professionals are creating branded content or native ads. This is sometimes referred to as "owned media" when it is created by the sponsoring company itself. Companies may create entire websites, magazines or video channels specifically for this type of "owned media” content. The communicator must have solid background information about the product, service or topic AND must know how to write like a journalist as part of the information tasks necessary to be successful. EXAMPLES 


\subsection{Storytelling and the Information Strategy}

The way information is crafted into the final media message depends on two key factors:

- how the message is being delivered (a story in a newspaper versus on a mobile device, a TV brand ad or one in an interactive magazine)

- the audience for whom the message is intended

The storytelling techniques you use must take into account the media format in which the information is delivered and the audience expectations for the message.

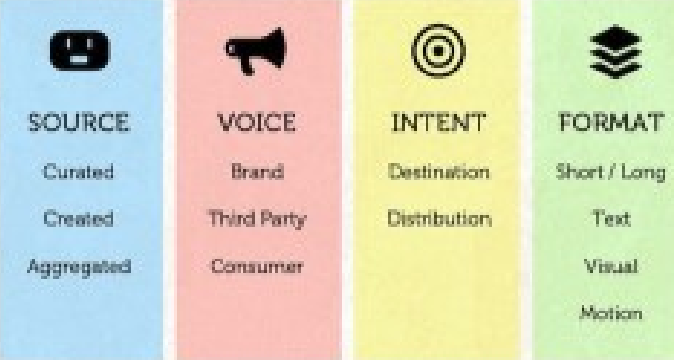

Beth Kanter - Storytelling- CC BY 2.0
While this course does not delve into the actual construction of the messages themselves - you will get those skills in your reporting or strategic writing classes - it is worthwhile to acknowledge some of the considerations that message creators must keep in mind - and the information requirements there might be for different storytelling conventions.

\section{Goals of Storytelling}

Storytelling can serve different kinds of goals. Determining the intention or purpose of the story or message is an important first step in crafting the message. As you have learned, messages can inform or enlighten people about current events or issues or about the availability of products or services. They can provide background and context to a discussion of ideas. Stories can be written to persuade people to make certain purchases or hold certain views. News, advertising and public relations messages perform some or all of these functions while employing different storytelling techniques and formats to communicate with audiences in the most effective way.

There are a number of different storytelling decisions to make as a producer of media content. Regardless of which type of media you are working within, it is important that you, the communicator, are aware of the fundamental storytelling devices you might want to use to tell your story in a way that is direct, efficient, and appropriate for the story's objective. Therefore, you will want to have a full and accessible set of tools that you are ready to employ for any kind of message, depending on the type of media you are creating, your chosen channel of communication, as well as the specific style, tone, and needs of your story subject.

\section{Characteristics of Good Storytelling}

Usually the word "story" implies something fictional. But in the case of media messages "story" refers to factbased information about products, or events, or the actions taken by a company. The distinction between fiction 
and non-fiction stories is an absolutely critical one for you to grasp. It affects every decision that you make about the selection and evaluation of information for messages.

Good storytelling consists of knowing your audience. Is the audience going to be reading the story, hearing it, experiencing it in a non-linear fashion online? What kind of background information does the audience for the story already have about the topic?

Good storytelling also begins with a foundation in the subject matter. The storyteller must have a firm grasp of the subject matter in order to effectively communicate the story to someone else.

Good storytelling demands that the storyteller have command of the mechanics of writing.

Good storytelling understands how different media elements play into the effective telling of the story.

Good storytelling demonstrates ethical standards for accuracy, truth, verifiability, sufficient evidence and information reliability. Non-fiction stories, especially, require solid grounding in factual information that can withstand scrutiny by the most skeptical audience members.

\section{Storytellers must deliver within the parameters and requirements of the story assignment.}

\section{They must:}

- meet the deadline

- follow directions on the expected length and focus for the story

- meet the expectation for clean, distribution-ready copy

- use proper grammar, word choice and style

- apply the appropriate story characteristics for the channel of message delivery

The information strategy skills you will learn in this course will provide you with the tools you need to meet these storytelling requirements. Moving confidently through the information strategy process will help you identify your audience, locate the relevant content for your message, ensure the accuracy of your information and provide the details that will make your message stand out. 


\subsection{Resources}

\section{ADVERTISING}

- Examples of Advertising Techniques: http://www.sales-and-marketing-for-you.com/advertisingtechniques.html

- How to Develop your Brand's Story: http://www.bulldogreporter.com/dailydog/article/pr-storytelling-howdevelop-your-brands-story

\section{JOURNALISM}

- The Transition to Digital Journalism: a guide to resources about storytelling online: http://multimedia.journalism.berkeley.edu/tutorials/

- Journalists as Storytellers: http://niemanreports.org/articles/journalists-as-storytellers/

\section{PUBLIC RELATIONS}

- Storytelling and PR: http://aboutpublicrelations.net/aa061001a.htm

- The Art of Storytelling in PR: http://prinyourpajamas.com/the-art-of-storytelling-pr/

EXPLORE CAREERS: SJMC's site for learning more about mass communication careers 


\section{Lesson 3. Question Analysis: From Assignment to Message}

\section{KEY CONCEPTS}

- Communication message tasks begin with an assignment.

- Communication assignments can sometimes be very specific, and sometimes quite vague.

- The scope of the assignment needs to be clarified as much as possible.

- Sometimes an assignment will be ambiguous and initial research must be done.

- The first "audience" that a communicator must keep in mind is the "gatekeeper" audience.

- One of the most important things to determine at this stage is the purpose of the message.

\section{LEARNING OUTCOMES}

After completing this lesson, you will be able to:

- understand the types of assignments that might trigger the need to develop a comprehensive information strategy.

- articulate the questions you need to ask of your supervisor/colleagues to clarify the message task.

- determine what the person giving the assignment requires.

- determine the parameters of the information task.

- determine the purpose of the message.

As students you've all dealt with frustratingly ambiguous assignments. Knowing how many pages you are required to write, how the document should be formatted, whether and how to cite the information used - all of these are specifics of the assignment that you hope your instructors spell out for you. If those specifics aren't clear, you ask your teachers to give you more detail on the parameters of the assignment and on the "metrics" that will be used to judge the quality of the work you turn in.

When on the job, the assignments you get will usually not have this level of detail. In fact, "deals well with ambiguity" is often a line on job descriptions about the ideal candidate. Clarifying the task will be one of the first steps the communicator must take when a supervisor throws out an assignment like, "One of our clients is interested in exploring e-wallets. What do we know about them?" or "We have to do a better job of getting legislators to understand our company. Do an analysis." or "There have been lots of motorcycle accidents in the past month - we ought to do an in-depth story.” 
Determining as completely as possible the "context” for the message will help you begin to put parameters around the task.

In this lesson we will discuss the aspects of a message assignment that you should clarify with the "gatekeeper." The more you know about what the "gatekeeper" in a communications organization looks for and values, the more you will be able to pursue a strategy that leads you to successfully fulfilling the message mission. 


\subsection{Understanding the Gatekeeper Audience}

As we will discuss in Lesson 4, determining and researching the key audience for the message you will be creating is one of the most important parts of message development. But there is another, perhaps even more, important initial audience for your work, and that is the person in the organization who will approve, support, or squash your ideas.

Referred to as "gatekeepers" these are the people within the organization who not only hand out the assignments, they are also the ones with the power to decide:

- which messages are produced

- who produces the messages

- where the messages will appear

- what the messages will contain

Examples of "gatekeepers" in communications or business organizations include:

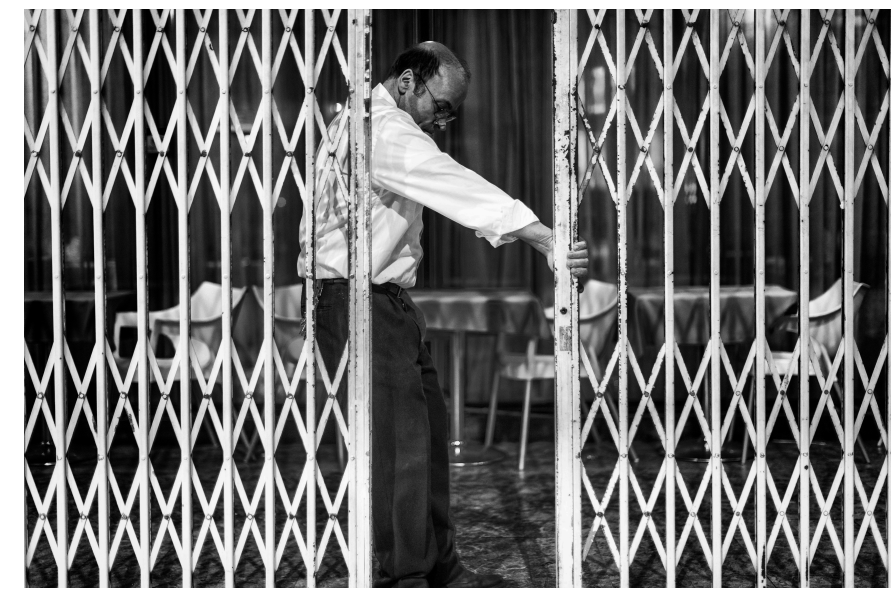

Gatekeeper - CC BY-SA 2.0

- a newspaper's assistant managing editors who assign stories to appropriate reporters

- a television station's producers and assignment editors

- advertising agency account executives

- public relations firm client services managers

- a corporation's chief communications officer who decides whether the new communications plan is ready to present to the CEO

An important function of gatekeepers is to maintain the standards and the "voice" that define the specific organization for which they are "keeping the gates."

Within a newspaper organization, the assistant managing editor who assigns stories to various reporters on a beat has the responsibility to decide whether the reporters' stories are acceptable before the stories are sent along to the next step in the process of getting printed in the newspaper and posted online.

Reporters learn to anticipate the kinds of stories that their editors (the gatekeeper audience members) want. One editor may respond positively every time a reporter writes a story that includes a quote from a particular source. That reporter will try to include that source in her stories as often as possible. In a television news operation, the newscast producer might respond well every time a reporter/photographer team does a story that is accompanied by particular types of images. Again, that reporter/photographer team will try as often as possible to select that type of video to please the producer and thus assure a spot on the newscast. 
In an advertising agency, the account management professionals perform a similar gatekeeper function. Client services managers in a PR firm perform the same function. They are responsible for contact with the client who is paying to have the ads created or the public relations work done. If the account manager is unhappy with the advertising or PR campaign that the other professionals have created, it may not get passed along for client approval. Communicators learn to adjust their efforts and create ads or PR work that account managers or client services managers are most likely to define as acceptable and ready for client review.

In a business, non-profit organization, government agency or similar types of institutions, the communications manager for the organization plays the gatekeeper role. Any content that appears on the organization's website, the social media content that is produced, the promotions sent to mobile devices and any other messages directed at the public go through a review process. Communicators inside an organization have to conform to the rules, processes and expectations of the communications manager if their work is going to be delivered to audiences.

At the initial stage in the message process gatekeepers are the ones who will be issuing assignments. They are the ones who will determine if you delivered what was requested and they are the ones you will need to work with to clarify the assignment so you have the best chance of successfully delivering what is needed.

Gatekeepers will have in mind the needs of the ultimate "client" for whatever work you produce. The editor of a publication will understand who the readers are and what they look for in the articles that run. The PR client manager will understand the objectives of the client for the campaign. The advertising account manager will know the advertiser's sales goals. The corporate communications manager will know what image the company is trying to project. Your job is to interpret the work assignment given you and know how the work you produce will ultimately help everyone's objectives be met. 


\subsection{Assignment Clarification}

The " 5 Ws and H" (Who, What, When, Where, Why, and How) checklist that journalists use in covering a story or that strategic communicators would need to consider when developing a campaign can be used with a slightly different orientation for communicators who need to clarify an assignment.

Let's imagine that in the strategic communications context your boss sends the following text: "Our client is interested in exploring bitcoin. See what you can find out." Or in the newsroom your editor drops by and says, “The Times had a big story about bitcoin. Should we cover this?” How do you even start? In upcoming lessons we will delve in to the kinds of questions you'll ask and answer when developing a research agenda (who is the audience, what are the angles of the topic, where might you find information.) But before you can begin to understand the specifics of the research task itself you need further clarification about the gatekeeper's expectations. Following are some of the kinds of questions you might ask to clarify the assignment.

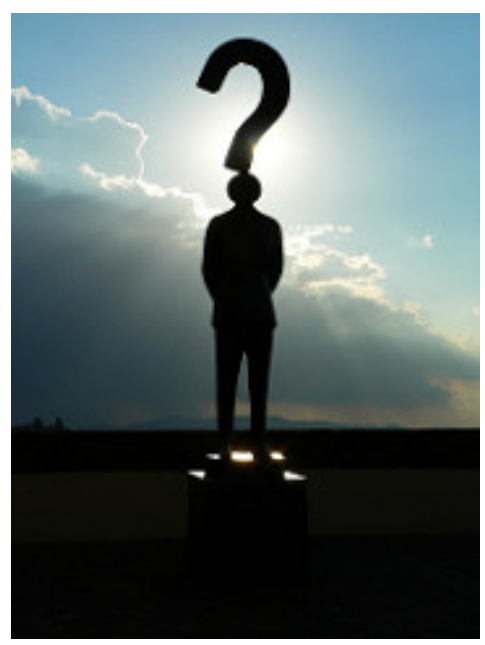

Marco Belluci - Question Mark - CC BY 2.0
WHO? Who will be seeing the report you produce? This will give you clues as to the nature of the language to use, the formality or informality of the report you deliver. Previous experience with this person or team will inform you about their expectations.

WHAT? What form should the information take? Learn if this is just an informal backgrounder, information needed to justify a whole new campaign or series idea, or a competitive intelligence report. Knowing what type of report or document is expected will help you set a framework for the task.

WHEN? When is the work to be delivered? Knowing the deadline or desired delivery date for your work will help you gauge what level of work can be done (and help you manage your boss' expectations.)

WHERE? Where will the report be delivered? Do they want a written report, a briefing at a meeting, a document shared on the office cloud?

WHY? Why is the information needed? Is a campaign / series already planned and they need concrete information to move the plan forward? Is this just exploratory to see if there is justification for a particular direction?

Once these questions are answered, the HOW to begin researching will be much easier to answer. Most of the assignments you are given are intended to ultimately lead to a communications message of some type. Whether it will result in a news release, or a new advertising campaign, or a news story, knowing as much as possible about the intended outcome of the research work you do will help you understand the amount and type of information you'll need to research.

Although the answers to the these questions might be revealed later in the process, it is important to understand that the answers will help form your information strategy. 


\subsection{Message Purpose}

Another important consideration when clarifying a message task is to determine the ultimate purpose of the message. Messages fulfill seven functions:

1. they provide information about the availability of products and services: advertising and publicity

2. they entertain: special features, advertising

3. they inform: basic news, advertising, publicity

4. they provide a forum for ideas: editorials, interpretive stories, documentaries, commentaries

5. they educate: depth stories, self-help stories and columns, informative pieces, advertising with product features and characteristics

6. they serve as a watchdog on government: investigative pieces and straight coverage of trials and other public events

7. they persuade: advertising, publicity, editorials and commentaries (ftnt 2)

Communicators pay attention to these expectations as they seek information for messages. In order for a message to have audience appeal, it must meet the audience's expectations in purpose and form. Analyzing the context for a message includes the task of clearly understanding the purpose of the message. All of the subsequent informationgathering steps are affected by this basic requirement. 


\subsection{Time / Space}

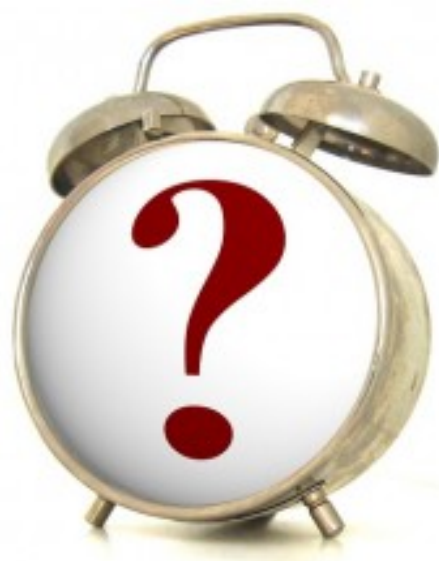

Alarm Clock-CC BY-SA 2.0
Messages must be tailored to meet the time and space constraints imposed by the context within which the message is being created. You cannot explore all information available for every message on every occasion. Deadlines and costs involved in collecting some information force you to make choices about particular angles and information sources.

A long, interpretive news story on which a reporter might work for days must use many information sources. That stands in contrast to a breaking news story about a fire that must be posted immediately to the news website or sent out as a 140 -character tweet.

The brand advertising campaign that will run over many

months and include ads in several media is likely to rest on a large information base. But one retail ad placed in a local newspaper by the neighborhood shoe store does not require such an extensive information search. You make choices about the management of both time and money based on the time and space constraints of your message task.

Time factors in broadcast news, for example, may be the major information constraints. If you have just 1 minute and 20 seconds to tell a story with words and pictures, you must tailor the information strategy to help in identifying the most efficient sources for telling that story.

Space factors may be the major information constraints for a message that will be delivered on mobile device. The efficient information search is essential to the audience's expectation of effective storytelling and the media organization's requirement for economy in producing a message. 


\subsection{Formats / Channels}

An important consideration when developing a research plan is the ultimate delivery method for whatever will be produced. You will learn a great deal in your reporting or strategic writing classes about how the format and channel(s) used for your message affect the actual creation of the message. For the purposes of clarifying your information task, consideration of format and channels can help define the scope of information needed.

For example, if you are assigned to cover a trial and expected to simply tweet ongoing developments, the information you need will be gleaned from your eyewitness account of the proceedings. But if you are expected to develop an in-depth story to run online and in

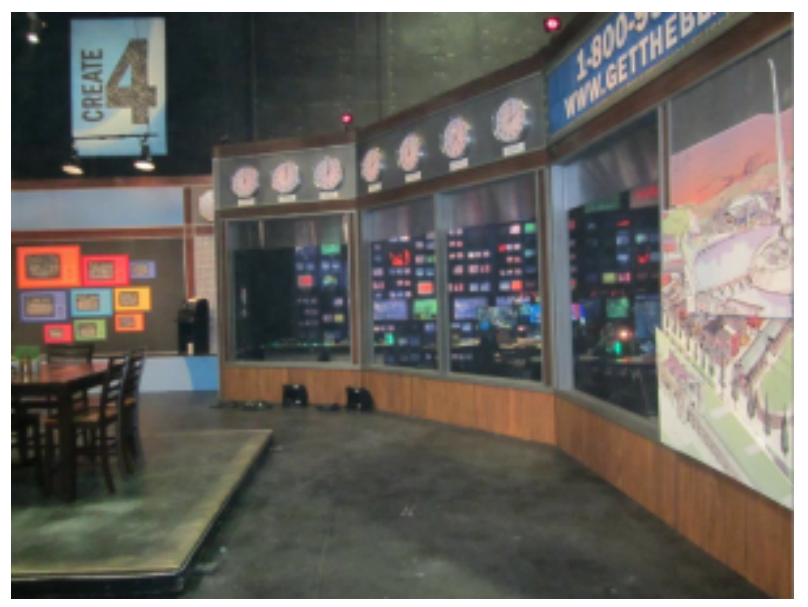

The Blaze Dallas Studios - CC BY-SA 3.0 the newspaper that will comprehensively explain the case, you will need deeper background, sources that can help you describe and explain facets of the cases from different perspectives, advice or insight from experts. Producing the story for a video news report will require finding sources you can get on camera or researching locations that can give visual appeal to the story.

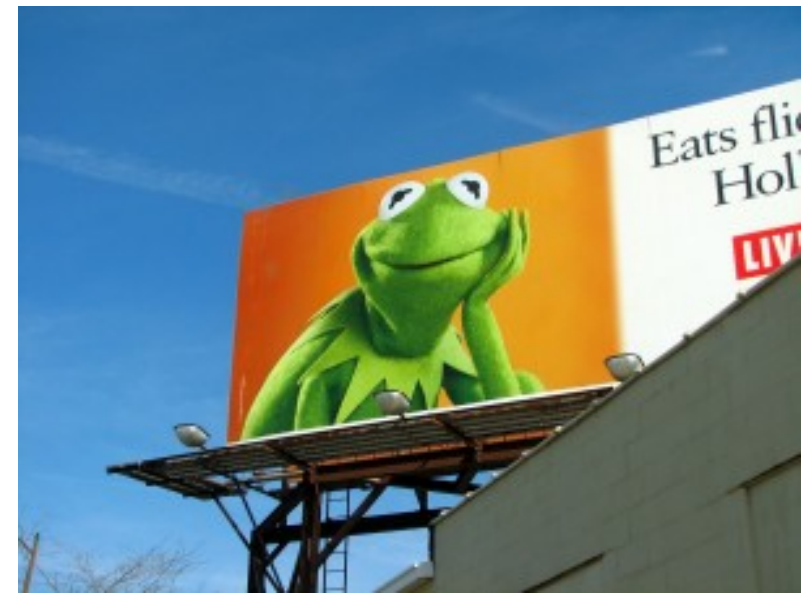

Jan Tik - Eats Flies, Dates a Pig - CC BY 2.5
If you understand from your assignment that the ultimate output of your work will be recommendations on a key message to display on a billboard it will make the scope of your information seeking different than if you are creating a multi-channel campaign.

All of these message context issues must be analyzed at the start of an information search. In upcoming Lessons we will begin to develop techniques for asking, and answering, questions about the audience for the message, the facet or angles of the topic or product being researched, and who are the likely sources of information on the topic. But it is only after asking and answering the basic questions about the initial task assignment that you can begin to delve into the creative work of developing a more clearly outlined information process. The rest of the information strategy is highly dependent on the parameters of the information task. 


\subsection{Resources}

- How to Get Clear Direction from your Boss, by Alexandra Levit, posted 3/18/13. http://quickbase.intuit.com/blog/2013/03/18/how-to-get-clear-direction-from-your-boss/

- Resolving Ambiguity and Uncertainty, posted 9/22/11. http://leadingstrategicinitiatives.com/2011/09/22/ resolving-ambiguity-and-uncertainty-strategic-thinking-part-4/ 


\section{Lesson 4. Question Analysis: Who's the Audience?}

\section{KEY CONCEPTS}

- There are multiple audiences for most mass communication messages and different audiences must be considered at different stages in the information strategy.

- Communicators must understand the characteristics and expectations of their audience(s) as they start their information strategy.

- Key to identifying the most "high-value" audience is understanding the hoped-for result of creating the message.

- Developing a list of questions that can be asked about the audience is the first step of the message analysis process.

\section{LEARNING OUTCOMES}

After completing this lesson, you will be able to:

- brainstorm the variety of potential audiences for a message.

- consider the different attributes or expectations that specific audiences might have and how they affect the development of your information strategy.

- articulate message "purpose” and understand how the intended message outcome informs the choice of message audience.

- develop a set of questions that will help identify "high-value” potential target audiences for a messages. 


\subsection{Types of Audiences}

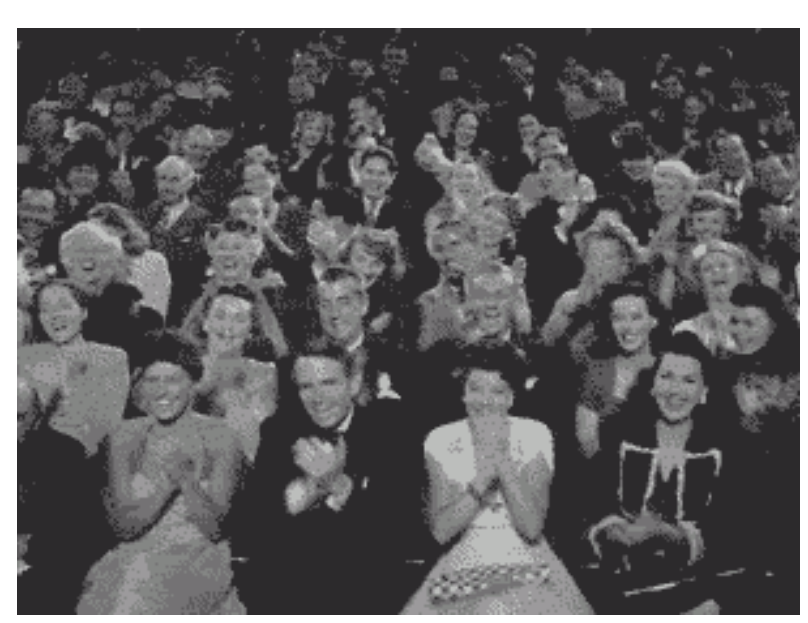

honey74129 - Audience Clapping - Public domain
As we begin the process of analyzing the message assignment archery might be a good metaphor to use. If the arrow is your message, the audience is the target you are shooting for. Without the audience "target” your soaring arrow will just fly through the air and land uselessly. Scoping out the target helps you adjust the way you deploy the arrow to most effectively hit the bullseye.

Whether you are working in a newsroom or in an advertising or public relations context, your ultimate goal as a communicator is to create messages / stories / advertisements / public relations materials that effectively engage the audience with whom you most want to connect. It is your ability to connect the message content

with the valued audience that will determine how successful your communications effort has been.

Advertisers want to expand their products' market reach. The advertising communicator's job, then, is to determine the story to tell about the product that will most effectively appeal to the audience that has been targeted for that expanded reach. They need to understand who the current audience is for the product.

\section{Questions advertisers will ask about audience include:}

- Who is the product not currently effectively marketed to?

- What do the people who use the product like, or dislike about the product?

- Who are the people who use a competitor's product and what do the competitors in the marketplace offer?

- What would an ideal customer for the product look like?

- Who buys similar products and who might find this product attractive?

Public relations professionals want to ensure positive opinions about their organization. The public relations professional's task, then, is to create messages that will influence the important stakeholders.

\section{Questions public relations professionals will ask about audience include:}

- Who are the people or groups we need to influence?

- What concerns might different stakeholders have?

- What impact would negative opinion by certain stakeholders have on the company? 
Journalists' communications work is intended to inform, entertain, persuade, mobilize and/or engage the readers or viewers of the publications for which they work.

\section{Questions journalists will about about audience include:}

- Who is reading/listening/viewing the news message?

- What is it that that audience already knows?

- What does the audience need to know?

As these examples indicate, each type of communicator has different types of people that they need to keep in mind and they need to understand different things about that audience they will be targeting. Before we discuss how to analyze these audience needs, we should point out two other audiences that communicators must consider as they develop their message. 


\subsection{Gatekeepers}

We've already introduced the concept of the "gatekeepers" and their importance in the message creation process. At the start of an information task, the most important audience might be the organizational gatekeeper who will give you an assignment and who you must please with your work. Journalists will want to keep the editor in mind as they set out to define the parameters of the assignment and strategic communicators will need to be sure they understand what their boss needs. Researching these "audiences” will be an on-the-job task and can require a clear conversation to clarify the assignment as discussed in Lesson 3. The gatekeepers' concern is that the message is constructed in such a way that the goal of the communication is accomplished. 


\subsection{Colleagues and Professionals}

Communicators also keep in mind their colleagues or professional audiences when they consider how best to accomplish a message task. These are the people you work with and others in the same profession who you want to influence or impress.

For example, public relations professionals quickly learn to produce news releases that fit the formula sought by the media organizations they are trying to influence. The only way to be effective with a news release is to have a news organization "pick it up" or run a story based on it (this is why PR is referred to as "earned media.") Effective PR specialists are those who can mimic the news style of their colleagues in the local media market and tailor their news releases so that they get the maximum exposure. In this case, the colleagues in the news organization are both part of the colleague AND the gatekeeper audience. Similarly, reporters might be tempted to write their stories in a way that they know (consciously or unconsciously) will avoid offending their most important sources (the professionals from whom they have to seek information on a regular basis).

Some advertising copywriters and art directors create ads with the hope that they will get nominated for the advertising awards that help boost careers and increase salaries. The awards are almost always judged by fellow advertising professionals.

These colleague or professional audience members exert an enormous influence on the way communicators in all media industries do their work. Communicators rely heavily on each other for ideas, and the rewards in most areas of communication work are measured by professional reputation and recognition rather than by high salaries. It is not surprising that communicators seek to create messages that will garner attention and recognition from peers in the industry.

Also, many communicators, especially those who work in news, are heavily reliant on information provided by others (government officials, industry sources, etc.). Therefore, communicators might be reluctant to do anything objectionable that will cause someone to "turn off" the information flow. That is one of the reasons news organizations may rotate journalists off a specific beat - they don’t want reporters to get too close to their sources.

And all communicators understand that if the communications they create are seen as unethical or irresponsible it harms not only their own professional careers but the credibility of the entire professional. As we will discuss in Lesson 7, it is essential to consider the legal and ethical implications of your information strategy and resulting message.

As important as it is to recognize the gatekeeper and colleague audiences when constructing a message, it is ultimately the target audience for the message that requires creative and careful consideration. Understanding to whom the message will be directed and doing the research to ensure you have identified and understand that "enduser” is a critical, and complicated, skill. 


\subsection{Target Audience}

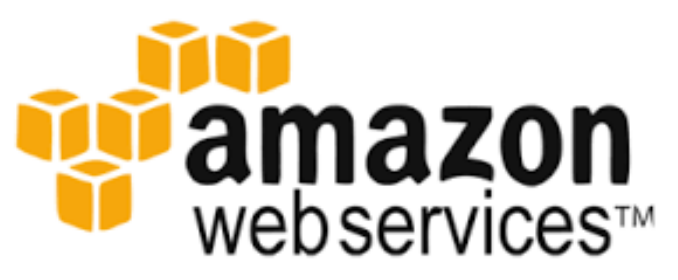

Amazon Web Service - CC BY-SA 3.0
This is the audience that most people think of when they hear the word. But all audience members are not identical. Therefore, communication researchers have devised many ways to categorize the target audience. Let's look at the the various ways target audiences might be understood.

\section{Target Audience Segments}

One way to distinguish different types of audience members is to identify the audience segment(s) into which someone might fall. Communications professionals, and especially advertisers, use a number of categories to more precisely identify who they should target with messages. Audience members can be segmented according to demographic, geographic or psychographic characteristics, or some combination of those categories. There are a number of sophisticated research tools and sources that provide detailed information about these types of categories for audience analysis. 


\subsection{Audience Segments: Demographics}

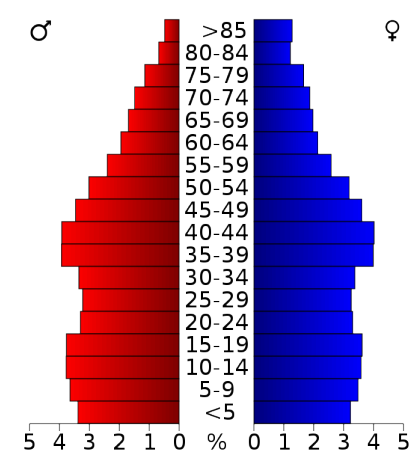

Mulat - Missouri age pyramid - CC BY-SA 2.5

There are social and economic characteristics that can influence how someone behaves as an individual. Standard demographic variables include a person's age, gender, family status, education, occupation, income, race and ethnicity. Each of these variables or characteristics can provide clues about how a person might respond to a message.

Advertisers are clearly interested in knowing, for instance, how age influences a person's need for goods and services. Think about the kinds of items teenagers purchase, the programs they watch on TV and online, and the magazines they read. Advertisers then compare those to the products that their parents purchase, the programs they watch, and the magazines they read.

The influence of an audience member's age is also a factor in the types of news messages that appeal to one group versus another. Younger people (teens, young adults) generally do not watch the national evening news on television or read a daily newspaper, for example. The news stories on those programs or in the newspaper reflect the knowledge that the audience is more mature, settled, and concerned about different topics and issues than are the younger members of the household. Each of the other demographic variables mentioned can be examined for their influence on messages and how they are tailored to meet specific audience characteristics. 


\subsection{Audience Segments: Geographics}

We all understand geographically-defined political jurisdictions such as cities, counties, and states. These are important geographic audience categories for politicians and for news stories or ads about politics and elections. Also, local retail advertisers want to reach audiences who are in the reading or listening range of the local newspaper or radio station and within traveling distance of their stores. The audience for a newspaper is generally defined as those within a specific metropolitan area-stories and ads are written to appeal to the residents of a welldefined locality. Local television stations tailor their messages to the audience reached by their broadcast signal.

Larger, more abstract geographic definitions help define the audience for national advertisers and those creating news or public relations messages for a regional or national audience. Washington Post reporter Joel Garreau (1989) argued that regional differences in North America (Canada, the U.S., and Mexico) are important markers for understanding differences in populations that span a continent. He invented nine "nations" or non-political regions whose boundaries don't correspond to any current political jurisdictions. They are New England, The Foundry, Dixie, The Islands, MexAmerica, Breadbasket, Ecotopia, The Empty Quarter, and Quebec.

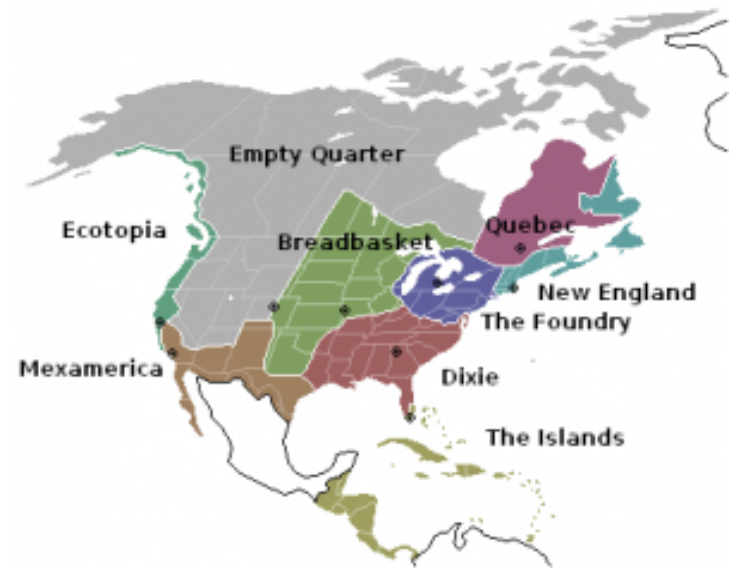

A Max J - Ninenations - CC BY 3.0

For one example of how Garreau determined the boundaries for each "nation," we can look at his examination of three major cities in Texas. By political considerations, the three are all part of one jurisdiction: the state of Texas. But to Garreau, Fort Worth is actually part of the Breadbasket because of its strong cattle-town heritage; San Antonio, with its large, urban Spanish-speaking community fits into MexAmerica; and Dallas is part of Dixie, with dramatic social change and economic growth.

These distinctions may be irrelevant to those who draw political boundaries, but the cultural implications are crucial for those who create messages. Audience members for some types of messages in San Antonio cannot be characterized as "Texans" or even "Southerners" if one of their main cultural and regional identifiers is their close affiliation with other inhabitants of "MexAmerica." Garreau’s characterizations have been widely accepted by media professionals, businesses and social scientists around the country.

Another geographic definition segments audiences into rural, urban, suburban, and edge communities (the office 
parks that have sprung up on the outskirts of many urban communities). These geographic categories help define rifts between regions on issues such as transportation, education, taxes, housing and land use.

Politicians have long understood that voters can be defined using these types of categories. Those who create media messages pay attention to these categories as well. Newspaper publishers in major metropolitan areas, for example, have long struggled with how to maintain their focus on the central city that defines the newspaper, while also attracting and keeping readers who live in the suburbs and work in an edge community high-rise office building.

Demographic and geographic audience characteristics are gathered from many sources. These include the U.S. Census as well as thousands of individual studies and research services conducted by media industry professionals. 


\subsection{Audience Segments: Psychographics}

\section{How To Use Psychographics To Understand Your Market}

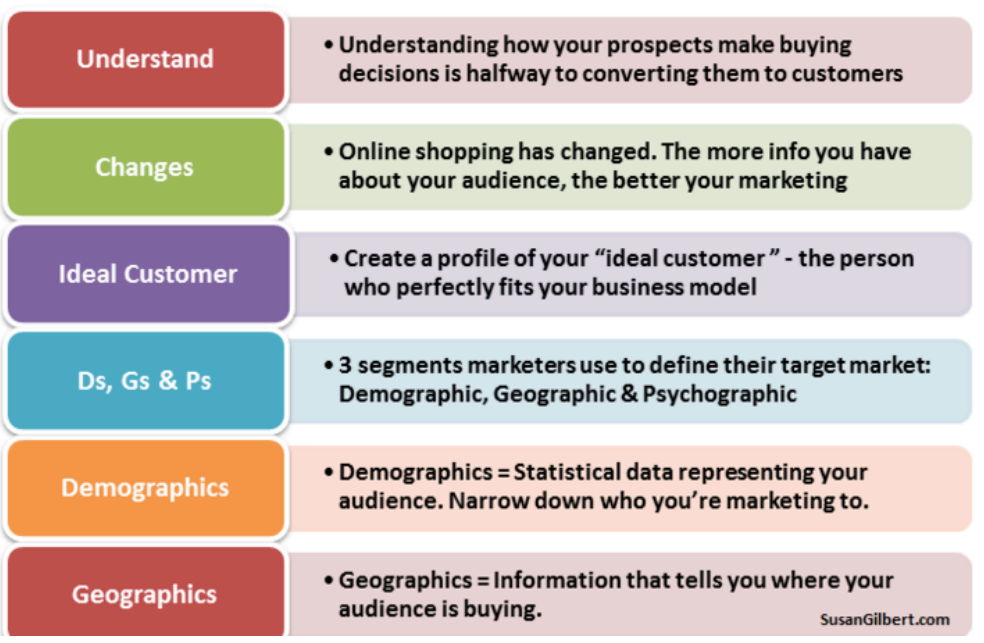

Karlhain - Different Ways to Use Psychographic Data in Online Marketing - CC BY-SA 4.0

Psychographics refer to all of the psychological variables that combine to form a person's inner self. Even if two people share the same demographic or geographic characteristics, they may still hold entirely different ideas and values that define them personally and socially. Some of these differences are explained by looking at the psychographic characteristics that define them. Psychographic variables include:

Motives - an internal force that stimulates someone to behave in a particular manner. A person has media consumption motives and buying motives. A motive for watching television may be to escape; a motive for choosing to watch a situation comedy rather than a police drama may be the audience member's need to laugh rather than feel suspense and anxiety.

Attitudes - a learned predisposition, a feeling held toward an object, person or idea that leads to a particular behavior. Attitudes are enduring; they are positive or negative, affecting likes and dislikes. A strong positive attitude can make someone very loyal to a brand (one person is committed to the Mazda brand so she will only consider Mazda models when it is time to buy a new car). A strong negative attitude can turn an audience member away from a message or product (someone disagrees with the political slant of Fox News and decides to watch MSNBC instead).

Personalities - a collection of traits that make a person distinctive. Personalities influence how people look at the world, how they perceive and interpret what is happening around them, how they respond intellectually and emotionally, how they form opinions and attitudes. 
Lifestyles - these factors form the mainstay of psychographic research. Lifestyle research studies the way people allocate time, energy and money. One of the most well-known lifestyle models is the Values and Lifestyles System (VALS ${ }^{\mathrm{TM}}$ ) devised by research firm Strategic Business Insights. The model Vars categorizes people according to their psychological characteristics and their resources. Advertisers use it to determine what kind of products and advertising appeals will best work with an anonymous audience member who falls into one of the eight categories, or mindsets, in the VALS ${ }^{\text {TM }}$ model.

For example, someone who falls into the "Striver" category is said to be seeking self-definition, motivation and approval, and is low on economic, social and psychological resources. The "Innovator" group is comprised of successful people with high self-esteem and high income, with a wide range of interests and a taste for finer things.

These categories are most useful for advertisers in helping determine a "unique selling proposition" that would be most appealing to one type of person or another, but they also help other message creators understand WHY advertisers support the types of media they do and why some types of messages are created while others are not. 


\subsection{Combining Segment Data}

As audience segmentation techniques become more sophisticated, we see new ways of organizing and clustering individuals according to a combination of characteristics. For instance, the Jefferson Institute has created a project called "Patchwork Nation."

According to their website, Patchwork Nation "aims to explore what is happening in the United States by examining different kinds of communities over time. The effort uses demographic, voting and cultural data to cluster and organize communities into 'types of place.' Patchwork divides America’s 3,141

counties into 12 community types based on characteristics such as income level, racial composition, employment and religion. It also breaks the nation's 435 congressional districts into nine categories, using the same data points and clustering techniques."

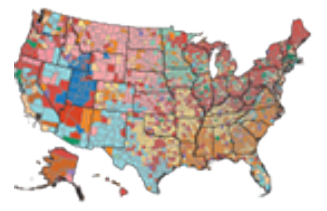

http://www.patchworknation.org/

The characteristics of Patchwork Nation locations incorporate demographic, psychographic and political data to generate a map of the country that might be used to define an advertising audience, explain voter behavior for a news story, or target a community for a PR campaign. Examining the elements of regional characteristics can give you ideas about the diversity of audiences and an appreciation for the challenge of understanding how best to reach specific segments. 


\subsection{News}

Journalists produce their work with the readers, listeners or viewers of the publication for which they work in mind. A journalist who works for the daily news organization in a town needs to understand the characteristics of subscribers. And if they work for a particular beat, for example, the business section, they need to understand what it is that readers of that section are looking for and how they would use the information they get.

Why does this matter? If journalists don't create stories that inform and engage their audience those people will find other outlets to satisfy their information needs. Journalism serves not only a public need, it is also a business and a business without customers won't be in business for long.

News organizations conduct user surveys and track audience behavior just as other kinds of companies do. The better journalists are able to understand their readership the better able they will be to anticipate and address their audiences needs.

\section{Quick brainstorming:}

Think about how the Miami Herald's audience might differ from the Minneapolis Star Tribune's (demographics, geographic, psychographic aspects) How might these audience characteristics influence a reporter writing about immigration for the Miami Herald versus the Star Tribune?

For those journalists who work as freelancers (defined by Merriam-Webster as "a person who pursues a profession without a long-term commitment to any one employer") it is essential that they learn about the target audience for the publication to which they want to pitch a story. If they don't understand the characteristics of the audience who reads Sports Illustrated versus The Atlantic, they will not be able to effectively position (or "pitch") their story idea.

In the case of pitching a story idea, they need to understand that the publication's editor is the ultimate decider on whether they get the assignment or not, and the editor's ultimate concern is to keep the publication's audience satisfied. In order for the freelancer to get the "gatekeeper's" go-ahead on a story idea, they must demonstrate they understand who the target audience is for the publication and what will appeal to them. 


\subsection{Advertising}

In an age of increasing competition and consumer choice advertisers must have a highly developed understanding of the audience (customers or consumers) they want to reach. Audience research is, perhaps, the biggest information gathering task for advertisers. Information about potential or desired audiences is required at every stage of developing an advertising campaign.

The kinds of questions an advertiser will want to answer about their potential audience include:

- Who are our current customers? You need to know who you are already reaching, and how to keep them as satisfied customers.

- Who are our competitors' customers? Understanding who uses the competitors' products or services is key to figuring out how to create a campaign that could convince them to try your company's products.

- What do our desired audience members watch / read? Knowing where to find the kinds of customers you want to attract is an essential part of media buying work. The dollars spent placing advertisements will be thrown away if the message doesn't reach the audience you desire.

- How happy are our customers with our products? Keeping a pulse on consumer attitude and opinion of your product will help to refine the story you want to tell.

\section{Quick Brainstorming:}

You're producing ads for a new energy drink. What attributes of the drink would you promote if you were placing an ad in Glamour magazine versus a commercial on Duck Dynasty? How would knowing the audience for those media outlets inform you?

Until you have a set of questions to ask about the target audience, you won't know how to go about finding answers. 


\subsection{Public Relations}

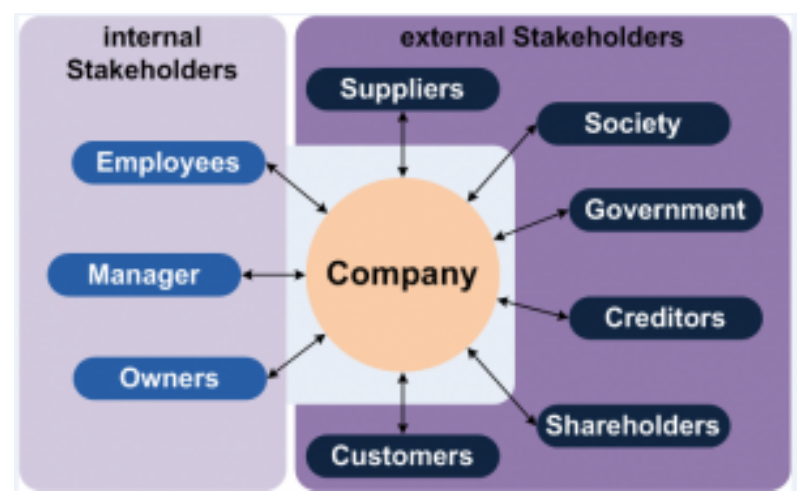

Grochim - Stakeholder - CC BY-SA 3.0
In public relations work the target audience is often referred to as the "stakeholder." Defined by MerriamWebster as "one who is involved in or affected by a course of action" the stakeholders are those groups of people that an organization must positively influence. Just as the advertising message is intended to influence customers to regard your product positively, the public relations message is intended to influence stakeholders to regard your organization positively.

Stakeholders whose opinions or actions can positively or negatively affect an organization include:

- Customers: people who don’t feel good about a company

won’t buy their products

- Investors: bankers, stockholders, financial analysts and others who have committed (or advise others to commit) funding to an organization won't maintain their support if they don't believe in what the company is doing

- Legislators / government regulators: lawmakers who feel a company or industry is doing harm, or who get complaints from their constituents, will be likely to propose restrictions or regulations

- Employees: the people who work within an organization must have high regard for their employer or they won't be good representatives of the organization

- Activists / philanthropic groups: organizations that have an interest in the area in which the organization operates can exert economic or policy pressure if they don't support the organization's work

- Business partners: most organizations work with a network of suppliers, vendors, and other types of business partners who help them maintain their position in their industry or field; partners are an important stakeholder audience for PR professionals

\section{Quick Brainstorming:}

A 14 year old died after drinking, over the course of a few hours, three of the energy drinks your company sells. Which "stakeholders" would you need to reassure that your product is safe? Why do they matter? 


\subsection{Who's the Audience for News?}

In some ways, the audience for journalistic messages is the most concrete and pre-determined of the three communications professions' work. Journalists write for publications or produce reports for media outlets that have a great deal of information about their subscribers or viewers. With the ability to track digital readership, journalists know what articles people read. At the start of the message analysis process journalists must ask a set of questions about their target audience that will help them identify the treatment of the topic about which they will be writing and make decisions about the kind of reporting they must do.

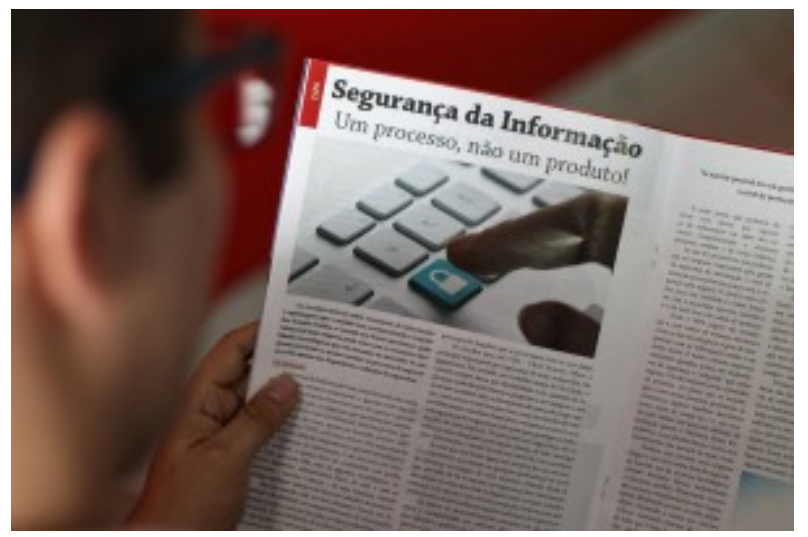

Luis Wilker Perelo WilkerNet : CCO Public Domain

Understanding the audience that uses the publication or media outlet for which they are producing a news report will help clarify some of the following questions:

- WHO: Who reads / views the publication? Who would be interested in this topic? Who needs to know about this topic? Who is the media organization interested in attracting with its offerings?

- WHAT: What would the potential audience member want to know about the topic? What kind of report would be most informative or helpful for the audience? What kind of information will be useful? What does the audience already know about this?

- WHERE: Where else do people interested in the topic find information? (For freelancers) Where should I pitch my story idea?

- WHEN: When does the audience need to get this information (is this fast-breaking news, or something that will be used as analysis after the event?)

- WHY: Why does the audience need to know this? Why does the audience care? Sometimes the audience member just wants to fill empty minutes with a news message (reading news briefs on a mobile device while standing in a line or eating alone at a restaurant). Sometimes the audience member needs to answer a specific question (who won the baseball game this afternoon? when does the movie start?). Each of these "why" questions suggests a different strategy for the communicator.

- HOW: How can we best communicate to the audience? How much background do they need to understand what we are writing about? How technical can we be? How might the audience react to this report? 


\subsection{Who's the Audience for Advertising?}

Advertising professionals have also developed a standard set of questions that they ask at the start of a message task, many of which specifically address audience considerations. These questions also address elements of the subject matter of the ads, the best approaches for creating the ad copy and placing the ads in the most appropriate vehicles. We will come back to many of these questions in subsequent lessons.

- What should our advertising accomplish? Again, sometimes the audience member just needs to find a nearby place to buy a specific product, or

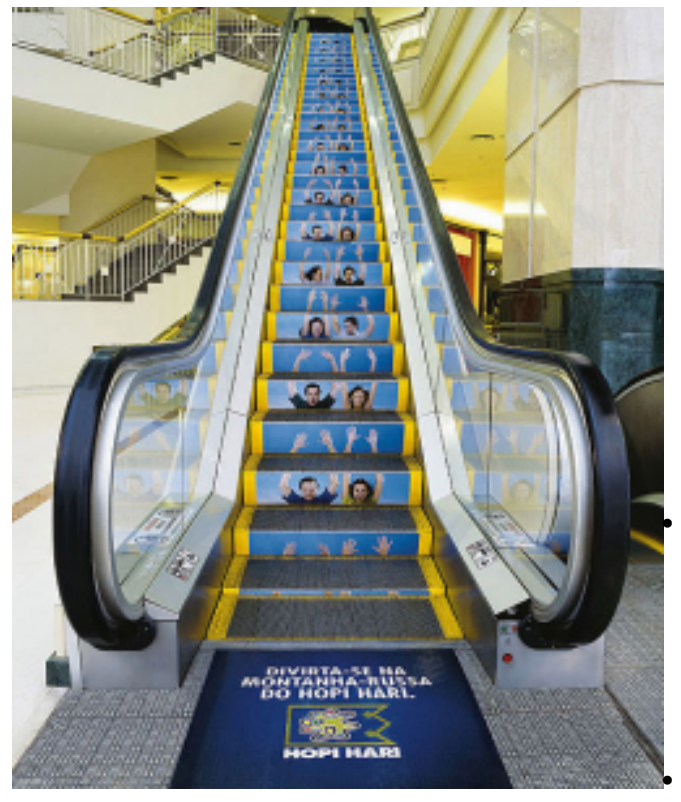

LiveU4 - Montaña Rusa Hopi Hari - CC BY-SA 2.0 the hours and phone number of a business. Filling that immediate information need for the audience member requires a different strategy than trying to encourage the audience member to change their brand loyalty, think positively about your service, purchase your product. You want to know if the ad is intended to fill an immediate information need or to include a "call to action" on the part of the audience member.

To whom should we advertise? Who was the target audience in previous campaigns and who has not been targeted yet that should be? Who are the competitors' customers?

What should we say that will most effectively convince the audience to respond to our call to action? What have our client's ads said to similar audiences in the past? What do our client's competitors' ads say?

- How should we frame our message for this specific audience? How will our proposed creative strategies work for this client's messages? How do our competitors position their creative strategies?

- Where should we place or message to reach this audience most effectively? Which media will best reach our target audience?

- How much should we spend in order to reach this audience in a cost-effective way? What has our client spent in the past? How much do our competitors spend? 


\subsection{Who's the Audience for Public Relations?}

Public relations professionals ask a similar set of questions when they are doing their strategic planning research. Again, these questions apply not just to the audience aspects of the message task but also to the other parts of the information strategy process.

- Defining the problem: Monitor audience knowledge, opinions, attitudes, and behaviors to answer the question, "What is happening now?" among our stakeholder audiences? In our industry or area of activity? Sometimes your goal is to help your client provide good customer service to the audience. Sometimes the goal is to positively affect audience members' opinions. You need to understand what you are trying to accomplish in order to be successful in reaching the audience with your PR message(s).

- Identifying the stakeholder audiences: Who has an interest in or to whom might the public relations message be addressed? Sometimes you are focusing on a single stakeholder and sometimes you need information for an entire campaign which would address a variety of stakeholder concerns.

- Planning and programming: Use the information gathered to determine what should be done to most effectively reach your stakeholder audiences. What type of message(s) will best address your goals and engage the audience?

- Taking action and communicating: Design a message or program to meet specific objectives by answering the questions: "How do we do it and say it to reach our audiences?” If your goal is to create content that encourages audience members to share (in other words, for them to become your "advocates" through word-of mouth-endorsement), you have to ensure that the content is useful and easy to share. 


\subsection{Summary / Resources}

It should be clear that for every type of communication message that this step of generating the questions you need to ask about the audience is very important. The number and variety of questions that might be asked about the audience also indicate the many different ways a communications professional can approach an information and message task. Brainstorming with colleagues and gatekeepers about the nature of the target audience at the start of the information strategy process is an essential step to ensure that you will be able to conduct an efficient and effective search for appropriate information.

Steps To Decoding Your Target Audience, by Jayson DeMers, Forbes, 8/27/13: http://www.forbes.com/sites/ jaysondemers/2013/08/27/6-steps-to-decoding-your-target-audience/

Garreau, J. (1989) The Nine Nations of North America. New York: Avon Books. 


\section{Lesson 5. Question Analysis: What's the Topic?}

\section{KEY CONCEPTS}

- Every media message is about something (a company, an event, a topic, a person.)

- No matter what that something is, there are multiple aspects or angles that can be examined.

- Analyzing the angles allows communicators to place reasonable parameters around a message’s content.

- Brainstorming angles and developing new ideas about a topic are essential to creative communications work.

\section{LEARNING OUTCOMES}

After completing this lesson, you will be able to:

- analyze a broad topic to identify angles or aspects that might be researched.

- tie the message content to the needs of the identified audience.

- generate new and interesting ideas for messages.

- develop point-of-view diagrams, idea maps, and other techniques to spur idea generation.

- understand how you can effectively use the above techniques in the development of story ideas.

- use observation as an idea generation strategy.

- understand how identifying relevant disciplines can aid in brainstorming topic angles.

- identify the conventional wisdom and stereotypes related to the topic.

\section{Overview}

If you would like to see steam coming out of a research librarian's ears, just go up and ask a question like, "Do you have anything on the environment?" A trained research librarian will quickly begin a "reference interview" designed to help the person asking that incredibly broad question to narrow and clarify his/her actual information need.

- What part of the environment? Air? Water? Soil? Weather? Plants? Animals?

- Is there a particular issue? Global warming? Pollution? Renewable energy?

- Is there a certain geographic area of interest? North America? Antarctic? Minnesota?

- Why are you seeking the information? Writing a term paper? Checking a specific fact? Just 
interested in keeping up on the topic?

In this lesson we will discuss the importance of having that "research interview" with yourself. In Lesson 4 you learned about the importance of asking specific questions about the audience for whom your message is intended. In this Lesson we will develop strategies for asking specific questions about the topic of your message and techniques for coming up with interesting, fresh, and effective topic angles. 


\subsection{What's the Angle?}

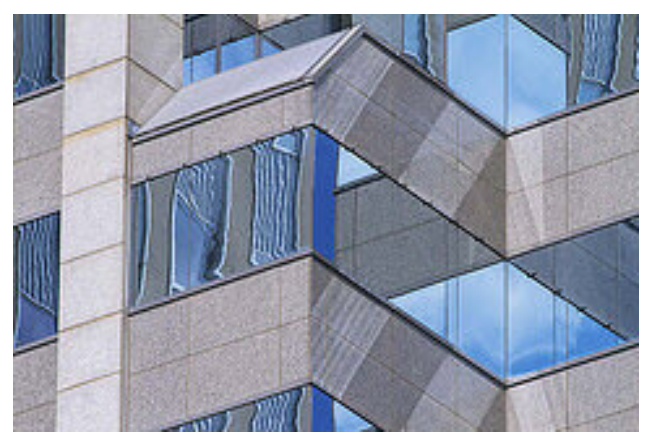

You arrive in your newsroom and the editor stops by to say, “ There's going to be a decision about the expansion of the light rail line. We need something for the local section.”

At the morning strategy meeting for the railroad company client your strategic communications firm represents the account manager says, "Our client is concerned that people aren't thinking positively about traveling by train. We need some ideas."

cobalt123 - Angling for Reflections (Chicago) For each of these scenarios, the topic is transportation by rail. But CC BY-NC-SA 2.0 depending on the audience that might be identified as the target for the message, the angle of that broad topic could be very different.

Let's play through scenarios for news and strategic communications. 


\subsection{News Angle}

For a local news story, the people that read the section are interested in or concerned about things going on in their community. There could be a number of angles about the light rail line and different questions that could be asked:

- ECONOMIC: What will be the cost of the line and impact on taxpayers?

- HOUSING: Will light rail affect property values for nearby homeowners and if so, how?

- QUALITY OF LIFE: Will construction disrupt current neighborhoods or businesses?

- PUBLIC SAFETY: What has the existing light rail line done to public safety, accidents or crime?

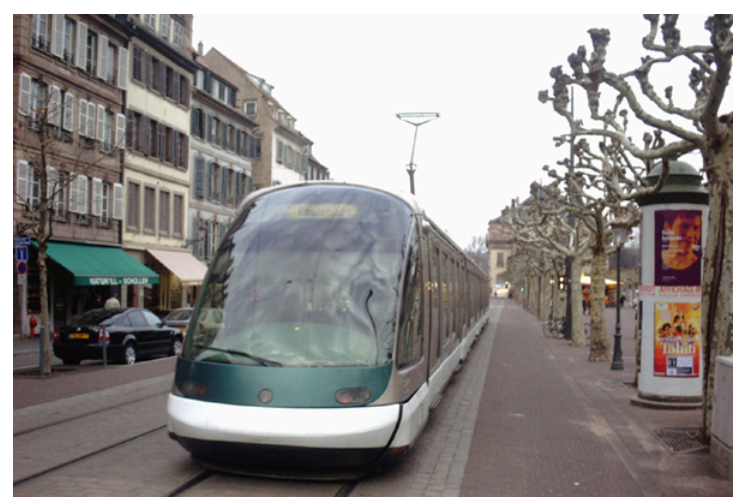

Pontauxchats - Tramway Strasbourg Broglie - GNU Free Documentation License

If the story was being written for a business news segment there would be a different set of questions based on the interests and needs of the audience for business news:

- How will construction affect the local economy or employment?

- What businesses might prosper (or be hurt) if the proposal goes through?

- What has happened to businesses on the current line?

- How will the construction contractors be selected?

Depending on the audience needs, the questions that might be explored about a broad topic like light rail transportation can quickly get quite specific. This specificity helps to narrow the focus of the information you will need to find. 


\subsection{Strategic Communication Angle}

In the case of advertising and public relations messages the target audience and the message's goals will be critical to figuring out the appropriate topic angle.

If, for example, the railroad's communication concern is how to expand the appeal of train travel to people not currently using trains, the questions you might want to ask (and answer) include:

- What methods of transportation are travelers currently choosing other than trains?

- What are the demographics of current train travelers (and what demographics might be ones to be targeted?)

- What reasons do travelers give for their choosing particular traveling modes?

If, on the other hand, the communications' goal is to gain support in the legislature for an expanded train system, key questions that maybe need answers include:

- What are the environmental advantages of train travel over other transportation modes?

- How might an expanded rail system benefit local economies (jobs, commuter travel, health of rural communities?)

Once again, the topic is broadly train travel, but the possible angles to the topic and the questions that must be examined become increasingly specific (and manageable) with some brainstorming. 


\subsection{Key Questions to Answer}

Here are some key questions to be answered in this step of the message analysis process:

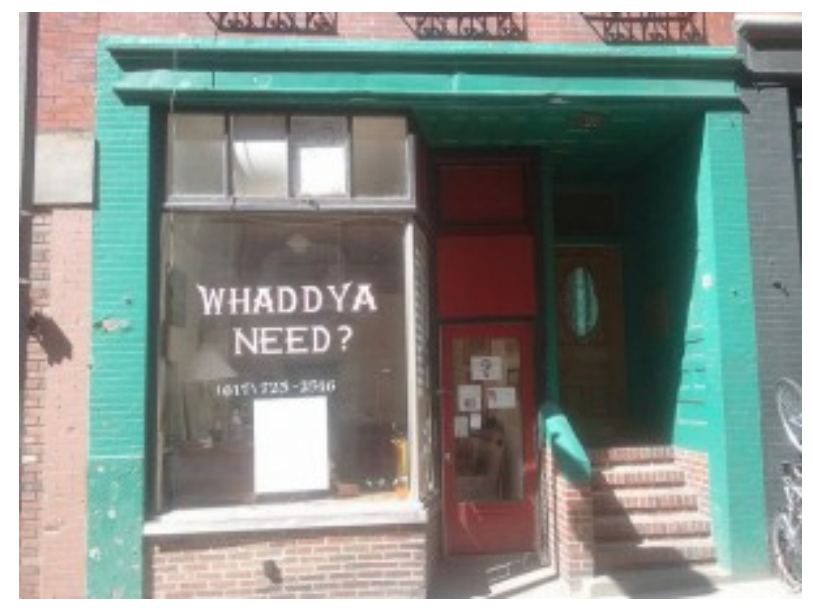

Mike Linksvayer on Flickr: Public Domain
Why has this topic or the need for this message come up?

What is the broad topic of interest? What product, service, event or issue at the center?

What are the possible "angles" of the topic that could be considered?

What must we know about the topic before beginning the information search?

Who would know about or have a perspective on the topic?

If you can clearly answer these questions, you'll have a

solid foundation for building your information strategy.

The communications objectives are different for journalists, advertising professionals, and public relations practitioners. So, too, is the information needed for each media professional to accomplish their message goals. Where a journalist may need to become an "instant expert" on a topic they will be covering, for the PR professional it may be more important to understand the prevailing opinions about the topic, and for the advertiser finding information that helps him understand the audience's interests in the topic to determine the most appropriate "selling proposition” would be key.

Let’s look at an example of answering these content questions from each perspective.

\section{Key Questions Scenario}

There is an explosion on an oil rig in the Gulf of Mexico resulting in a devastating oil spill affecting vast stretches of the Gulf Coast.

Journalism: Your editor tells you to work on a story about the repercussions of the oil spill. The general topic is "oil spill” or, to be more specific, this particular oil spill.

What might one of the angles be for this broad topic? Certainly the environmental issues being raised are one important angle. But even that is a broad topic that can be broken down into water quality, impact on birds, impact on fish, or impact on wetlands and beaches. If you picked economic issues as the angle there could be more specific focus on the economic impact on tourism or "Big Oil” companies or southern Louisiana fishermen. Depending on the angle you pick 
you'd need to make sure you understand the terminology used by specialists and identify some of the kinds of people who would have an understanding of the topic. These potential sources will be among the first stops on your path for seeking information.

Public Relations: You work in the PR department for the oil company which owns the rig. You would be concerned with understanding the groups of people with whom you need to communicate. You would want to launch your crisis communication plan if you had one. You would need to understand thoroughly the nature of the situation, what happened and why. You would need to identify the potential stakeholders that might be affected by the spill. You would have to find information about how other companies facing similar situations managed their communications. You would need to understand the actions the company is taking and be able to talk positively about them to the media.

Advertising: Your advertising agency is doing the ad campaign for the Department of Tourism for one of the states affected by the oil spill. The information you need could include what potential visitors' concerns and fears are about the conditions in your state, actions the Department of Tourism is taking to minimize impacts on visitors, and the programs and plans tourism-related businesses are implementing to keep visitors coming. 


\subsection{Idea Generation}

Every message begins with an idea. While it is true that many tasks are assigned by others, the actual creative work of crafting a message still rests on the skill and imagination of the individual doing the information searching and writing (that's you!)

One important skill that good communicators develop early in their careers is the ability to understand what it is possible to ask about. Any idea is fair game. Because solid information strategy skills allow you to find answers to just about anything, you are not limited to those questions that can be answered easily and quickly. Advanced

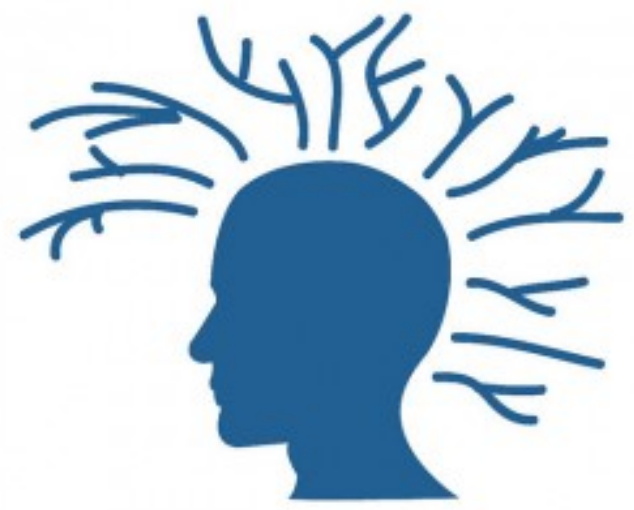
methods for finding these answers free you up to ask unusual, different, and perhaps difficult questions.

A variety of techniques help you generate ideas for messages. Brainstorming, making idea maps and point-ofview diagrams, keeping a journal or daybook for

Greg Williams: CC BY 2.0 scribbling notes, and reading everything you can get your hands on are all methods you can use to provide grist for the idea mill. A well-developed sense of curiosity will open you to new ways of looking at the world around you. Common sense and healthy skepticism (not cynicism) keep you grounded.

Donald Murray, in Writing for Your Readers (1992), describes the idea-generation techniques of idea mapping and creating point-of-view diagrams for communication professionals. Idea mapping, he explains, is a more creative way of exploring a subject than using traditional subject outlines. The central, broad subject or topic is drawn in a circle on the middle of a page. All of the related ideas that occur to the "mapper" are drawn out along lines that emerge from the center circle. The new lines stemming from the center idea are like branches on a tree, each of which may have more related, narrower ideas that branch out from the ideas derived from the center.

In idea development, this technique is not intended to serve as a definitive method of topic outlining, but as a quick and intuitive first step in thinking about possible angles of the topic. You may need to spend no more than five minutes making a map.

A point-of-view diagram uses a similar technique. A subject or topic is again drawn in a circle in the middle of a page. Draw as many "arrows" pointing inward — toward the central topic_-as you can imagine. The arrows represent the different people or organizations whose points of view on the subject or topic can be tapped. By diagramming the topic in this way, you can generate a variety of perspectives on that idea and even begin to identify possible audiences or interviewees for the message.

It is easy in the idea generation stage to fall into overuse of clichés and stereotypes. It is a challenge finding a fresh, 
unique perspective for the message on which you are working. One of the best ways of ensuring that you'll avoid clichés and maintain a fresh perspective is to truly understand all angles or perspectives from which a message topic might be seen.

As a journalist dealing with the issue of the U.S. government drilling for oil in the Alaskan wildlife refuge, for instance, you would probably expect widely varying perspectives from an environmentalist, a major oil company executive, the governor of Alaska, from a political science professor at the University of Minnesota, and from a park ranger in Alaska. As an advertising professional for the National Park Service, you might use many of these same sources to understand the topic even though your intent for the information will be quite different than the journalist's. For any types of media, however, getting these collective, diverse perspectives will help you to find a fresh approach for addressing this issue. This will also help you narrow a broad topic to an interesting and manageable sub-topic. 


\subsection{Observation for Idea Generation}

You should also consider yourself and your personal observation about what is going on around you as a key source of ideas. Having a "nose for news" generally means that you are tuned in to your surroundings and can gauge when something is "off” or different and worth checking into. For example:

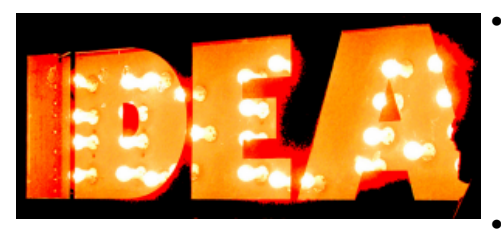

Mike Linksvayer: Public Domain

- Noticing the long lines in front of the automatic teller machines, for example, may be the start of a PR effort for your bank client to improve customer service

- Observing that a waterfront is eroding from the massive number of people who jog by the lake shore can lead to a series of news articles on conflicts between the goals of recreation and preservation in park systems.

- Seeing "teachers wanted" classified ads may signal the education reporter that a decade of teacher layoffs is ending.

- Standing in the grocery checkout line behind teenage shoppers can alert the advertising researcher to do further study on which family members purchase the groceries.

Keeping your eyes open, being curious about what is going on around you, listening in to what people are talking about - all of these are ways that you can generate new ideas or develop fresh angles on a topic.

Bus stop posters, bumper stickers, bulletin board copy, T-shirt messages, and other informal messages visible in every community (and in digital sites like Pinterest) can also trigger ideas or perspectives for the more formal part of the information strategy.

If you are in charge of an advertising account for a shoe manufacturer, being attuned to what people are wearing in different situations might give you an idea for an interesting approach to take in an ad campaign.

If you are writing about light rail issues, attending meetings where community members express their concerns will give you tips on aspects of the topic that you need to research more deeply.

Communicators need to keep their eyes open to these informal information sources. They can provide clues about changing public opinion, lifestyles and attitudes in an area - and can signal emerging trends. 


\subsection{Types of Observation: Routine}

Routine observation is the most frequently-used type of observation. It is "routine" in that it involves simply going to the scene of the action and observing. Professionals in all fields of mass communication perform these routine observations. The things that you might see and hear can spur new ideas.

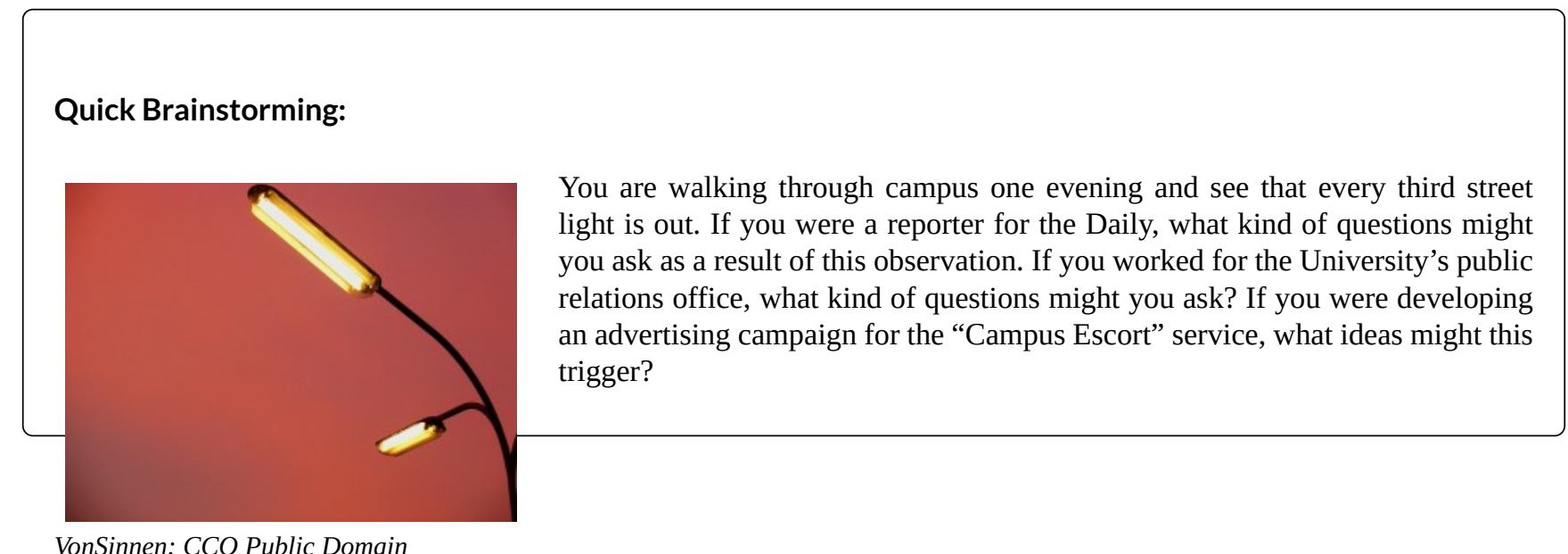

VonSinnen: CCO Public Domain 


\subsection{Types of Observation: Participant}

Participant observation involves joining or living with a group and becoming a part of the action. Members of the group being observed — for instance, prison inmates - may or may not know the observer's true identity, but he or she is seen as being part of the group.

This method of observation is common in sociological and anthropological research, as well as in communication research. It allows the information gatherer to get direct experience and to reduce reliance on the expertise or testimony of others. In becoming part of the "scene," the observer begins to understand it as an insider and come up with ideas that might need to be explored.

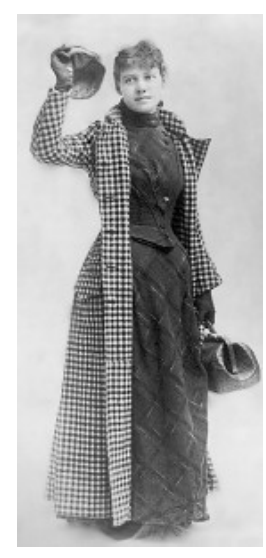

Nellie Bly. Library of Congress. Public Domain
Nellie Bly was an early proponent of participant observation as a way to get an enterprising news report. She arranged to have herself declared mentally incompetent in order to be committed to a mental hospital so that she could see, first-hand, the conditions in which mental patients lived.

Participant observation is an expensive technique, requiring a substantial amount of time in the field. It is also fraught with ethical and legal issues. Members of ABC News' Prime Time Live got jobs in several Food Lion supermarkets in order to place hidden cameras and capture video of employees re-dating the expiration labels on old meat and, in some cases, repackaging the meat to be sold as fresh. The report resulted in a lawsuit against $A B C$ and in a jury verdict that awarded Food Lion \$5.5 million in damages. The television network eventually prevailed in having the verdict overturned, but not until it had spent millions in legal fees. (Barringer) This is why it is important to consider the ethical and legal implications of the techniques you employ in researching as we will discuss in Lesson 7. 


\subsection{Types of Observation: Unobtrusive}

\section{Types of Observation: Unobtrusive}

In some circumstances, unobtrusive observation may be more effective than participant observation, especially if the observer's presence will change the situation under observation.

Hidden camera investigations have traditionally been one of the most obvious types of unobtrusive observation examples. After careful deliberation within the news organization about the ethical and legal ramifications of using a hidden camera, a journalist may use unobtrusive observation techniques that capture activities or conversations. Investigative reports may rely on such observation

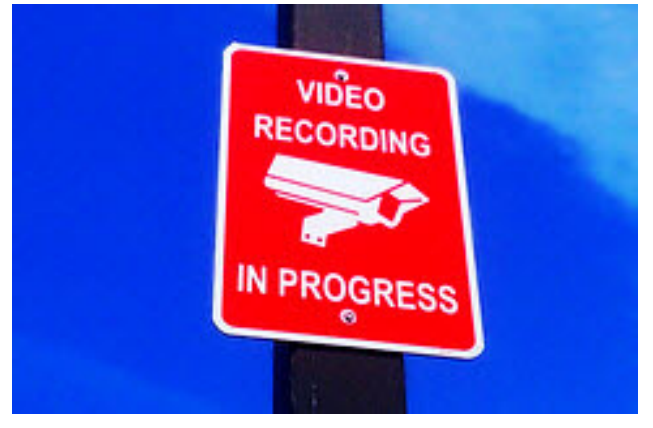

Mike Mozart: CC BY 2.0 techniques as a way to document improper behavior or malfeasance.

Unobtrusive observation techniques also are used by advertising professionals. A very large Chicago agency had an ongoing research project in a town of 8,000 to 12,000 about 150 miles from Chicago. Advertising researchers visited the town on a regular basis and politely listened in on conversations in coffee shops and churches, hairdressers' shops, and taverns.

The agency professionals were trying to learn what is important to average folks, what occupies their hearts and minds. In the process, they thought they would gain clues as to why people don't always follow cooking directions for frozen pizzas, or what they really think about prunes. The advertising professionals learned to prepare themselves well for their visits. One agency employee's too-hip hairdo marked her as an outsider in her observer role, while another employee learned that driving a pickup truck rather than his Audi to town would help him blend into his observation environment. (Stern)

A more recent version of this type of observation involves ad agency personnel asking consumers to take video cameras into their homes to record their every-day activities in the kitchen, while cleaning the house, and other typical household behavior. The idea is to learn more about how consumers use products in their day-to-day lives rather than in the artificial environment of a focus group room or a mock living room set up in a research lab. Viewing videos posted by consumers on YouTube as they talk about how they use various products, along with their opinions about them, would be another way of conducting an unobtrusive observation. 


\subsection{Types of Observation: Social Listening}

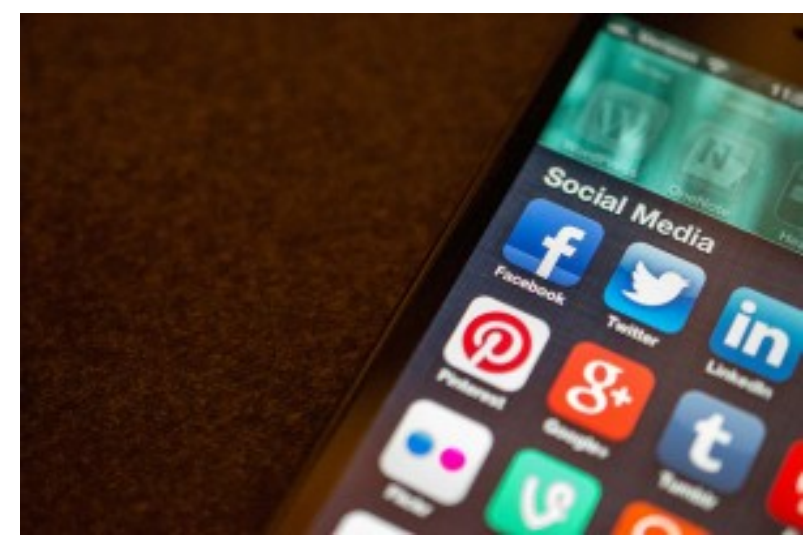

Jason Howie: CC BY 2.0

The rise in social media has provided communicators with another excellent technique for using unobtrusive observation for idea generation. Reading over the comments on a Facebook page for a group of fans, or the user comments on a news story on a topic might give you an idea for a fresh approach to covering a story or an issue that you had not even considered.

For public relations professionals, social listening can lead to important insights on issues that might be brewing. "Sentiment analysis" (also referred to as "opinion mining”) is one of the emerging skills required for savvy PR practitioners. It requires consistent attention to the online opinions and reactions in different social media platforms. While there are sophisticated tools to analyze large numbers of postings, even routine scanning can give you ideas for themes or trends that might require attention.

Advertising professionals can use the comments in social spaces to learn more about positive, or negative, opinions there might be about a product (or about the competition.) These comments can provide fodder for ad copy or inspire a new direction for a campaign. 


\subsection{Narrowing the Focus}

These techniques of idea mapping and observation can help you think expansively about the potential aspects of a topic but no one, especially not a busy reporter or strategic communicator juggling multiple clients' demands, can address all of those aspects. What is needed now is a way to narrow the focus.

The following set of questions can help you identify and define a more specific aspect of a topic on which to focus.

- What disciplines of knowledge might deal with this topic - and what would their focus be? To understand "disciplines of knowledge," think about the departments that offer majors on a university campus - economics, political science, biology, etc.

- What parts of the city / state / country / world are dealing with this - or how are they dealing with it differently?

- Is this a new topic? How has it evolved over time? Where might it be going in the future?

- What kind of groups have a stake in this topic and what are their positions?

Once all of these questions have been posed, you are in a position to focus selectively on some aspects of the larger question and develop an exacting standard for raising questions and seeking information to address your information needs. Going through this routine frequently allows you to revise or refine the question, making your information seeking tasks much more manageable.

For example, if the broad topic is, "homelessness" the formula for focusing the topic might work this way:

Disciplines: Economics, sociology, urban planning, and psychology are a few of the disciplines that might provide insight - each would have a specific aspect on which they focus - and their disciplinary focus might inform your own.

Geographic limits: Although homelessness exists throughout the U.S., how the condition is understood and approached varies from community to community and from state to state. In one area concerns about

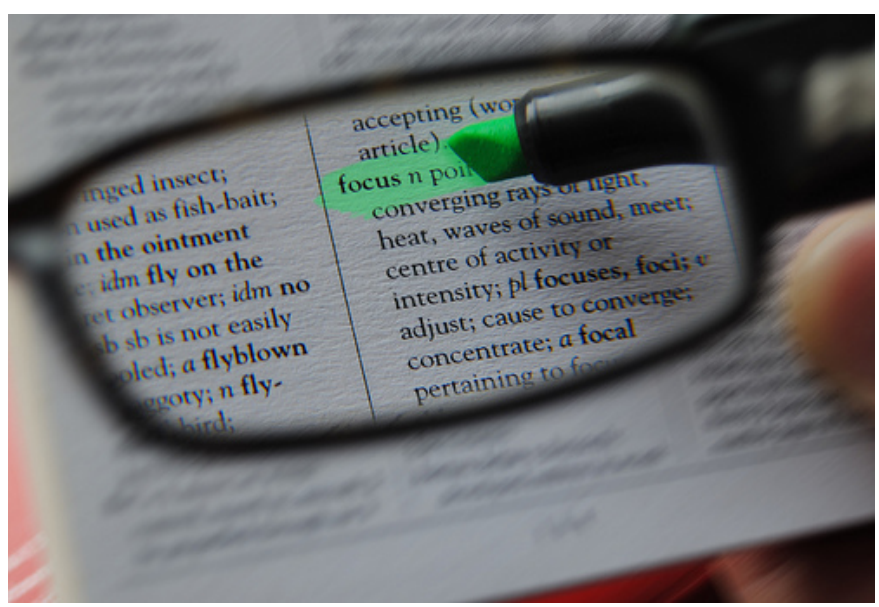

Mark Hunter: CC BY 2.0 immigration policy might be big while in another it might be how to help the homeless during cold winter weather.

Time period limits: Much of mass communication work emphasizes recency. Therefore, the newest information is likely to be stressed. However, trends in homelessness over time (particularly the last decade or so) will surely 
help put the problem into an historical context. And some types of messages would benefit from an overview of how homelessness has been handled throughout many decades since this is a problem that has been with us for a very long time.

Stakeholders: Academics, politicians, social workers, activists and advocates for the homeless have entirely different ways of approaching the issue and defining the problem. The homeless themselves are certainly another stakeholder, and one that isn’t often featured in messages about the problem. 


\subsection{Conventional Wisdom}

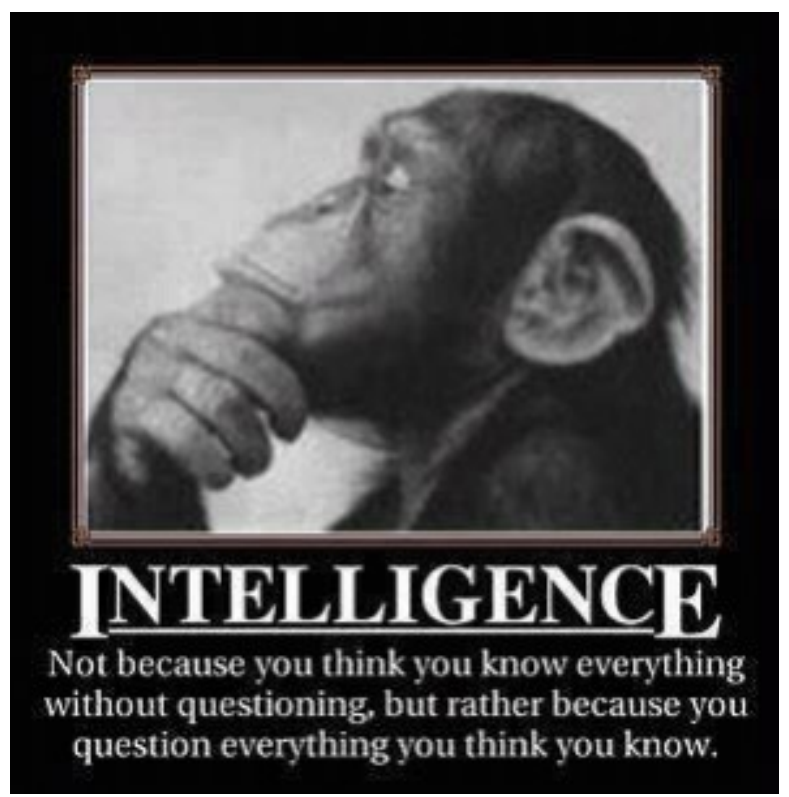

Digital Ralph: CC by 2.0

For reasons of time savings, you often concentrate on obvious or simple approaches to a message. But this may lead to a message that does nothing more than convey the conventional wisdom in an area, failing to provide the audience with a more creative, original, or, perhaps, accurate approach. The information strategy process provides you with a method for identifying fresh angles or new twists on a topic. One of the advantages of using ideamapping and point-of-view diagrams is that they help you identify what we think we know about a topic and to challenge yourself to come up with a fresh approach to the topic.

The media are often accused of being trapped by conventional wisdom. In order to get beyond the conventional wisdom, it is first necessary to understand what it is. Conventional wisdom usually contains a grain of truth. It is different than faith, blind prejudice, or stereotypes. The essential elements of conventional wisdom about any topic can usually be demonstrated in some sense. For example: conventional wisdom says that cats are difficult to train, Midwestern universities have good hockey teams, and women are good listeners. Each of these is based on some socially-arrived-at assumptions about reality.

Conventional wisdom abounds in every field and for every topic. Advertisers and marketers operated under the assumption that women generally were not big purchasers and users of technology, until a study done for a women's magazine showed that 65 percent of the women surveyed had purchased a personal computer for home use in the previous two years. And 53 percent of those surveyed said that advertising for computer-related products did not appeal to them because it was aimed at men. Advertisers trapped by the conventional wisdom about who purchases products and services lose opportunities to create messages with a fresh, new and effective appeal. 


\subsection{Conclusion/Endnotes}

One of the most important skills communicators can develop is a method for quickly and creatively analyzing potential angles or aspects of a given message topic. But that is just the first step. Just as important is learning how to focus, out of all the possible angles, on the one aspect of the topic that best matches the audience needs and the communication objectives.

As with all skills practice, open-mindedness, and curiosity will serve you well as you develop these skill sets.

\section{Endnotes}

Barringer, F. (1999, October 21). Appeals Court Rejects Damages Against ABC in Food Lion Case. New York Times. Murray, D. (1992) Writing for Your Readers: Notes on the Writer’s Craft from the Boston Globe. Guilford, CT: Globe Pequot Press, 2 ed.

Stern, A. (1991, April 29). Ad Agency Seeks Small-town Guide to Consumer Taste. Star Tribune, 3D. 


\section{Lesson 6. Question Analysis: Who Contributes Information?}

\section{KEY CONCEPTS}

- There are identifiable sources for all information.

- These sources have their own processes and motivations for information creation.

- Communicators need to use a variety of sources based on the context and content of their message task.

- Sources can play different roles and serve as different types of contributors depending on the context.

- Different disciplines of knowledge contribute different perspectives and focus on a topic.

- Libraries collect and make accessible information from all the contributors we’ve identified.

- Libraries have different characteristics and contents.

\section{LEARNING OUTCOMES}

After completing this lesson, you will be able to:

- identify the broad characteristics of public-sector institutional, private-sector institutional, scholarly, journalistic and informal contributors of information for messages.

- understand the nature, characteristics and limitations of information available from these contributors and sources.

- identify the relevant disciplines of knowledge that can contribute to an information strategy.

- identify the specific perspective a discipline of knowledge provides on a topic.

- identify the types and characteristics of libraries that might contribute to an information strategy.

\section{Overview}

Continuing with the archery analogy from Lesson 4, when you are deciding the best way to hit your target, you need to choose the appropriate type of arrow. Good archers understand that some arrows are made of carbon and are very light but shatter easily; aluminum arrows break less easily and are stiffer; wooden arrows use feathers rather than plastic for the vanes at the back end and should not be used with high-power bows. Each arrow type is chosen for its characteristics and the type of target the archer is trying to hit.

Similarly, there are many different possible contributors to an information search for a message task. One of the key analysis tasks at the start of your information strategy process is to brainstorm the possible contributors 
that might meet your information needs. This lesson will outline the types of contributors that are useful for communications professionals, how and why they create the information they create, and some of the types of message tasks they can help you accomplish.

\section{Where Information Comes From: An Overview of Contributors}

Whether you are seeking a specific fact, a good anecdote to illustrate your story, background information about the product or service you are advertising, or promotional or persuasive publications to understand different points of view, you will need to know how to find, and use, the information provided by public-sector and private-sector institutional sources, scholarly sources, journalistic sources and informal sources.

Understanding how, and why, each of these types of sources create information is one of the most important skills you will need as you start your information strategy. 


\subsection{Institutional Sources}

An institution, broadly defined, is "an organization, establishment, foundation, society, or the like, devoted to the promotion of a particular cause, product, or program. " You can see that this is a catchall term that can cover all kinds of contributors. Therefore, it helps to break this large category into two very different kinds of institutions: Public and Private.

The corner drug store is in the private sector, while the police precinct station next door is in the public sector. The elementary school maintained with tax revenues is part of the public sector, while the church-affiliated school is in the private sector.

These lines are hardly neat, however. Almost all private colleges, for instance, enroll students whose financial support comes partly from state and federal sources. Most corporations are in the private sector, but some operate with charters from the federal government, such as Amtrak (rail service) or the Corporation for Public Broadcasting.

Institutions in both the public sector (governments at all levels) and the private sector (businesses, political organizations, trade and industry associations, foundations, religious organizations, unions and professional associations, etc.) generate information for a number of purposes. You must recognize that institutions develop information for their own internal purposes and may be disclosed to you selectively and with a specific purpose in mind. Organizations as different from one another as the U.S. Department of Defense and the Women's International League for Peace and Freedom share this characteristic.

Let's discuss the distinctions between the types of institutional sources and describe how and why they create and contribute information of use to researchers.

1. http://dictionary.reference.com/browse/organization 


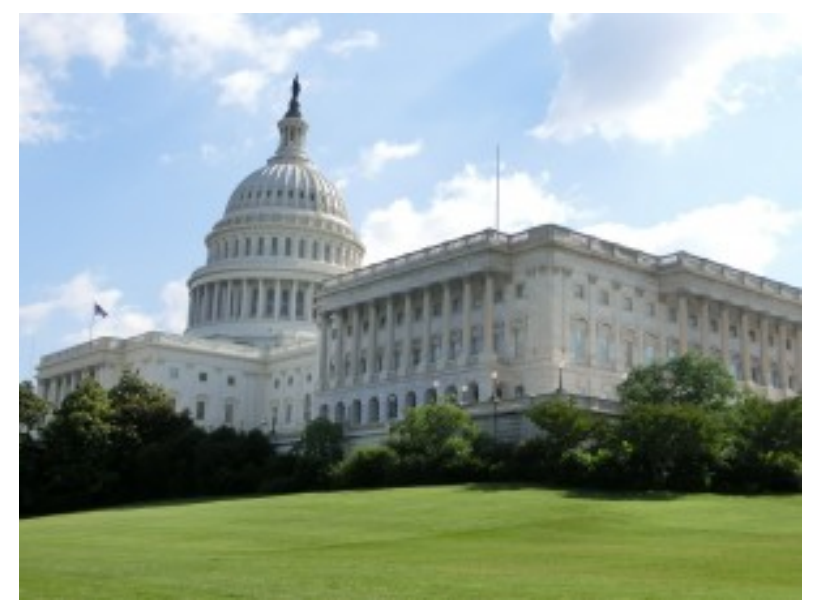

Jens Junge: CCO Public Domain
Public institutions are, essentially, all of the agencies, offices, and other entities that constitute local, state and federal governments. These organizations are funded by tax dollars and operate in the service of the citizens that pay those taxes.

The information they generate comes from the work they are charged with performing. The output of agencies which regulate particular industries might include databases of licenses issued, rules and regulations for the operation of an organization, analyses of business conditions, censuses of operations. The output of agencies that monitor the environment, or transportation, for example, would be reports and studies and statistics that

track current conditions or make projections.

\section{Organization of Public-Sector Institutions}

One way to picture the complex organization of public-sector institutions that generate information is to visualize the information as it is presented below.

\begin{tabular}{|l|l|l|l|}
\hline Branch & Local & State & National \\
\hline Legislative & City Council & Legislature & Congress \\
\hline Judicial & Municipal Courts & State Courts & Federal Courts \\
\hline Executive & Mayor & Governor & President \\
\hline
\end{tabular}

Each level and each branch of government generates information. The information sources are so voluminous that it would require a book for each of the branches to discuss comprehensively the material available at each level and in each branch, and the tools to locate that material. The important thing for you as a communications professional is to understand that each level of government generates information that is likely to be important for most messages you will work on and that there are efficient and effective ways to locate that information if you know how and where it is generated. 


\subsection{Private Sector Institutions}

Private-sector institutions are funded by revenues made from the sale of products or services, through investment by stockholders, or through donations. There are two types of private-sector institutions: for-profit and non-profit. Under for-profit institutions there are two types: Publicly-held and privately-held. The distinction is important because different types require different kinds of reporting of information.

\section{For-profit private-sector institutions:}

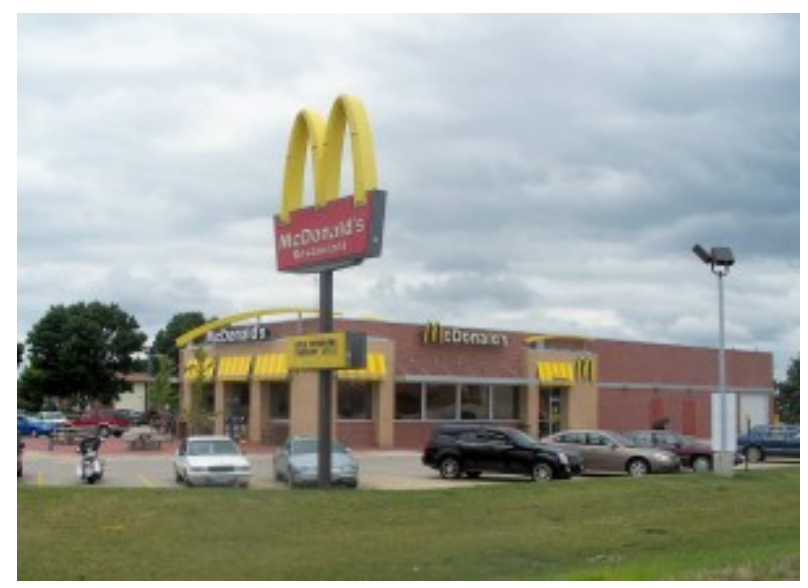

Astros4477: “New McDonald’s restaurant in Mount Pleasant, Iowa“- CC BY 2.0

By definition, a for-profit institution "is a corporation that is intended to operate a business which will return a profit to the owners." "There can be two types of for-profit private-sector institutions: publicly-held and privatelyheld. The distinction between the two is that the publiclyheld corporation sells stock in the company - the public, therefore, can essentially be "co-owners.” Privately-held corporations do not sell stock; all of the company's assets are in private hands.

For-profit private-sector institutions generate multiple types of information in support of the running of the business, to promote their products, or as required by the government. The required documentation for government differs with publicly-held corporations requiring more reporting than privately-held corporations (this is due to the government's interest in protecting citizen's investment in companies.)

Unlike public-sector institutions where some neutrality of position is expected, private-sector institutions may be more agenda driven since their information is generated to support their product, organizational goals or policy line. Much of what private-sector institutions produce is for their internal use only, but some is created for use both inside and outside of the institution.

\section{Non-profit private-sector institutions}


Non-profit private-sector institutions differ from the forprofit in their ultimate objective. The for-profit's goal is to generate revenue through the sales of goods and services. The non-profit's goal is to influence, persuade, or receive support for a cause. They generate donations that support the efforts of the organization but that funding is invested back into the organization, not as revenue that delivers income to "owners."

Non-profits are organizations like associations, churches, fraternal organizations, and other groups that have a focused set of activities that support the interests or concerns of the organization.

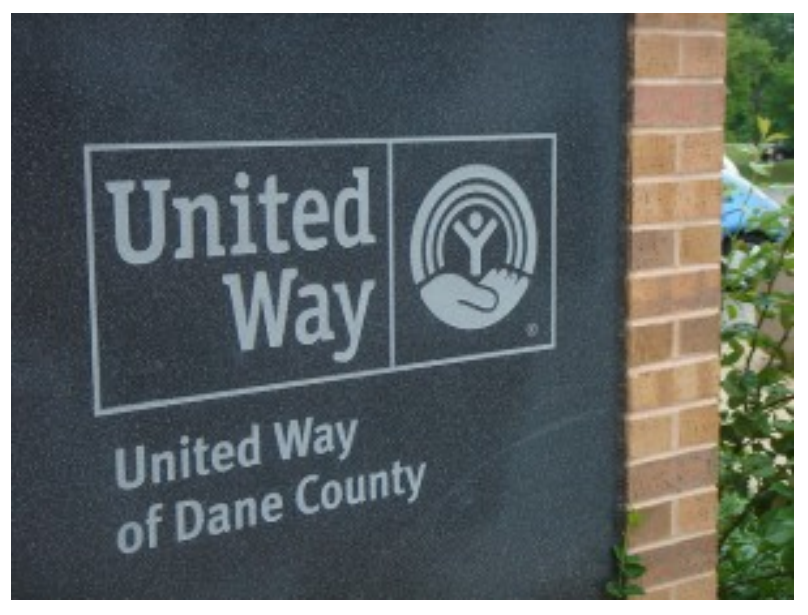

Channel 3000 Communities: CC by 2.0

In both for- and non-profit private-sector institutions, information is generated and used for different purposes: some because law requires they make the information available, some to promote the organization, some to satisfy the organizational mission to inform the public or stakeholders about an issue or topic, some to support the network of members of the organization. The information may be available in databases of statistics, on institutional websites, as part of media kits prepared by the public relations department, in directories or annual reports, and in many other formats.

Private-sector institutions generate both public and private records about their own activities.

Private information created by both for-profit and non-profit private-sector institutions is intended for use by the company or organization and can be difficult to obtain by someone outside the institution. These can include:

- internal correspondence

- proprietary product recipes or unique manufacturing processes (for profit)

- marketing research about their customers or constituencies

- business plans for product line expansions (for-profit) or service expansions (non-profit)

But other records generated by private-sector institutions are public and more easily obtained. These can include:

- Public financial disclosure documents if they sell stock to shareholders or operate as a non-profit institution with tax exemption

- Compliance documents if they operate in an environment that requires licenses or regulatory oversight

- Information verifying compliance with tax laws, social security contributions, worker's compensation payments for employees

- Evidence they are complying with federal and international trade and commerce laws and regulations if they operate overseas 
You have legal and legitimate access to much more information from private-sector institutions and through public records than you would likely ever think to request. In fact, the potential problems involved in seeking information about for-profit and non-profit institutions is not the chance that your requests might be denied but, rather, that you will be overwhelmed by the quantity and complexity of it all.

You can reasonably expect for-profit and non-profit institutions to be reliable, accurate and complete in their information-producing and -disseminating functions. But you should not expect the information to be neutral in respect to social values and social structures. Nor should you expect that institutions will remain static as laws change and as social values and structure evolve. Rather, you should recognize that when you use information from these institutional sources, you have to decode the biases, assumptions and vested interests inherent in the information. 


\subsection{Scholarly Sources}

Another major category of information sources is scholarly information produced by subject experts working in academic institutions, research centers and scholarly organizations. Scholars generate information that advances our knowledge and understanding of the world. The research they do creates new opportunities for inventions, practical applications, and new approaches to solving problems or understand issues.

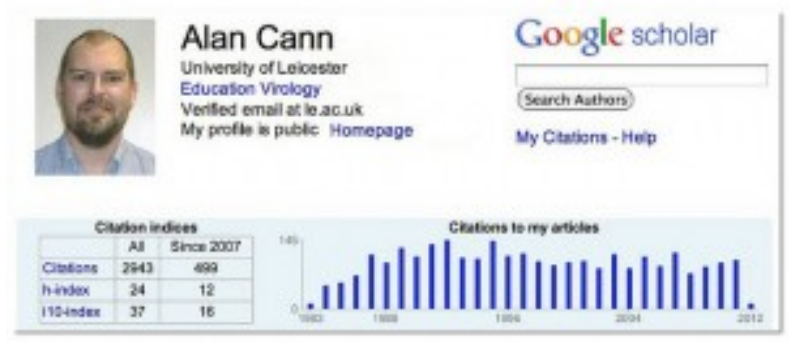

Alan Cann: CC BY-SA 2.0

Scholars introduce their discoveries to the world in a formal system of information dissemination that has developed over centuries. Because scholarly

research undergoes a process of "peer review" before being published (meaning that other experts review the work and pass judgment about whether it is worthy of publication), you can be assured that the information you find from scholarly sources has met the standards for accuracy, credibility and validity in that field.

Academics, researchers and students at universities make their contributions to scholarly knowledge available in many forms:

- masters' theses

- doctoral dissertations

- conference papers

- academic reports

- scholarly journals

- books

- individual scholars' web pages

- web pages developed by the scholars' home institution

All serve the purpose of publishing and distributing the new knowledge gleaned from the research efforts of these scholars. 
Journals that publish scholarly contributions are different than the journals that might be published by an institution such as a think tank or by a media organization. Scholarly journals have a board of editors and a panel of peer reviewers who will determine whether the submitted material has sufficient merit to be published.

Materials from scholarly sources are usually found most readily in libraries with large collections of scholarly journals and books. Some scholarly materials can be located in the sponsoring institution's library. For example, a dissertation written by a University of Texas student would be available at the University of Texas library.

There are now "digital only" scholarly publications which uphold the same rigorous peer review and high academic standards as their printed predecessors. An example is the Journal of Interactive Advertising. Research projects and papers of professors, doctoral students and researchers can be found on university websites. In some cases, institutional sources - such as associations - will make compilations of scholarly papers available, like the Association for Education in Journalism and Mass Communication's database of AEJMC conference papers.

The supporting datasets used to analyze the research are rarely available online, but the clever communicator will know that the database must exist and that the scholar will be the source they need to contact to find out about it. Since one of the tenets of scholarly research is replicability, scholars have an interest in making their data available.

Making distinctions between types of disciplines may help you determine the types of scholarly information sources that are most useful for your purposes. The clearest distinction is between the sciences and the humanities. The scientist and the humanist use different sorts of research methods and study different phenomena. They publish their findings in forms that are characteristic of their disciplines and make these documents available through a variety of tools.

Scientists seek experimental validity by studying the natural world and examining the regularities or irregularities that seem to govern natural phenomena. Their methods must be open to scrutiny and, in the best of circumstances, must be reproducible by others following the same procedures. Experimental validity, rather than individual interpretation of events or phenomena, is paramount. Immediacy in sharing results is very important for professionals in the scientific fields, so scientists rely on the research report and journal article.

The humanist's method is shaped for interpretive validity; that is, the humanist tries to interpret a poem, a painting, a novel or a musical score by presenting an interpretation that will be considered valid. Humanists study the products of human imagination and combine a personal, unique perspective with the framework of accepted concepts and knowledge that their discipline provides. Humanists rely on books as the primary method of expressing their knowledge of a field because the book allows the in-depth exploration of context that characterizes humanistic investigation.

Social and policy scientists rely on a combination of experimental and interpretive methods. They have adopted the scientific method for much of their work and exhibit the same concern for openness and validity exhibited by scientists. However, because the subject of much of their study is human social activity, social scientists work interpretively as well. For the most part, they are concerned with the present and with the implications of their work in social organizations and in public decision making. Social and policy scientists publish their findings in a number of forms. Journals are important, but research reviews, yearbooks and handbooks are also valuable.

While it is easy to understand why it is important for scholars to share their work among themselves, why would 
scholars want to share their information with you as a communications professional? For one thing, scholars are as eager as anyone else to have their work recognized and appreciated. Taking a call from a reporter or public relations specialist seeking the most reliable "expert" on a particular subject is an ego-boost for the scholar who is used to toiling in relative anonymity in the quiet of the academic or research center environment.

Another motivation for scholars to talk to you is that they might be conducting their work with the help of a grant or financial backing from a foundation or research organization that would appreciate wider distribution of the findings and a larger public audience for the organization's work.

In fact, it is your job as a communications professional to ask scholars who is supporting their work financially. It is not unusual for scholars to have grants from large companies (pharmaceutical companies, for instance) or government agencies (the U.S. Defense Department, for instance), and the work they do may reflect the interests or priorities of the funding source.

Scholars typically must reveal their funding sources in manuscripts they submit to journals for peer review so the experts reviewing the work know who "paid the piper" and who may be "calling the tune." This is not to disparage the independence of scholars who work with grant funding but rather to alert you, the information seeker, to ask for full disclosure about the nature of the funding of the scholarly work you intend to use in your research. Bias comes in many different forms and even if a funding source is a reputable governmental organization such as the National Science Foundation (NSF), you should acknowledge that the agenda and interests of this organization are important for understanding the perspective of that research.

Much of the work you do as a communications professional requires you to range across many disciplines of knowledge and skim across many fields of expertise. That usually means that you will not, as the media professional, become an "expert” in any one subject area.

You must rely on scholars to help you accurately interpret information for your audience. You seek the help of scholarly sources to identify emerging social or scientific trends, to decipher specialist information or jargon that you cannot understand, to comment on the work of other scholars, to critique institutional policies or procedures, and for a wide variety of other purposes. The main use of scholarly sources in mass communication messages is as a source of expertise and knowledge about audiences, subject matter, or effects of messages.

As you move through the information strategy process, you will begin to identify the individual scholars and/or the scholarly publications or resources that are most appropriate for your message task. For instance, if you are working on the advertising account for a new type of low-fat snack food, your initial discussions about the product with the client may direct you to several researchers whose work documents the dietary effects of the new food.

If you are writing a news story about the possible effects of a new government-imposed tariff on imported steel, you are likely to want to discuss the policy with economics scholars who study trade policy whose names you find in the transcripts of testimony before Congress about the policy.

If you are preparing the news release about the introduction of curtain airbags in next year's models, your supervisor may ask you to seek the expertise of a scholar studying the effects of the new devices on the injury rate in auto accidents.

In every case, the scholarly source is intended to provide credibility, depth, balance and/or expertise to your 
message. Rather than asking your audience to trust that you, the communicator, just happened to get it right, you seek the help of scholarly sources to ensure that audiences are receiving complete, accurate, and fair information in their news stories, advertisements and public relations messages. If you choose your scholarly sources carefully and with attention to their credentials, expertise and relevance for your topic, you are likely to produce a much more reliable and credible message for your audience. We will go into more detail about locating and using scholarly sources in later lessons. 


\subsection{Journalistic Sources}

Another major category of information sources is journalistic materials produced for a general audience and distributed through the popular media (newspapers, magazines, radio, television, Web sites, etc.). Journalistic sources also include industry-specific news sources such as PRWeek, Advertising Age, or Editor \& Publisher magazine—we will commonly refer to these specialized business oriented sources as trade publications.

Much of the work that media professionals do relies on the previous journalistic work in that area. The basic rule to "check the clips" before starting on any information task applies to newsrooms of all types. Advertising libraries maintain "tear sheet” files of ad examples from magazines and newspapers in a myriad of product and service categories so ad professionals have some idea about how a particular item has been advertised before launching off on a new campaign. Public relations professionals are judged, in part, by the coverage their clients receive in the popular media and therefore use a variety of means to document where their news releases were published in media outlets.

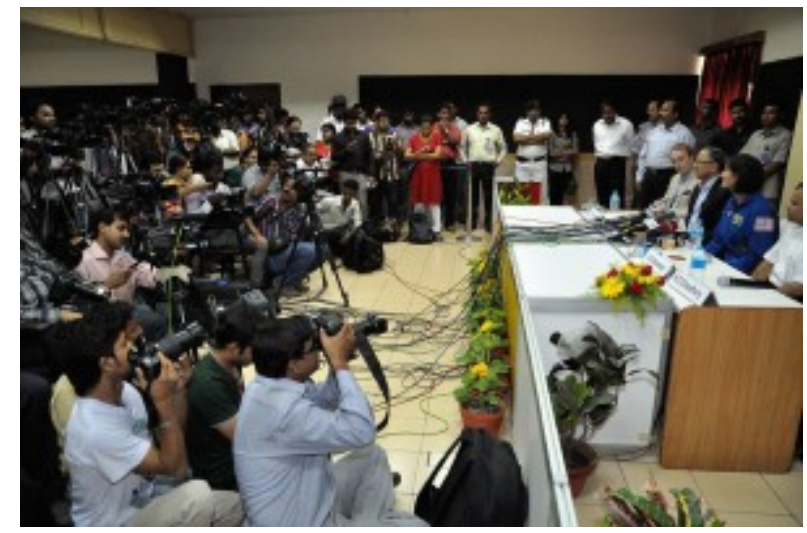

Biswarup Ganguly: CC BY 3.0 Unported

News media moved to digital production of their newsprint products more than thirty-five years ago. News organizations, with rare exception, now have a digital version of their print, television or radio counterpart available on the Web. And in the last decade, many digital-only news publications have been created. What this means for the communicator is unprecedented access to the news coverage from journalistic organizations around the world.

Many news sites will give access not only to current stories, but to the archive of previously published stories. Sometimes free, sometimes for a fee, these archives will be important resources to communicators needing background on a topic or event. Often, news sites will make the databases of statistics they have used to report a story available. The "computability" of the digital space allows the user of a news database to find the crime statistics, or school test scores, for example, for the specific area they are interested in.

Many journalistic organizations are making interactive, digital versions of their publications available in addition 
to their print versions, so you can see all the articles and ads as they appeared in the print publication. This is of particular interest to strategic communicators who need to track the placement and play of stories and ads.

As potential contributors to your information search, journalistic sources might be helpful in generating ideas for your news message (how have others written about this and what could we choose as a new "angle"), identifying possible problems or crises you might need to address with your PR messages (a news report identifies falling public confidence in your client organization), or suggesting an opportunity for a new ad approach (a news report might document that more women are doing home repairs so your client home improvement store should target women).

Depending on the context of the information request you present them, you will get different kinds of information from journalists as interviewees. If the media organization itself is the focus of the research, the information you will get is likely to be the "party line" of the organization. If you are tapping one of the employees of a media organization about a story they have written, you are likely to get more of a personal view of what went on in the crafting of that message. If you are seen as any kind of competitor, you are unlikely to get any information at all. The products of journalistic organizations are messages and if the journalist believes you are going after the same sort of message, that reporter won’t be a very willing contributor. 


\subsection{Informal Sources}

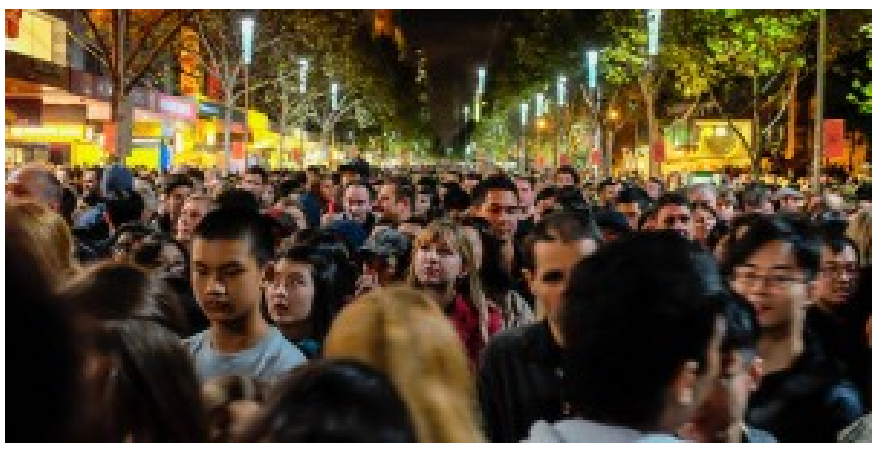

Scott Cresswell: CC BY 2.0

Getting started on a new subject and grounding the information in "reality" are just two challenges you'll face early in the information strategy. The best route to meet both of these challenges can be consulting people informally and observing the world around you.

When describing how informal sources might be helpful, we are talking about what people know, feel, and believe from their life experiences. A person you might consult as an informal source might also be an institutional, scholarly, or journalistic source in another context - one in which the information you are trying to get from them is related to their work.

Monitoring online forums, chat rooms and social networking sites has become a routine part of a communicator's daily work routine. These sites allow individuals to share what is sometimes a disconcerting amount of personal information about their lives, interests, activities, acquaintances and future plans. Social networking sites as sources of information from informal contributors provide the communicator with a rich vein of material that was once non-existent or nearly impossible to tap.

The ability to find informal sources and "listen in" on what they are talking about has been greatly enhanced with the rise of social networks and microblogging services like Twitter. A challenge, though, is

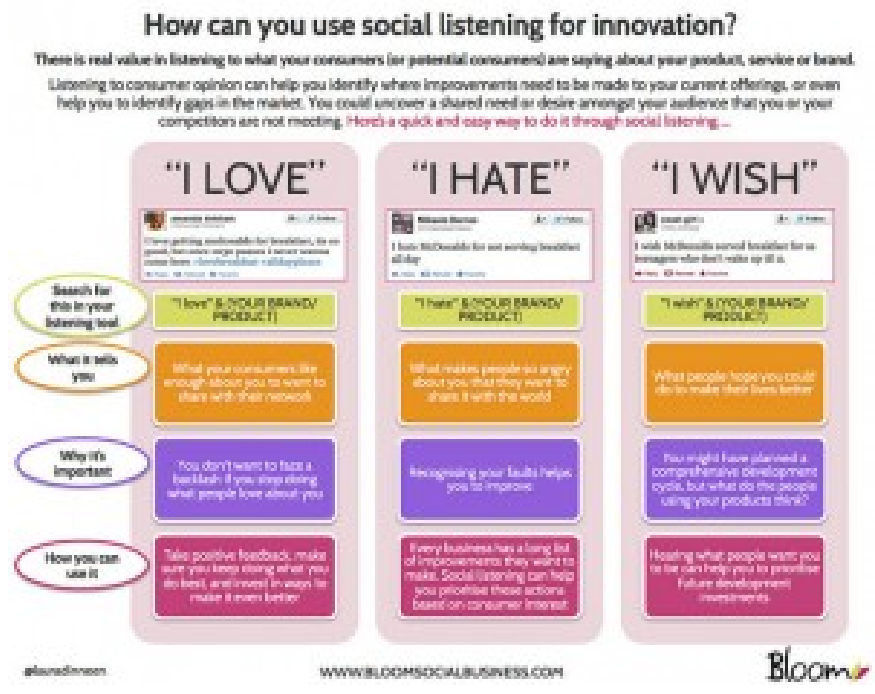
identifying those messages truly contributed by unaffiliated people and messages that look like they are from "informal” sources but which are actually marketingsponsored messages.

Even at their best, informal sources provide just a portion of the information that is needed for a message. Informal sources may be incomplete, outdated, self-serving or contain errors of fact or interpretation. They are most likely to provide you with a "slice of life" perspective rather than an informed, credible perspective that other types of sources might provide. 


\subsection{Disciplines of Knowledge}

Another major aspect of identifying possible contributors involves drawing the boundaries for the information strategy.

It is never possible to examine an idea in its entirety. You have to carve out a manageable portion of an idea if you are going to make your deadline and do a credible job with the message. When drawing these boundaries for the strategy, it helps to think about how and where information is produced. For this, you need to identify the disciplines of knowledge production in a subject area.

Information does not exist in the environment like some kind of raw material. It is produced by individuals who work within a particular field of knowledge

and who use specific methods for generating new information. Disciplines are knowledge-producing and -disseminating systems. Looking through a college course catalog gives clues to discipline structure. Fields such as political science, biology, history and mathematics are unique disciplines with their own logic for how and where new knowledge is introduced and made accessible.

You must become comfortable with identifying the disciplines that might contribute information to any strategy. You must learn how to:

- move seamlessly from one discipline to another

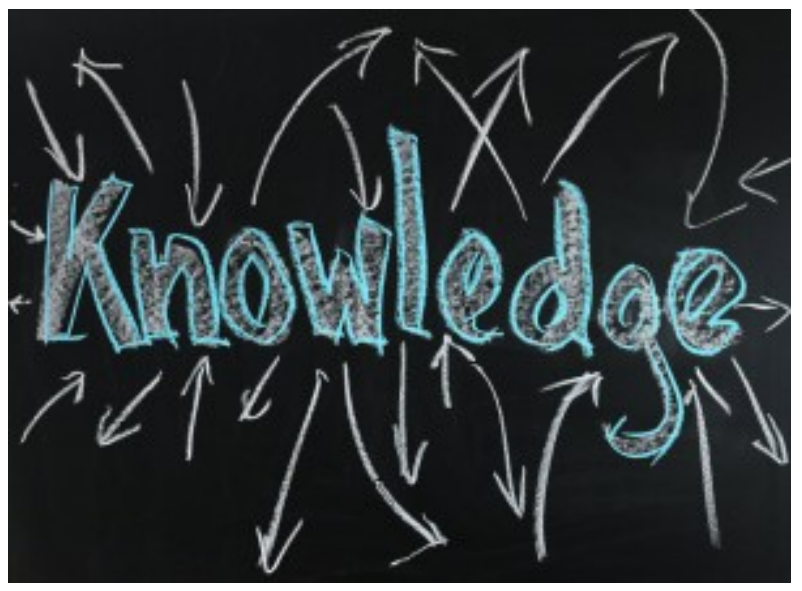

geralt - Knowledge - CCO during your strategy

- compare and evaluate information that comes from a variety of perspectives and knowledge systems

- decode the way people talk about a topic within a discipline

For example, think about the disciplines that might contribute information to a search on the topic of the role of sports in society. Try to anticipate the type of perspective each discipline might have on the topic. Consider the following types of questions as you examine what different disciplines might contribute:

- What is important about the topic to the people in that discipline?

- What is most likely to be the focus of their study about the topic?

- What perspective would they be likely to have on the topic?

We might identify three disciplines that have something to say about the role of sports in society: medicine, 
sociology, and economics. What would each of these disciplines raise as key questions or issues related to that topic?

\section{- Medical scientists}

- how sports affect individuals' health and well-being

- sports injuries

- physical conditioning for those who take part in sports

- life-expectancy for those who regularly exercise

\section{- Sociologists}

- how sports affect social relationships

- how society treats its sports heroes

- how young people are socialized into the ideal of team cooperation

- differences between boys and girls and their participation in organized sports

\section{- Economists}

- financial aspects of sports

- the kinds of economic contribution a major-league sports franchise makes to a city

- public financing for building new sports facilities when a team threatens to leave

- management-labor relations represented by negotiations in major league sports contracts

So we see that a single topic can be approached from many different perspectives depending on how the disciplinary boundaries are drawn and how the topic is framed. This step of the information strategy process requires you to make some decisions early on in order to focus the topic on a manageable and appropriate scope for the rest of the strategy. 


\subsection{The Library as Contributor}

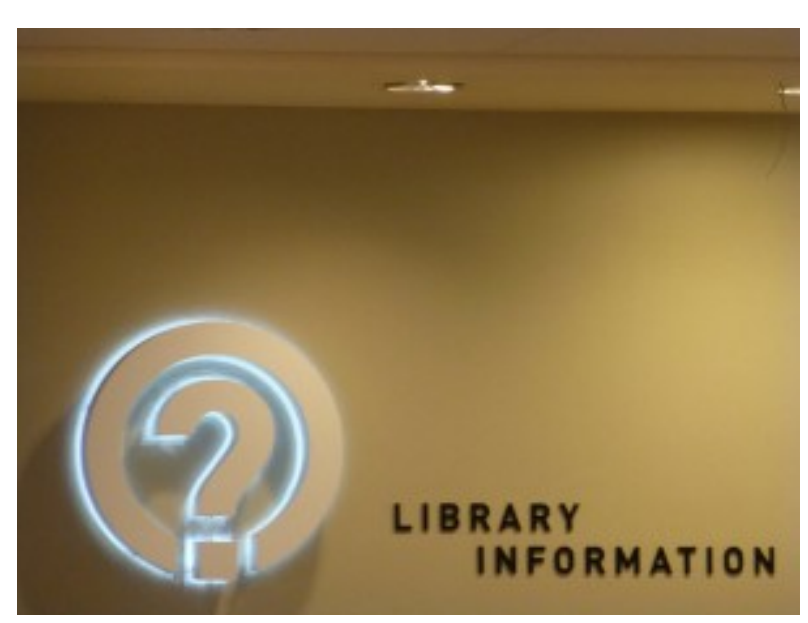

Berkeley Public Library: CCO 1.0
For all that it offers in the information gathering process, the most essential resource for information from all types of contributors is the library. Libraries can be affiliated with a particular contributor type or they can be totally independent entities that contain information from different kinds of contributors.

Libraries are storehouses of recorded knowledge in print, digital, and other formats. But with all of the digitally stored and accessible information available from any computer with access to the Internet, it may not be easy to see why you would need to use the resources of a library at all.

The main reason why libraries continue to be major

contributors to the communicator's information process is that library material has been organized, indexed, and coherently arranged for ease of use. Despite the best attempts of the creators of some of the best digital services, most still lack even the more rudimentary organization schemes and retrieval systems that have been in use in libraries for centuries.

Quality control is an even worse problem for some digital services. Libraries continue to be among the few information repositories that clearly organize their collections and allow for evaluation of the relative quality and usefulness of almost everything retrieved.

Libraries are set up to preserve, collect, and make accessible recorded intellectual products. Most libraries have

- a catalog that lists the contents of their collections

- both book collections and periodical / magazine collections

- the tools (indexes, abstracts, bibliographies) to help searchers find what they need in the collections

- access to the Internet

- access to electronic databases of information

- the most important resource of all - the librarian or archivist - the person who knows the most about the collection and about how best to use it

It is especially important when you are working under a deadline and need accurate, appropriate, and verifiable information to understand how libraries differ from one another and how those differences affect the information 
strategy. Especially for freelance communicators and for those working in organizations without an in-house library, it is useful to know about the kinds of libraries that may be available in the community. There are five types of libraries that are important for communicators: public libraries, academic libraries, special libraries, archives, and media-organization libraries. 


\subsection{Types of Libraries: Public}

Public libraries exist to serve a very special function. The need for an informed electorate is considered so important that residents are willing to tax themselves to make libraries available to the entire community.

Many public library collections reflect the history and makeup of the neighborhoods in which they are situated. They may include materials in the languages of the most dominant ethnic groups of that section of the city. The materials you will find in the public library reflect this community mission. The collection reflects the library's attempt to meet the recreational and day-to-day informational needs of the general public.

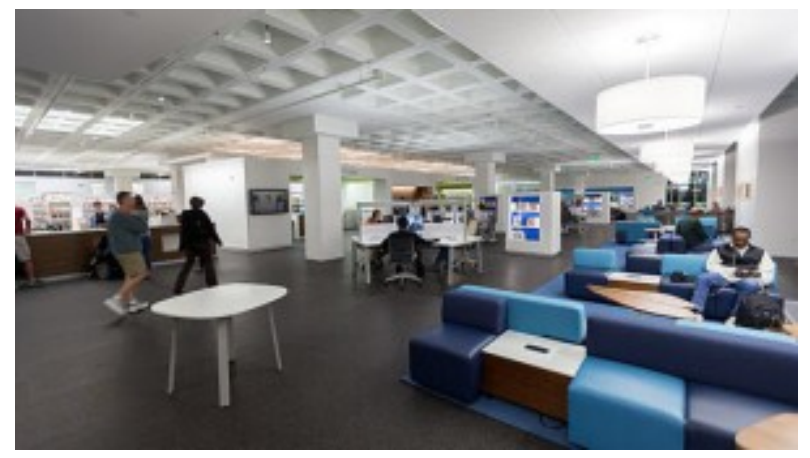

Most public libraries are not equipped to handle in-depth or technical research projects or questions but it might

John Benson - Madison Public Library - CC BY 2.0 well be the best source for in-depth and retrospective information about the community: telephone books and city directories, electoral-district maps, photographs of city landmarks over the years, and other community-related material.

At the start of your information strategy process, you might determine that it is crucial for you to have locallyrelevant information about your topic, your community or your audience. In that case, some of the resources available from a public library might be good contributors to your process. 


\subsection{Types of Libraries: Academic}

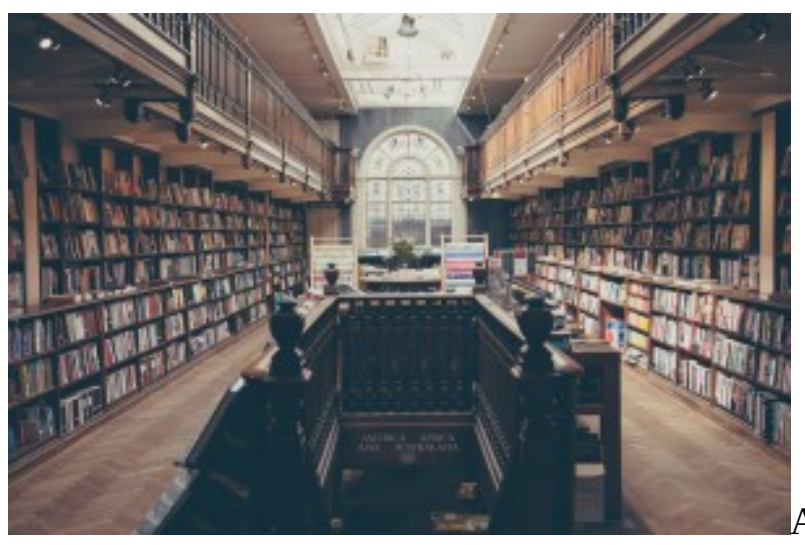

Academic libraries serve a very different function from the other types of libraries. These collections exist to support the teaching and research needs of the scholars, students, and researchers of the institution with which they are affiliated. Large academic libraries collect scholarly materials published in many languages and from all over the world. Even small academic libraries reflect the teaching mission of the institution. Specialized, technical, detailed materials are the norm in most academic collections of any size.

Unlike use of public libraries, use of academic library collections may be restricted to some extent. You may have to apply for a special privilege card or pay a fee in order to gain access to the online catalog and check out materials, or you may only be able to use materials if you go in person to the library. In extreme instances, unauthorized users may not even be able to enter the building.

However, if the topic you are researching is of a national or an international nature, if it involves specialized or technical subject areas, or if it is likely to cover controversial ideas, then an academic library collection is probably one of the best places to look. In addition, if you have been a student at a university and are an alumni society member, it is likely that you have free access to that library system and to a network of materials from other academic libraries as well. 


\subsection{Types of Libraries: Special}

The term special refers to a broad category of various kinds of libraries. The collection, the clientele, or both may be special. For instance, most companies have some kind of library or information center that houses the books, journals, documents, and material relevant to that industry. Historical societies usually have libraries. Museums have libraries geared toward the subject matter of the museum collection. The Folger Shakespeare Library in Washington D.C. is a special library in the sense that it collects books and materials by and about Shakespeare. Insurance companies, law firms, churches, hospitals, oil companies, and banking institutions are other kinds of places where a special library might be located. The Special Libraries Association has 26 different divisions of special librarians in its membership.

You may want to use these special libraries for the kinds of unique materials they make available. For instance, if you are involved with an advertising campaign for a brand of beer, you may wish to use the library collection at the brewery in order to get an understanding of the history of the company and the nature of past campaigns. If the information is not proprietary (that is, held by the company to be private because it involves trade secrets or financial information), you may want to look for clues about the unique brewing process or chemistry that sets that brand of beer apart from its competitors.

Special library collections may or may not be open to the public because corporate secrets are often housed alongside the usual industry or company information. The best rule of thumb is to check the website and call ahead as the hours and visiting policies are likely to differ from collection to collection. 


\subsection{Types of Libraries: Archives}

Archives differ from libraries in mission and operation. Whereas libraries have a selective collection development policy, archives attempt to be a comprehensive collection of a business, organization or social movement. An archive is responsible for keeping a permanent record of the history, transactions, and operations of whatever it is that is being archived and thus, the materials in an archive usually do not circulate.

There are governmental archives responsible for keeping the permanent record of that organization or branch. The National Archives in Washington, D.C., for example, maintains treaties, maps, photographs, motion pictures, sound recordings, correspondence files, and other documentation of the operations of the administrative branch of the federal government.

Corporations and businesses house archives that serve both a public relations function and provide historically accurate information about the company and clients. For instance, the Coca-Cola archive includes such materials as original Coke bottles, print and broadcast ads, drugstore signs, decal-covered serving trays, and other Cokerelated paraphernalia. The manager of the archive is called upon regularly by the legal department to produce documentation to protect the Coca-Cola trademark.

At the start of your information strategy process, you may determine that it is crucial for you to gather information about the history or operation of the organization or business you are reporting on or for whom you are preparing a strategic communications message. That organization's archive is the place to start. 


\subsection{Types of Libraries: Media}

The libraries supported by media organizations are types of special libraries. Both the materials and the clientele are unusual. As the likely first stop for the communicator during the early stage of the information search, media libraries are crucially important. Many media organizations - whether in the business of producing a newspaper, a national magazine, a local television news broadcast, advertising campaigns, or public relations materials - have some sort of library collection or research function.

The in-house library of a newspaper office may have a small, current collection of major reference tools (dictionaries, directories, almanacs), may subscribe to a handful of magazines and journals, may have access to online database services, and most likely is staffed by a professional librarian. But by far the most important resource, in the opinion of a newspaper staff, is the back files of the newspaper itself.

Today, every large circulation newspaper has its content stored and searchable through an digital library system. With the growth of online news publications, the challenge of reconciling the archive of the print edition of the newspaper and the digital version of the newspaper has grown and often news organizations will have two separate and not entirely equal database representations of news products they create.

Broadcast news libraries may not have as many of the print and digital reference tools found in a newspaper or magazine library, but they do have a major resource for their employees - the archive of tapes or digital files of previous broadcasts. When you see file footage flashed on the screen during a television news report, you are seeing one use of this archive of materials. Broadcast news organizations keep archives of their own broadcasts, but journalists also have access to Web-based archives of streaming audio/video files through services such as those provided by the Vanderbilt Television News Archive. Current clips can sometimes be found using YouTube, Google News or Yahoo! News.

Strategic communications agency libraries are designed to meet the information needs of communicators creating the ads or news releases, preparing the media kits, conducting the market research, studying audiences or clients, and developing "new business pitches.” The library for an advertising agency or department, for instance, may include tear sheets, pages ripped out of magazines and newspapers that serve as examples of ads for particular products or services. The library may have files of pictures and photos so artists have examples if they need to draw a cheetah or a cricket bat. The library has industry and trade information so communicators can do background research on potential and current clients and their products and services. And these libraries have all of the specialized market and audience research tools that help determine message context. A public relations agency library will subscribe to the important media tracking services and provide access to the databases and digital services that help the PR professionals follow news about their clients.

Media organization libraries, then, serve a special function. Those creating messages must have at their fingertips examples of the own organizations' output; materials produced by other communicators around the country or the world; information about the industries, products and audiences for whom messages are produced; and general fact-finding sources for quick reference. 


\subsection{The Library in the Process}

As we've indicated, the library houses information from all contributors - public-sector institutional, privatesector institutional, scholarly, journalistic and informal. No matter what you are looking for, a library is likely to have at least a portion of what you need. As such, the library is an integral part of your information-gathering routine.

Libraries make accessible the materials you need for your initial message analysis work, for your topic-specific information-gathering needs, for your in-depth information evaluation requirements, and for your synthesis work as you create the message. In other words, libraries contribute to every step of the information strategy, not just at this early step of the process.

\section{Planning Your Strategy}

Identifying a number of the possible contributors to your information strategy at this early step of the process will help focus your efforts and narrow the range of information you need to locate and evaluate. It is an important time-saver and a key aspect of your work as an efficient and effective communications professional. 


\section{Lesson 7. Question Analysis: What are the Ethical and Legal Considerations?}

\section{KEY CONCEPTS}

- Media message creators work within a set of social, legal and ethical expectations and responsibilities.

- Anticipating potential ethical or legal issues will help ensure there are no issues when the message is created.

- The interpretation or relevance of particular ethical standards will vary in different organizations.

- Communicators must understand how to operate within an organization's particular culture in order to be successful.

- There are laws and regulations that affect both the gathering and the use of information in media messages.

\section{LEARNING OUTCOMES}

After completing this lesson you will be able to:

- recognize the social constraints under which communicators work.

- identify the characteristics of ethical thinking and the forms of ethical decision-making that guide mass communication professionals.

- identify the positive and negative obligations that communicators weigh in their work.

- consider the cultural climate within an organization.

- articulate some of the legal and regulatory standards that must be considered by communicators as part of an information strategy process. 


\subsection{Social Responsibility}

In Lesson 1 we discussed the personal attributes that will help you succeed on the job. There are also standards for conducting your professional work ethically and legally that must be understood and heeded. Missteps in these areas will undermine not only your own credibility but can have wide ranging repercussions for the organization and profession within which you work.

Following is a discussion of the levels of responsibility that affect the information you gather and use, and the messages you create. Once you understand the constraints you must acknowledge in your work as a message creator, you'll be able to think strategically about the information you need to create that outcome. Having this foundation will also help you evaluate the appropriateness of the information you find. 


\subsection{Analyzing Ethical and Legal Considerations - Overview}

Being a socially responsible communicator requires attention to both ethical standards and legal requirements. First, we need to draw a distinction between ethics and law.

\section{Distinction Between Ethics and Law}

\section{$\underline{\text { Ethics }}$}

- A branch of philosophy

- Deals with values relating to human conduct

- Concerned with “rightness” and “wrongness” of actions

- Self-legislated and self-enforced

- Sometimes difficult to determine because of competing, equally-valid possible choices

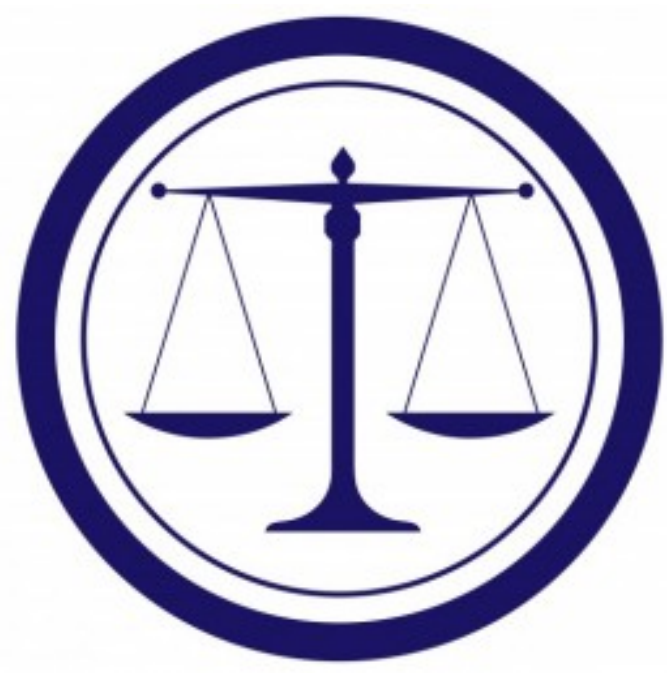

$\underline{\text { Law }}$

Karen Arnold - Scales of Justice - Public domain

- Derived from ethical values in a society

- Formally / institutionally determined and enforced through courts and law enforcement officials

- Easily determined because it is a matter of statute and the legality of an an action and consequences for not adhering to the law is spelled out

In the previous lessons on developing your information task list and determining questions to answer, we've focused on specific information seeking goals. In each of the communication professions there are key legal considerations that must be understood that will either help, or hinder, the seeking of information to meet those goals.

In news, for example, if some of the information needed requires the use of public records then an understanding of public records and privacy laws will help you know what it is possible to get, and how to legally use these records.

In advertising, you might want to make the most of the attributes of the product you are promoting, but you will need to abide by laws dictating the substantiation of product claims.

For public relations professionals, you may need to issue a corporate response to a crisis, therefore it is 
important to understand the requirements or restrictions of corporate disclosure laws. We will discuss these legal perspectives later in this lesson.

Socially responsible communicators are not content with just staying on the right side of the law. While the law embodies a significant portion of our values, individuals and organizations that want to be considered socially responsible must go beyond the rough requirements of the law itself and adopt higher and more thoughtful standards.

In some cases these standards may have a legal basis as well as an ethical one. Following these standards requires the communicator to consider both "positive obligations" (things that you must always strive to do) or "negative obligations” (things that you must guard against doing). 


\subsection{Obligations in News}

Let's look at the positive and negative obligations that apply to those crafting news messages. These are drawn from the Code of Ethics of the Society of Professional Journalists, a long-standing professional association for news professionals.

\section{POSITIVE OBLIGATIONS (goals you try always to achieve)}

1) Seek truth and report it. This requires that you:

a. test the accuracy of information from all sources.

b. fairly represent multiple perspectives and viewpoints.

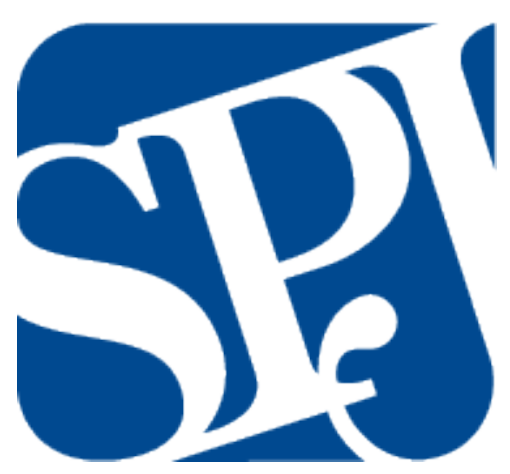

c. identify sources whenever feasible so the public may judge the Society of Professional Journalists $\log o$ reliability of the information.

d. safeguard the public's need for information.

Despite the rhetoric of First Amendment attorneys, the public does not have a "right to know" per se. The First Amendment to the Constitution of the United States says that citizens have a right to assemble, speak, practice their chosen religion, petition the government for redress of grievances, and that the Congress shall make no law limiting the freedom of the press. It does not address the public's "right to know" anything. But most communication scholars acknowledge the crucial role that the media play in nurturing an informed electorate and citizenry.

2) Minimize harm. This requires that you:

a. avoid privacy violations. Only an overriding public need can justify intrusion into anyone’s privacy and such intrusion may invoke legal sanctions if a source can demonstrate harm. In the context of information seeking, information that can be found should not necessarily be used.

b. be cautious about naming criminals before the formal filing of charges, identifying juvenile suspects or victims, or seeking interviews or photographs of those affected by tragedy or grief.

3) Act independently. This requires that you:

a. be wary of sources offering information for favors or money.

b. disclose potential conflicts of interest. IE: failing to label the content from a video news release in a TV broadcast story is a breach of ethics. 
102 Information Strategies for Communicators

c. hold those with power accountable.

4) Be accountable. This requires that you:

a. admit mistakes and correct them promptly. Libel law may be invoked if the mistake injures a news subject.

b. stand up for what is right in the media organization.

c. abide by the same high standards to which you hold others.

\section{NEGATIVE OBLIGATIONS: (actions that must be avoided)}

1) Plagiarism. Never, ever, ever represent someone else’s work as your own. Never. Ever.

2) Concealing conflicts of interest, real or perceived, in seeking or using information. If you have a stake in the outcome of what you are reporting on, you must acknowledge it and perhaps suggest that someone else cover the story.

3) Distorting the content of news photos or video. Image enhancement for technical clarity is permissible, but any other type of manipulation must not happen.

4) Eavesdropping. Listening in on others' conversations, electronically or otherwise, is a form of information stealing and may invoke wiretapping laws or other legal sanctions.

5) Breaking the "contract" with a source. Publicly identifying a source who provided information confidentially, for instance, is both an ethical and a legal violation. We will discuss the details of the source contract in the Lesson 9 on Interviewing.

These are a sample of the negative and positive obligations that help you weigh your decisions when a situation arises in your information gathering for a news message.

Ethical thinking requires that you establish for yourself, ahead of time, how you value these various obligations and which take precedence in your own scheme of decision-making. You also must be fully aware of how your media organization has ordered these priorities for their own publications, and comply with the standards that your organization has established. 


\subsection{Obligations in Advertising}

Just as in news, advertising professionals adhere to a number of constraints when gathering and using information, regardless of the type of advertisement they may be creating. We can once again understand these in the context of positive and negative obligations. These are drawn from the principles and practices of the Institute for Advertising Ethics.

\section{POSITIVE OBLIGATIONS}

1) Create messages with the objective of truth and high ethical standards in serving the public. Advertising is commercial information that must be treated with the same accuracy standards as news and there may be legal repercussions if the standards are not upheld.

2) Apply personal ethics, like being an honest person, in the creation and dissemination of commercial information to consumers.

3) Clearly distinguish advertising from news and editorial content and entertainment, both online and offline.

4) Clearly disclose all material conditions, such as payment or a free product, that affects endorsements in social media and traditional message channels. This is both an ethical and a legal requirement, enforced by the Federal Trade Commission and other regulatory bodies. For example, a blogger who is paid by a company to spread positive information about the company's product or service must disclose she being paid for her opinions

5) Treat consumers fairly, especially when ads are directed at audiences such as children. In fact, the legal requirements for advertising aimed at children are increasingly stringent.

6) Follow all federal, state and local advertising laws, and cooperate with industry self-regulatory programs for the resolution of complaints.

7) Stand up for what is right within the organization. Members of the team creating ads should express their ethical or legal concerns when they arise. This is a good example of the personal ethics that must factor into decision-making in creating messages.

\section{NEGATIVE OBLIGATIONS}

These are obligations that represent both an ethical and, in most cases, a legal/regulatory element. The National Advertising Division of the Council of Better Business Bureaus, the National Advertising Review Board, the Federal Trade Commission, the Federal Food and Drug Administration and many other bodies enforce these obligations when necessary. 
104 Information Strategies for Communicators

1) Do not plagiarize. Never, ever, ever represent someone else's work as your own.

2) Do not use false or misleading visual or verbal statements.

3) Do not make misleading price claims.

4) Do not make unfair comparisons with a competitive product or service.

5) Do not make insufficiently supported claims.

6) Do not use offensive statements, suggestions or pictures.

7) Do not compromise consumers' personal privacy, and their choices as to whether to participate in providing personal information should be transparent and easily made. 


\subsection{Obligations in Public Relations}

Let's look at the positive and negative obligations that help PR specialists gather and use information responsibly. These examples come from the Public Relations Society of America Member Code of Ethics. Once again, many of these obligations refer to both ethical and legal responsibilities.

\section{POSITIVE OBLIGATIONS}

1) Serve the public interest by acting as responsible advocates for those the PR firm or professional represents.

2) Adhere to the highest standards of truth and accuracy while advancing the interests of those the PR

firm or professional represents.

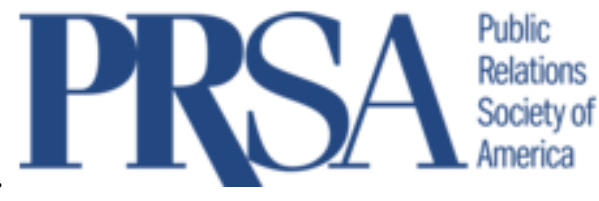

3) Acquire and responsibly use specialized knowledge and experience in preparing public relations messages to build mutual understanding, credibility and relationships among a wide array of institutions and audiences.

4) Provide objective counsel to those the PR firm or professional represents. For example, the best advice for a client may be to admit wrongdoing and apologize. The PR practitioner must objectively weigh this advice and offer it if it is the best option.

5) Deal fairly with clients, employers, competitors, peers, vendors, the media and the general public.

6) Act promptly to correct erroneous communication for which the PR firm or professional is responsible. Again, failure to do this could invoke both ethical and legal sanctions.

\section{NEGATIVE OBLIGATIONS}

1) Do not plagiarize. Never, ever, ever represent someone else’s work as your own.

2) Do not give or receive gifts of any type from clients or sources that might influence the information in a message beyond the legal limits and/or in violation of government reporting requirements.

3) Do not violate intellectual property rights in the marketplace. Sharing competitive information, leaking proprietary information, taking confidential information from one employer to another and other such practices are both legal and ethical violations. 
106 Information Strategies for Communicators

4) Do not employ deceptive practices. Asking someone to pose as a "volunteer" to speak at public hearings or participate in a "grass roots" campaign is deceptive, for instance.

5) Avoid conflicts of interest, real or perceived. PR professionals and firms must encourage clients and customers as well as colleagues in the profession to notify all affected parties when a conflict of interest arises. 


\subsection{Levels of Social Responsibility}

You can see from the sampling of positive and negative obligations that as a communications professional you must weigh a wide variety of considerations when gathering and using information to create a message. The intended audience, the purpose of the message, the intent of the communicator, the ethical considerations, the legal constraints and many other variables help determine how you pursue the information strategy.

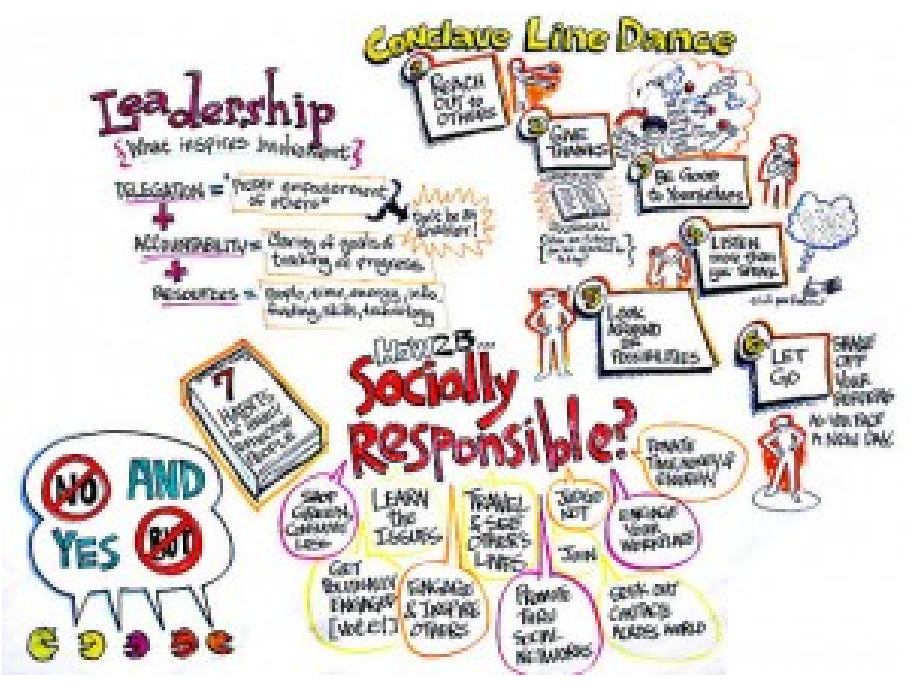

Peter Durand: CC BY-NC-ND 2.0

As a communications professional you must also conduct your work in the context of a commitment to social responsibility at a number of levels. Because mass communication messages are pervasive and influential, media organizations and professionals are held to high standards for their actions. The social responsibility perspective helps outline how this works.

There are three levels of responsibility that affect your work as a communicator. These are:

- SOCIETAL: the relationships between media systems and other major institutions in society.

- PROFESSIONAL / ORGANIZATIONAL: your profession's and your media organization's own self-regulations and standards for professional conduct.

- INDIVIDUAL: the responsibility you have to society, to your profession, to your audience and to yourself.

We'll examine each of these in turn. 


\subsection{The Societal Perspective}

The societal perspective examines how media institutions interact with other major institutions in society. As a communications professional, it is important to understand the societal implications of your work and the rules under which you operate.

Professional education and licensing have been traditional means by which society has sought to ensure legal and ethical behavior from those who bear important social responsibilities. For law, medicine, accounting, teaching, architecture, engineering and other fields of expertise, specific training is followed by examinations, state licensing and administration of oaths that include promises to live up to the standards established for the profession.

However, there is no U.S. law that requires communicators to be licensed. Without the power to control entry into the field and withdraw the license to operate as in these other professions, it is even more important for mass communication professionals to police themselves. Especially in light of the huge explosion of "fake news" being generated by individuals with political, cultural or financial motives, legitimate news professionals must defend their crucial role in society.

Let's look at examples of the way the media interact with other major social institutions. One of the major tenets of journalism is the goal of exposing public officials or business executives to public scrutiny. This "watchdog” role, one of the most important functions of the press, is used to justify journalists' behavior in investigating what public officials or corporate executives are doing and whether or not they are meeting their responsibilities to constituents, citizens or shareholders. The First Amendment protects journalists' rights to challenge government power.

However, serious observers argue that when overly aggressive investigative techniques expose individual politicians or corporate executives to scrutiny about their private lives that may have nothing to do with the performance of their official duties, it causes cynicism, it undermines public confidence in major social institutions, and it drives people away from participation in public and civic engagement. How far does the "watchdog” role go? When is a journalist crossing the line from examining public behavior to voyeurism about private lives?

Similarly, strategic communications professionals face questions about their interactions with other major social institutions. There is more and more agitation for government regulation of advertising because people perceive that advertisers do not police themselves enough. 


\section{Did You Buy \\ Skechers Toning Shoes?}

\section{You may be eligible} for a refund.

\section{go to FTC.gov/skechers}

In 2012, the Federal Trade Commission imposed the largest fine in its history on the company that manufactures Skechers athletic shoes and apparel. The company paid \$40 million because its ads falsely represented clinical studies backing up claims that Shape-Ups, Resistance Runner, Toners, and Tone-Ups would help people lose weight, and strengthen and tone their gluteal, leg and abdominal muscles. The ads used lines such as "Shape up while you walk," and "Get in shape without setting foot in a gym.” As part of the settlement, Skechers had to take down the advertising and inform retailers to remove the deceptive claims. It also agreed to stop misrepresenting any tests, studies, or research results regarding toning shoes. And customers who purchased the shoes or apparel were able to file through the FTC for a refund from the company. (Bachman)

The example points out the interactions between advertisers, government regulators and the public at the societal level.

Another example points out the social responsibility interactions between advertisers, corporations and the customers they serve around the sensitive issue of personal privacy.

The social network Facebook, used by 900 million people worldwide, agreed in June 2012 to pay \$20 million to settle a lawsuit in California that claimed Facebook publicized that some of its users had "liked" certain advertisers but didn't pay the users, or give them a way to opt out.

The so-called "Sponsored Story" feature on Facebook was essentially an advertisement that appeared on the site and included a member's Facebook page and generally consisted of another friend's name, profile picture and a statement that the person "likes" that advertiser. The suit was one in a long list of complaints against the social media giant and other online organizations such as Google that appear to be working with advertisers to intrude on consumers' privacy. (Levine \& McBride)

A group of digital advertising trade organizations called the Digital Advertising Alliance is concerned enough about advertisers’ interaction with consumers, technology companies, 
privacy advocates and federal/state regulators that it has created a way for people to opt out of having their online behavior tracked. A turquoise triangle that appears in the upper right-hand corner of banner ads on web sites allows users who click on it to remove themselves from having personalized advertising directed at them.

The group created the option in reaction to pressure from other institutions, including the Federal Trade Commission, which are threatening to regulate mobile and digital privacy and exert more control over children's privacy online. The example points out how various societal-level institutions interact to impose social responsibility on media practitioners if they do not regulate themselves.

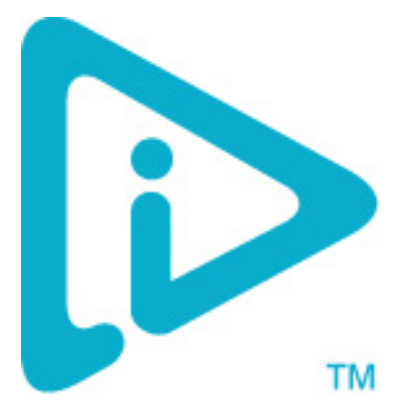

Digital Advertising Alliance

As strategic communicators have adopted social media platforms to distribute their messages, scrutiny by other societal institutions has increased. The Federal Trade Commission was so concerned about claims being made by advertisers and PR practitioners via social media that they updated their social media guidelines in 2013.

The new FTC guidelines require social media marketers to:

- fully disclose their sponsorship of the information. If an advertiser has hired a blogger to endorse a product or service, the blogger MUST disclose that he or she is working for that advertiser; if a PR firm posts positive comments about its clients on social media, the firm MUST disclose that they are working on behalf of the client. Further, the disclosure must be clear and conspicuous; it cannot be buried in the fine print.

- monitor the social media conversation and correct misstatements or problematic claims by commenters.

- create social media policies to instruct employees about the expectations and practices that will be enforced.

The mention of company-specific social media policies leads us to the next category of responsibility: the professional or organizational perspective. 


\subsection{Professional and Organizational Perspective - Journalism}

In addition to the societal level of interactions, communication organizations and professionals engage in selfcriticism and set standards for their own conduct and performance as information gatherers. One of the most conspicuous examples of this lies in the proliferation of codes of conduct for mass communication activities at all levels. As our discussion of positive and negative obligations (above) demonstrated, every mass communication industry develops these professional and organizational guidelines for its practitioners.

In the news industries, codes have expanded in number and scope over several decades. Organizations that have adopted such codes include the American Society of News Editors, the Society of Professional Journalists, the Associated Press Managing Editors Association, the Radio Television Digital News Association, and the National Press Photographers Association. Individual news organizations and publications frequently establish their own codes to which they expect their staffs to adhere. 


\subsection{Professional and Organizational Perspective - Advertising}

Advertising codes reflect some of the specific criticism directed at the field, such as charges of deceptive advertising, unfair stereotyping, false testimonials and misleading claims. Organizations as diverse as the Wordof-Mouth Marketing Association, the Children’s Food and Beverage Advertising Initiative, the Pharmaceutical Research and Manufacturers of America and the Beer Institute have guidelines and codes for the content and placement of advertisements in their respective industries or for the audiences with which they are concerned.

For instance, here is a portion of the Advertising and Marketing Code for the Beer Institute. Any advertising professional working with a client who sells and advertises beer would need to adhere to this industry code.

"Brewers should employ the perspective of the reasonable adult consumer of legal drinking age in advertising and marketing their products, and should be guided by the following basic principles, which have long been reflected in the policies of the brewing industry and continue to underlie this Code:

- Beer advertising should not suggest directly or indirectly that any of the laws applicable to the sale and consumption of beer should not be complied with.

- Brewers should adhere to contemporary standards of good taste applicable to all commercial advertising and consistent with the medium or context in which the advertising appears.

- Advertising themes, creative aspects, and placements should reflect the fact that Brewers are responsible corporate citizens.

- Brewers strongly oppose abuse or inappropriate consumption of their products.” (Beer Institute)

Individual advertising agencies and corporate advertising departments also have codes and standards to help employees recognize and deal with ethical questions.

Most media outlets accept or reject ads submitted to them using a set of guidelines about what types of ads are acceptable and what type of content they will allow.

For example, here is a portion of the policy for acceptance of advertising that appears in Texas Parks and Wildlife Magazine

- All advertisements are subject to approval of Texas Parks \& Wildlife Department (Publisher), which reserves the right to reject or cancel any ad at any time if the ad does not conform to the editorial or graphic standards of the magazine as determined by the Publisher.

- Advertisements that are not appropriate for viewing by youth will not be accepted. Advertisements will not be accepted for tobacco or alcohol products. (Tex. Parks \& Wild. Code §11.172(c); 31 Tex. Admin. Code \$51.72. Other products that are not compatible with the mission of the Texas Parks and Wildlife Department will also not be accepted. 
- Advertisers must keep in mind the diverse audience of the magazine when determining the suitability of an ad. That audience includes hunters, anglers, campers, bird watchers, state parks visitors, other outdoor enthusiasts and readers of all ages including children. (Magazine Advertising Policy)

Any advertising professional gathering information and creating an ad for a product or service that might appear in this magazine would need to be aware of the publication's organizational level guidelines about acceptable advertising, and the societal level regulations (Texas state laws) about tobacco or alcohol advertising in this publication. 


\subsection{Professional and Organizational Perspective - Public Relations}

Public relations practitioners, like advertising specialists, work closely with clients. Through these associations, legal and ethical decisions often arise as clients and publicists discuss information-gathering strategies. For example, the Securities and Exchange Commission monitors the way corporations report their financial affairs, scrutinizing information about stock offerings and financial balance sheets for accuracy and omission of important facts. Their objective is to ensure that investors and stock analysts can get accurate information about the companies that are offering securities.

Increasingly, legal and ethical standards are holding public relations practitioners, along with stockbrokers, lawyers and accountants responsible for the accuracy of information they communicate to the public. When public relations professionals find themselves on the losing side of an important ethical question with a client, it is not unusual for them to resign their positions as a matter of principle.

The Public Relations Society of America's Code of Ethics emphasizes honesty and accountability, in addition to expertise, advocacy, fairness, independence and loyalty. The public relations code, like those for advertising and journalism, reflects the concerns of society as well as the practitioners who adopt the codes. Provisions of all the codes are designed, at least in part, to provide the public with reasons to have confidence in communicators' integrity and in the messages they create. Of course, the codes are also there to help keep communicators out of court.

For example, a large multinational PR firm resigned its account with a major tire manufacturer just months after landing the account. The reason was that the tire manufacturer failed to disclose to the PR firm that it knew about defects in its tires that had caused a number of fatal accidents. The PR professionals decided they could not ethically represent the tire manufacturer to the public under such circumstances and ended their relationship with

the company. The PR firm's adherence to professional and organizational standards was more important than the income that would have been generated from the account with the tire manufacturer. (Miller) 


\subsection{Individual Perspective}

There is an individual level of responsibility for your own behavior. As a communications professional, you may find yourself confronting conflicting obligations in your daily routine. You will be doing your work in a decidedly ambivalent atmosphere. News professionals are criticized for reinforcing the assumptions of those in power and ignoring reality as experienced by most of the population. Advertising is criticized for contributing to materialism, wasteful consumption, and the corruption of the electoral system. Public relations is criticized for creating and manipulating images on behalf of those with narrow interests, failing to give public interest information a priority.

In confronting your social responsibility using the individual perspective, you are likely to place duty to yourself at the top of the list. You always need to abide by your own moral standards. But this may conflict with more worldly ambitions - desire for recognition, advancement, and financial security. The duty to the organization may be at odds with the loyalty to colleagues or to the profession. Let's look at a few examples that illustrate these tensions.

\section{Am I Comfortable Working on Advertising for This Client?}

Individual-level responsibility may arise when ad professionals object to ads they have to work on or have to accept. It is usually not necessary to violate your own standards.

Concerns about taking on an assignment will be something to discuss during the message clarification step. If, for example, you are a strict vegetarian, it may be difficult for you to work on a campaign to sell bacon.

Or let's say that you are the advertising manager for a local magazine. You receive an ad that you think is offensive, even though the product or service being geralt-Untitled-CCO advertised is perfectly legal and the company is a big advertiser in your publication.

You don't have to accept that offensive ad, but you also don't have to forgo the ad revenue for your publication (again, we're weighing two competing obligations-your obligation to your own standards against your obligation to your media organization to generate revenue).

The way to resolve this dilemma is to call the ad agency and ask for another version of the advertisement. Advertisers almost always have another version in anticipation that some media outlets will refuse to run a potentially-offensive version of an ad. With this solution, you can adhere to your own standards and still generate revenue for your publication by accepting the more appropriate ad. 


\subsection{Legal Considerations - Journalism}

There are entire texts and semester-long courses that examine the specific laws and regulations under which mass communicators operate. We will discuss here briefly a few of the most relevant types of legal and regulatory constraints that affect communicators' gathering and use of information in messages in this lesson. We will return to some of these examples in more depth throughout the rest of the lessons where appropriate.

\section{Journalism Law and Regulation}

You will learn about the relevant legal and regulatory framework for your career as a journalist in later classes. We will mention just a couple of examples that demonstrate the way that laws and regulations affect journalists' information strategy process.

Federal, state and local law outlines the way journalists gather information. For example, photographers/ videographers have a constitutional right to photograph anything that is in plain view when they are lawfully in a public space. Police officers may not confiscate or demand to view journalists' photographs or videos without a warrant. However, the right to photograph does NOT give journalists the right to break other laws. For example, you may not trespass on private property to capture an image.

Likewise, there are a wide variety of laws that detail the types of information that are accessible to the public, including journalists. Public records laws will be discussed in more detail in Lesson 13. Suffice it to say that journalists have many tools in their toolbelt when they are seeking access to public record information.

Libel law defines the ways that journalists USE the information they gather in their messages. Again, there are many nuances in libel law and journalists generally defer to the experts within their media organizations when questions arise about whether a particular item in a news story exposes the news organization to a charge of libel. It is most important for you, as an information gatherer, to understand that best practices require you to doubleand triple-check any facts, claims or evidence you intend to use in a message and to vet that information with the appropriate gatekeepers in your organization. 


\subsection{Legal Considerations - Advertising}

The advertising substantiation rule is of paramount importance for anyone collecting and evaluating information to use in a comparison ad. The advertiser must be able to substantiate any claim about a product or service with information that backs up such claims. This means that you, as the advertising professional, will follow a comprehensive information strategy in preparing the background information for any such ad.

The main governmental regulatory agency for advertising is the Federal Trade Commission. The FTC regulates unfair and deceptive practices on a case-by-case basis and occasionally with industry-wide regulations.

The FTC has the power to require that advertisers prove their claims. If the FTC determines that an advertisement is deceptive, it can stop the ad and order the sponsor to issue corrections. Corrective advertising provides information that was omitted from a deceptive ad. Some companies are fined for their illegal acts. It is extremely rare, but someone could also be jailed for a deception.

Many states also have laws that regulate deceptive advertising. Individual consumers also have the right to sue companies for deceptive advertising.

The advertising industry also has a two-tiered self-regulatory mechanism. Advertising that is charged with being deceptive can be referred to the National Advertising Division (NAD) of the Council of Better Business Bureaus. For cases that are not satisfactorily resolved through NAD, appeals can be made to the National Advertising Review Board. The Board can put pressure on advertisers through persuasion, publicity or even legal action if it is deemed necessary. 


\subsection{Legal Considerations - Public Relations}

Public relations firms increasingly are investigated along with the corporations they represent in situations of litigation, disputes about investor relations, etc. In fact, after a number of highly publicized cases of major corporate financial malfeasance came to light, public relations departments and firms reviewed their own roles in unwittingly misleading the public about the financial health of organizations that were in deep trouble. In another example, athletic apparel giant Nike was taken to court by a workers' safety advocate because it released press statements defending its reputation against charges of mistreating overseas workers. The news releases were said to represent false advertising. The case served as a wake-up call to public relations firms that send out press releases every day. (Egelko)

In a relatively new twist, a number of "guerilla marketing” firms tout their ability to generate "buzz" about products and services on web sites populated by teens. The firms were recruiting young people with promises of gifts and access to the newest gadgets. In exchange, the teens agreed to go online to popular social networking sites and sing the praises of the products they had received and encourage their peers to buy the merchandise, all without disclosing that they were actually working for a marketing firm.

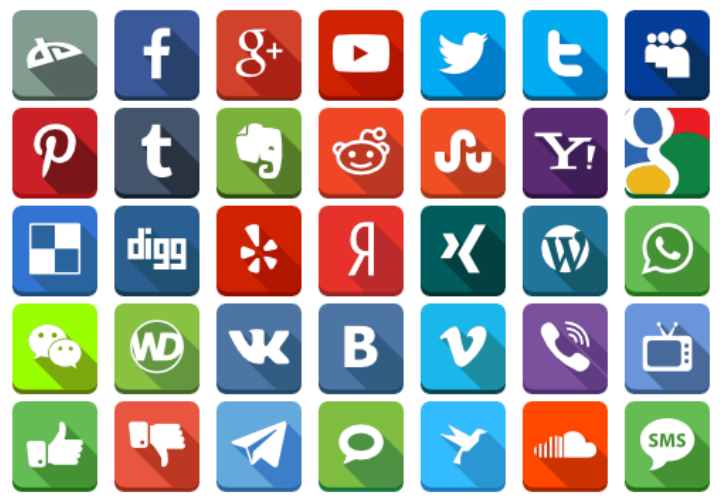

These practices raised ethical questions about the truthfulness Pixabay of messages that fail to disclose conflicts of interest (one of the negative obligations mentioned earlier). When confronted with ethical concerns, many of the marketing and promotion firms claimed that if someone asked, their operatives were instructed to say that they were working for the movie studio, the gadget company or the bubble gum producer. But how many audience members, especially younger ones, were likely to ask?

As we've said, the Federal Trade Commission has now ruled that "word-of-mouth" endorsers of products or services (such as those who post positive messages on social networking sites, etc.) must disclose that they are being compensated with money or free goods and services as part of their posts to these sites. Guidelines originally issued by the Food and Drug Administration regarding direct-to-consumer pharmaceutical advertising now include similar advice for any person or company making claims about medical, food or cosmetic products through social media. 


\subsection{Social Responsibility and the Information Strategy}

All of these levels of responsibility influence how communicators weigh their actions and make their decisions. Societal expectations, organizational and professional routines and norms, and individual standards are going to play a role in each decision you are faced with making. As long as you have a systematic method for evaluating each situation and for applying your professional standards, you should be able to make your information decisions in an ethical and defensible manner.

The information strategy provides you with the skills to ensure that you don't have to resort to inappropriate, unethical, or illegal means to gather information. If one method of gathering information seems inappropriate, your skill with a well-developed information strategy means you can use another, more appropriate, method to find what you need. Being a highly skilled information gatherer in an information-overloaded society brings credibility to you and to your organization.

Further, using an explicit information strategy helps you explain your standards to others. When the public, colleagues, or supervisors challenge the information on which you base a message, you can present an ordered, rational account of your information search and selection process. Using the standards and methods available in the information strategy allows others to evaluate your skill and expertise as a communications professional. 


\subsection{Endnotes / Resources}

\section{Endnotes:}

Bachman, K. (2012, May 16). Skechers Settles Deceptive Ad Case with FTC for \$40M. AdWeek, at http://www.adweek.com/news/advertising-branding/skechers-settles-deceptive-ad-case-ftc-40m-140577 captured on July 26, 2012.

Beer Institute Advertising and Marketing Code, at http://www.beerinstitute.org/tier.asp?bid=249, captured on August 15, 2017.

Egelko, B. (2003, September 13) Nike settles suit for \$1.5 million, San Francisco Chronicle at http://www.sfgate.com/ default/article/Nike-settles-suit-for-1-5-million-Shoe-giant-2589523.php, captured on July 26, 2012.

Levine, D. and McBride, S. (2012, June 18). Facebook 'Sponsored Stories' Lawsuit: Company to Pay \$10 Million Settlement. HuffPost Tech Blog at http://www.huffingtonpost.com/2012/06/16/facebook-sponsored-storieslawsuit-10-million_n_1602905.html, captured on July 26, 2012.

Magazine Advertising Policy, Texas Parks \& Wildlife magazine, at http://www.tpwmagazine.com/advertising/policy/, captured on July 26, 2015.

Miller, K. (2000, September 7). Firestone’s PR Firm Resigns, Washington Post at http://www.washingtonpost.com/wpsrv/aponline/20000907/aponline231008_000.htm, captured on July 26, 2012.

\section{RESOURCES:}

A collection of news organizations' ethics codes can be found at The Center for Journalism Ethics' Ethics Resources page. 


\section{Lesson 8. Research Skill: Searching}

\section{KEY CONCEPTS}

- Effective searching must start with a set of questions you need to answer.

- There is a logical and orderly process by which information becomes part of a searchable database or repository of material.

- Different types of sources are searched in different ways and are found in different types of databases.

- Constructing a search strategy requires understanding the structure and content of the database in which you are searching.

- Constructing a search requires understanding of the terminology of the topic as used by different types of disciplines or contributors.

- Systems used for information searching on the web have vastly different characteristics, content and lead to very different search outcomes.

- Libraries contain vast varieties of search systems and it requires familiarizing yourself with the structure of the library website to locate the resources.

- Searching is often a multi-step process with one search informing how to structure the subsequent search.

\section{LEARNING OUTCOMES}

After completing this lesson, you will be able to:

- identify and define the contents of a database, how the contents were gathered, and select the database(s) mostly likely to help answer your question.

- distinguish between types of reference tools.

- maximize the search options available in different search engines to construct the most effective search.

- take advantage of subject headings or classification schemes when searching and understand how to consider terminology in your search.

- construct a "Boolean equation" as part of your search strategy.

- understand what is and isn’t found in "surface” web searches compared to “deep” web searches. 


\subsection{Getting Started on Your Information Strategy}

It should comes as no surprise that the first of the "Research Skills" we will discuss is the one about how to effectively conduct a search. Unless you have been handed the exact URL for an online document or you know right where a book is on a shelf, you will need to conduct a search in a database to find where useful information might be found.

Searching usually involves goal-directed and highly targeted information strategies using well-established sources of information found in many types of information spaces - libraries, databases, public records repositories, and so forth. When we talk about the specific kinds of research skills related to locating certain kinds of information (public records, surveys, information about individuals or companies, etc.) you will need to have the ability to:

- find an appropriate databases to search

- construct an effective search equation

- evaluate and assess what you found

\section{Getting Started on Your Information Strategy}

In the section on Question Analysis we worked on developing a list of information tasks that you must undertake to get the information needed for your message assignment. These tasks and the questions that must be answered are crucial at the start of your information strategy.

Searching will be your first step to completing most information tasks. Whether your task is to find a quick fact (What does the W in George W Bush stand for?), a particular public record (I need the 10-K reports for our three main competitors), to get ideas or background (What kind of coverage has there been on digital wallets?), audience data (What is the demographic profile of people who buy energy drinks?), or a welldocumented government statistic (What is the population of Duluth?), searching will be required.

There are a number of things that stand in the way of finding good information when you start your strategy:

- You may not know where or how to start.

- You may be asking a question that is too specific.

- You may be asking a question that is too broad.

- You may not understand the relevance of things you find as you search.

- You may not be focusing on likely sources for the information you are seeking. 
Developing your search skills and knowledge of how and where searching is done online will help you address each of these issues.

\section{Databases Are Not All Created Equally}

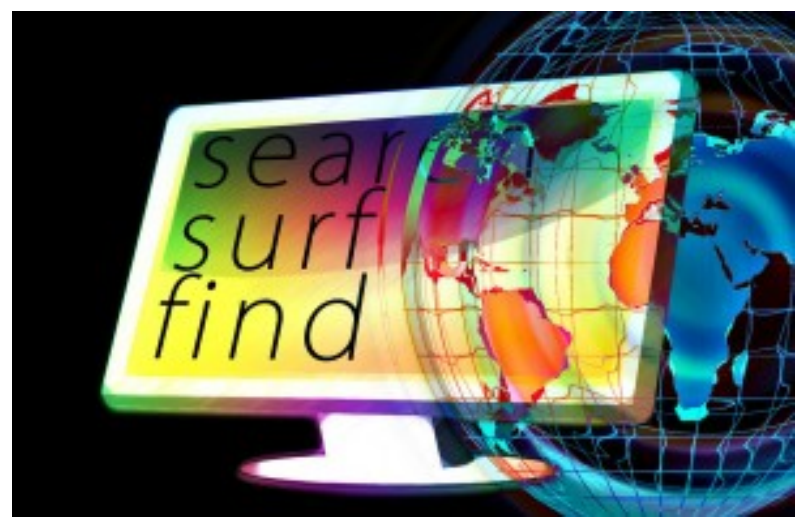

geralt - Search, surf, find - CCO
Virtually all of the resources you regularly use online are giant databases. Google is a database with links to material stored on web sites. Facebook is a social media site with a database you search to find friends or people with particular characteristics. The library digital catalog has a database that will help you locate resources the library has available or database services it subscribes to.

Completing any information task will require skilled knowledge about how to locate and use databases with the kinds of information that will help answer your questions.

But remember, it starts with the questions. No one clicks on Google and thinks, "I'm going to search the topic 'Google'.” Instead, you click on Google with a clearly defined topic that you need to research, and an information task you must accomplish. This will help you create a question to answer which will inform how to structure your search query.

For example - if the topic you need to learn about is "food insecurity" there may be a number of tasks:

Task: Get a clear idea of the definition of the term

Question: What does “food insecurity” mean?

Search: “food insecurity” AND definition

Task: Need experts or people involved in the area that I can talk with

Question: Are there any associations that deal with "food insecurity”?

Search: “food insecurity” AND association

Task: Get data that can help me understand the scope of the issue

Question: How many people are affected by “food insecurity”?

Search: "food insecurity” AND statistics 
We understand that students these days believe they know how to search just fine, thank you very much. But the ease of "Googling” makes it easy to be a lazy and uninspired researcher. Just relying on doing a Google search without understanding and exploring the vastly rich and diverse search resources available will prevent you from becoming a truly inspired, clever, and resourceful researcher.

And this is what employers are looking for. In a survey in 2013, 93\% of the 318 employers surveyed by Hart Research Associates for the Association Of American Colleges And Universities said what they most highly value in a new hire is "a candidate's demonstrated capacity to think critically, communicate clearly, and solve complex problems.”

Honing your search skills requires all three of those capacities. 


\subsection{One-step / Two-step Research}

Research resources can be categorized in one of two ways. One-step resources refer to those that provide the available information directly. Look up "beagles" in an encyclopedia and whatever information that reference book has about beagles will be in the "article”. Examples of one-step reference works are dictionaries, encyclopedias, directories, almanacs, yearbooks, and syndicated market research sources.

Two-step resources differ in that they indicate where information you might want resides and you have to take a "second step" to

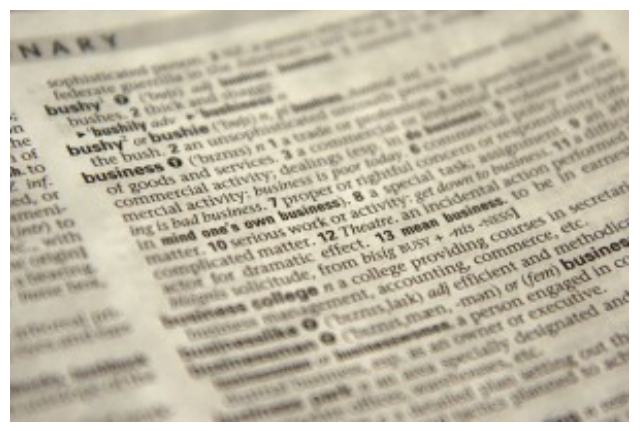

Dictionary - CCO actually get the material. If you search for "beagles" in the library catalog, for example, it will point you to where on the book shelf a guide to raising beagles sits. Examples of two-step resources are library catalogs, publication indexes, abstract services, bibliographies, and news aggregation services.

\section{Reader's Guide to}

periodical literature In the pre-digital era, printed two-step tools, like the Reader's Guide to Periodical Literature, would enable researchers to look up a keyword and get citations to articles on that topic. They would then have to find a physical copy of the magazine and locate the article within the magazine.

Today, the two-step tool (of which Google would be an example) often provides a ready link to the material being indexed.

Each type of one-step and two-step tool is useful at various stages of the information process. At the beginning of your information gathering process, some of the uses might be checking terms so you know what you are talking about, finding contacts that will be useful to talk to, or locating facts and figures that might give you an interesting angle. During the search, these tools will be fact-checkers, and reality checks for the things you hear / discover in your research. When you are at the point of writing or developing the final message, these are the tools that will help you tie up loose ends, find interesting facts to brighten the piece, or give it context.

In order to give you a sense of the rich variety of one-step and two-step research resources available (many or most now online) here are some of the categories and types. 


\subsection{One-step Research Tools}

\section{ENCYCLOPEDIAS:}

General Encyclopedias: Cover a wide range of topics and different audiences. For example, the World Book Encyclopedia is aimed at a young audience and has a simpler reading level and less detail while the Encyclopedia Britannica is written for a more mature audience and is written with much greater authoritativeness.

Subject Encyclopedias: Allow greater depth and specificity and more detailed entries on narrow topics.

Examples: Encyclopedia of Pop, Rock, and Soul,
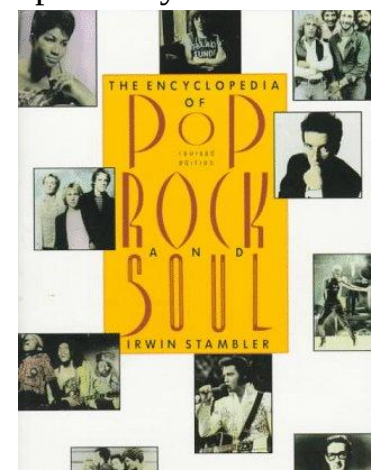

Stanford Encyclopedia of Philosophy.

Wikipedia: Although its status as a credible source of information is tenuous, any discussion about information sources in this era cannot ignore Wikipedia, by far the most widely viewed central source of information about everything — excluding search engines—-for Internet users.

DICTIONARIES: Since the communicator's stock in trade often is the word, the usefulness of a dictionary may seem obvious. Just as with encyclopedias, not all dictionaries are the same. For instance, the Oxford English Dictionary is recognized as the most authoritative source for looking up the etymology, or origin and evolution, of words.

General Dictionaries: These are your standard dictionaries of words in use in a language.

Specialty Dictionaries: There are rhyming dictionaries, dictionaries of acronyms and abbreviations, anagram, and homophone dictionaries, to name a few of the many varieties.

Subject Dictionaries: Law, medical, science and technology, slang, engineering, biographical, music — these are some of the types of special dictionaries that deal specifically with the language of a discipline, science or topic.

DIRECTORIES: Among the most useful kinds of one-step tools in the library are directories. Whether it is a familiar telephone directory, the ZIP Code directory, or something a bit more esoteric — such as the Prairie Directory of North America - the directory is an important source of information for mass communicators. 
Publication Directories: These will help you locate newspapers and magazines and broadcast outlets. The Gale Directory of Publications and Broadcast Media, for example, is organized by geographic area and by media outlet name. Market and economic data, summaries of population, statistics on agriculture and industry, and maps are included, making it of tremendous value for advertisers trying to identify how best to reach a particular community. The UMN library has a resource page on a number of these types of directories.

People Directories: Whether you are looking for a specific person whose name you already have or a particular type of person (an academic expert on nuclear power, the public information officer for the state Department of Education), directories are going to be the most useful starting points.

Institution Directories: As we've discussed, public-sector and private-sector institutions, scholarly organization and many other types of institutions generate important information for communicators. Using any of the directories that guide you to these institutions will help you identify the right organization and the appropriate people to contact.

ALMANACS AND YEARBOOKS: An almanac is an annual compendia of facts, figures, and tidbits of information.

General Almanacs: These cover popular information - such as The World Almanac or the Information Please Almanac.

Subject Specific Almanacs: The Almanac of American Politics, for example, compiles information or biographical data about a topic or person not included in more general almanacs.

Yearbooks: These are the year-end wrap up publications that cover the latest developments. The United States Government Manual publishes information on the activities, and chief officers of all agencies within the federal government. Many professions and industries also have yearbooks. For example, the newspaper industry has the Editor \& Publisher Newspaper Data Book.

There are also subject-specific yearbooks, such as the Statesman's Yearbook, the Europa World Year Book or the CIA World Factbook, which provide current information on countries and international organizations. 


\subsection{Two-step Research Tools}

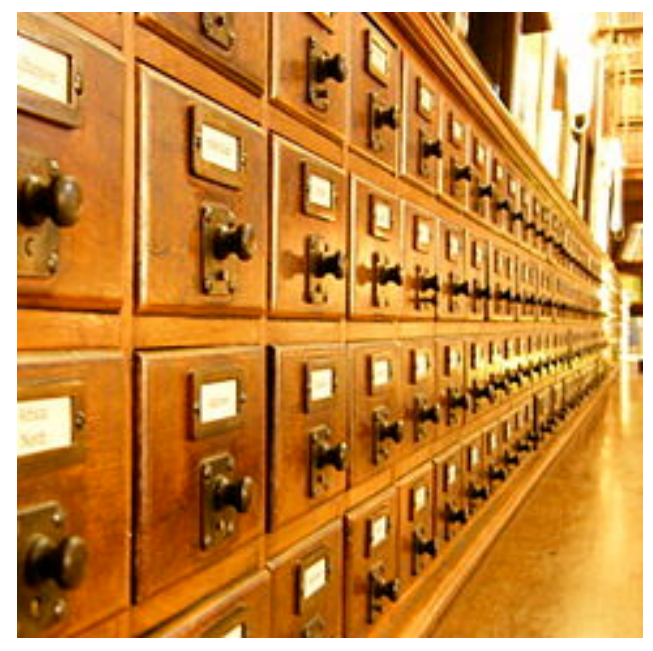

Stuart Caie - Card catalog - CC BY 2.0
Library Catalog: key to the entire collection of information. The catalog details the holdings of the library and includes information about how each item may be located.

Indexes and Abstracts: the classic "two-step" tool. An index is a listing, usually alphabetically arranged by subject categories, of articles and materials that have appeared in other publications. There are indexes to magazine, newspaper, and journal articles; poems; plays; songs; speeches, etc.

The abstract is an index with a brief, non-evaluative summary of each article being described. Oftentimes, the well-written abstract has the substance of the article so you can get what you need simply from the brief description provided - you don't have to take that "second-step" to find the article itself.

You can see the tremendous variety of indexes in UMN library’s list of Periodical Indexes here.

Some of the reference resources discussed above are still published in paper form but many, if not most, are found digitally online. As online resources, you will have multiple entry points into the material. Learning how the repositories of information are compiled, and searched, is the next step for developing your researching skills. 


\subsection{Basics of Searching on the Web}

There are two types of databases for searching on the web. There are site-specific search engines that locate material contained within a specific website, and there are web search engines that locate information widely from across the web. Both of these types of search engines have the same sorts of functions. What differs between them is how the database being searched was created, how searches within that database are best conducted, and what kind of information you'll be retrieving from the database.

The first thing you should do when you go to an unfamiliar search site (or even one you've been using, but with some degree of frustration) is to find the search "help" file. Spending a few minutes with the help file will get you ready to do a thorough and effective search.

\section{Directories vs. Indexes}

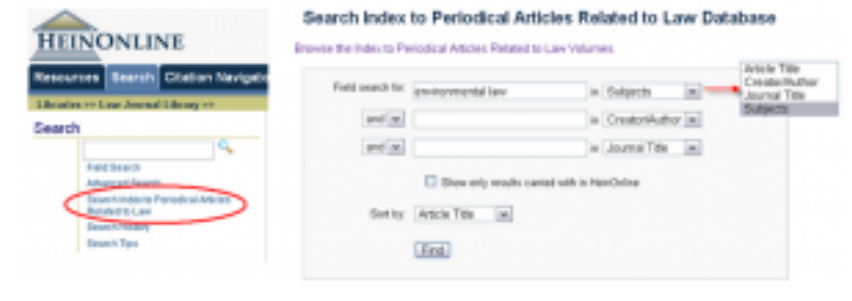

http://help.heinonline.org/

The most important distinction for you to understand about a web search site is whether it is a directory or a machine-indexed search tool.

A directory search engine has hierarchically organized lists of subject categories. Its databases are compiled and maintained by humans, and these directories allow users to browse by subject in search of relevant information. Examples of directory search sites are Yahoo! and online library catalogs.

Instead of relying on humans to enter the information about sites, machine-indexed search engine sites rely on software. This explanation of how "spider" (sometimes referred to as "robot") software works comes from founder Danny Sullivan’s Search Engine Watch. Sullivan writes:

"The spider visits a web page, reads it, and then follows links to other pages within the site. This is what it means when someone refers to a site being "spidered" or "crawled." The spider returns to the site on a regular basis, such as every month or two, to look for changes. Everything the spider finds goes into the second part of a search engine, the index. The index, sometimes called the catalog, is like a giant book containing a copy of every web page that the spider finds. If a web page changes, then this book is updated with new information. Sometimes, it can take a while for new pages or changes that the spider finds to be added to the index. Thus, a web page may have been "spidered" but not yet "indexed." Until it is indexed - added to the index - it is not available to those searching with the search engine." (2002)

A few examples of machine-indexed search engine sites are Google and Bing.

Database "scope": It is important that you understand the scope of the contents contained in whatever database you are searching. The scope defines the range of materials that the database indexes. Google, for example, aspires to index all the contents of web sites in the surface web. Google News, however, indexes only news stories. Google Scholar indexes articles found in scholarly publications. The New York Times 
web site also has a database of news stories, but they would only be those published in the New York Times. And the Star Tribune has two databases of news stories on its web site - one with stories published by the newspaper online in the past 3-4 years, another with stories published in the newspaper since the 1980s. Knowing the scope of the database you are using will help you know where you are likely to find the kind of information you need. 


\subsection{The Deep Web}

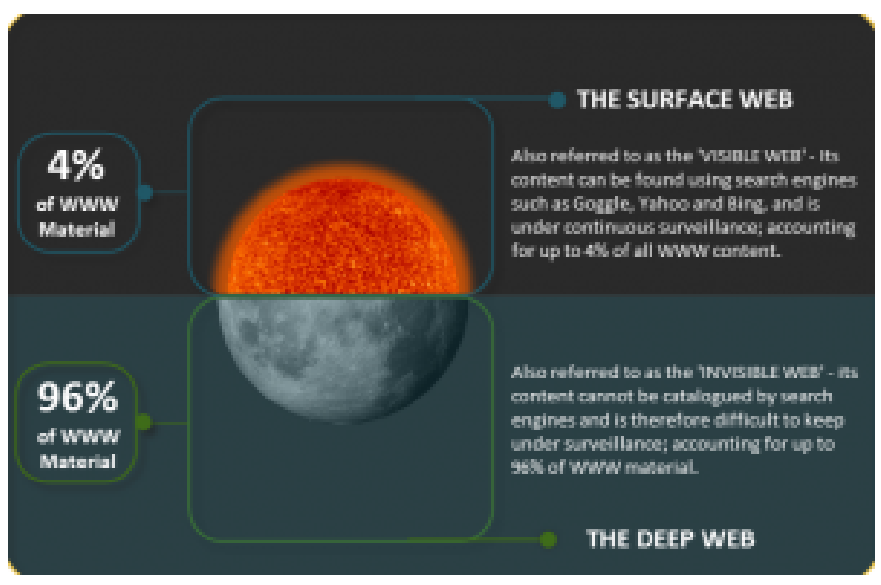

By T (Own work) - Deep web diagram - CC BY-SA 3.0
There are billions of web pages connected through the Internet. However, estimates are that traditional search engines on the web index just a small fraction of those pages. The rest has come to be known as the "deep web.” This "deep web " consists of material in databases embedded in websites, Flash animations, information that is password protected or behind registration screens that cannot be "spidered,", and "dynamic" content of various sorts such as airline flight schedules and news pages that are updated minute-by-minute.

Notably, this information is not necessarily completely "buried" and inaccessible to you as a user. Rather, much of this information is that which cannot be accessed through broad search engines such as Google or Yahoo!. It is important for you to know, then, that the material accessible to you through a web search site is significantly limited in scope - there may well be valuable information out there that you will have to dig a little more deeply to find.

If you need to do a thorough search on a topic, particularly one for which important information would be found inside a database, a directory, or in an Excel spreadsheet, you will have to look into the hidden nooks and crannies of the web to find what you need.

Some of the search engines that claimed to provide results from the deep web are no longer around. The experts now suggest that you identify some of the specialized search engines in the specific field or area of interest and use those to locate materials that the huge general search engines can't reach. Examples include Economagic for data files, charts and Excel files for a vast array of economic data or Guidestar for information from and about the hundreds of thousands of non-profit organizations in the U.S. 


\subsection{The "Disappeared" Web}

\section{Not Found}

The requested URL. /oldpage html was not found on this server

Apache/2.2.3 (CentOS) Senver at www.example.com Port 80

One of the greatest fallacies of the information age is that the information found online is secure. Nothing could be further from the truth. After a candidate loses the election, her campaign website comes down. When a news organization puts a new publication system in place, the contents of its former website might disappear. Some information, like user comments, might be ephemeral or updated information will overwrite what was previously there.

Archiving "born-digital" content is an issue more specialists are paying attention to and there are some efforts to capture the web that searchers should be aware of.

A massive effort to archive the web is available through the Wayback Machine from the Internet Archive. They capture websites (somewhat sporadically) which allow people to retrieve web page contents by entering the URL of the site. Searchers can see what a site, and links, looked like - sometimes from 10-15 years ago.

It is also possible to look at the "cached" version of a website if the current site appears to be unavailable. For example, you might search Google for a topic or issue and when you click on one of the top search results, you get the dreaded "404 not found error," meaning you can't link to that site. Sometimes this is because the server is temporarily down, sometimes it is because the site may no longer exist. In that case, you can click on the little green down arrow right next to the URL in the Google results listing to see the "cached" version of the site. That is the version of the site that was "spidered" or "crawled" before the site went dark or the server became unavailable. In most instances, you will be able to look at the home page of the site but the links on that home page may no longer work. But at least you can see what the home page looked like before the site disappeared. 


\subsection{Key Words and Subject Headings}

People in different disciplines have their own jargon and terminology for discussing their field and the ideas they work with. You must know how to decode this language in order to be able to talk to experts, understand what they are writing, and make the material clear for the non-specialist audience that will see the final message.

The language of a topic is also the key that opens the door to effective searching. Language is the access code through which formal collections of information in libraries and databases are indexed and organized. In addition, terminology shifts over time with the introduction of new words and as some language falls out of use and is replaced.

Political perspectives also play a role in decoding language. A body of water in the Middle East is called the Persian Gulf by some and the Arabian Gulf by others, depending on their political perspective. Think about the different connotations of the terms "pro-choice" or "pro-abortion;" "right-to-life” or "anti-choice." You must understand how the audience will react to language and terminology choices. During your information search you must use appropriate terminology to locate relevant information.

\section{Subject Headings}

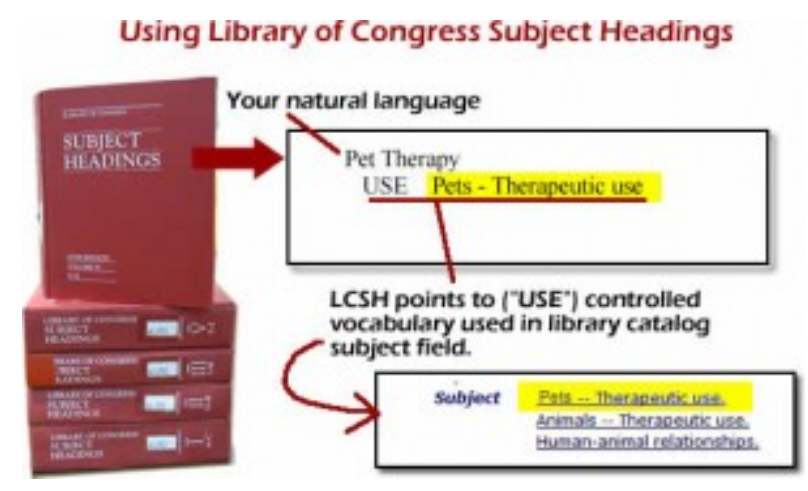

A major characteristic of information searching is the use of subject terms or headings. The major purpose of subject headings systems is to provide a standardized method of describing all information in the same general subject area so that everything pertaining to a topic can be identified. When you are searching for information in print or digital form, you are likely to have a general notion of the topic area you are researching rather than a detailed list of authors or titles of materials you are seeking. For that reason, information catalogers and indexers have tagged records with subject headings as a finding tool.

Indexers spend enormous amounts of time developing subject headings that accurately reflect the structure of information in a subject area. You can use these subject headings in many ways. They appear on the records in a library's catalog; they appear in the entries of indexes and the headings in abstracts, or they may be used to organize material on web sites.

Information organizers may use the subject classification system created by the Library of Congress, a system that is called the Library of Congress Subject Headings and which is particularly appropriate for very large collections. 
Smaller collections may use the Sears List of Subject Headings. Special collections may have their own subject headings, such as the Medical Subject Headings used, obviously, in medical collections.

You do not need to know the intricacies of these systems. The point is that you can be a much more efficient information searcher if you know how to use the specific subject headings for your search. 


\subsection{Search Logic and Boolean Connectors}

Strategic searching in databases requires constructing a "search equation" that details the relationship between the words you use. That is, knowing how the words you type into a search relate to each other is important because your decisions about how to enter the terms will greatly affect the results. Boolean logic is the phrase used to describe the system that applies to electronic search logic.

Mathematician George Boole invented Boolean logic with the publication of the system in a thesis in 1854. It was of little interest to anyone at that time, as it dealt with pure logic, and was mostly forgotten.

However, with the advent of computing, computer developers realized that Boolean logic, which had little practical use in the 19th Century, was ideal when applied to searching computerized databases.

Boolean logic uses three 'logical operators' to represent relationships between terms and define what a search should find. These 'operators' are AND, OR, and NOT.

The relationship between terms connected by Boolean logic are represented in this diagram:

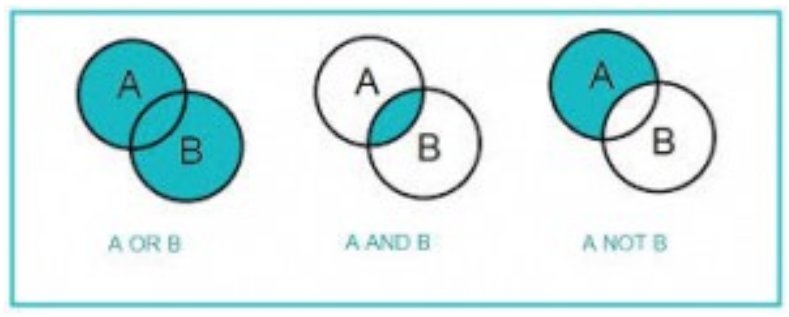

You use Boolean logic in your web searches without realizing it. When you enter two different words in Google, there is an implied Boolean connection between the two words. The "default" logical connection between terms entered in Google is an "AND."

If you use the "advanced search" template that many sites offer, complex boolean relationships can be constructed and you can more elegantly control the relationship you want between your search terms.

For example, if you wanted to find out information on the behavior characteristics of three different dogs (westies, aussies, and collies) and you type behavior westies aussies collies in Google's search bar, you will get results that have ALL of those terms when what you want is the behavior of any of those dogs. Plugging the search terms into the advanced search box lets you retrieve that have articles about the behavior of any of the three. 
136 Information Strategies for Communicators

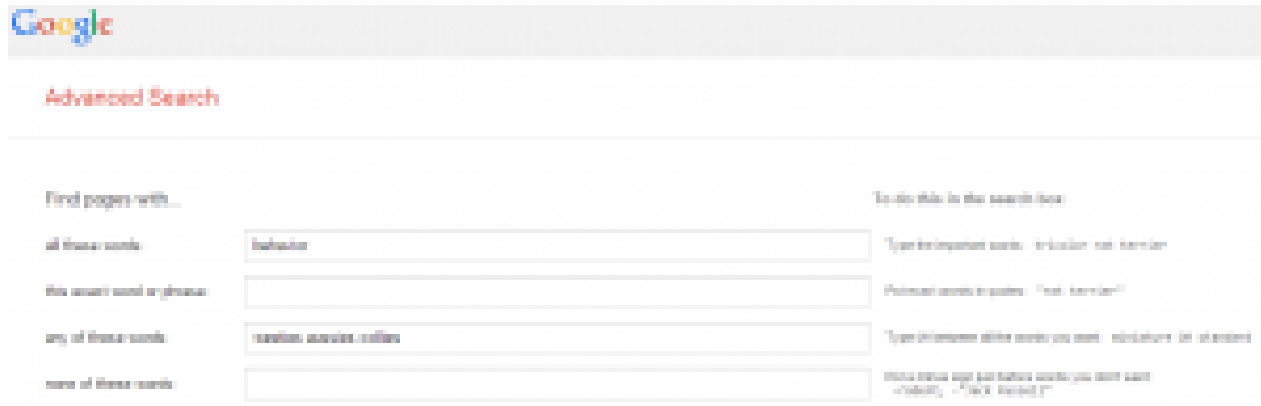

A basic tutorial on the use of Boolean logic and Boolean operators is found here. If you don't know how to represent the relationships between words in a search equation, review the information so you are able to improve the precision of your searching. 


\subsection{Searching Fields}

A database record usually contains different "fields" of information that describe the resource it has indexed. Learning to search within specific fields can help you pinpoint the kind of information are seeking.

\section{Fields might include:}

- Author

- Publication

- Date of publication

- Keywords used (in a directory)

- Type of material

When you are searching in a structured commercial database like Academic Search Premier you'll have a large selection of fields to search - here are some of them:

- TX All Text

- AU Author

- TI Title

- SU Subject Terms

- AB Abstract or Author-Supplied Abstract

- KW Author-Supplied Keywords

- GE Geographic Terms

- PE People

- CO Company Entity

- IC NAICS Code or Description

- SO Journal Name

These fields can be used to develop very specific search equations.

Using the "advanced search" feature on most web-based search engines offers the opportunity to specifiy the field 
in which you want your term to appear. Google’s advance search, for example, lets your search for terms within certain kinds of top-level domains (.edu or .gov, for example) or for specific types of files (.pdf or .xls) Searching within fields allows the savvy searcher to construct a very specific search. 


\subsection{Contributors of Information and Database Searching}

The five different contributors of information generate their own types of database resources that communications professionals can search.

Public-sector Institutions: Databases of licensing information, lawsuits, nursing home inspection reports - all of the kinds of public records documents that government agencies generate are housed in specific databases. (More information about public records will be found in Lesson 13.) To find appropriate databases that might contain information you need, you have to go to the agency that would have generated the information - but that requires thinking about the topic you are researching and determining the type of agency at different levels of government that might deal with that topic. From there, you need to go to the website for the agency and locate where and what kind of databases they maintain. Public-sector institutional documents are also searchable through databases produced by private-sector commercial firms such as Accurint or Westlaw.

\section{Key resources for finding public-sector institutional databases:}

- USA.gov: This resource provides a comprehensive database of information from federal, state, local and tribal agencies that generate public-sector information

- Government Databases by Subject : This compilation provides an interesting sampling of public-sector institutional databases

Private-sector Institutions: While most commercial databases are products of private-sector institutions (for example, Lexis-Nexis, Academic Search Premier, Factiva), here we are talking about the kinds of databases that private-sector institutions might make directly available to researchers. Searching within a private-sector institution's website is a type of database containing the contents they want to share with the public. Corporations will also create databases to support their commercial enterprises. For example, General Mills' product locator http://www.generalmills.com/ProductLocator.aspx is a database for consumers looking for local availability. Ford Motor Company has created a database to allow owners to see if their specific vehicle is subject to a recall - you search by your car's VIN (vehicle identification number.) http://owner.ford.com/servlet/ ContentServer?pagename=Owner/Page/RecallsPage The use of databases to compile large sets of private-sector institutional information is widespread and researchers need to be clever to find and use appropriate information.

Several alert or filter services that are especially useful for advertising and public relations professionals to monitor for-profit and non-profit institutions include Business Wire and PR Newswire. Both services allow you to customize your search preferences so that you automatically receive information (news releases, stock price information, analysts' reports, alerts of news stories about those companies or organizations you are interested in) every time something important happens.

Many for-profit and non-profit institutions have also created their own information services. For instance, the Gatorade Sports Science Institute, a division of the beverage company, produces sports and nutrition information and publishes materials in bulletins and newsletters that are sent to thousands of sports medicine professionals in print and via email. 
Scholarly Sources: Although Google is a private-sector institution, when talking about databases which contain information generated by scholarly contributors, you must consider Google Scholar. This database indexes the articles in thousands of scholarly publications and websites. In addition, the information that is written by scholars can be found in the individual databases of the journals that the private non-profit association or organization might publish. For example, the Journal of Public Relations Research has a searchable database of articles from the journal on its website. You can search within the current issue or over all the past issues. http://www.tandfonline.com/toc/hprr20/current\#.U7HPao1dX3B

Scholarly source information is also located through hundreds of databases produced by private-sector institutional sources who are in the business of selling subscriptions to their services. These databases are most often accessed through a library.

Journalistic Sources: Databases of the stories and articles generated by journalistic contributors usually consist of two different types. On a news organization's website you will find a search function that retrieves material that has been published on the news organization's website. There is usually another, separate search function as well - one that will search a different database containing the stories that were published in the newsprint newspaper (and it usually contains material going back several decades.) Searching news databases is a good example of the need to understand the "scope" of the database's contents so that you go fishing in the datahole most likely to help you catch what you need. For an example of two search engines on a news website look at the Star Tribune:

- Website Search: (in upper left hand corner) http://www.startribune.com/

- Newspaper Articles Archive: (going back to 1986) http://www.startribune.com/help/120225044.html

Again, journalistic sources are also accessible through databases produced by private-sector institutional sources and found in library collections.

Informal Sources: Informal sources don’t create databases, per se, but the material / photos / postings they generate become part of databases. If you search for photos of cute cats in Pinterest, you'll find pages that have been compiled by informal sources, for instance. Using the search function on social networking sites allows you to identify informal source information that has made its way into these private-sector institutional sources' databases. 


\subsection{Tracking Your Search}

As you can see from all the discussion about searching, finding a good database to search and constructing an efficient and effective search strategy can be time consuming. So, when you have found a good search string, save it, and have one of the many available tracking services regularly conduct the search for you and deliver the results to your mailbox.

Many web search engines provide the ability to save a search and get updates on new material that fits that search.

An excellent example is Google Alerts. alerts.google.com

Set up a search string, tell Alerts how often you want to be updated, what kind of resources you want the tool to check, and it will do the work of keeping up to date on a search topic for you.

There are specialized tracking tools, too. Many state legislatures or courts have a way you can be apprised of changes to bills, or the progress of legal cases. Again, it just takes having a good search strategy in hand to use one of these, essentially, automated search systems.

In conclusion: Searching is a complex skill that requires resourcefulness in scoping out where the best search sites will be, cleverness in selecting relevant keywords, efficiency in using search fields to the maximum effectiveness, and care when evaluating your results. As with any complex skill, practice, patience, and an inquiring mind will serve you well as you try to master it. 


\subsection{Resources/Endnotes}

\section{For more information about how to construct search equations and develop keyword lists:}

- Developing an Effective Search Strategy, University of Southampton, 2003. www.studyskills.soton.ac.uk/ studyguides/Search\%20Strategy.doc

- Formulating your Search Strategy, University of Saskatchewan, 2014. http://libguides.usask.ca/ SearchStrategy

- Keyword Searching: Finding Articles on your Topic, 2014. http://academicguides.waldenu.edu/ content.php?pid=205436\&sid=1714352

- “How do I come up with the best keywords for my searches?”, Bucknell University, 2014. http://bucknell.libanswers.com/a.php?qid=90516

Key words and SEO (Search Engine Optimization)

- How to Do Keyword Research Using Keyword Planner, by Jesse Modoono, January 24, 2016: http://blog.jimdo.com/how-to-do-keyword-research-using-keyword-planner/

\section{Endnotes}

Sullivan, D. (2016, November 29). How Search Engines Work at https://www.linkedin.com/learning/danny-sullivan-onseo/how-search-engines-work captured on August 15, 2017. 


\section{Lesson 9. Research Skill: Interviewing}

\section{KEY CONCEPTS}

- Communicators conduct interviews for a variety of purposes.

- Interviewees are motivated to share information for a variety of reasons.

- The information people share in interviews is based on their expertise, experience, self-interest, proximity and other factors.

- There are a variety of tools and strategies for locating appropriate interviewees.

- Selecting appropriate interviewees and evaluating the information they provide is a major information task for all communications professionals.

- Preparing for an interview must be tied to the question analysis and to the interviewee's background.

- Interviews must be conducted ethically, and the information generated by them must be used ethically and legally.

\section{LEARNING OUTCOMES}

\section{After completing this lesson you will be able to:}

- differentiate between different purposes for conducting interviews.

- understand different types of interviewing methods.

- understand different categories of potential interviewees.

- search for interviewees using appropriate tools and strategies.

- understand how to select and gather background information about interviewees.

- understand interviewee characteristics based on the type of information contributor s/he represents.

- understand interviewee rights and the interviewer / interviewee contract.

- understand basic "interviewing etiquette." 


\subsection{Interviewing as a Research Skill}

Interviewing will be your bread and butter as a communicator. It is the means by which you will elicit information from people, get new perspectives, and achieve new understandings.

Tapping into people - primary sources - through interviewing is a skill honed over time. In this lesson we will talk about the types of interviews, how to select interviewees based on your information task, and the steps involved in the interviewing process.

Interviewing is a technique that is incorporated at more than one point in the information seeking process. Advertising researchers might use focus-group interviews to learn about issues they intend to examine more extensively through survey interviews later in the research process. News reporters do a preliminary set of interviews, along with background research in the news archive, in order to get themselves up to speed on the issues of the story they are covering. Public relations practitioners often interview sources such as company officials when writing news releases.

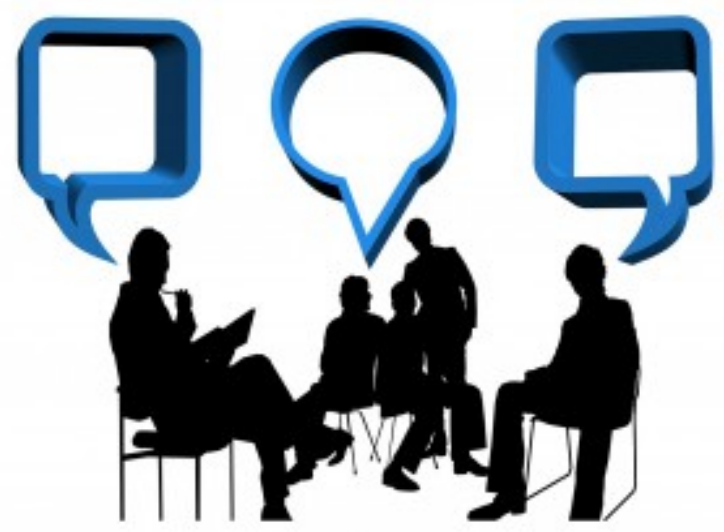

geralt - Exchange of ideas - CCO

Interviews differ according to purpose, format, and medium. The techniques used for interviews also differ depending on the goal you hope to reach through the interviewing process. 


\subsection{Purposes of the Interview}

Communicators share a number of goals in their information-seeking interviews irrespective of whether they work in news, advertising, or public relations positions. For example, a corporate official of a firm that manufactures street-sweeping equipment might be interviewed on a given day by a news reporter asking questions about unusual capabilities of a new piece of equipment being marketed, by a member of the firm's public relations staff who is working on an article for the employee magazine, or by a staff member in the advertising agency that handles the advertising for the firm.

Many of the questions they ask will be similar but some will be distinctive, reflecting the differences in the ultimate use of the information. Their common goal is the gathering of accurate, factual, and comprehensive material that will contribute to an appropriate and interesting message.

Sometimes the content of an interview is used strictly as background or just to inform the reporter or strategic communicator and only small portions of the actual interview content will be seen in the story, ad or PR piece. In other cases the interview itself is the story.

For instance, in the verbatim interview, the dialog of the interview is reproduced for the reader. The interviewer's question is printed as it was asked, followed by the response. The technique is used principally in magazines, usually with a source who is very newsworthy or who is a recognized expert. The interview itself is preceded by a short introduction that establishes the context of the interview and gives background material on the interviewer and the topic. (Example: Keith Richards interview in Esquire.)

The goals of the interview may vary by the intended use for the information (for advertising, public relations, or journalistic purposes) and by the type of story that is being told (business, human interest, civic issues.)

Here are some different types of interview goals and how they may fulfill different information tasks. 


\subsection{Purposes / Information Gathering}

Most communicators use interviewing to meet the information task of backgrounding themselves on their topic/ client/industry and gathering basic information. Think about the street-sweeping equipment example. Depending on the purpose, and audience, for which you are crafting the message, you will seek different kinds of basic information:

- PR piece in the company's magazine for employees and shareholders: you'd ask questions about the impact of the new equipment on the work force of the firm.

- Advertising campaign: you'd focus on acquiring details about the effectiveness of the machine - perhaps even operating the equipment to get a feel for the product.

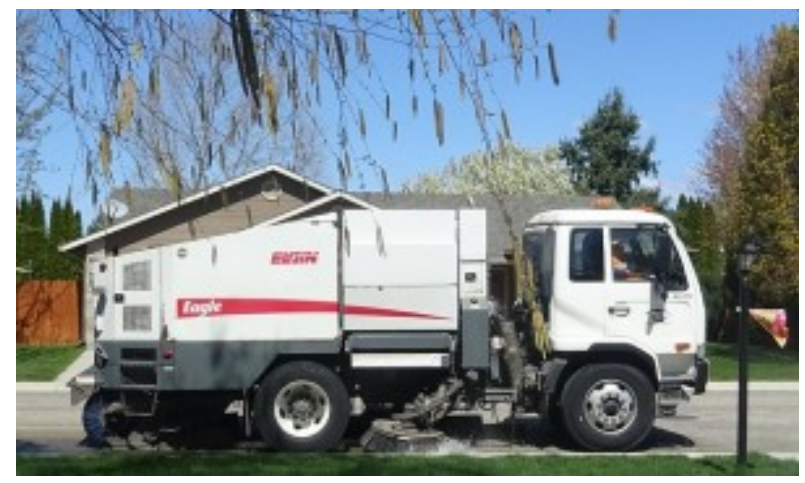

- News report: you'd want to learn about the debbienews - Street sweeper - CCO effect of the equipment on street cleaning in the city, on the firm's profitability, or the bidding process that resulted in the selection of this particular equipment.

In each of these instances, the interviewer is engaging the company representative in a dialog that recognizes the ultimate interest of the audience in particular questions about the firm's decisions and behaviors. The information task in this type of interview might be getting hard facts, opinions, attitudes, or anecdotes. 


\subsection{Human Interest}

Your information task might be to gather insights about people and give you the detail that adds interest to your story or copy. These interviews are less about facts and figures and more about impressions, ideas, and emotions. In these human-interest interviews:

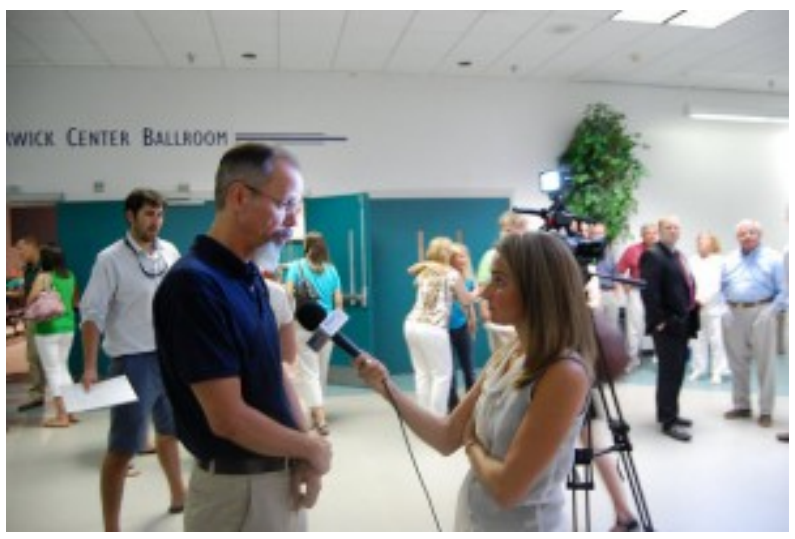

Photo by Lilibeth Serrano, Public Affairs Specialist, USFWS: CC BY 2.0

- Journalists look to get a good story, get the flavor of an experience, and, possibly, get some ideas on how to proceed with the writing

- Advertisers will interview people who might become part of a testimonial ad

- Public relations practitioners will be looking for stories that they can pitch to feature segments of morning television shows or features sections of news sites 


\subsection{Corroborative}

Sometimes the task is to follow-up on another interview. This follow-up interview can provide you with either corroborating, or conflicting, opinion or information. Journalism, in particular, is often said to be about "truthtelling" - in fact it needs to be about "truths-telling" - the truth according to different constituencies in an issue might be very different. These interviews might involve asking the interviewee to reflect on what some other interviewee said. 


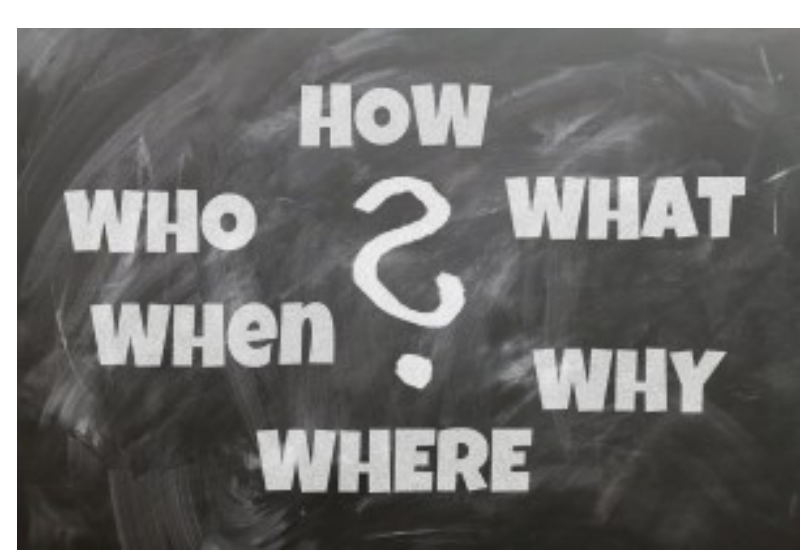

geralt - Untitled - CCO
Good investigative reporters know their information task includes tireless checking of often dull material. Multiple interviews are the rule for investigative journalism. In addition to extensive use of records and documents, investigative journalists try to run down all relevant leads and double- or triple-check all facts. Interviews often lead to additional sources that must be checked out. The investigative report provides perhaps the widest range of interviewees of any type of reporting and cover every type of contributor. 


\subsection{Opinion Seeking}

Perhaps the information task is to understand public opinion. An interview might take place through a poll or focus group session seeking information about consumer behavior and attitudes. The results of a consumer poll may also be included in the actual copy of an advertisement ("J.D. Power and Associates reports that car brand X had the highest rating among new car purchasers.”)

Public relations research relies on poll or focus group data to measure public opinion as part of a campaign to change attitudes. The results of a poll might also be used as part of a public relations campaign to persuade policymakers about decisions they are considering.

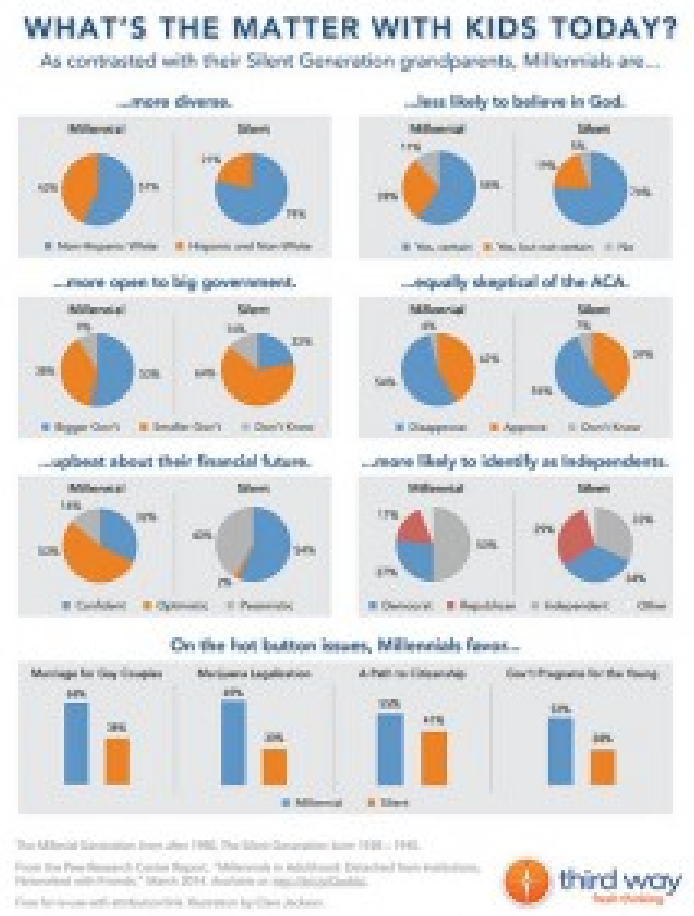

Third Way Think Tank: CC BY-NC-ND 2.0 


\subsection{Methods: Face-to-Face}

Conducting an interview in person is certainly the preferred method for communicators, whether they are interviewing for a news story or conducting focus groups.

\section{Advantages of face-to-face interviews}

- Picking up clues about the person, beyond what they say (tone of voice, body language)

- Holding the interview in the interviewee's "space" allows you to observe their environment, giving clues about the person and providing "color" for the story

- Interviewee can be recorded

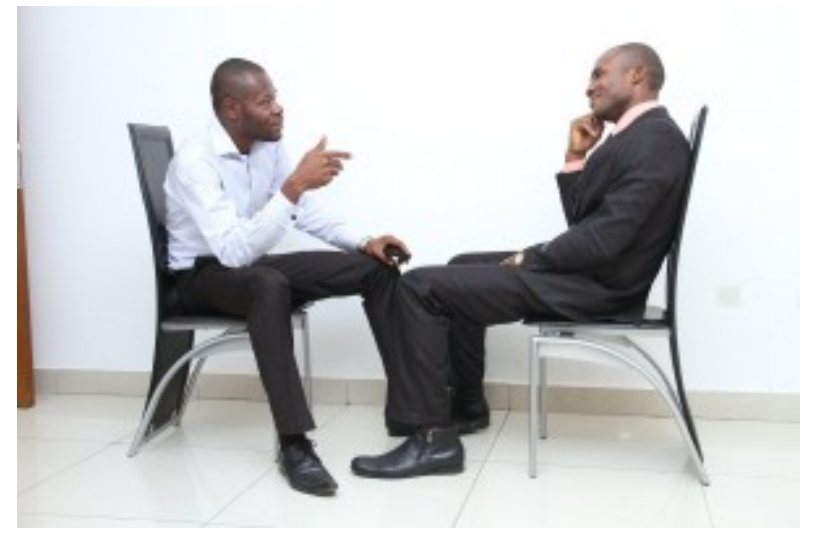

adabara - Interview - CCO

- Longer, more complex question strategy can be used

- Interviewee can respond to visual images or objects

- Non-verbal responses to questions or displayed objects can be part of the information gathered

- Interviews can be edited but still maintain the feel of a live interview

\section{Disadvantages}

- Labor and transportation costs for the interviewers' training and travel to and from the respondents' locations can be high

- Interviewees can be reluctant to allow strangers into their homes or offices

- Interviewer's appearance, age, race, sex, dress, or nonverbal behavior may affect respondents' answers to survey questions. 


\subsection{Methods: Telephone}

For journalists who need to get information from busy or distant experts, the telephone interview is the second favorite method for interviewing. It is a widely used approach for advertisers and public relations professionals who need to speak to clients about the message campaign, or to potential audience members to get the prevailing opinion about a topic or product.

\section{Advantages of telephone interviews:}

- Still get the verbal clues of tone of voice and emotion

- Convenience for interviewer (no travel required) and interviewee (no stranger in your space)

- Interviews can be recorded (if agreed on by the interviewee)

\section{Disadvantages:}

- Visual clues from the interpersonal interaction are missing (unless you are using Skype or some

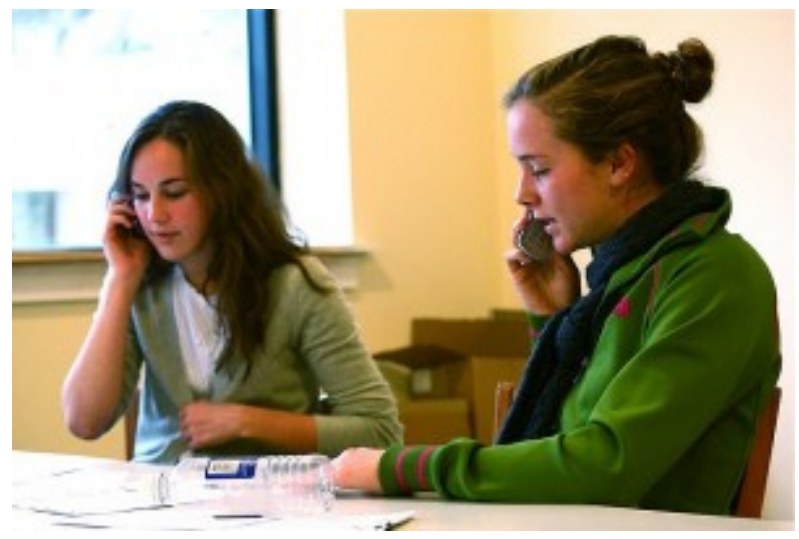

Steven Depelo - CC BY 2.0 other live video link)

- Easier for the interviewee to cut short a phone interview by hanging up if it becomes uncomfortable or confrontational versus if someone is in your physical space

- For strategic communicators, the way that tele-marketing phone calls have tainted phone interviews can lower the response rate to phone requests 


\subsection{Methods: Digital}

Digital interviewing is becoming a popular method for initial contact with a prospective interviewee.

\section{Advantages of digital interviews:}

- It is easy to establish basic information exchange without playing "phone tag”

- Some interviewees are more comfortable and feel more in control of what they say by writing out a response to a question rather than saying something "off the cuff”

- If the interviewee shares his/her social networking page, you have access to a lot of additional information about the person's activities, friends/colleagues and preferences

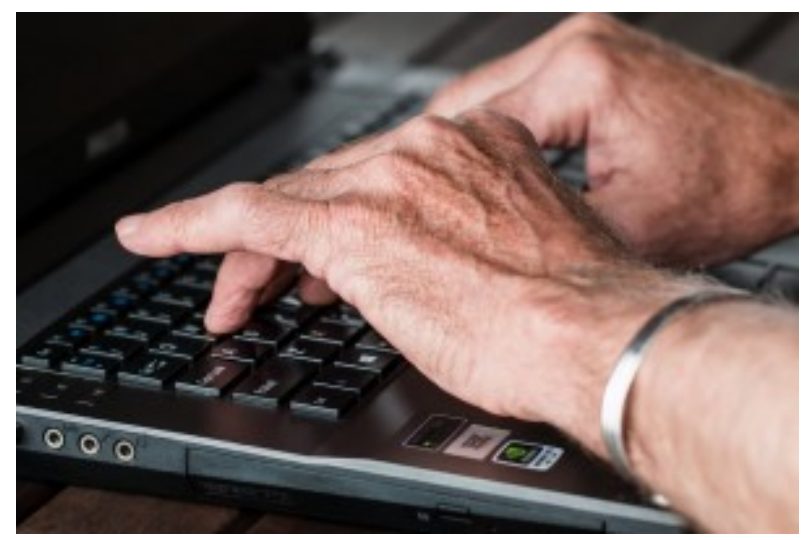

stevebp - Typing - CCO

\section{Disadvantages:}

- It can be hard to ensure the person from whom you want the response is actually the one responding.

- Visual and auditory clues are missing making the information gathered through the written word interview easier to misinterpret.

- For surveys, digital requests for response can be seen as spam and either filtered or easily discarded 


\subsection{Methods: Focus Group}

Up to this point, only two-person interviews have been discussed. However, group interviewing and eliciting information from a large number of people through polling / surveying is also an important information gathering technique for communicators.

In focus groups, you meet with a small group of interviewees who have agreed to discuss a topic or a product. You have a list of questions you present to the interviewees, probing for details and encouraging those in the group to respond to other interviewees' comments. Subjects for discussion arise from the group, as well as from your agenda of questions. A special strength of the focus group is its capacity to raise issues and enlarge the scope of the discussion.

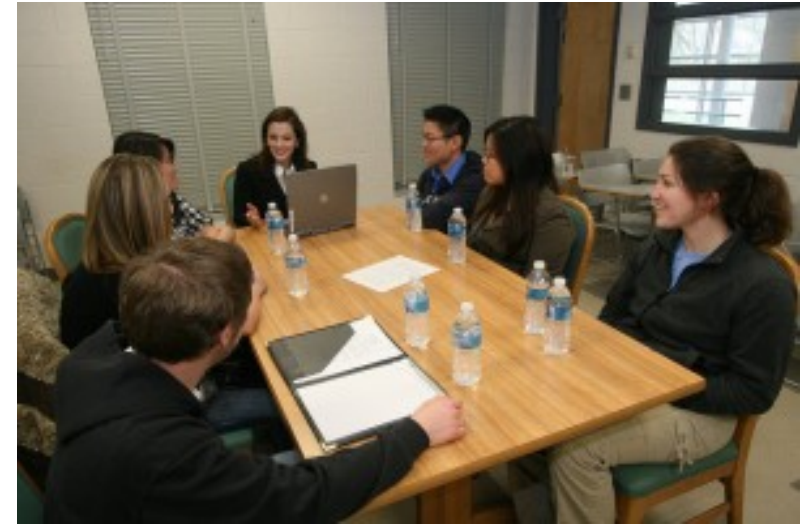

Penn State - CC BY-NC 2.0
Focus-group interviews are prominent in advertising and marketing research and less frequently used in news and public relations work. Potential members of focus groups can range from grade school students, gathered to taste and judge a new snack, to retired people who discuss the services of travel agencies.

The moderator of a focus group lets the discussion flow freely while it is moving productively and producing useful comment. Tasks include making certain that main points are covered, being receptive to new points that arise, and making sure that each respondent has a chance to talk. The moderator also has the task, at the outset of

the discussion, of telling the group how the interview works, of setting up recording equipment and explaining its use to members, and of collecting any permissions that are required of the participants. Focus-group sessions typically are recorded and transcribed for ease of later analysis. Group members are told the method of recording and the subsequent use of their comments. Paying participants a small sum is a typical practice.

Group interviewing is also used in news reporting. For news work, where direct quotes generally are required, group interviewing presents some difficulties. Even if the session is recorded, identifying the voices accurately is difficult (unless it is videotaped.) Under some circumstances, however, group interviewing has advantages. You may find that individuals are unwilling to be interviewed for attribution but are willing to have their stories told as a part of the group's story. For example, for a story on alcoholism, members of Alcoholics Anonymous may relate their experiences to one another while you listen.

Having permission to record the discussion is important in such group interviews, although the recording generally is flawed by extraneous sounds and inaudible voices. As a precaution against flaws in the tape, you should take as many notes as possible. Further, you should, at the end of the session, pass around paper and a pencil, requesting names, telephone numbers and e-mail addresses to contact for later clarifications and as a check on accuracy. While this may seem to violate the "anonymity” provision, group members may have come to 
trust you during the meeting, and some may be willing to be called after the interview so their comments can be clarified or verified before the story is written. In addition, follow-up telephone calls may elicit other important information that did not emerge during the group interview. 


\subsection{Methods: News Conference}

News conferences range in style and size from televised presidential news conferences, with hundreds of reporters assembled, to informal sessions, with one source and a handful of questioners.

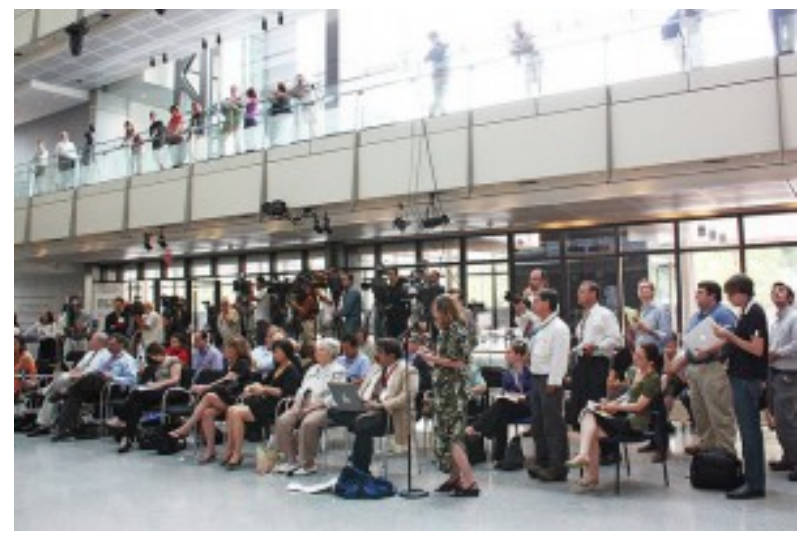

$N A S A-C C B Y 2.0$

The news conference undoubtedly is the journalist's leastfavorite method of news gathering. From the viewpoint of the source, the news conference is a time-saving convention. But from the reporter's perspective, there is little to recommend it. If the news conference is televised, reporters for newspapers find that their questions and the answers to them have been broadcast on television or placed as a video file on a news Web site before they can write their own stories.

Follow-up and clarification questions are difficult at large news conferences. Reporters who have prepared particularly well often do not reap the benefits of their preparation. They may not have a chance to ask their questions, and, if they do, they reveal their lines of inquiry to competitors.

Despite the limitations of news conferences, they continue to be a standard method that busy or celebrated people use for giving information to the media. Behind the scenes at press conferences, the work of public relations staff members is critical. For many news conferences, public relations staff have prepared handouts that give the essential information about the announcements to be made that day.

In these packets, reporters find the basics related to the announcement - names, titles, dates, places and decisions - that free them to ask more substantial and interpretative questions than they otherwise would be able to ask. From the viewpoint of the public relations staff, these information packets are designed to promote accuracy in the news reports that follow the conference.

Questions in news conferences should be short. Reporters who seem to be making speeches instead of asking questions draw the anger of their colleagues. So do the unprepared, whose questions do not advance the topic but require the source to repeat information that well-informed reporters have already acquired. Well-prepared and attentive listeners are in the best position to present important follow-up questions during news conferences. 


\subsection{Preparing for an Interview}

The information strategy is critical in helping you identify people who might be good sources of information for your message and, therefore, good interviewees. But it is also important to arm yourself with background information on the topic of the interview so you can go to the interview prepared.

Pre-interview information backgrounding will help you:

- Identify key issues to raise in the interview

- Uncover conflicting opinions or perspectives for clarification by your interviewee

- Ground yourself in the basic terminology and concepts of the topic so you don't ask "teach me the topic” or uninformed (i.e. stupid) questions

- Identify the areas in which the interviewee would have substantive information to share

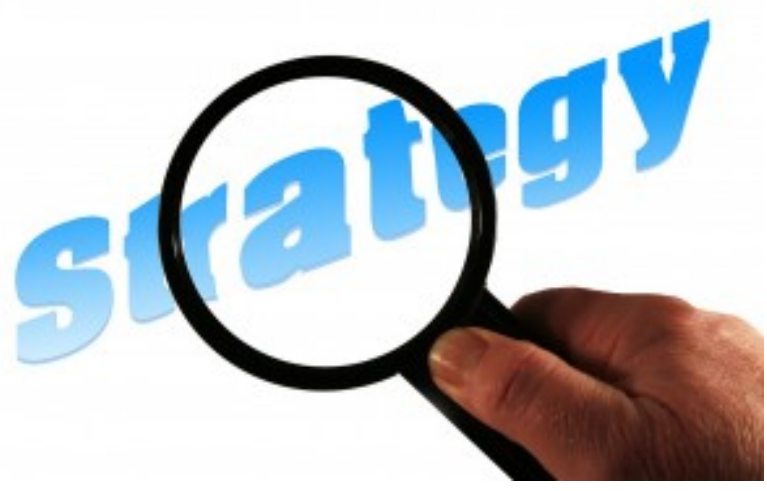

- Understand what has already happened, who the geralt - Strategy - CCO "players" are

This background check might be as basic as reviewing a Wikipedia entry about the topic of the interview. This can give you key dates, data, and terminology and provide you with an historical and / or geographical perspective about the issue. But remember that if you intend to use the information in Wikipedia in your message, you must "second source" it.

Scholarly or scientific topics require a background check in the relevant literature of that discipline. This will give you a head start on decoding the jargon that is likely to be used by interviewees, and will alert you to the current state of knowledge on that subject or where there might be controversies.

For topics currently in the news, checking news archives will give you a sense of some of the coverage of the topic and the key events or angles that you might want to address with your interviewee.

You might want to check the social networking sites to see if there is a Facebook page of supporters (or detractors) on the topic to see what the "buzz" is, check prevailing opinions or see the kinds of issues that are being raised that you might want your interviewee to address. Checking a Twitter feed on the topic (by using a "hashtag" like \#theatershooting or \#globalwarming) might lead you to resources that people recommend or provide some insights into people's views.

As a strategic communications professional, preparation before meeting with a client is essential. You'll want to be sure you understand the client's core business and the issues they are facing that your communications message 
will address. Showing that you are aware of both the information the client has prepared about itself and the comments being made about the company and its products/services in the blogosphere or on social networks will give your clients confidence they are placing their message tasks in competent hands. 


\subsection{Information Contributors as Interviewees}

The information strategy model identifies five types of information contributors: public-sector institutional sources, private-sector institutional sources, scholarly sources, journalistic sources and informal sources. You may choose your interviewees based on the type of contributors you need to tap to meet your information task. Interviewees differ based on the type of information contributor they represent. Let’s talk about each. 


\subsection{Public Sector Contributors}

Public-sector institutional sources are among the most important for some types of communicators to interview. Whether it is the investigative journalist seeking a statement from the state's Department of Natural Resources spokesperson about new limits on hunting in the state, the business reporter gathering information from the federal Commerce Department about import/export regulations, the PR professional working for the university athletic department seeking clarification about how to submit federally-mandated information about scholarships for athletes or any other myriad of purposes, public-sector institutional sources are crucial interviewees.

\section{Local government interviewees}

How do you locate the appropriate public-sector institutional source for your interview purpose? Local governments provide substantial help to communicators and community residents who search for information. Most local governments maintain websites that allow citizens to search for information; fill out applications for license and permit requests; send e-mail messages to city officials and staff; and learn of city activities, proposals, development plans and other important aspects of civic life. These websites also identify the various public officials, staff members and related individuals who keep the local government functioning smoothly.

Many local government offices and agencies now maintain a social networking presence along with more traditional sources of information. For instance, when the City of Minneapolis launched a new "311" mobile app for people to use to make service requests, they included an announcement about the app on the City's official Facebook page. In addition to seeing the City's announcement and identifying the relevant city officials to interview, a communicator could also read the reactions posted on Facebook from citizens who had downloaded the app and started using it.

\section{State government interviewees}

Like cities and counties, states have established websites where they provide access to information about the individuals working for the state. For example, the state of Minnesota's "Northstar" Web site is found at www.state.mn.us/. State and local government information on the Web is indexed at www.usa.gov/Agencies/ State_and_Territories.shtml

State government agencies also have a social networking presence with Facebook pages and Twitter feeds. Take care that you have found the government sanctioned profile when searching in social networking sites, however, as there are often pages with similar names that are not official government sites.

You will usually seek interviews with a limited number of state officials rather than from a wide range of them.

The ad agency that has the tourism account might do most of its business with the staff of the departments of tourism, economic development and natural resources.

A public relations staff member with the Association for the Blind, for instance, may have frequent contact with the state officers of the departments of health and education administration. 
Legislative reporters, obviously, will be broadly familiar with the state legislature as an institution. They frequently seek interviews with officials from both the legislative and the executive branches of the state government. You can contact the various departments and agencies directly to seek specific interviewee information.

\section{Federal government interviewees}

A comprehensive guide to federal government information is at www.usa.gov

Federal offices employ public information officers who are responsible for assisting information searchers in locating material and identifying interviewees.

In addition, each member of Congress has an office and staff that constitute a separate information factory. If you need to interview a member of Congress, there are established press offices and procedures for making those arrangements.

Sometimes it is more effective to interview a legislators' staff rather than the member of Congress his/herself. Each legislator has staffers who are responsible for the bulk of the work done by that member of Congress. Individual members' websites (as members of Congress, not their political campaign/ election sites) or the websites of the House or Senate are appropriate search resources for staffers' names and titles.

As with local and state government agencies, many federal government agencies now host a Facebook page, send information out using Twitter and engage the general public through many of the digital gathering places that are now so common. Again, be

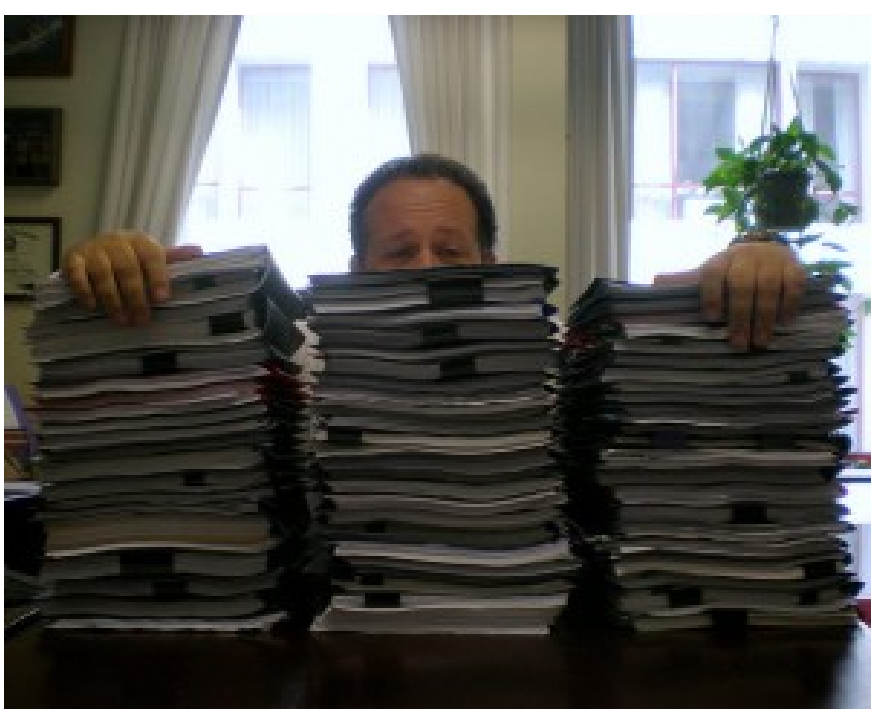

Kevin Harber - CC BY-NC-ND 2.0 certain you are looking at the official page or feed if you use social networking information from any government agency.

As with any other interview, the best strategy for public-sector institutional sources is to go into the interview extremely well prepared. Because many of them are savvy interviewees, institutional sources will try to take your measure and determine how likely they are to be able to dominate the interview. They can usually tell within the first few questions whether or not you've done your homework.

The best advice is to know your stuff and approach the interview with an attitude of professionalism seasoned with empathy and friendly openness. Assume that institutional interviewees are talking to you in good faith and with the intention of being forthcoming unless and until they prove otherwise. Public-sector institutional sources are public servants and there is a presumption that they will interact with the public, including communicators, on an open and straightforward basis.

It is possible to ask difficult questions while still remaining on friendly terms. For instance, you can ask a 
government official about a controversial decision by phrasing a question such as, "Some of your critics suggest that your tax proposal will provide large advantages to the wealthiest citizens at the expense of those in the bottom third of the earning brackets. How do you respond?” This type of question phrasing helps you retain your "neutral” stance, without putting you in the role of adversary and forcing the interviewee into seeing you as the "enemy."

A very important strategy for successful interviews with public-sector institutional sources is to gain the trust of your source. That is why it is so important for you to cultivate sources that you may need at some point in the future, even when you aren’t seeking something specific.

In other words, identify the people you are likely to need to talk to on a regular basis in your line of work (your public-sector institutional ad clients, the government officials on your beat, the PR officers in the agencies you interact with) and those people who have connections to other potential important sources.

Talk to those people on a regular basis, just to check in and touch base, and to let them get to know you as a conscientious and professional practitioner. Then, when you need to conduct a formal interview with that person or people within that person's network of acquaintances, your contact knows you and knows that you can be trusted to do a good job .

No matter how hard you try, however, there are times when you will need to talk to someone you haven't previously interviewed, someone who knows nothing about who you are, or someone who is well-trained to resist your questioning.

The most important strategy for you is to stay in control of the interview. Asking vague questions or demonstrating that you aren’t well prepared assures that your savvy interviewee will be in control. Avoid this.

Good interviewers know how to establish rapport without fawning, know how to admit when they don't understand something without sounding ill-prepared, and know how to ask sophisticated questions without sounding too clever for their own good.

Well-trained public-sector institutional sources can avoid answering questions in any number of creative and frustrating ways. Author Sally Adams lists the strategies that institutional sources (in this case, politicians) use to deflect questions:.

- ignore the question

- acknowledge the question without answering

- question the question

- attack the question

- decline to answer

- make a political point, for example attack an opponent

- give an incomplete answer 
- repeat a previous question

- claim to have answered the question already (ftnt 1)

Many sources may use some or all of these tactics. The sophisticated interviewer understands this ahead of time and knows how to counter. In almost every case, you can get the interviewee back on track by using some stock phrases or understanding responses that demonstrate that you are going to be persistent.

For instance, in response to an interviewee who gives an incomplete answer, you can use the stock phrase, "tell me more about ...” In response to an interviewee who ignores a question or acknowledges a question without answering, you can use the stock phrase, "let's return to the issue of...” And always, ask every institutional interviewee, "How do you know that? What is your evidence?" 


\subsection{Private Sector Contributors}

Maybe you are working as the corporate communicators specialist for a major business in your community and you need to determine how the CEO wants to position the decision to open a new factory overseas. Maybe you are producing advertising for your computer manufacturer client and you need to understand what types of ads have worked in the past. Maybe you are writing about a possible financial scandal at the non-profit foundation in your state that is supposed to help low-income residents gain employment skills. In each case, you want to interview the key people who work at those institutions to get the benefit of their expertise. For these examples, you know the name of the specific person or people you need

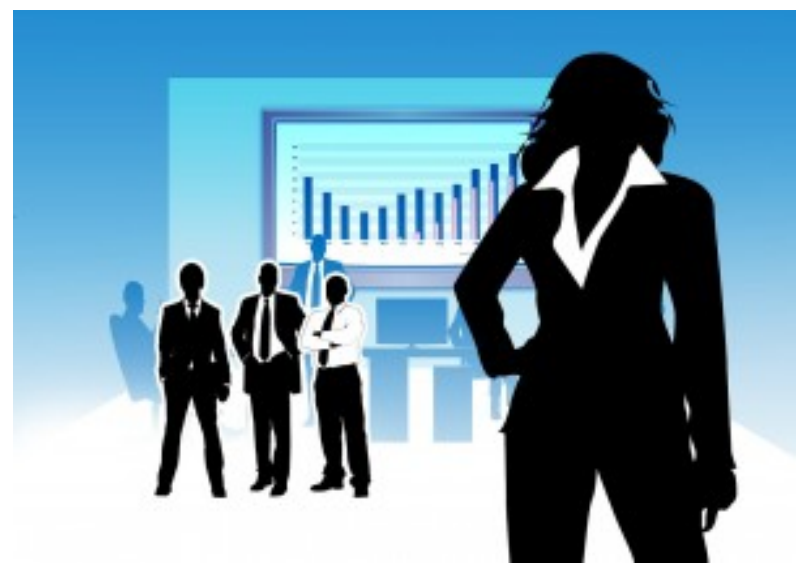

geralt - Executive businesswoman - CCO to interview.

Other times, you may need to identify an appropriate private-sector institutional source who can speak knowledgeably about your topic or issue. Using some of the search tools mentioned here can help you identify the right person and prepare for the interview.

The Who's Who volumes (Who's Who in America, Who's Who in the Midwest, Who's Who in the Press, etc.) are sources of biographical information about an entrant. These are good resources only if you have a specific name you are looking for.

"Biography master indexes" can help you locate biographical information published in various books, magazines, and newspapers. These are valuable resources for communicators because they provide supplemental or supporting information about individuals beyond what you can get during an interview. If some facts have to be verified, if the person in question will not agree to an interview or is unavailable, these biographical references are often the only method for gathering the required biographical information. A resource guide to biographical sources in the UMN library can be found here.

Hundreds of online news sites and news indexes can help you locate background information about possible interviewees. The powerhouses of news searching have been the large commercial database services such as Newsbank, Proquest Dialog, LexisNexis or Factiva. These provide cross-title searching of multiple news organizations' materials - for a fee. These large subscription database services are best accessed through a public or university library, or through the media organization library that may have subscriptions to one or more vendors for all staff to use.

The growth of news websites has been a boon to the researcher. Even publications too small to have been attractive to the major news database vendors in the past now have their articles available in electronic backfiles. So if you want to be sure you've done a thorough job of identifying background information about a private- 
sector interviewee as part of your preparation for an interview, you would want to identify the news organization websites on which you want to search.

NewsLink - Find newspapers, magazines and radio / TV websites by region and by category.

Radio Locator — Links to more than 10,000 radio station websites and more than 2,500 audio streams from radio stations in the U.S. and around the world.

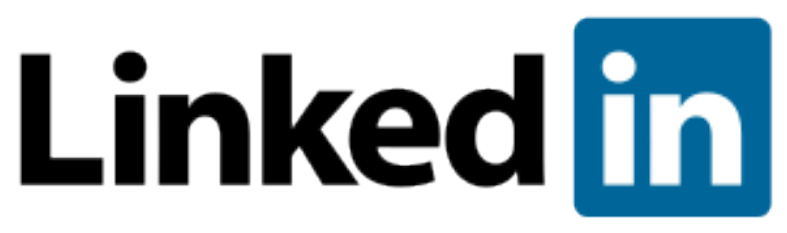

Public domain
LinkedIn is the social networking site used by individuals and organizations to advance their professional careers and institutional goals. Once you create a LinkedIn profile, you have access to thousands of individuals and organizations. The more contacts and connections you have through your profile, the more contacts you will see when you conduct searches. You can follow a company LinkedIn page if you are doing advertising or PR work for that organization. You can locate specific individuals by name or conduct searches for types of people (business managers using Six Sigma management techniques; CIO’s at consumer electronics companies, etc.)

Private-sector institutional interviewees pose special challenges for communicators. Many are well-trained to talk to communication professionals, wary of saying too much and sophisticated in their ability to take control of an interview. Particularly for private sector institutional sources such as business executives or advocacy group spokesperson, you have to be diligent in your preparation and persistent in your questioning to generate anything new or useful from an interview and to counter-act the spin they might put on the information.

Sources such as senior business executives are likely to be surrounded in their day-to-day activities by people who defer to them. They are not used to being asked rude or challenging questions, or to being subjected to criticism about their actions. Therefore, you need to phrase your interview questions in a way that demonstrates respect.

Just as with public-sector institutional sources, it is possible to ask difficult questions while still remaining on friendly terms. For instance, you can ask an executive about a controversial decision by phrasing a question such as, "Some of your critics suggest that discontinuing that product line will allow your competitors to enter the vacuum created. How do you respond?” Maintaining your neutral stance during the interview is crucial to a successful interaction.

Business executives are especially well trained not to reveal too much information. They are concerned about sharing something that might affect a company's stock price, about inadvertently providing information that might advantage competitors, or about somehow putting their company in a bad light.

Assume that a business interviewee has been briefed about you and your media outlet before the interview. Before you can even schedule an interview, you may be asked to provide information about the topic of the interview and some of the questions that might be asked. This forces you to think carefully about your interview purpose and to structure questions that optimize your efficiency for generating the information you need. You will rarely have the chance to go past the allotted amount of time with a business interviewee, so you need to get into the substance of your interview quickly. 


\subsection{Scholarly Contributors}

While it is easy to understand why it is important for scholars to share their work among themselves, why would scholars want to share their information with you as a communications professional? For one thing, scholars are as eager as anyone else to have their work recognized and appreciated. Taking a call from a reporter or public relations specialist seeking the most reliable "expert" on a particular subject is an ego-boost for the scholar who is used to toiling in relative anonymity in the quiet of the academic or research center environment.

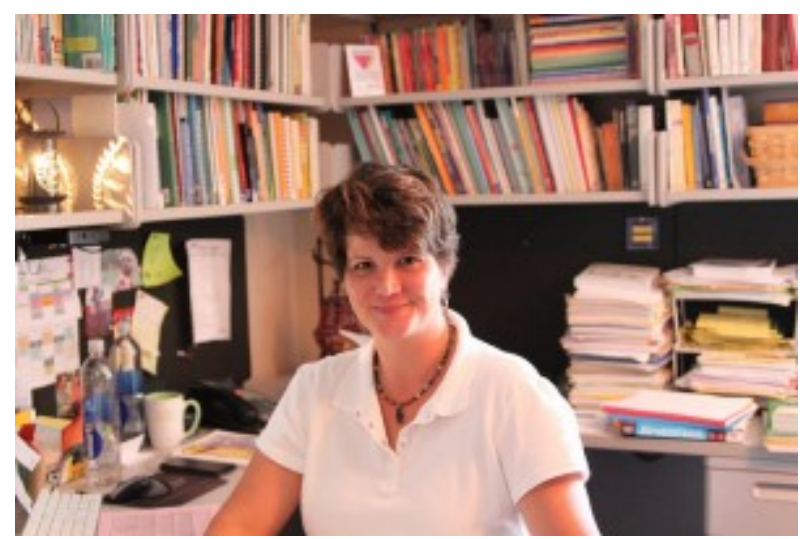

dr. coop - Professor Gray in her office - CC BY-NC 2.0

Another motivation for scholars to talk to you is that they might be conducting their work with the help of a grant or financial backing from a foundation or research organization that would appreciate wider distribution of the findings and a larger public audience for the organization's work.

In fact, it is your job as a communications professional to ask scholars who is supporting their work financially. It is not unusual for scholars to have grants from large companies (pharmaceutical companies, for instance) or government agencies (the U.S. Defense Department, for instance), and the work they do may reflect the interests or

priorities of the funding source.

As they have done with many other information niches, Google has created a resource for drilling down into information generated by scholars. Google Scholar describes itself in the following way:

"Google Scholar provides a simple way to broadly search for scholarly literature. From one place, you can search across many disciplines and sources: articles, theses, books, abstracts and court opinions, from academic publishers, professional societies, online repositories, universities and other web sites. Google Scholar helps you find relevant work across the world of scholarly research.”

One of the most helpful parts of Google Scholar is the "cited by" feature. If you locate an article of interest you can click on the "cited by" link. This pulls up a list of other articles that referred to the article you are looking at. This can help determine the influence this particular scholar and his/her ideas have had on other scholars and their work. In addition, it can help you locate other scholars you might want to interview.

Any group with a fairly sizable membership usually publishes a directory. The Encyclopedia of Associations is perhaps the best place to begin a search for any type of organization or association. By searching in this directory, you will find the names of the officers and key staff of professional associations. In the past, directories of scholars published by different associations or scholarly societies would have been one of the only resources for locating people who are studying certain topics. 
Now, there are a variety of resources that let you tap into networks of scholars and find people with specific academic interests and expertise. Here are two rich resources for finding scholars.

ProfNet.com: This resource for experts and journalists was created by PR Newswire, a public relations dissemination service. Communicators can send out a request for experts, detailing the story they are working on, their deadline, and other aspects of the message they are working on and experts will contact them to be interviewed. This is a way that both are served; the experts have the potential for their names to appear in the news as people with valuable things to say, and the journalists are able to connect with relevant sources.

Academia.edu: Taking a page from other social networking sites, Academia.edu seeks to link the worldwide community of researchers and scholars (1.6 million are in the network currently.) Searching for a topic in Academia.edu will bring up profiles of people who have joined the network. In addition to people, a search in Academia.edu will find research papers, special research interest groups, journals and research centers.

In addition to these services an excellent technique for locating scholarly sources is to contact the public information office of your local university or community college campus to ask for a referral to a local expert in your subject area. Many times the public information office maintains an internally-generated database of scholars at that institution who have agreed to speak with communicators on a variety of topics. Some universities now post a list of subject experts publicly on their Web sites.

Some examples of these university generated lists of subject experts include these at the University of Southern California or at Washington State University,

LinkedIn is also used by scholars. You can locate specific scholars by name or conduct searches for types of people (scholars studying HIV transmission, scholars who claim expertise in nuclear engineering, etc.)

Conducting an efficient and focused interview requires considerable preparation. This is especially true for the interviews you do with scholars. The worst thing you can do in an interview with scholarly sources is ask the interviewee to "teach me the topic." Someone who has spent a career studying a specialized and focused sliver of a complicated discipline will not appreciate being asked to summarize his or her entire field in a few convenient sound bites.

Further, it should be unnecessary for you to ask the academic expert for basic information about the field that you could easily find in books and in other publications. If anything, it will be to your great advantage as an interviewer to enter the interview prepared with some background knowledge about the subject.

In fact, scholars usually delight in being recognized for their expertise and sharing their knowledge in a discussion with a communicator who demonstrates some familiarity with the field. Many of the topic backgrounding strategies we've already discussed help you prepare for your interviews with scholarly sources. You will also be able to speak intelligently about the field, using the appropriate terminology and buzzwords that are important to the knowledge-creators in that area.

There are a variety of methods you can deploy to get appropriate biographical and background information about your interviewee before you show up in her office or call him on the phone. These include the routine to:

1) Contact the public information office of the scholar's institution and ask for that person's resume, or, 
as they call in the academic world, his or her curriculum vita (CV). This summary of a scholar's career is usually a public document and you may even be able to find it online by searching the Web site for that institution or that scholar's specific academic department. A curriculum vita typically lists scholars' degrees, their publications, the courses they teach, the research grants they’ve received, the conference papers they’ve delivered, etc.

2) Check to see if the scholar you will be interviewing has a profile on a social networking site such as LinkedIn or Academic.edu. They may link from their profile to a personal webpage containing their CV.

3) Check to see if the scholar has a Twitter feed or participates in the "public arena" in other ways through mass media. Perhaps the person has published opinion pieces in his or her local newspaper, or has a blog where more informal types of information are shared.

Researching someone's background helps you decide whether the potential source has the needed knowledge, expertise, reputation, background and characteristics to warrant an interview. These biographical information searches also help you develop an agenda of questions. If conflicting information turns up in the preliminary information search about the person's background, you can use the interview to clarify and correct those problem areas.

\section{Tips for Interviewing Scholars}

- Schedule the interview as far in advance as possible

- Explain the topic, the context, and the probable use of the information to give the interviewee time to prepare

- Ask permission to record the interview on audio or video

- Use the principles of interpersonal communication

- Be cordial, smile, make eye-contact right away

- Start with some small-talk or make a personal observation to get interviewee at ease

- Appear curious but not pushy or cynical

- Use your biographical backgrounding of the interviewee to ask about something you know interests your source

- Don’t talk too much

- Remember, you are there to get the source to talk, not to show off your scintillating personality

- Get comfortable with silence - resist the inclination to jump in and ask the next question as soon as your source is finished speaking

- Ask questions that will generate the most information and keep the interviewee talking 
- Don’t ask yes/no questions

- Don't ask about things you should already know from your background information unless there is some discrepancy you need to clarify

- Ask lots of "how?” and "why?” questions

- Use summary questions throughout the interview. ("Let’s review what we’ve covered...," "I want to be sure my notes are accurate. First,...," or "Let me check to make sure I understand your points....”)

- Don't let pride get in the way of a good interview

- Don’t be afraid to ask if you don’t understand something

- Remember, there are no dumb questions when it is in the context of avoiding a misinterpretation or a mistake

- Keep asking until the material is clear so you'll be able to make it clear to your audience

- Clarify jargon or specialized terminology. (A good question to ask in that situation may be, “How would you explain that to a layman?”)

Scholarly sources typically are not experienced interviewees. You may be the first person who has ever called or e-mailed to ask for an interview, which puts you at an advantage in one sense, but poses some special problems in another. The advantage for you is that, unlike highly "coached” institutional sources from business or politics, your scholarly source is usually not polished in evading or skirting difficult or provocative questions, meaning that you are going to get an "honest" view of their expertise and opinions.

The disadvantage is that the person may be nervous, apprehensive about how you are going to conduct the interview and use the information, and fearful of saying or doing something that will hurt his or her reputation or standing in their academic community. There are several ways to deal with this particular problem. The most effective, as we've already stated, is to be totally prepared for the interview by knowing as much as possible about your source and the topic before you ever make the call. A nervous interviewee will be put very much at ease when he or she realizes that you've done your homework in advance.

Another strategy is to use an interview technique in which you demonstrate that you understand the interviewee's agenda. The source has probably been thinking about the interview, rehearsing what to say, feeling nervous about making the right points and being clear. How do you let your source know you understand his or her agenda? You might start this way: "I have six questions I think are important for you to answer. After we finish with those, I will ask you whether we've left out any important information. And I will make sure you have my phone number and e-mail address so that if something occurs to you after I leave, you can contact me.”

This saves time and prevents a "filibustering" interview, which happens when your sources become concerned after your first question that they will never be allowed to say what they think is really important. They may then react by immediately going off on a tangent from which it is nearly impossible to recover and bring them back 
to your point. By setting up your questions to recognize the interviewee's perspective, the source knows that he or she will get a chance to identify important information even if you miss it in the first pass. Again, this points to how important it is for you to become knowledgeable in advance of the interview about some aspects of the source's particular work and expertise.

\section{Avoid the "Expert on Everything" Syndrome}

A particularly vexing problem for media professionals who are searching for appropriate scholars to help with their messages these days is overuse of a small subset of possible interviewees. An enterprising journalist discovers a good scholarly source who returns phone calls on time, who speaks in clear language rather than obscure jargon, who has impeccable credentials in their subject specialization, and who knows how to provide provocative quotes and sound bites. That source gets interviewed and quoted in the journalist's work.

Soon 10 or 20 more journalists will find that interview archived in a database or on a website and call the same person. Pretty soon, that scholar is a recognized "pundit" in his or her area, and gets more opportunities to interact with media professionals than his or her expertise or credentials may warrant. Or, regardless of how outstanding his or her credentials, some scholars are simply used so much by popular sources as to obscure audiences from the complexity and differing perspectives in the field that may emerge if media professionals were to sample from a greater variety of expert sources.

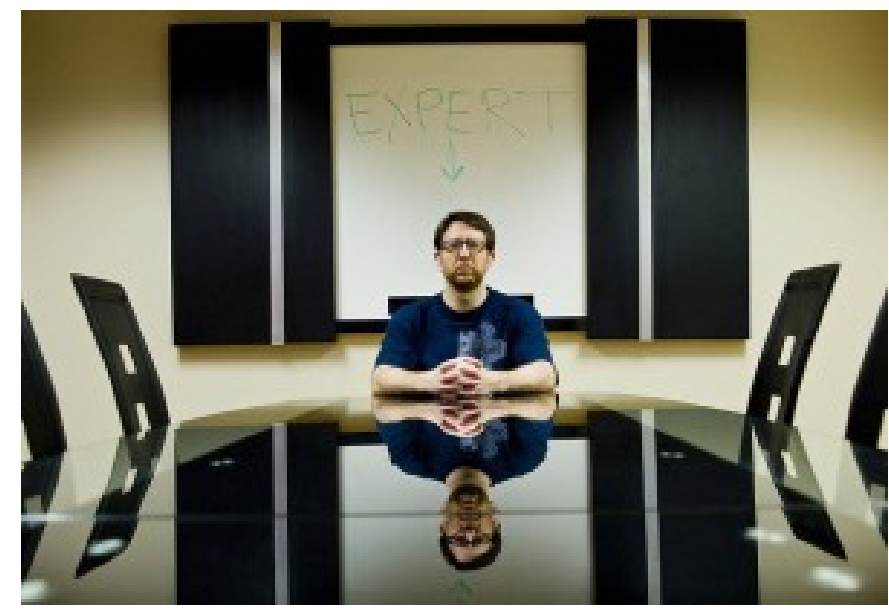

Remember, it is hard for any human being to resist the urge to respond to the promise of flattery, attention and wide recognition. Especially with scholarly sources, who are usually not celebrities and who are sometimes diffident and hard to interview, it is tempting to use the same people over and over because they make the journalist's job easier.

This is a serious error. Most scholars work in highly specialized sub-fields of widely disparate disciplines of knowledge and expertise. An expert on the political situation in Kenya is usually not qualified to speak equally authoritatively on the political situation in Egypt just because both countries are in Africa. Do not fall for the easy, lazy way out. You need to use the techniques we've mentioned throughout this lesson to identify the scholars who are truly appropriate for your message, not those that have become "pundits" for one reason or another.

\section{Beware of the "Research Center"}

Another serious error is to assume that anything or anyone associated with a "research center" is producing independent scholarship. Quite the opposite. There are myriad numbers of think tanks, research centers, institutes and foundations that publish journals that appear scholarly, provide "fellows" for interviews with communicators who ask, write "briefing papers" and call news conferences to announce their "findings", and otherwise mimic scholarly endeavors.

But their purpose is to advance a particular point of view, usually politically or socially aligned with one side of 
the opinion spectrum or the other, and they are perfectly willing to let you believe their work, publications and "fellows" are independently scholarly.

Don't be fooled. These institutions have an agenda and are operating with a different set of standards and procedures than are legitimate scholarly institutions or scholars. Remember that true scholarly work is characterized by peer review of findings, independent authority to conclude what the findings and evidence support regardless of sponsorship or ideological concerns, and something called “academic freedom.”

Once again, asking how a particular research center or individual scholar's work is funded and how their work is reviewed before publication is the best method for ferreting out these differences and nuances. If you want help determining whether a publication or journal is peer reviewed, you can also turn to an independent reviewing source such as Ulrich's Periodical Directory, to help you determine whether a particular title is a popular, scholarly or trade publication. 


\subsection{Journalist Contributors}

Public relations professionals interview journalists on a regular basis, but not usually as sources to be quoted in messages. Rather, the PR professional interviews the journalist about the types of stories the PR specialist might successfully "pitch" to the publication for which the journalist writes. Journalists and PR professionals can help each other as long as each recognizes that the other has a legitimate, but decidedly different, role to play in generating information for an audience.

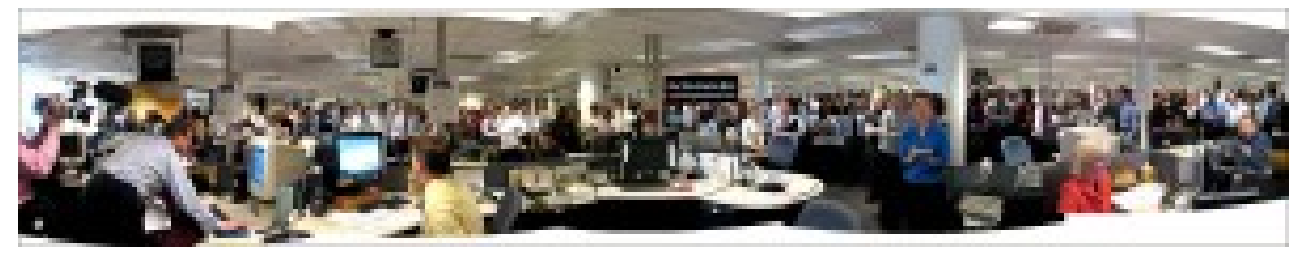

Keith Jenkins - Washington Post Newsroom - CC BY-NC-ND 2.0

Journalists, for whom interviews are the mainstay of their work, are notoriously reluctant interviewees themselves. Unless they are promoting themselves for a book, have just won an award, or are one of the pundits found on television "talking heads" news programs, journalists would much rather be the interviewer rather than the interviewee.

If you are looking for personal commentary, insight, or advice from individual journalists, first you have to find them. You might locate the name of a reporter you'd like to talk with from a byline on a story. Some news organizations include email addresses on their reporters' bylines. Most news organizations have on their Web sites a listing of names and contact information for people in their newsroom.

If you don't have a specific name of someone and are just looking for a journalist who has experience or knowledge about a particular story, posting a question to a listserv or social networking site where journalists correspond might be a useful tactic. Tell them you are interested in someone who has covered, say, the rising cost of prescription drugs and ask them to email you offline. You might also try searching the Resource Center maintained by the Investigative Reporters and Editors organization to find specific types of stories. If you find a story similar to the one you are working on, you can then contact the journalist who worked on that piece. 


\subsection{Informal Contributors}

What motivates an informal source to talk with you?

- Are they outraged at something and want to get their viewpoint heard?

- Are they concerned and want to help tell the story?

- Have they been paid a stipend to participate in your focus group?

Consider, too, why you want to talk with them:

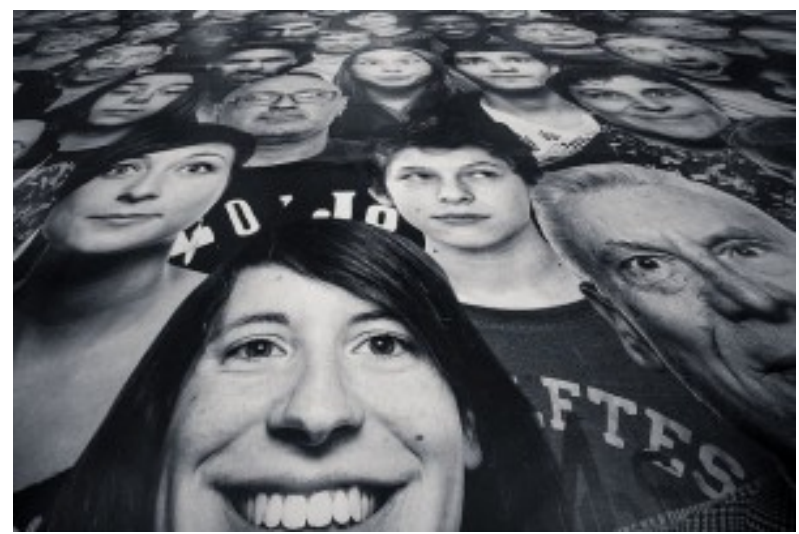

- Are you trying to fill in the details about an event from eyewitnesses, in which case you need to

Stefano Montagner - People - CC BY 2.0 talk with several sources?

- Are you interested in opinions to give a broader perspective to the topic you are covering?

- Are you looking for a better way to reach your audience for an ad campaign?

The art of interviewing is complex and your approach to different kinds of sources will be different. With informal sources, the better you can determine motivation and mood, the better you'll be able to figure out what to do with the information and reactions you get.

Among the most valuable people-finder resources on the Internet are the telephone directory services. A service such as AnyWho allows you to look up by name, by phone number, or by address. For example, if an accident happens around a particular address, you could use this reverse look up by address to find the names and phone numbers of the people who live there who might serve as eye-witnesses.

Pipl searches the "deep web" for information on specific people. The Pipl search engine locates information that cannot be be found using regular search engines. You can search by name, email, username or phone number and the Pipl search engine will generate results from public records, social media posts, online shopping sites where someone posts reviews, and more.

Spokeo is another search engine that scours the digital world for information about individuals. It can be searched by name, email, phone, username or address. Journalists can use it to locate public records and social networking information about individuals. Strategic communicators can use it to find background information about clients or donors.

Facebook is the familiar social networking site with now more than 1 billion users across the globe. Depending 
on the privacy setting an individual has chosen to apply, you may be able to locate the person you want to find via Facebook. Media organizations can also create Facebook sites to solicit comments, feedback and information from customers or audience members. Using Graph Search on Facebook, you can combine more than 100+ personal details to conduct a search. For instance, you can search for "people who work at ABC company in New York," or "photos taken at the World Cup by people from the United States," or "sports teams liked by CEO's," or "Democrat women who like guns," or any other myriad of combinations. The possibilities are endless, as are the pitfalls for unethical or unscrupulous use.

Twitter is the micro-blogging site that has been described as the SMS of the internet. Individuals and organizations have established Twitter accounts and their Tweets can be searched in a number of ways. One of the most useful search tools for Twitter is Keyhole, which allows you to search in real time by hashtag, @ sign, keyword, mention or URL. Strategic communicators routinely monitor the Twitter-verse to detect audience chatter about clients, journalists use Twitter to locate individuals on the scene of breaking news who are Tweeting, or to find mentions of individuals in other people’s Tweets. Again, the possibilities are immense.

In a recent incident where a planeload of passengers was required to sit on the tarmac for six hours, a reporter found someone who had been through the experience from a posting on a Twitter feed. The reporter then contacted that Tweet source directly to conduct an interview using that person as an eyewitness to the airline's and the airport's handling of the problem.

Digitally-based “review” sites such as Epinions (products and services), Yelp (restaurants) or TripAdvisor (travel destinations, hotels and amenities) provide access to individuals who have personal opinions they share concerning their experiences. Of course, you must verify any information you find using these sites, contact the individuals who posted the information to get permission to use that information, and recognize that many of these sites include positive reviews posted by employees of the company who want to help make a good impression.

If you were preparing a "pitch" for a new advertising account for a hotel chain, you would certainly want to search reviews sites such as TripAdvisor to see how travelers have been rating the hotels before deciding you wanted the business. If you were doing PR for a company whose product has been recalled, you would want to search Epinions for information from people who purchased the product and are now discussing the recall.

Scanning social networking groups for relevant types of people is a good technique for finding useful contacts who may be otherwise difficult to identify. If you are covering a story about a disease, you might contact an association that has expertise about that disease to see if they will put you in touch with some people who are living with the disease. But it is likely that the people suggested by the association have been pre-screened and coached on how to talk to the media. If you want truly "person on the street"-type sources to talk about their experience with a disease, you're better off going to a social networking group on that topic and either identifying some people through their posted messages or by sending a "I'm interested in talking with..." type of message to the group.

Many of the informal sources you interview will be inexperienced. When interviewing these sources, understand that they may not appreciate the implications of talking with you. It is even more important to disclose to the inexperienced source exactly how you will use the information revealed during the interview with him or her. In the news setting, interviewees must understand that what they say can be used in the news report with their 
name attached. In the case of a focus group, the moderators ask participants to sign a release stipulating that they understand how the information is going to be used. 


\subsection{Evaluating Interviewees}

Evaluating the credentials of those who might be interviewed is a small research task in itself. A sensible first step is to review all of the background material you have already collected about your information tasks and to make a list of those who have written or spoken on the subject.

For example, consider the background research for an advertising campaign on behalf of the Coalition for Literacy. The coalition seeks volunteers to work with functionally illiterate adults. Potential interviewees include officials of the coalition and of other groups concerned with adult illiteracy. Annual reports,

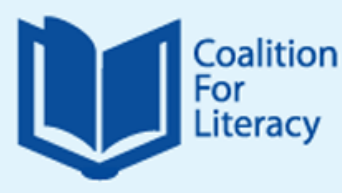

http://www.coalitionforliteracy.org/

newsletters, and boards of directors' minutes of meetings also reveal names of important individuals in this field. Government documents display the names of members of Congress who have shown concern about the problem and the identities of specialists who have testified before congressional committees. Some of these specialists have published articles on the subject in scholarly journals and have been quoted in news magazines.

Another type of expertise you might seek is that of people who have themselves experienced the disability of illiteracy. Their expertise may not be evident in the indexes and journals, but members of the literacy organizations probably can help you to locate them. Perhaps some of the formerly illiterate adults have gone on to become volunteer teachers or members of the groups combating illiteracy. You can search a "create-one-yourself” social network site such as Ning.com to find people who have created an online community for those dealing with the issue.

After drawing up a roster of promising interviewees, you need to check the reputation of those on the list. You can do this by checking such standard reference sources as Who's Who. In this case, Who's Who in Education may include biographical information on some of those who have written on the subject or spoken before congressional committees. In addition, clicking on the author's name on Amazon.com may reveal titles of relevant books written by these people.

Credentialing potential interviewees by their digital profile is now an important step for communicators to take. Checking social networking sites to see what people say about themselves, what interests they have, the people they know and connect with can give you important information about a potential interviewee's likely contribution to your message. Professionals are likely to have a LinkedIn page; "informal" sources are likely to have a Facebook page, and many individuals "live" in more than one digital community that represents various aspects of their interests and connections. 


\subsection{Planning Interviews}

Once the interview roster is ready, you can determine the willingness and availability of the sources. Some potential interviewees may be unavailable - out of town or tied up with other responsibilities. Others may be unwilling to be interviewed. Some may have research results that they do not wish to make public yet. Others may prefer to send you a copy of their testimony before Congress and save the time an interview would take. Some specialists who are unavailable will suggest others as substitutes. However, a good percentage of people on a well-constructed source list should be available.

Careful planning of interviews involves a number of steps and almost innumerable considerations.

Interviewee's conditions: In some cases, the interviewee stipulates some conditions for the interview which can include:

- Amount of time they will talk with you

- Interview method (face-to-face, telephone conversation or online)

- Permission (or not) to record the conversation

- Request that another person be present (their lawyer or agent).

- Request that they review the material before you may publish or use it

- The "contract" for the way the information will be used in the message (see more about this below)

Review your own material: Looking over material gathered earlier in the information process will help you devise a strategy for using the interview to fill in questions, corroborate information, or to discover new angles to take.

- What is disputed? Can inconsistencies be explained or resolved? What is the significance of the disputed facts?

- What unexplored aspects of the subject should be developed? What is "new" that should be reflected in my questions?

- What questions are appropriate to each interviewee?

- What sensitivities and special perspectives should I be aware of in asking questions of each interviewee?

- What information in my files may need updating or confirming?

- What human-interest information can be elicited from the interviewee? 
Consider interviewee “inhibitors:” Interview preparation also involves getting ready for the social and psychological aspects of the interview. Before you draft your questions, consider the situation of the interviewee. People may have competing demands for their time. They may have painful memories of the topic you want to explore with them. They may not trust your motives in seeking the interview. This might make some interviewees unwilling to share information.

Other factors may affect the interviewee's ability to share accurate information (as opposed to their willingness to do so). The person's memory may have faded, they may not accurately recall the sequence of events, they may be confused by your questions. All of these inhibitors affect the way you approach your subject and the types of questions you ask. 


\subsection{Interview Questions}

Having assessed both the information needs and the interviewee's potential to respond, you are ready to develop an agenda of questions. These should be a comprehensive list of questions, setting forth everything you would like to know. The interviewer might ask some of these questions of a number of respondents while other questions might be designed only for a particular interviewee.

\section{Types of questions}

Except in survey research interviews, openendedquestions are most effective. An example of an open-ended question is when the focus group interviewer asks, "Now that you've tried our new product, tell me what you think about it.” Open-ended questions have the advantages of inviting interviewees to provide more specificity and depth in their response. In journalistic interviews, open-endedness is stressed, for it leads to spontaneity, interpretation by sources, cues for additional questions, and quotable phrases. An open-ended question in a journalistic setting might be, "What do you think about the new tax proposal?”

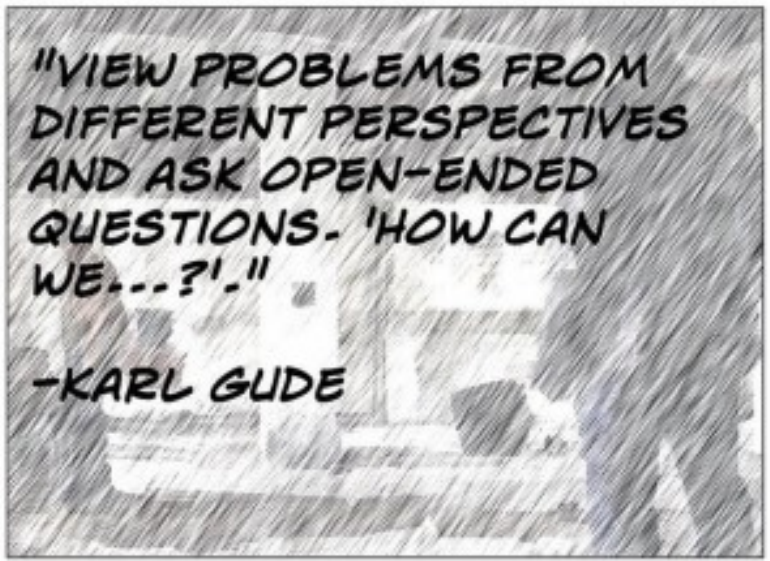

Ken Whytock - Invite open ended questions - CC BY-NC 2.0

In the closed-endedquestion, the respondent must select

one of a set responses provided by the interviewer. For example, most questions asked in Gallup and other polls are closed-ended: "How do you feel about the economy of the United States at this time?" "Very optimistic," "somewhat optimistic," "neutral," "somewhat pessimistic," or "very pessimistic.” One advantage of closed-ended questions is that a large number of interview responses can be analyzed relatively quickly and inexpensively.

Closed-ended questioning in the journalistic context is usually problematic. Compare the closed-ended question, "Do you think the new tax proposal is good?" with the open-ended, "What do you think about the new tax proposal?” Which will elicit more information and opinion from the interviewee?

\section{Question Order}

Arranging the questions into an effective agenda is the next step. Many interviewers use a strategy of beginning with reassuringly easy questions. Some may be questions verifying that what has been learned through earlier parts of the strategy is, indeed, still accurate and up-to-date. While the opening questions may be simple, experienced interviewers avoid overly broad questions that send the interviewee off the topic or set off an avalanche of irrelevances.

Generally, experience suggests that embarrassing, touchy, or ego-threatening questions best be kept until late in the interview. By then, the context is well established and you have had a chance to develop a persona as a fair, accurate, and sensitive individual. Touchy questions always bring about the possibility that the subject will declare the interview to be at an end. In that event, at least you have the earlier portions of the conversation for 
the record.

Each question in the interview agenda can give rise to additional questions. Some of these are follow-ups, such as requests for more information based on the idea just stated by the source. If you are too tightly tied to your own interview agenda, you may neglect to use appropriate follow-ups.

But don't forget your original question agenda once the follow-ups begin. Rigidly adhering to the question agenda promotes one kind of completeness at the expense of expanding the topic and developing its new dimensions. Experienced interviewers learn, in time, to walk the line between the two hazards. 


\subsection{Contract with the Interviewee}

Perhaps the most crucial step in planning and conducting interviews is establishing the contract with the interviewee. The contract with an interview source is a legal contract that must be upheld once it is agreed upon. This was established in a U.S. Supreme Court decision in the Cohen v. Cowles Media Co. case.

You must be aware that there are different kinds of source attribution that you can use. You should be certain that your interviewee understands these options and what they imply about the information, and you both need to agree upon how the information will be attributed in any message you produce. The types of attribution in news stories can be:

- For attribution: everything the interviewees say will have their name attached and you can use the information in any message you produce

- Attribution by title only: the interviewee's identity is protected in the message, identified only with something like "a highly placed official” or "sources close to the president"

- No attribution: the interviewee agrees to talk but the information will not be attributed in any way in the message - "CBS News has learned..."

- No publication, or deep background: the information can't be used in any way except to inform the communicator, sometimes referred to as "off the record."

Your goal is to be sure your source understands how the information from the interview is going to be used before you ask any questions or start to gather any information. For most types of interviews, a "for attribution" agreement is the appropriate arrangement. Most news interviewees want to be recognized for their expertise or input into a story.

Participants in a strategic communications focus group sign releases indicating that they understand the terms of the interview and how the information will be used. It is not unusual for the focus group to be recorded while clients and researchers watch and listen to the focus group participants from behind a two-way mirror so participants must be told that they are being observed.

Respondents to a survey interview are generally assured that their responses will remain anonymous. The survey interviewer will typically ask whether the respondent would agree to provide a name and contact information for a follow-up individual interview after the survey results are analyzed. But it is always within the survey respondent's right to say no and withhold their individual identifying information.

Interviewees who seek to avoid a "for attribution" agreement may be doing so because they want to protect themselves from the consequences of their words. Or they may be floating a trial balloon to gauge public opinion in advance of an official announcement. Or they may be leaking damaging information about a competitor. Any agreement other than a "for attribution" interview should put you on alert to be especially vigilant about checking the interviewee's information against independent second and third sources of information. 
Interviewees, particularly ones with controversial or damaging information about an organization with which they are affiliated, might seek an "off the record" status for their interview with you. Journalists normally attribute all information in a story because without attribution the reader or viewer cannot really judge the validity of the information presented. So before you agree to this condition in an interview ask yourself these questions:

- Do I have enough information to make this decision?

- Is this story important enough to justify using an anonymous source?

- Is this anonymous material confirmed by a reliable second and third source?

- Can I explain in the story the reason for the anonymity?

- What is the journalistic purpose of reporting this information without attribution? Is this a story that simply cannot be gotten or told without use of anonymous sources?

- Would more reporting get this material on the record?

- Does my editor or producer know enough about this source to justify my offering a verbal contract?

- If the story quotes an anonymous source, will it still be accurate, complete, fair and balanced? (Some reporters have a rule that they will not use comments or personal attacks about another person from an anonymous source.)

- Does the source understand the meaning of anonymity? Does the source know that at least the editor or producer will need to know his/her identity?

- How far will I and my organization go to protect this person's identity? Will my organization back me up if I am sent to jail to protect my source?

- Can I tell the reader enough about the anonymous source so he/she can judge the validity of the comment?

- Would this story be improved if I cut the anonymous material

Be sure you understand the policies of your media organization before you give ANY promise to a source.

Sometimes you can persuade a source who is reluctant to speak on the record to agree to attribution of a quote-you might explain certain benefits to the source for being identified that they don't realize. Try to read back individual quotes and point out that each one is not so damaging or problematic. A good reporter can sometimes get an entire interview back on the record.

This is not a generally-recommended practice, however. Anything that confuses the clarity of the contract you made with the source at the start of the interview should be avoided. That way, there can be no disputes with sources or supervisors about the terms under which the interview was conducted or the agreements that were made about the use of the interview information. 


\section{What kind of contract?}

Compare these two sources in a recent news story. What kind of "contract” was established for each?

1. Meanwhile, a federal source law enforcement official told The Associated Press late Saturday that a semi-automatic assault rifle used by the shooter jammed during the attack, forcing him to switch to another weapon. The official, who spoke on condition of anonymity to in order to discuss the investigation, said that the jammed weapon had a high-capacity ammunition magazine.

2. The Aurora police chief says the trap was meant specifically to kill a police officer who might have opened the door. "We sure as hell are angry," Chief Dan Oates said about the trap being aimed at officers. 


\subsection{Recording the Interview}

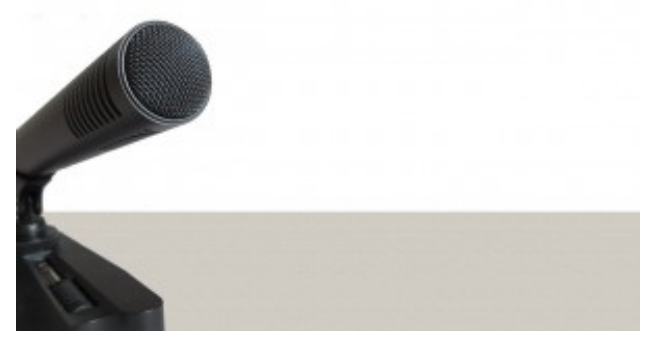

Think about how you will record the interview. Will written notes, a digital audio or video recording, or an e-mail transcript of questions and responses be the best way to keep track of what goes on during the interview? You have to let your interviewee know how you will record the interview. It is a breach of ethics, and in some states illegal, to record someone without their knowledge. If you use a digital recorder, always use it in conjunction with a notebook.

Focus group sessions are almost always recorded for later review by the ad and marketing researchers. Participants must sign a release Sophieja23 - microphone - CCO indicating they understand the session is being recorded and how the information will be used. 


\subsection{Some Interviewing Cautions}

No matter how careful you are in selecting your interviewees, planning your questions and actually conducting the interview, there are many ways for things to go wrong. Here is a cautionary tale that illustrates some of the problems that might arise.

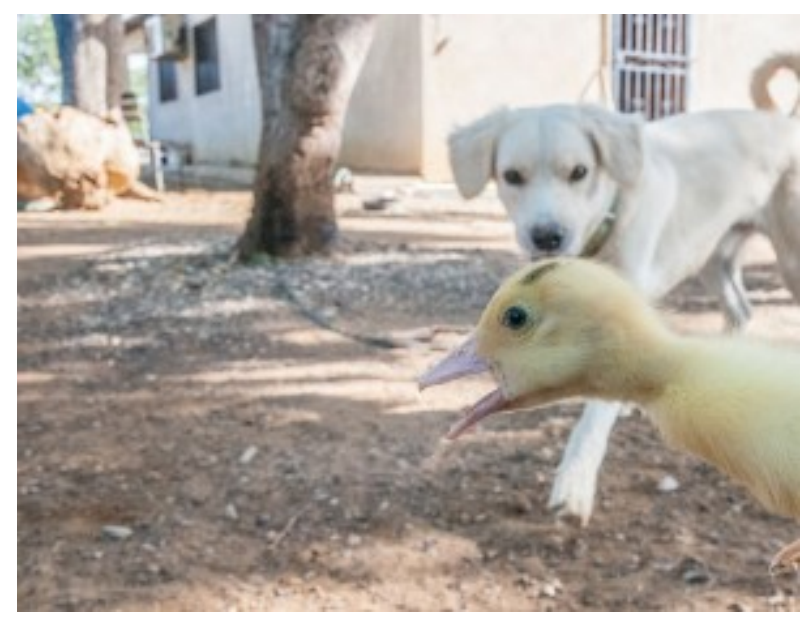

Dog and duck - CCO
An investigative reporter for a local TV news station in Minneapolis, MN had what sounded like a hot tip. It appeared that a Minnesota puppy mill might be sending dogs to a meat market in New York City’s Chinatown.

The reporter called the shop in New York and asked "Do you sell dogs?" The man who answered the phone said, "Yea. We sell dogs.” Reporter: "Dogs for people to eat?” The man: "Uh, yea. We sell many kinds of meat." The reporter asked again, "Dogs for people to eat?” The man: "Yes." The reporter subsequently went on the air with a sensational story that alleged that the puppy mill owner in Minnesota was selling puppies for food. The story and video was also posted on the station's web site.

Now, substitute the word "ducks" for "dogs." Those two words might sound the same over the phone, and in fact, the New York shop sells ducks for food, not dogs. The man who answered the phone misunderstood the reporter's question, and the reporter misunderstood the man's answer in a cascading comedy of errors.

A simple communication error led to a major faux pas for the reporter and the TV station. The story was pulled from the website and the station issued a terse "no comment" when questioned about the error.

Listening skills are as important as speaking skills. And double- and triple-checking the "facts" of an interview are equally important. 


\section{Lesson 10. Research Skill: Evaluating Information}

\section{KEY CONCEPTS}

- All information gathered during the execution of your information strategy must be evaluated.

- The standards you apply and the things you look for when evaluating information depend on the source of the information.

- Evaluation of information is an iterative process that happens at all stages of the information strategy process.

- Asking independent, critical questions about the information generated by an information strategy is essential.

- Shoddy evaluation skills can have repercussions on the quality of the message created and on the credibility of the work.

\section{LEARNING OUTCOMES}

After completing this lesson, you will be able to:

- identify some of the standards for information evaluation.

- apply critical thinking to the examination of evidence.

- identify some of the tools and techniques that help you verify information.

\section{Overview}

The most challenging work in the information strategy process is often the evaluation of the information you've gathered. Media professionals make critical decisions about information throughout the information strategy process.

For example, during the process of refining your possible audience for an ad introducing a new type of mobile phone, you realize that some of the information sources you have identified come from specific phone companies that are touting the qualities and characteristics of their customers. This would lead you to recognize that each of those companies has its own point of view and perspective on its customers (and a specific objective for the message,) and those perspectives may or may not coincide with the audience your client wants to reach. You would need to be sure that you had other, independent sources of information about mobile phone owners to complement the specific company data. 
Or, you might realize during an interview with a source that the person has described the details of an event in slightly, but importantly, different ways over the course of your two-hour discussion. This would lead you to recognize that the person's memory may be shaky, so you would need to find other eye-witnesses to compare their accounts with your source's or ask follow-up questions to clarify the discrepancies.

You apply your information evaluation skills as you move through the information strategy. Critical thinking, evidence-based analysis, and healthy skepticism (but not cynicism) are the tools of the skilled information evaluator. 


\subsection{Thinking Critically about Information}

We live in an information-inundated world. Making sense of facts, opinions, assertions, claims, and appeals has become such a challenge that educators from preschool through higher education now recognize the importance of teaching critical thinking skills. You are especially responsible for applying critical thinking to the information you may use in messages. There are many formulas for critical thinking, but the underlying skill is the ability to ask intelligent questions that help you decide which information to accept on behalf of your audience.

The information strategy you apply as a mass communication professional will usually result in generating far more information than you could ever use in any particular message. Your powers of critical thinking and careful scrutiny are crucial at every step in the process.

\section{Evaluating information requires:}

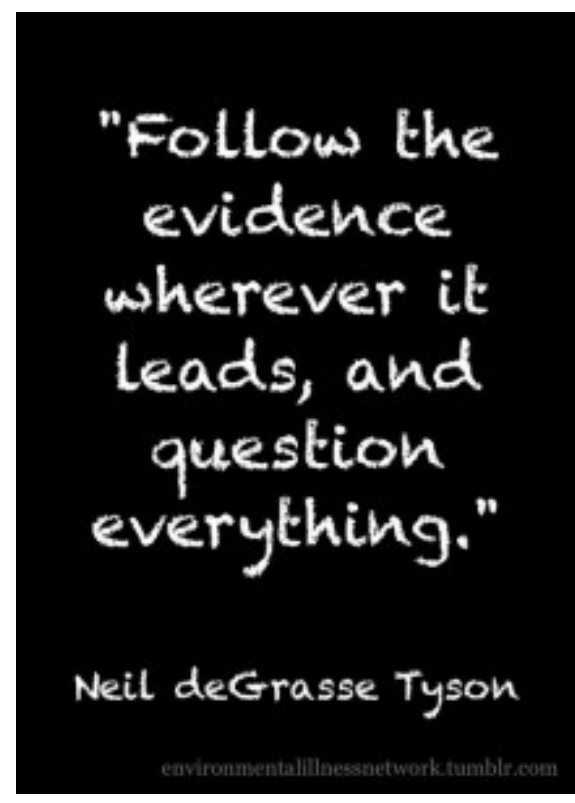

- Careful, detailed analysis

- An eye for discrepancies

Environmental Illness Network: CC BY-NC-ND 2.0

- Attention to accuracy

\section{Communicators ask themselves a set of questions:}

- What should be verified?

- What needs to be reinvestigated?

- What is the element of risk involved in using the information?

- What are the consequences of putting this information into the public arena?

By asking yourself these kinds of questions, you begin to develop patterns of verification and pathways for tracing information. You need to develop alternative interpretations of facts in order to protect yourself against being taken in or to avoid spreading mis-information.

This evaluation process also helps communicators create fresh and effective messages. News professionals want to figure out other possible meanings of information, to avoid the "handout syndrome." For example, a journalist receiving a news release about the amazing new features of some just launched product will check with independent experts in the field to get their take on the claims. Advertising professionals want to be creative and original in their selection and use of information for their attention-grabbing messages. Public relations professionals want to select the "best light" material so they and their clients can be sure to target messages properly and in ways that will have the intended effect. 
When evaluating the information found via the Internet there are some foundational ideas that need to be remembered.

- The Internet did not invent misinformation or disinformation

- The Internet did not create rumor mongering and propaganda

- The Internet is not responsible for dirty data and stupid statistics

All of these have been around forever. The Internet is just a new distribution outlet. The Internet does make it possible for misinformation, disinformation, rumor mongering, dirty data and stupid statistics to be distributed more quickly and widely than in the past. It is incumbent on you, as the communicator, to develop ways to detect and avoid these information traps. 


\subsection{Tests of Evidence}

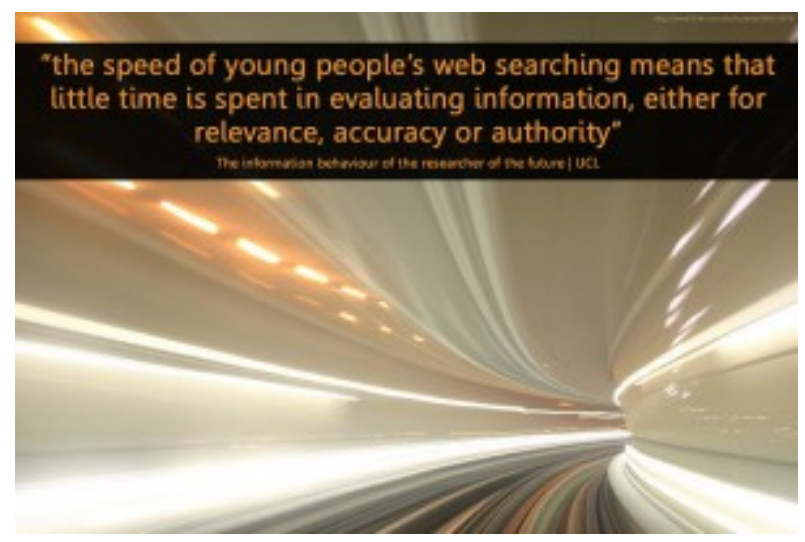

Will Lion - proper browsing - CC BY-NC-ND 2.0
One of the best "checklists" a communicator can integrate into their reflexive evaluation practice is the "tests of evidence.” (Jensen) Evaluation of the "evidence” is part of the deliberation process in many professional areas. Courts of law and legal professionals (law enforcement officers, lawyers, judges) are concerned about the admissibility of evidence, the appropriateness of evidence to the making of a case, and other judicial standards. Rhetoricians and scholars of debate concentrate on the types of data that communicators can consider as evidence, sources of evidence, and the classification of evidence for the purposes of effective persuasion or debate.

For mass communicators, the use of standards in considering the information / evidence you discover during your information seeking tasks takes on a slightly different hue. Evidence can be in the form of written materials (articles, books, letters, court records, websites), oral communications (interview testimony, focus group sessions), or personal observation, knowledge or experience.

You can apply traditional tests of evidence to all the information that you gather through the information strategy process. When skillfully applied, these tests of evidence can alert you to potential problems or inconsistencies in information, to the gaps or "holes" in your information search, and to areas that require further investigation.

The tests of evidence - also known as standards of evaluation - as they apply to mass communication information gathering are:

\section{Clarity}

During an interview with a person who witnessed a holdup, you discover that the witness can be clear on just two points about the robbery and the perpetrator. You would have to evaluate the testimony of the witness based upon their clarity and you may decide that the evidence is not trustworthy and can't be used. Similarly, as an advertising account executive you might decide that the advertising campaign goals of the client are unclear, requiring further information gathering before you can effectively plan the campaign.

\section{Verifiability}


A famous author may write an autobiography that includes a number of impressive claims about his or her education, achievements, and financial success. You may be unable to verify that the author actually attended the schools because enrollment and alumni records may not include the author's name. You would have to do further research to determine the truth of the author's claims. On the strategic communications side, an advertising client may wish to make claims about the superiority of the company's product but may not be able to provide the substantiating documents to verify the claims. If this is the case, then you can't create an ad which makes that kind of claim.

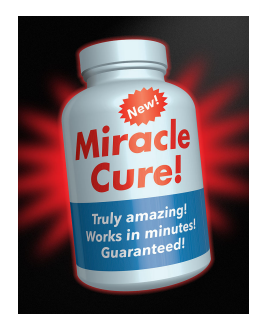

Miracle Cure public domain

\section{Accuracy}

You are a reporter attending an event as an observer and count about 75 people in the audience. Two hours after you get back to the newsroom room, the event sponsor sends out a news release claiming that about 250 people were there. You would reject that news release on the basis of accuracy.

\section{Recency}

A public relations firm working on the problem of airport noise for an airport commission needs the most recent figures on the number of takeoffs and landings since expansion at the airport. Information about how recent flight activity compares with pre-expansion activity is also useful. Or, an ad campaign for a new brand of pizza might require the most recent information about consumer preferences and media habits of pizza eaters. You would reject a marketing study that was two years old on the basis of the recency test.

\section{Relevance}

An advertiser evaluating market research about consumer characteristics must decide whether the research is relevant to the product or service being advertised. A particular market research study about people who buy chicken may or may not be something that is relevant to an advertiser for a turkey company. Or, a reporter writing about the nation's fiscal policy may reject the notion of interviewing an expert on monetary policy based on the relevance test.

\section{Reputation}

People, institutions, and print and digital records have reputations. A reporter might try to arrange an interview with a government official who has a reputation for being candid and forthright on the issue of tax reform. The same reporter might avoid another official because of his or her reputation for stonewalling the press. Or, a public relations practitioner may rely on a scholarly study of the effects of factory emissions on air quality rather than on a study done internally by the factory's own staff because the PR professional knows that the public will hold the independent study in higher regard.

\section{Sufficiency}

You're in charge of the ad campaign for a new chain of teen athletic clothing stores. You get a marketing research report from a group that monitors teen spending. However, the category for teen spending in the area of clothing does not break down the specific clothing types—-the report is not "sufficient" or complete in its analysis of teen 
spending for athletic clothing. This report, then, would be rejected on the basis of the sufficiency test because the data available are not adequate for you to make decisions on the direction of the campaign.

\section{Internal Consistency}

You might decide not to use a particular document because, for example, the figures about average household income used on page 15 of the study are inconsistent with those on page 38, indicating a serious internal consistency problem. This should make you question the accuracy of all the data if there is so little attention to detail. Or, the testimony of an interviewee varies widely over the course of a three-hour interview, suggesting that the interviewee is being inconsistent in his story.

\section{External Consistency}

Two reports on the implications of a change in property taxes come to different conclusions about the projected tax on a $\$ 300,000$ house, alerting you that there is an external consistency problem with the evidence. Further information is therefore needed to clarify the inconsistency. Or, an advertising firm conducts its own research about the market for a new brand of jeans, and the conclusions differ from those of an industry-wide research project about the same product, suggesting an external consistency problem. Using reports of breaking news from multiple sources (eyewitness Twitter posts, Associated Press wire service filings, etc.) can be a challenge in evaluating the consistency of information as an event is unfolding.

\section{Comparative Quality}

Decisions about what constitutes "good" information or the "best" information are necessary at some point. Through a comparison between two studies of new parents, an ad researcher preparing an ad campaign for a new line of strollers might decide that the study that specifically addresses new parents' leisure activities is the most useful compared to a report on the impact of parenthood on their careers. Or, a reporter might decide that among all the interviews she conducted with "experts" on the subject of rising health care costs, two stand out as being the most informative and containing the freshest perspectives on the topic.

\section{Contextuality}

All information exists within a particular context. An interviewee's comments at one point in an interview cannot be taken out of context of the rest of the interview. You also cannot take isolated figures from a report about the incidence of police loafing on the job and report them out of the context of the rest of the report. The complete context may indicate that the problem is not widespread. Both the context and the time period within which information exists must be recognized and respected. If the context or time period cannot be determined, the information is suspect.

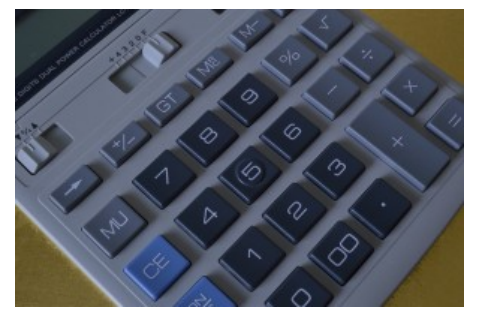

\section{Statistical Validity}

It is not necessary for you to become a statistician in order to test the validity of statistical claims. Simple questions about the method of gathering the statistics, the method of analyzing the data, and the standards for drawing the conclusions from the data are within your ability.

Calculator - CCO

\section{Ambiguity}


Words and phrases have amazing flexibility, suggesting one meaning to some and another, very different, meaning to others. Think about the different connotations of the words "terrorist" and "freedom fighter," the words "tax increase" and "revenue enhancement," or the words "layoffs" and "reorganization.” The words carry entirely different meanings and these meanings change even more when the word or words are placed in the larger context of a sentence, a paragraph, or a fully-developed document, speech or publication. You need to be able to recognize and flag the key words or phrases that can convey the main point in any document, interview transcript, Web page or other source of information. Pay attention to the role these key words play in the overall argument or conclusion the information source wants to make.

There are many examples of how the tests of evidence are applied in mass media message-making:

- Fact-checking articles that appear in a magazine

- Evaluating information about audiences and consumers for advertising and marketing decisions

- Verifying information for news accounts

In the context of this course, knowing how to apply the tests of evidence as you find and evaluate information is one of the key skills that must be developed.

Tests of evidence also must be considered when thinking about the audience for your message. Is the material understandable, believable, useful to the point being made, from a familiar source? If not, you may need to collect more evidence than you'd normally need to gather and present if you are to overcome the audiences' natural skepticism.

For example, if a fast food restaurant is going to make a claim in an advertising message that its food is healthful, you need to understand that the audience will demand a higher level of evidence than would normally be the case because it is counter to common sense that such food is healthy. 


\subsection{Evaluating Observations}

Fundamentally, all the content of mass communication originates with observation. In news reporting throughout most of the nineteenth century, a high percentage of the information originated with the reporter as the observer. Today, reporters and other mass communicators rely on others - from citizens with mobile phone cameras to specialists in various fields - as their observers for much more of the information that is transmitted.

When three tardy whales became stranded in the fall ice off the coast of Alaska, journalists from around the world converged on the area to cover the story. They described, taped, and photographed what they saw. But for additional sources, they used local villagers, marine biologists, state historians, engineers who knew about equipment to keep ice from forming, ice-breaking ship experts, meteorologists, and economists who could talk about the effect of so many visitors on the local economy.

Together, these varied and expert observers undoubtedly gave a more complete and accurate account of the stranded whale situation than reporters could merely using their own powers of observation.

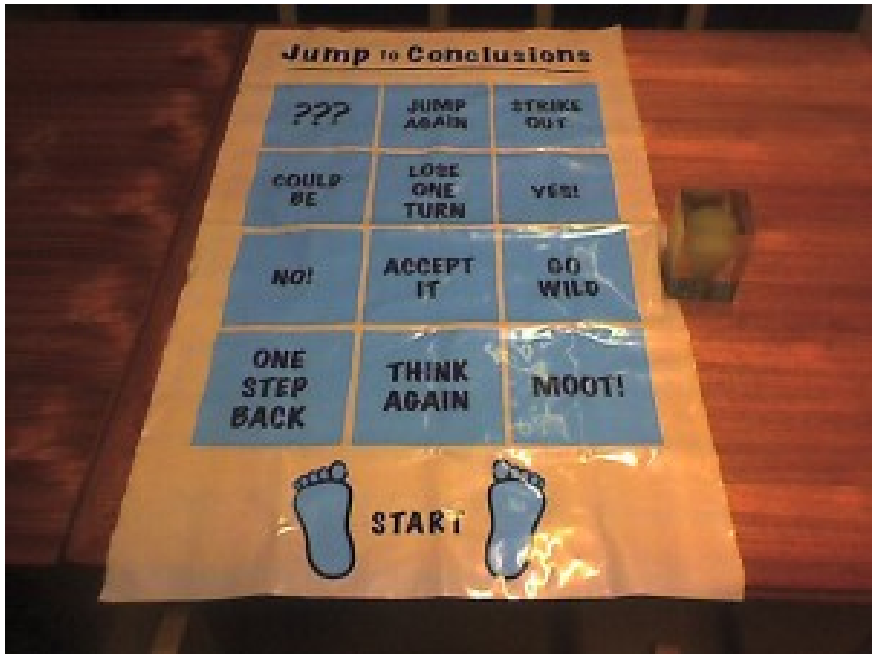

Photo by the Jof: CC BY-NC-SA 2.0

An important qualifier about information that is collected through observation (yours or others'), it that observation derives from a single perspective with a particular point of view and that the information gathered through this method is always filtered through inferences and interpretations by the observer. In the case of the whales an outside observer at the scene might infer that this situation highly unusual and upsetting.

However, local villagers might tell the observer that every fall a few tardy whales are trapped by ice and die or are killed by hunters, that this is part of a relatively natural process. The villagers might even add that any whale so unwary as to stay too long in waters that freeze should not be freed to propagate its defective genes. What may seem like a tragic incident, the death of these trapped whales, to others would be a fitting and appropriate turn of events.

Bias on the part of the observer invariably affects the observation process. Professional communicators try to be aware of bias in themselves and in others upon whom they rely. They are aware that all individuals have assumptions about the world - beliefs about what is ordinary and normal, as well as convictions about what "ought" to be. These convictions influence what is perceived and how the perceptions are interpreted. It is the part of the communicator's role to understand the underlying biases that those who provide information might have, helping to put their observations into a more accurate context.

The effect of the observer on the scene is an additional factor to be reckoned with. The presence (or intrusion) 
of observers can change the event being observed. This is most clearly seen in confrontations that take place specifically for the purpose of attracting media attention. Even in a mundane an event such as a parade, the bands make sure they are playing when they pass the television cameras. Similarly when an observer visits a classroom, kindergarteners (and their teachers too!) adapt their behavior to the presence of the stranger.

Observation, then, is affected by the inherent perceptual limitations of the observer, expectations, inference, bias, and the effect of the observer on the action. The mass communicator as an observer may be more or less affected by these factors than are others who supply information to the communicator. Skill, experience, and awareness of the problems in accurately observing events can help to counteract the inevitable difficulties of observation. 


\subsection{Evaluating Visual Information}

Verifying the accuracy of visual information is another challenge for communicators trying to apply the tests of evidence to information. The increasing use of freelance images and video opens the media to the possibility of fraud.

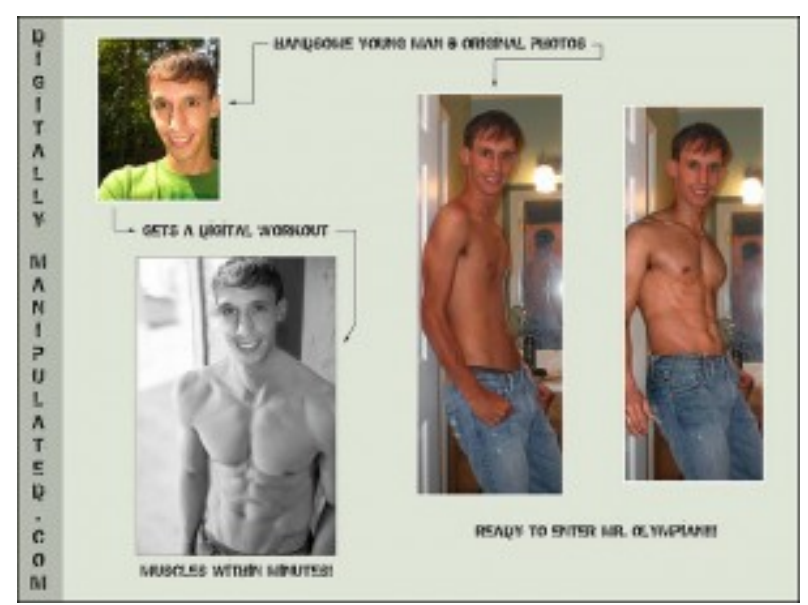

Digitally Manipulated - Manipulation - CC BY-NC-ND 2.0
With today's computer and photographic equipment, there are more and more sophisticated ways to manipulate images. Rank amateurs can use digital techniques for doctoring photos, creating video of things that never happened, and causing all sorts of mischief with visual information. And now that every mobile device includes a camera, eye-witness photos and videos are posted online almost instantaneously any time an event occurs that might have even the remotest likelihood of being newsworthy.

The growing availability of such images has led to a number of services that attempt to verify whether a picture has gone through manipulations of various sorts. For example, a company called Fourandsix offers forensic image analysis using something called FourMatch. The software extension for Photoshop tests a JPEG image to determine whether it is an untouched original from a digital camera. If it appears that an image has been manipulated, the savvy communicator will reject it on the basis of the verifiability test of evidence.

The online Verification Handbook provides multiple chapters and specific resources and tips for verifying information of all types, but especially for material shared on social media sites, sometimes referred to as "usergenerated content.” Here are some of the book contributors' best advice:

\section{Verifying user-generated content (from Verification Handbook)}

- Start from the assumption that the content is inaccurate or been scraped, sliced, diced, duplicated and/ or reposted with different context.

- Follow these steps when verifying UGC:

- Identify and verify the original source and the content (including location, date and approximate time).

- Triangulate and challenge the source.

- Obtain permission from the author/originator to use the content (photos, videos, audio). 
- Always gather information about the uploaders, and verify as much as possible before contacting and asking them directly whether they are indeed victims, witnesses or the creator of the content.

The book pays particular attention to the skills needed to verify user-generated images or video:

\section{Source (or Provenance)}

For verifying provenance of images (ie: where the original image came from)

- Use Google Image Search or TinEye to perform a reverse image search. If several links to the same image pop up, click on "view other sizes" to find the highest resolution/size which usually is the original image.

- Use software like Photoshop or free tools such as Fotoforensics.com or Findexif.com to see information about the model of the camera, the timestamp of the image, and the dimensions of the original image.

- Use Geofeedia and Ban.jo to identify the GPS data from the mobile device that uploaded the image.

\section{For verifying provenance of video:}

- Use acronyms, place names and other pronouns for good keyword search on video sharing platforms such as YouTube, Vimeo and Youku.

- Use Google Translate when dealing with contents in a foreign language.

- Use the date filter to find the earliest videos matching the keywords.

- Use Google Image Search or TinEye to perform a reverse video thumbnail search

\section{Date}

Verify the date and approximate time, particularly when dealing with photos/videos:

- Check the weather information on the day and the location where the event happened. Is the weather condition the same from the (local) weather forecasts and other uploads from the same event? Use Wolfram Alpha to perform a search (e.g., "What was the weather in London, England, on January 20, 2014?”).

- Search news sources for reports about events on that day.

- Using video and image search (YouTube, Google, TinEye, etc.), see if any earlier pieces of content from the same event predate your example.

- For images and video, look (and listen) for any identifying elements that indicate date/time, such as clocks, television screens, newspaper pages, etc.

\section{Location}


- Does the content include automated geolocation information? (Services such as Flickr, Picasa and Twitter offer the option of including location, though it is not foolproof.)

- Find reference points to compare with satellite imagery and geolocated photographs, such as:

- Signs/lettering on buildings, street signs, car registration plates, billboards, etc. Use Google Translate or free.orc.com for online translation.

- Distinctive streetscape/landscape such as mountain range, line of trees, cliffs, rivers, etc.

- Landmarks and buildings such as churches, minarets, stadiums, bridges, etc.

- Use Google Street View or Google Maps' “Photos” function to check if geolocated photographs match the image/video location.

- Use Google Earth to examine older images/videos, as it provides a history of satellite images. Use Google Earth’s terrain view.

- Use Wikimapia, the crowdsourced version of Google Maps, to identify landmarks.

- Weather conditions such as sunlight or shadows to find approximate time of day.

- License/number plates on vehicles

- Clothing

\section{For Videos:}

- Examine the language(s) spoken in the video. Check if accents and dialects match up with the geographical location. Ask those who speak the language for support.

- Are video descriptions consistent and mostly from a specific location?

- Are videos dated?

- If videos on the account use a logo, is this logo consistent across the videos? Does it match the avatar on the YouTube or Vimeo account?

- Does the uploader "scrape” videos from news organizations and other YouTube accounts, or do they upload solely user-generated content?

- Does the uploader write in slang or dialect that is identifiable in the video's narration?

- Are the videos on this account of a consistent quality? (On YouTube go to Settings and then Quality to determine the best quality available.) 
- Do video descriptions have file extensions such as .AVI or .MP4 in the video title? This can indicate the video was uploaded directly from a device.

- Does the description of a YouTube video read: "Uploaded via YouTube Capture”? This may indicate the video was filmed on a smartphone.

The fact that the book includes an entire chapter on this topic demonstrates the importance of these skills and the seriousness of falling prey to a manipulated image.

It is not just digital manipulation that causes problems. There have also been several incidents of staged photos. Soon after the 9/11 disaster a photo was circulated of a tourist on the World Trade Towers as one of the planes approached. This list of the ways to analyze the photo is a good lesson in applying logic.

Another classic (and infamous) example occurred after the death of England's Princess Diana, her companion, and their driver in a gruesome automobile accident in Paris in 1997. Shortly after the world learned of the accident, a photo appeared on the Internet and was subsequently distributed by several news services and published on the front page of a French newspaper. The photo showed a mangled Mercedes with a blonde victim in the back seat and rescue workers and emergency vehicles surrounding the crash site. Even the most rudimentary check of the authenticity of this photo, however, would have revealed that the rescue workers' uniforms did not match any used by Paris fire brigades and the phone number visible on the side of a rescue vehicle would not work anywhere in France. (Harmon)

There is a related problem in using satellite images. Several firms now sell satellite images as a commercial venture. Interpreting information from a satellite photo requires expertise usually not available in news organizations.

The choices made by photographers can greatly influence the emotional impact of an image. The photographic processing and framing can be manipulated by the photographer to generate a wide variety of effects.

The old saying, "A picture is worth a thousand words" was never true (photographers have always chosen the way to represent their images and a photo was never an objective representation of reality), but now it is even less useful as a way to think about visual information. Again, common sense and a critical mind will help avoid problems. 


\subsection{Evaluating Websites}

Obviously, the same tests of evidence discussed earlier must be applied to information you find on a website. You need to determine the reputation or authority of the information producer, the accuracy of what you find online, the recency of the information, the completeness of the data, and so forth.

There are many more clues and tips for helping assure you are thoroughly assessing the information you find on a specific site. One of the main considerations when determining how or if information on a website can be used is to understand the reason the online information producer is making the information available. The website's main goal might be:

- Advocacy: attempting to persuade or influence opinion toward a particular position or point of view

- Marketing: using the site to promote a particular product or service by providing information to consumers or to other businesses

- News: publishing news and information by media companies is an alternative to their traditional delivery methods.

- Personal expression: creating personal sites, blogs, or social networking pages allows individuals to express their interests and unique perspectives.

The bottom line here is it's like the old computer adage: garbage in / garbage out. So, if you want to ensure that you are not producing garbage, make sure you don't use it.

If you ask, and answer, the following three questions when you go to any website, you should be able to avoid misusing or misunderstanding the information you find:

- Who is sharing this information?

- Why are they sharing it?

- How do they know what they claim to know?

Let's look at Wikipedia as an example of evaluation. Categorizing Wikipedia is difficult because its contributors may be scholarly experts in their fields, they may be private citizens with some professional or personal knowledge about a topic, but they may also be individuals with misguided information or pranksters whose goal is to deface of this popular site. It also contains obscure information from popular culture or other realms that you may want to learn something about and its contributions are sometimes highly informative and accurate. Because the sources of the information cannot be easily verified or the motivation for providing the information determined, Wikipedia entries can only be used with skepticism and require "second-sourcing" from more authoritative information contributors. 
Reading the “About Us” information on any website will give you valuable information about the site creators' agenda, backers, and mission. But be sure to critically evaluate the self-description and remember the importance of understanding "ambiguous" terms as discussed earlier in this lesson.

Remember also the contributors to the information search that the information strategy model identifies. Privatesector institutional sources are likely to host sites that advance their business, point of view or support for a particular policy or program. Journalistic organizations host websites to disseminate their news content and gather information from their readers. Scholarly websites produced by universities, research centers or individual scholars are generally designed to highlight the academic work of that institution or individual researcher. Informal sources may host family websites, hobby websites, sites to spread a personal philosophy and for many other purposes. It is your responsibility to identify the type of contributor who created that site when you are deciding whether or not to use any information you find there.

Here is a link to a little cartoon with a good explanation of how to evaluate a website: https://www.youtube.com/ watch?v=aem3JahbXfk 


\subsection{Stop that Rumor}

As we discussed earlier, the Internet has made possible the rapid and broad dissemination of both good information and bad. Luckily, there are resources to help identify, and background, some of the hoaxes and rumors so rampantly spread on the web. One of the best is Snopes where they diligently identify and background a vast array of Internet-generated misinformation.

After the exposure of individuals and organizations generating enormous amounts of false and misleading information during the 2016 presidential campaign, major news organizations and social media organizations pledged to work harder to ferret out such material. Facebook and Google both developed filters that helped bring legitimate information to the top of their news feed and search algorithms and to tag or identify information from sources known to peddle false stories and claims. News organizations and academic institutions beefed up their fact-checking operations and began openly calling out individuals and organizations that were poisoning the information environment with falsehoods and wild assertions. Educators scrambled to develop media literacy tools to help the average news consumer sort through the sludge. One group of educators even developed a game to help players discern real news from fake news.

Get to know these kinds of sources and use them regularly to avoid being taken in by bad information or perpetuating it by sending it along to others.
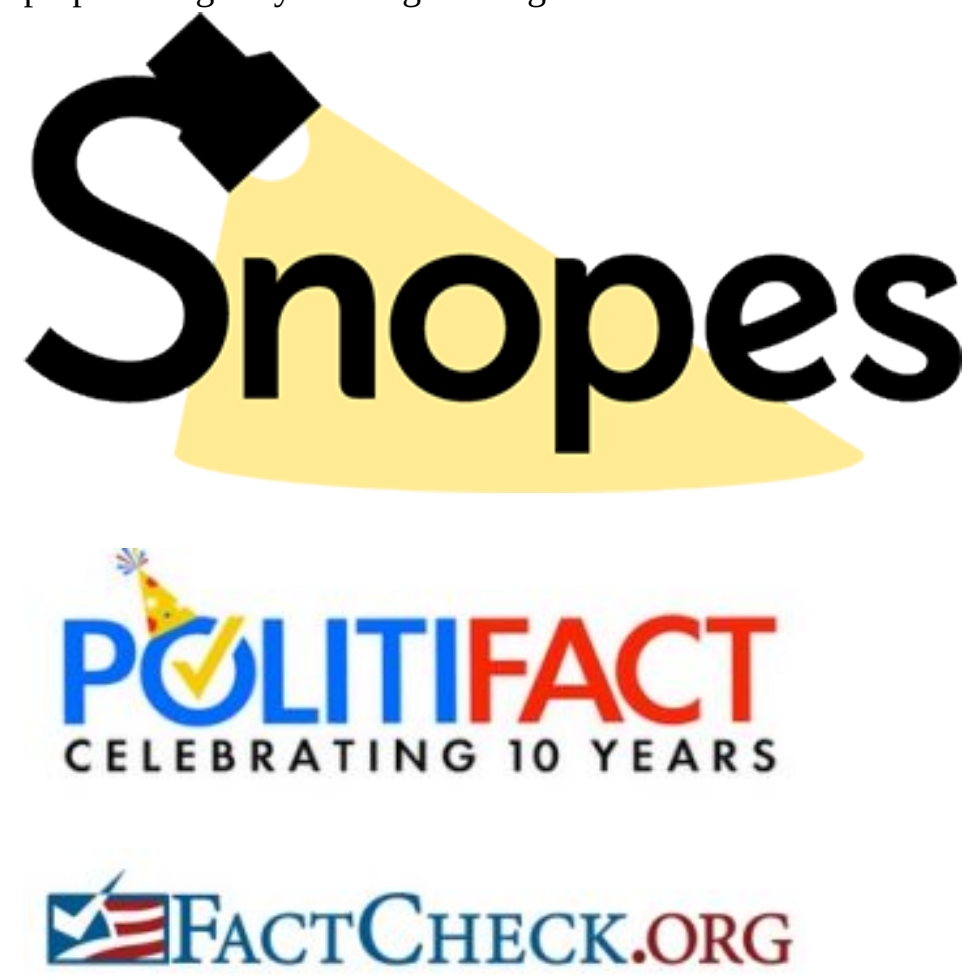


\subsection{Evaluating Information Subsidies}

An information subsidy is something that is provided to the communicator at a lower "cost" than if the communicator had to go out and generate that information from scratch.

Media professionals gather information from a wide variety of sources using an array of techniques. Among the richest veins of material are the information subsidies created by organizations and institutions. These information subsidies come in the form of news releases, media kits, sound-bite-ready interviewees, briefing papers, privately-funded research studies, and thousands of other sources of facts, figures and interpretations. The organizations create them based on their own research and to promote their organizations’ needs and interests.

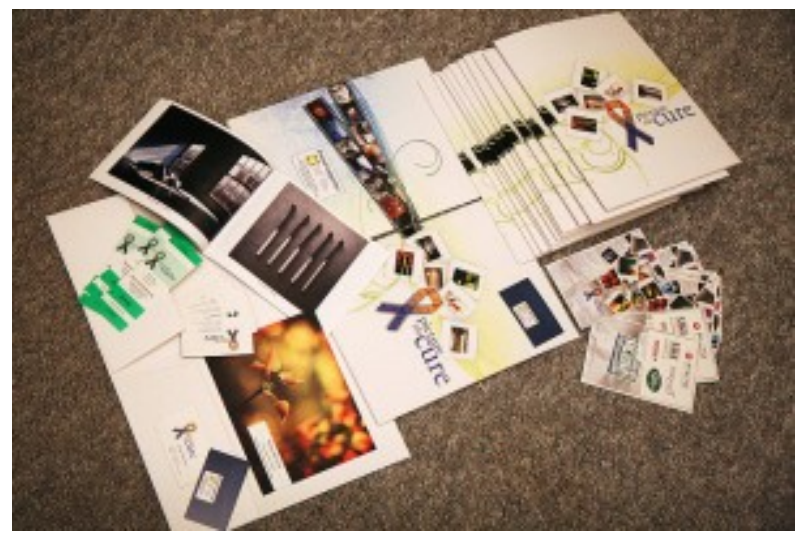

You must acknowledge that selecting information

Irina Souiki - Preparing the media kit - CC BY-NC 2.0 subsidies from a particular organization will lead you in some directions and not others; that you are, by definition, being exposed to one particular point of view when you select some information subsidies and not others. You are obligated to determine whether that point of view is appropriate for your message, and to tell the audience where your information came from.

For example, a "campaign watchdog group” once released a study detailing millions of dollars of political contributions by trial lawyers. The group who claimed that trial lawyers were exerting undue influence on political campaigns decried this "special interest" money. The study was widely reported in mainstream media reports.

But the Washington Post discovered that a tobacco company, Philip Morris, funded the study and their PR firm created the group who did the study. The "campaign watchdog group” was, in fact, a PR tool intended to generate press coverage favorable to the client's causes.

Why would the tobacco company's PR firm do this? Big business in general does not like trial lawyers, and tobacco companies, specifically, do not appreciate trial lawyers' meddling in their affairs through filing lawsuits and damage claims. It was in the interest of tobacco companies to secretly create the "watchdog” group, fund a study that found fault with the behavior of trial lawyers, and then provide those figures to the media with the veneer of respectability and independence the "watchdog” group provided. (Marcus)

This does not necessarily mean the study itself was fraudulent. In fact, the findings were based on public documents available from every national and state political campaign about which groups give money to candidates.

But the vested interests of the providers of the information subsidy were highly relevant to the question of whether the media should have reported on the study the way they did. 
The example is a reminder about why it is important to try to evaluate the special interests or hidden affiliations of people or organizations that are providing information subsidies. Media professionals have the responsibility to find out who is providing an information subsidy, for what purpose, and with what intention.

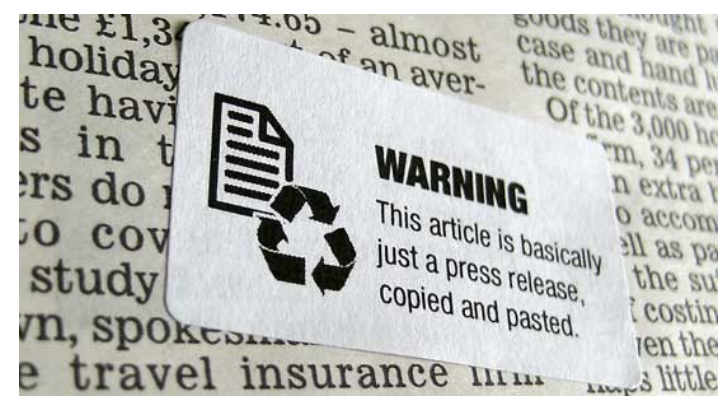

Sunlight Foundation
There have been attempts to help information gatherers detect when a news story might be a thin rewrite or cut-and-paste of news releases, one of the most common types of information subsidies for journalists. An organization called Churnalism.com was an independent website built by a British non-profit organization to help information gatherers distinguish between original journalism and repackaged information subsidies. Although its funding has been problematic and it is currently offline, reading about some of the examples of "churnalism" in this article will help you

understand the issue.

There is nothing wrong with using information from a news release. The problem arises when a news release is presented verbatim or with no original information added in a news organization's content without being labeled as sponsored information. The Churnalism site allows you to paste a URL or a bit of text from information you found and check to see if it comes from a news release. You can imagine that this tool is also useful for PR practitioners who want to track how their news releases are being used by news organizations.

The 18th century preacher and poet William Ellery Channing was talking about personal integrity when he said, "It is not the quantity but the quality of knowledge which determines the mind's dignity." ${ }^{1}$ But in the context of message creation it holds true that "It is not the quantity but the quality of information which determines the message's viability.” As you begin the task of evaluating information for specific research tasks, remembering this will help you select, and reject, material from which you will craft your message. 


\subsection{Endnotes/Resources}

\section{Endnotes}

Harmon, A. (1997, September 22). Diana Photo Restarts Debate Over Lack of Restrictions on Internet Postings. New York Times at http://www.nytimes.com/1997/09/22/business/diana-photo-restarts-debate-over-lack-of-restrictionson-internet-postings.html captured on July 27, 2012.

Jensen, J. (1981). Argumentation: Reasoning in Communication. New York: Van Nostrand.

Marcus, R. (1996, September 30). Tobacco Lobby Created Campaign 'Watchdog'; Nonprofit Groups Tied to Philip Morris Monitored Trial Lawyer Donations. Washington Post.

\section{Resources}

Tutorial on Evaluating information found on the Web: https://library.uaf.edu/ls101-evaluation 


\section{Lesson 11. Research Skill: Managing and Synthesizing Information}

\section{KEY CONCEPTS}

- A variety of digital tools help communicators manage and analyze the information they've gathered.

- The most creative part of an information strategy is connecting disparate pieces of information into a a new idea.

- Synthesis consists of collecting and discarding from among the information generated by the information strategy process.

- Information synthesis is done within the context of the message audiences’ needs.

- Information generated through the information strategy process enables communicators to make a strong case for their story idea or campaign approach.

\section{LEARNING OUTCOMES}

\section{After completing this lesson you will be able to:}

- identify some of the information management tools appropriate for your task

- understand how to find the theme or focus for your message

- organize the information for the message

- ensure that the information in the message meets the needs of the audience

- generate ideas for how to make the background information you have gathered "come alive"

\section{Overview}

Once you are satisfied that the information you've gathered and evaluated is as solid and reliable as you can possibly expect in the time available, you need to spend some time organizing and synthesizing all the material in advance of actually pitching your idea or writing the story, the ad, or the news release. This essential step of organizing the information you intend to use when writing will save you time and ensure you don't miss important pieces of the topic. Just as you did as you began the evaluation and selection process, you'll keep in mind what you have established about the purpose and the intended audience for the message as you start this sorting and synthesis step.

There are dozens of software systems to help you organize the material you've gathered as part of your 
information strategy. Some of these are called "project management” tools, others are designed to help you manage citations to documents you've gathered, still others are designed to help you brainstorm about what your gathered information means. Depending on your personal preference, you may determine that it is better for you to manage your information using old-school techniques such as transferring things to $3 \times 5$ cards, using manila file folders or using whiteboards or pinboards to organize material.

No matter what your preference, you WILL have to figure out an appropriate organization scheme for the information you've gathered before you can start to understand what to make of it and how it can help you with your message task. 


\subsection{Synthesizing the Information}

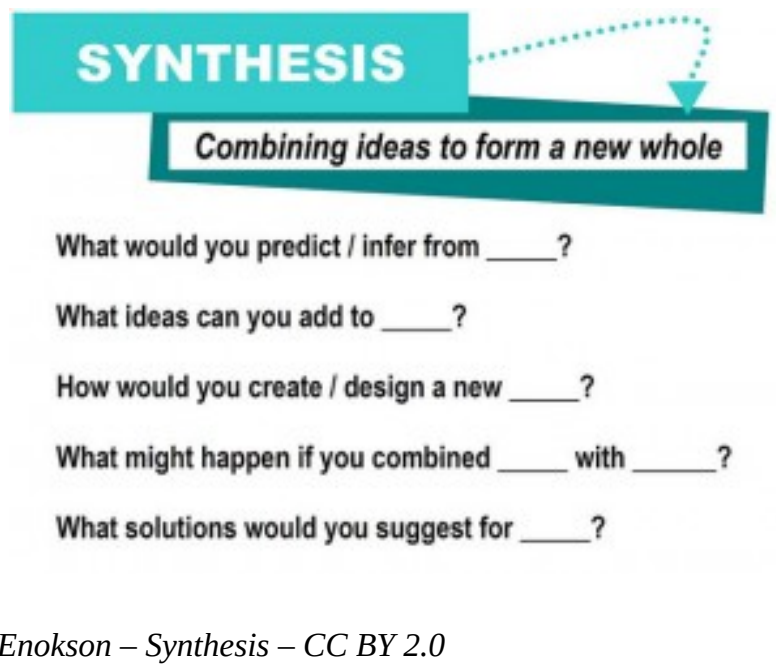

After you have completed the bulk of the information strategy process, you will have a great deal of information from which you will pitch your idea and/or craft the message. You will have eliminated any material that you've found to be erroneous or questionable, updated facts that are not current, identified differences in viewpoints, and put into context information that reflects special interests.

Even after you've sorted and selected, you will still have much more information than will ever actually be used in the message. If you don't have much more material than you need for your message, you have a different kind of problem - a faulty information strategy may be the cause. Or, if you find discrepancies in data between sources you've used, you will need to re-examine the information you've located.

For example, if the message you're preparing is about adult illiteracy, during the evaluation step you will have reviewed the material for your tests of evidence such as accuracy, verifiability, external consistency, etc.. You may have found some information in your search from studies produced by organizations attempting to attract potential donors to campaigns against illiteracy. You might then suspect that these organizations have an incentive to exaggerate the prevalence of adult illiteracy. If this is the case, you would evaluate this information carefully and report the agenda of the information source to the audience.

If the statistics on adult illiteracy are not consistent across separate studies, you'll need to go to additional sources, perhaps retracing earlier steps taken in the information strategy. At this point, you may loop back through the process as you seek to plug holes in the information you need as you prepare the message. 


\subsection{What Have You Found?}

Organizing and synthesizing the information you find is the way information becomes your own to use. You should be prepared to summarize, interpret, explain and analyze as you research. You cannot skip this step and truly own the information you find. Any form of cutting and pasting OR copying OR highlighting indicates only that you have located information. It does not indicate that you know how you would use it to answer the questions you developed in the message analysis part of the process.

Using information without taking the steps to organize and synthesize almost always leads to some form of plagiarism. Once again, the communicator asks a set of questions:

- What does the gathered information, evidence, material mean?

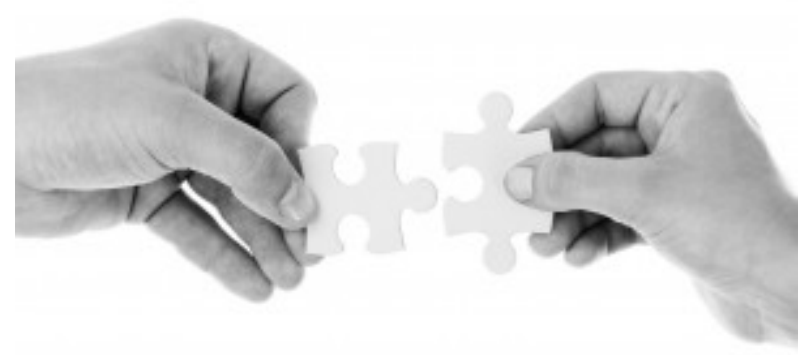

- What are the implications?

- What is the context within which the information is presented? PublicDomainImages - Connect - CCO

- How will the message be crafted to generate interest and attention?

- Does the information meet the needs of the audience?

Communicators can put any face on the information they choose. The challenge always is to present information in as complete, balanced, interesting and accurate a way as possible. The communicator may decide at the synthesis part of the process that additional information is needed. It helps to keep an eye out for holes in the logic of the argument you are making.

Think of the message as an exercise in convincing someone of the logic of your story (as in news story, ad copy, PR release, web site). If you are “pitching” your idea to editors, PR or ad clients or workplace colleagues, they will expect you to have a convincing argument for your approach to the message. The synthesis step of the information strategy process is where you build your case. 


\subsection{Finding the Focus}

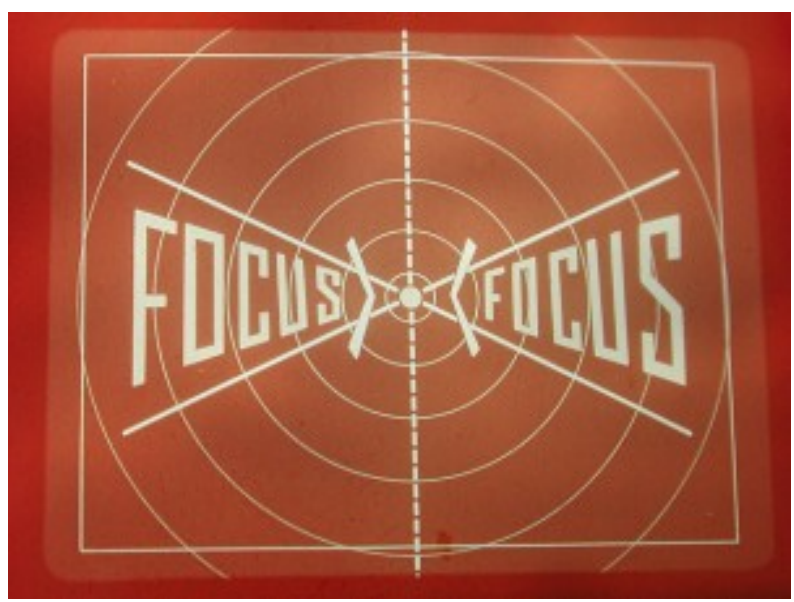

Bart Everson - Focus Focus - CC BY 2.0

Even with the message purpose and audience clearly in mind, the process of synthesizing all of the information and data you have gathered from different types of contributors through different methods can be a difficult process. This process is also particularly hard to describe as it takes place in many varied ways inside the minds of creative communicators. Look through some of the questions that communicators should ask themselves as they sort through their compiled information and select for use in their message.

For the news process, Carl Hausman (1990) provides this set of questions that contribute to the decision-making required for synthesizing information.

- Is it news?

- Is it true?

- Is it fair?

- Is it logical?

- Is it distorted?

- Is it libelous or an invasion of privacy?

- Has the story been ethically researched and presented?

- Is it worth the consequences?

Patrick Jackson (1994), former editor of the trade periodical pr reporter, suggested five basic questions in assessing a public relations message: 
- Is it appropriate? For the sender? For the recipient?

- Is it meaningful? Does it stick to the subject, and is it geared to the interests of the audience?

- Is it memorable? Does it employ devices - including verbal, graphic, and aural imagery - that people will remember?

- Is it understandable?

- Is it believable? Does the source exhibit trustworthiness and expertise?

A checklist of critical thinking questions created by M. Neil Browne and Stuart Keeley (2001) provides a heuristic for handling the challenge of synthesizing information:

- What are the issues and the conclusions?

- What are the reasons?

- Which words or phrases are ambiguous?

- What are the value conflicts and assumptions?

- What are the descriptive assumptions?

- Are there any fallacies in reasoning?

- How good is the evidence?

- Are there rival causes?

- Are the statistics deceptive?

- What significant information is omitted?

- What reasonable conclusions are possible?

Imagine a wall-to-wall mural with a montage of every kind of face one can see on a city street. How can you select and arrange the material so it will connect with these potential audience members?

Pretend you are telling the story to your mother. Does she understand what you are talking about?

Can you compose an "elevator speech" that you would deliver while riding from the ground floor to the 15th floor with the person you need to impress with your idea?

Start each day with two questions at the top of your computer screen: "What's the news? What's the point?” These help derive theme, focus, and (sometimes) the "voice” of the story.

Make a list of the elements the message must include. Since each story, ad, or public relations release 
212 Information Strategies for Communicators

can contain only a small fraction of what the communicator has collected, this can help establish focus and identify what is essential to the theme and what is peripheral. 


\subsection{Fitting Things Together}

Recall our discussion of idea mapping, point-of-view diagrams, and identifying conventional wisdom from the message analysis part of the course? These techniques can also be used in the synthesis step as you review what you've collected. It will also help answer the questions you posed for yourself at the start of the information process.

One big challenge is to see how the information fits together. Think about it as weaving a fine fabric as opposed to making a quilt.

- If you are just stitching together pieces of information that you've gathered, without trying to interweave the different elements, you're making a quilt. It might hang together but it looks like it was pieced together from lots of separate elements.

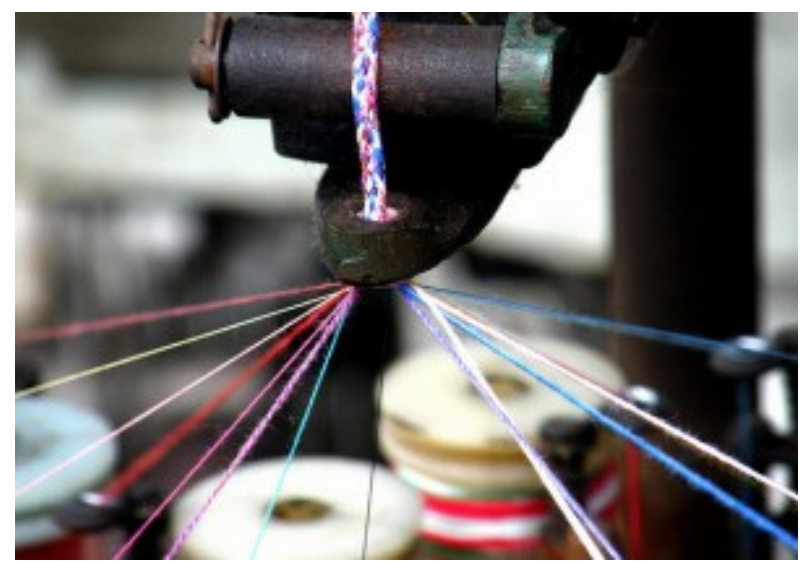

- Weaving a fine fabric requires you to take each piece of information and treat it like a thread in

fauxto_digit - Bob and Weave - CC BY 2.0 the loom. You must be able to see how each thread relates to all the others, see where some things can blend together, where some things stand out and how it all is interconnected. That is what you are trying to do with the synthesis process.

You can use a number of techniques for accomplishing this:

Compare - how is the information from different sources alike and different? Why? Compare and contrast what you have and see where new pieces of information can be developed to add to your overall understanding. See where there are two or more perspectives on a topic or issue and compare the points of view.

Select - use the evaluation skills we've discussed. What is most useful? Try outlining the elements of the message. Try using a data-crunching tool like those from database or spreadsheet software. Try composing a timeline.

Organize - what is the best way to organize the information? Cluster things together and determine a logical order of presentation - chronological, alphabetical, cause and effect, compare and contrast, similar and different.

Analyze - what ideas can be combined? What should be kept separate? Start to draw inferences (recall our discussion during the observation portion of the course - you can start to come to some conclusions). Identify trends, interpret the data, solve the problem, make a decision, apply the information. Formulate the new ideas that will be the foundation for your message. What can you add that is new, or that helps interpret old information? Recall our discussion about going beyond the conventional wisdom in an area.

Review your results - have you addressed the questions you posed at the start of your information strategy 
process? Have new questions arisen during the process? Is there extra or repeated information that you can eliminate? Where are the "holes" in the information or in your understanding of the information? Are there other ways to view the information or additional perspectives that you should be considering?

Credit your sources - provide attribution for interviewees, cite documents, refer to additional sources of information that the audience can tap, credit those who helped (news researchers, market researchers, interns, etc.) 


\subsection{What Synthesis Helps You Do}

At the end of the synthesis process, you should be able to identify four things for any message:

\section{For Journalistic Messages}

- The news - what happened? What is the point of this story?

- The context of the news - what is the relevant setting or background that helps explain this news event or issue? Why are we telling this story here and now?

- The angle or focus of the story — what do you want the audience to take away?

- The significance of the story - why does this story matter? What does this story have to say about life, the world and the times we live in?

\section{For Strategic Communications Messages}

- The strategic goal for the message - what strategy are we pursuing with this message? How does this message help us reach our strategic goal?

- The target audience for the message — who will we target and how will we reach them?

- The unique selling proposition - what are we selling (product, service, idea, point of view) and how is it unique? What might some creative strategies be?

- The context for the message - what else does the audience know and how do we respond to that? 


\subsection{Examples of Synthesis}

Let's look at how the synthesis process works in media messages. An ongoing advertising campaign illustrates some of these techniques. One important use of background information is to identify trends in population and consumer preferences in order to develop products and ad campaigns.

The Dodge automobile company has, for years, used its understanding of the changing trends in automobile and truck ownership to design ad campaigns that cleverly synthesize several themes.

\section{Click to see a Dodge commercial from the 1960s.}

Notice the way the ad interweaves appeals to audiences by psychographic, demographic and lifestyle characteristics. The car is not just touted for its powerful engine but also for the way it can "convert" to a "wagon" to carry water skis, picnic supplies and other family-related gear.

When the Japanese automobile company Toyota ran into significant trouble with their vehicles' braking systems and consumers and regulators started raising questions about their quality control, Dodge capitalized on the opportunity to distinguish their products from Toyota and the other foreign competitors that have always scored very high with U.S. consumers.

\section{Click to see a Dodge commercial from 2010.}

Notice how the ad uses a psychological appeal to the "home-grown" aspect of Dodge vehicles and to the patriotic theme of buying American. The commercial appeared on the usual television programs targeted towards men (sports programs, etc.) but it also appeared on sitcoms and programs with a female audience as well. The example points out how the ad staff used synthesis of information about who is buying cars to come up a way to communicate to a new audience through new choices for creative elements and media purchases.

News professionals also use their synthesis skills to tell stories. Synthesis skills help you get the story right, provide context, help the audience understand larger trends and put things together rather than seeing things as isolated, disconnected, random occurrences.

The Minneapolis Star Tribune ran a story about the loss of 750 Minnesota jobs to Florida when the telemarketing firm Fingerhut decided they needed a bilingual work force in order to have successful telephone transactions with Spanish-speaking potential customers. (Berg \& Apgar) The resultant news story used the Fingerhut incident to provide larger context for the event. Why did this major company feel it had reason to move its operation? Business forces showed the company an important trend, and the reporter and editors thought it was also important for the audience to understand that trend.

Reporters gathered background information about the makeup of the U.S. population, including census figures showing that Hispanics made up a substantial percentage of the population and would overtake African Americans in the next decade as the largest minority group. Data also showed both native-born and immigrant population growth among Spanish-speaking residents. Reporters used U.S. government figures to show that 32 million 
Americans spoke a language other than English at home and one-third of school kids in major cities spoke English as a second language.

Reporters also provided information about differences in cultures. Hispanics tend to be more reluctant than other immigrant groups to embrace English quickly. For evidence, reporters pointed to Spanish-language Yellow Pages issued in most Sun Belt cities and the fact that the number of Spanish-language radio stations had doubled to more than 400 in the previous decade. Univision and Telemundo, the top Spanish-language TV networks in the U.S., were strong promoters of their culture and of consumer products for the Hispanic community.

Fingerhut moved to Florida because, at the time of the story, the work force there was 18 percent bilingual and Spanish-speaking customers were the company's fastest-growing market segment. The news story provided information about other companies that were scouting opportunities to sell to Hispanics, including local giants such as Target and Wells Fargo Bank.

The news story talked about government agencies that try to accommodate Spanish speakers, such as the IRS, which offers tax forms in Spanish, the communities that provide ballots in Spanish, and states that offer drivers' tests in Spanish. Reporters also talked about the controversy that these accommodations engendered. Reporters consulted social scientists who discussed the history of cultural integration, close ties between the Spanish language, Mexican culture, and early U.S. expansion. The story also talked about laws established in 23 states to require English as the official language, and legal challenges to those statutes.

In short, reporters and editors used their information selection and synthesis skills to give an isolated news event greater context than it otherwise might. They used their synthesis of information to provide multiple perspectives, trends, and supporting evidence. The news event was not just a one-day story about Fingerhut moving jobs, but rather an opportunity to discuss legal issues, social and cultural issues, and economic issues in a way that was engaging and understandable.

The synthesis process also applies to you if you are writing academic reports and projects, an especially important point because the synthesis process in academic writing is often overlooked. When you are working on a scholarly term paper or project, you want to be able to understand and restate the meaning of all the information you have read and be able to draw conclusions from it. In addition, as you do scholarly writing, you need to apply the same skeptical eye when evaluating academic sources of information as when you would judge material for a media message. Try to organize material around themes, ideas, perspectives, and points of view. 


\subsection{Plagiarism}

As we have discussed in previous lessons, it is critical for you to give appropriate credit through footnotes or source attribution for ideas and information that you use in your writing. Further, the issue of plagiarism is very serious. It is crucial, then, that you learn the proper method for crediting the source of your information, no matter where it came from.

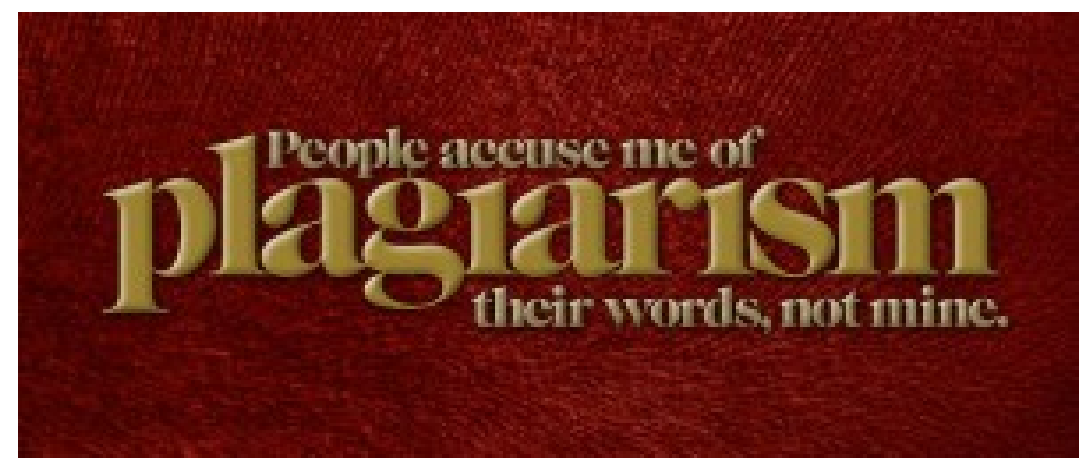

brett jordan - Caught Stealing - CC BY 2.0

Ignorance about what is and is not plagiarism is not a good excuse for committing plagiarism, nor is it likely to stand up as an excuse that others will believe. In cases where you are not sure if you're drifting into the realm of plagiarizing material, you are much better off citing the information and providing quotation marks when appropriate rather than making it seem as if you are representing another's work as your own.

The synthesis step provides you with the last chance to identify missing information, catch errors, and make final decisions about the shape of the message. Along with the message analysis step that starts the information strategy process, the synthesis step is the most difficult task you face in your message process. 


\subsection{Endnotes / Resources}

Berg, S. and Apgar, S. (1996, May 5). Spanish speakers are fastest-growing consumer segment. Star Tribune, A1. Browne, M. N. and Keeley, S. (2001). Asking the Right Questions, 6th ed. Upper Saddle River, NJ: Prentice-Hall) Hausman, C. (1990). The Decision Making Process in Journalism. Chicago: Nelson-Hall.

Jackson, P. (ed). (1994) Practical actionable research for public relations purposes. Exeter, NH: PR Publishing. 


\section{Lesson 12. Information Resources: Publications}

\section{KEY CONCEPTS}

- Every type of information contributor generates publications that can be of use to communicators.

- Identifying the type of publication (through analysis of intended audience, source of the publication, and other indicators) is important for evaluating the information you find.

- Depending on the information task, different publication types will be more appropriate than others.

\section{LEARNING OUTCOMES}

After completing this lesson you will be able to:

- identify the type of publication based its characteristics.

- evaluate the best resource for locating articles based on the kind of information or the source of information needed. 


\subsection{Publications from Contributors}

No matter how you conduct your information strategy, you have one more conceptual skill to master before you can begin to make sense of what you find. As we've discussed throughout each of the previous lessons, the five contributors to the information search produce different types of materials for different purposes. Let's discuss the types of publications these contributors produce. 


\subsection{Public-Sector Institutions}

Government agencies generate huge amounts of information and much of it gets issued in the form of publications that are usually public. We will discuss specific types of public records and methods of locating those in Lesson 13. Here we are talking about the types of publications issued by public-sector institutions.

Let's say that you are working as a PR specialist for the National Football League's Players Association (the union for football players) You need to find information to answer the question your information strategy has posed about the long-term health effects of head injuries on professional football players in order to understand one of the issues facing members of the union. One of the types of information that can be useful is likely to be accessible in publications produced by relevant government agencies.

For example, The Centers for Disease Control and Prevention has produced a publication about how to avoid concussions in football and how to recognize their symptoms, especially in young athletes. They have also produced a publication for coaches. Those resources could prove useful for your work as a PR specialist for the professional players association. You also might need to examine publications produced by state government agencies (e.g. the State Department of Education may have publications regarding athletic injury prevention for schools in the state). Local government publications might detail the Parks and Rec summer leagues and the types of injury prevention activities they are supporting. Because there appears to be a strong connection between repeated head injuries in youth sports and long-term damage among professional athletes, all of these types of public-sector publications could inform your work.

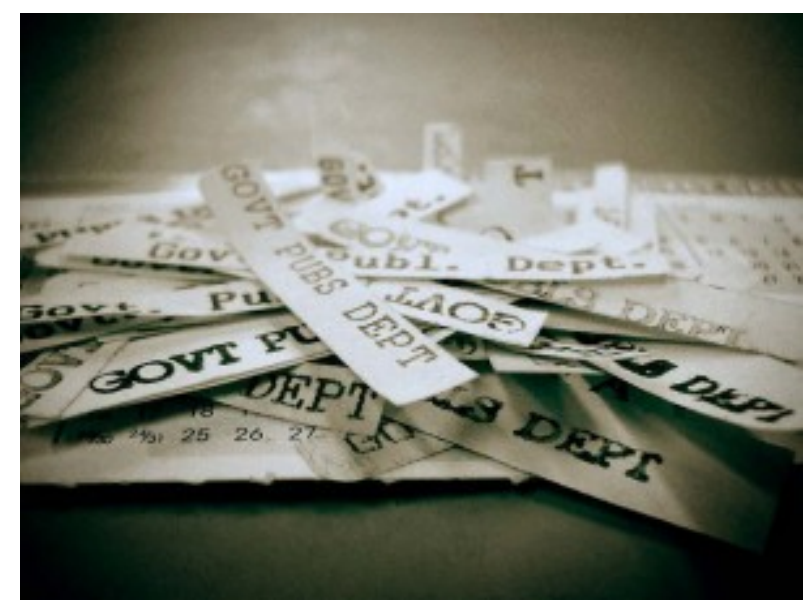

Shelly - DSCN0123 - CC BY-NC-ND 2.0

\section{Federal Government Publications}

The federal government of the United States has no close competitor as a generator of information. Its information production takes place not only in the nation's capital, but also in federal offices in all 50 states and at diplomatic posts and military installations around the globe.

In fact, the federal government produces so much information that it is impractical to try to enumerate all the types 
of public record materials that their activities generate. It is easier to discuss the types of "information functions" the government fulfills. The federal government serves five major information functions:

\section{Collecting and producing statistics}

Some of the publications from the federal government are collections of of statistical information that the government routinely collects. We'll discuss some of these kinds of statistics produced by government agencies in Lesson 14.

\section{Keeping a record of government activity}

Whenever Congress holds hearings, passes legislation or conducts its business, publications are generated. The executive branch agencies, including the Office of the President and all cabinet offices, are obligated by law to document their activities. Judicial actions by courts must be recorded. The infrastructure for locating such information is extensive. A meta-search engine created by the U.S. Government Printing Office called MetaLib is a great starting point for locating government records from a huge number of federal government sources. Legislative committees also have research staff that generate information and produce reports on behalf of the committee. The Congressional Research Service (CRS) was created by Congress in order to have its own source of nonpartisan, objective analysis and research on all legislative issues. Their reports are available to those who request them or to those who conduct a search on the websites that collect reports such as the Federation of American Scientists.

\section{Tracking research activities funded by the federal government}

Organizations or agencies that receive a federal grant to conduct research must prepare regular reports that

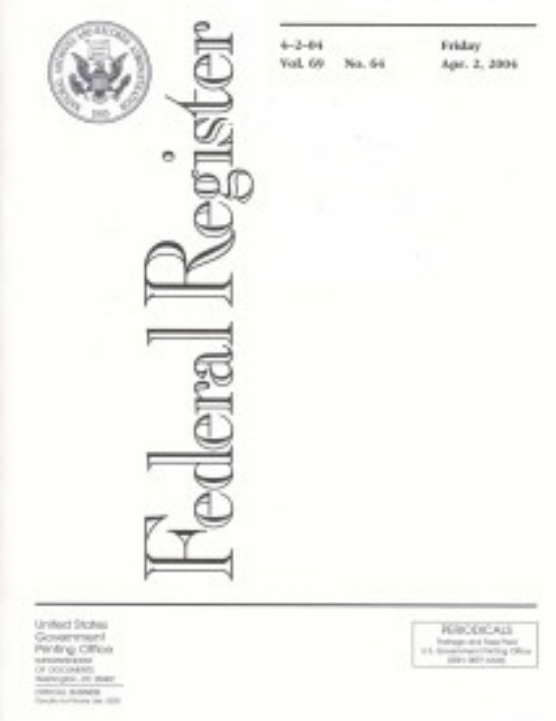

outline the progress of their work. These reports

are collected by the Federal Research in Progress database. Many agencies that conduct research also post their research activity reports on the agency website. For example the National Institutes of Health makes all NIH grant information available online.

\section{Publishing general information for citizens}

The federal government is willing, and in some cases eager, to provide some information to all who seek it. They produce prodigious numbers of publications and websites for general readers. This is especially the case with 
consumer information through the Federal Citizen Information Center at the Publications.USA.gov website.

\section{Serving as an information clearinghouse}

Some information is deemed so important to collect and archive that the federal government fills that purpose. The Education Resources Information Center, the National Technical Information Service and the National Library of Medicine are three such clearinghouses. Each produces its own databases and the information you find there is publicly available to anyone who asks.

State and local government agencies produce similar types of publications - everything from media kits \& news releases to minutes of meetings to newsletters and magazines that focus on state or local issues. Monitoring the offices with which you have regular contact for these types of routine communications is essential for you to keep up with your media assignments.

A comprehensive guide to federal, state and local government publications is at www.usa.gov

\section{International Government Publications}

You occasionally need records from international agencies such as the United Nations, the World Court, or the World Bank; or from regional agencies such as the North Atlantic Treaty Organization (NATO), the North American Free Trade Agreement (NAFTA) Secretariat, or the European Union (EU).

International agencies and commissions meet regularly to deliberate on subjects such as agricultural production, the world's money supply, labor issues, nutrition, disarmament, and trade. Each agency produces information about its decisions and the reasons for its actions.

These agencies also publish periodicals, generate and interpret statistics, and issue news releases about their areas of interest. This material is usually available on the agencies' websites or through their public information offices. Many of these international agency documents are also available in the federal depository libraries that house U.S. government documents. 


\subsection{Private-Sector Institutions}

Private-sector institutions issue massive amounts of information, again some of it in the form of materials that are designed as publications for internal and external audiences. For example, many large companies publish "house organs” or magazines that feature information about the company’s products and services, industry developments, the community activities and "good deeds" the company has done, employee awards and accomplishments and similar types of information.

Publicly-held private-sector institutions (those that sell stock to shareholders) are required to produce annual reports. These publications provide valuable insight into the financial details of a company as well as the values of the company and the concerns it is addressing. These financial reports must also be submitted to the federal government via the Securities and Exchange Commission and then become public records.

Private-sector institutions might make publicly available a white paper or policy document that details the current state and possible avenues for addressing a particular issue affecting their organization. Part of the intention with this publication is to affect policy, influence stakeholders or

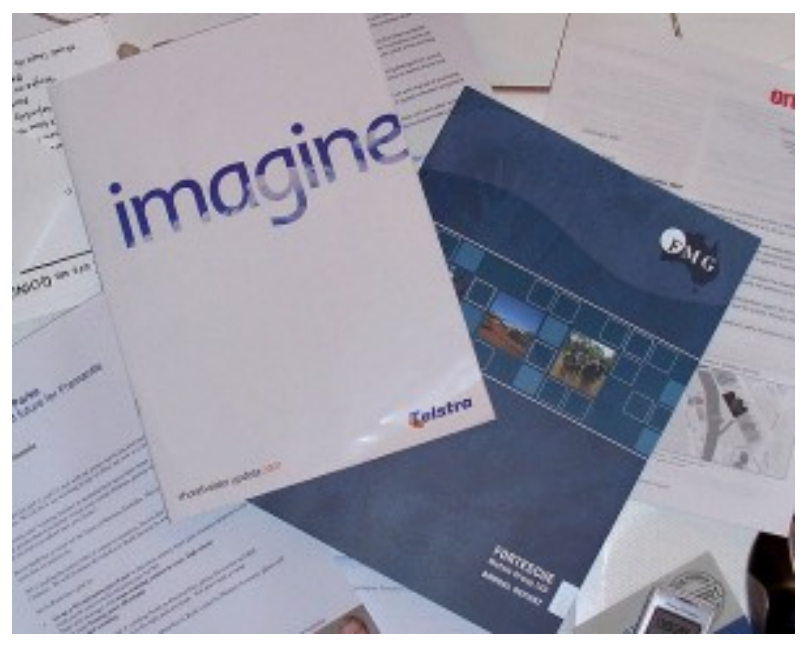

Hourann Bosci - A pile of annual reports - CC BY-SA 2.0 position the institution for more favorable treatment or improved reputation in public opinion.

Another category of publications from private-sector institutions is their promotional materials — product catalogs, media kits, news releases, enthusiast magazines (sometimes called “owned media”) and related publications and digital content intended to be persuasive with customers and journalists.

Private-sector institutions are required to file information about their financial political activities through the Federal Elections Commission, although these publication requirements have been weakened by recent Supreme Court rulings. Nevertheless, private-sector institutions sometimes produce publications about their involvement in political activities even if the data about donations to specific candidates or causes is not available. 


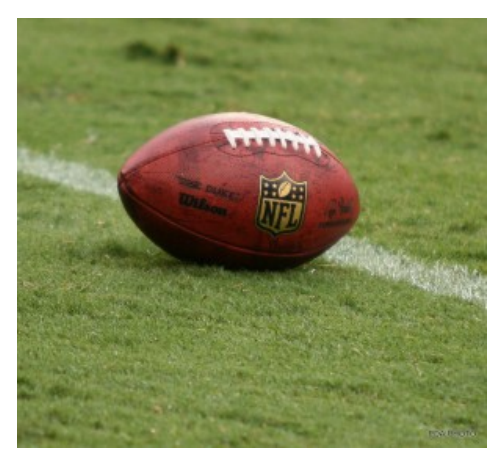

Flickr
Sticking with our NFL example, If you need to find publications produced by the private-sector NFL Players' Association, their website provides access to their "Community News" publication along with many other publications they have issued for and about their members. If you wanted to know what the private-sector NFL itself was doing/saying about the issue, their website would provide access to the League's publications and reports they have issued. The Brain Injury Association of America would be another private-sector institution you might want to tap. As an advocacy organization, they would provide publications and documentation of their activities in trying to influence public policy and raise awareness around brain injuries among government, business and sports leaders. 


\subsection{Scholarly Sources}

The main objective of scholarly sources is to report on new knowledge or experimentation and to share that information with the appropriate specialist audiences. Scholarly journal articles, research reports, conference papers, books, reference guides and the myriad of other formats for scholarly publication delivery reflect this purpose.

Critical to understanding scholarly sources is understanding the peer review process during which the ideas are subjected to close scrutiny by experts in the field who decide whether or not the information is fit to be published and shared with the scholarly audience. Peer review is what distinguishes scholarly publications from journalistic or trade publications where an editor, not a panel of academic peers, determines whether or not something is ready for publication.

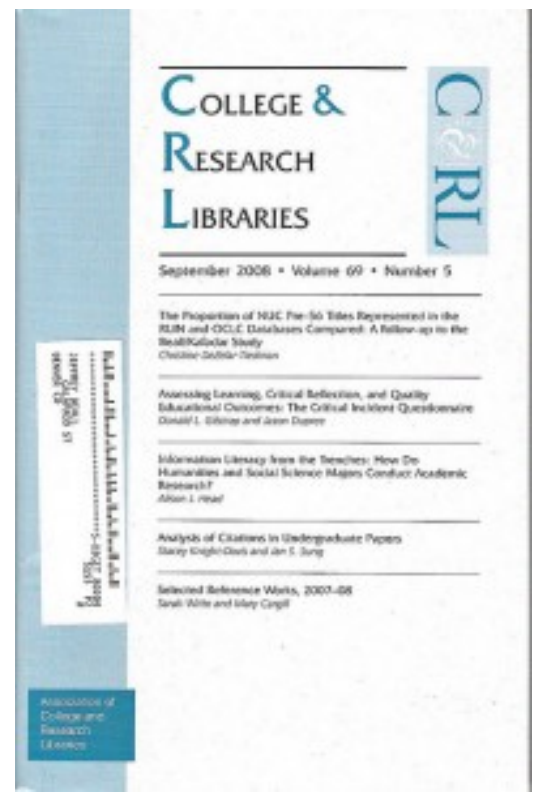

Jeffrey Beall - College and Research Libraries - CC BY-ND 2.0
Scholars use scholarly journals for keeping up with research, to find other scholars doing similar work, and as teaching resources. Most information created by scholars is produced, collected and arranged according to subject areas, or disciplines. Much of the information generated by scholars is published in journals and on websites where the findings are open to scrutiny by other scholars and general readers. These publications are typically found in library collections and can be searched through specialized databases that libraries pay for and make available to users.

If you are looking for authoritative information about a topic or an area of endeavor, chances are there are scholarly publications that have addressed it. For example, EconLit indexes hundreds of the world's major economic journals. A communicator searching in this index will locate information from the top scholars and work that has been fully peer reviewed. Many of the articles included in indexes and abstracts are now available in "full-text" which provides "one-step" access to the articles themselves.

The variety of resources on any given topic can be illustrated in this image 
from the University of Minnesota library web site.

\section{LIBRARIES}

Services -

Seavch > MNCAT Discovery: find books, journals, articles, modia and more.

Resources

Featured Items

COURSE PAGES

Depertment *

Add:

Go

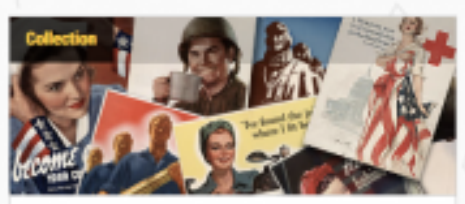

DATABASES

War Posters Collection

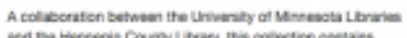

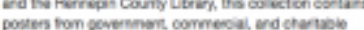

By subject

Academic Seaveh Premier

Business Souree Promier

Googin Schols

STIOR

MCAOMEDEX

MeA int Bblograpty

Pyyeinfo

Publued | Ond Medine

What of Scienoe

RESEARCHER \& INSTAUCTOR SUPPOAT

Coppright | Meda Sarvices

aLarring Support

Oxa Managemem

U of M Digital Conservancy

Course Reserves

On the homepage there is a directory of "Databases" organized by title of the index or tool. Or you can search for a database by the topic of your information need. So for your search on information about football brain injuries, you could use the pull-down menu to search for the databases that would lead you to scholarly publications in the Health Sciences.

This would help you locate the scholars who have been producing authoritative published research on the topic for a number of years. Your report would be incomplete without including such findings, along with interviews with the researchers who conducted the studies. 


\subsection{Journalistic Sources}

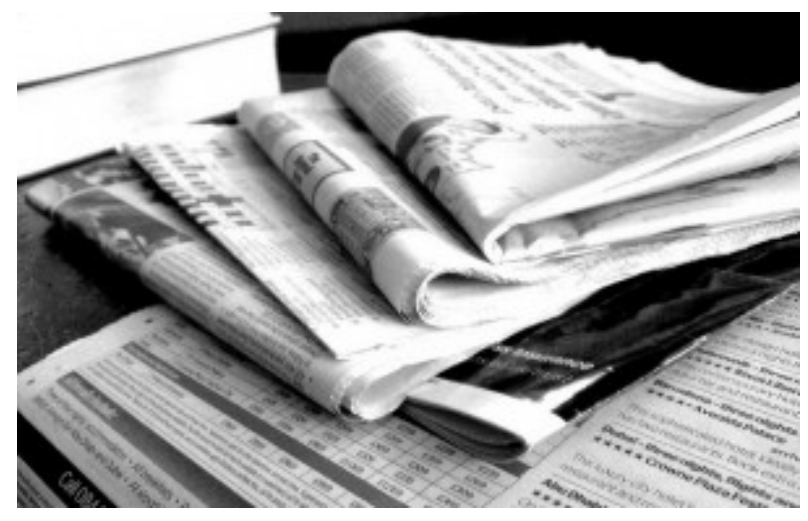

Jon S-Newspapers B\&W-CC BY 2.0
These are probably the most familiar types of publications for the general audience. The news magazines, websites, blogs and related types of publications provide access to hundreds of thousands of reports on an unimaginable number of topics and issues. No competent information strategy can ignore these types of publications. So for your information task about football player head injuries, reports published in journalistic sources would be widely available.

Journalistic sources also produce publications for their advertisers. Media kits, promotional documents and advertising rate sheets help advertisers decide whether

they should place an ad in a particular journalistic publication or on its website or mobile publication. These are considered business-to-business publications and are not widely available to the general public the way the media organization's news reports are. They would also fall into the category of "private sector" contributed information since the purpose is promotion of the business rather than the journalistic mission that news stories have. 


\subsection{Informal Sources}

Informal sources may produce publications in the form of blogs, personal websites, and related "non-official" documents. For example, a retired professional football player may produce a blog about his health challenges since retirement, and some of that information may be related to head injuries. These sorts of informal publications would provide insight into individual experiences, but you would need to supplement these publications with information from more formal sources before including any of it in a media message.

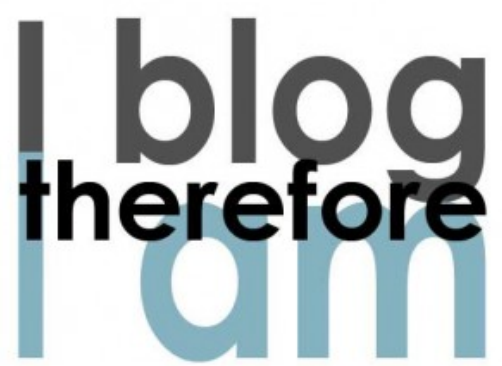

alamodestuff - I blog ...-CC $B Y-N C-N D 2.0$ 


\subsection{Popular, Scholarly, Trade Periodicals}

One of the specific types of publications your search may uncover are articles that have appeared in periodical publications. A "periodical” is a publication that

appears at regular intervals. Most of the time, the term periodical refers to things such as magazines, newsletters, journals, gazettes and similar types of publications in print or in digital form.

If you are using material that appeared in a periodical publication you need to recognize the distinctions between a popular periodical, a scholarly periodical or a trade periodical. These three types of periodicals have vastly different audiences, purposes and means for generating information.

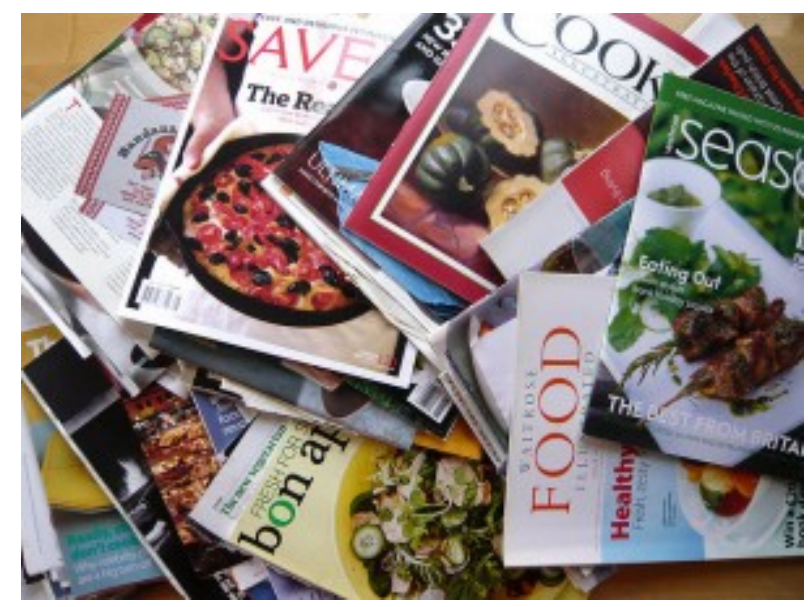

Popular periodicals roughly correspond to "Journalistic Jessica Spengler-Magazines - CC BY 2.0 Sources" on the information strategy model. Scholarly sources are self-evident on the model. Trade sources roughly correspond to "Private-Sector Institutional Sources" on the model. As an information searcher, you need to understand these distinctions and know what they mean for your information search. 


\subsection{Popular Periodicals (aka "magazines")}

\section{Characteristics that help you identify a periodical as popular:}

- Tend to have short articles (1-5 pages)

- Cover a variety of topic/subject areas (Time, The New Yorker, National Review). Conversely, they may cover a single subject area - Sports Illustrated or Audubon are good examples - with the intention of informing or entertaining the readership

- Have articles that do not contain a bibliography or a cited reference page. The reader cannot check the author's information by tracking down and reading the original information source

- Are intended for a non-academic, nonspecialized audience

- Use conventional/conversational language, as opposed to a specialized vocabulary

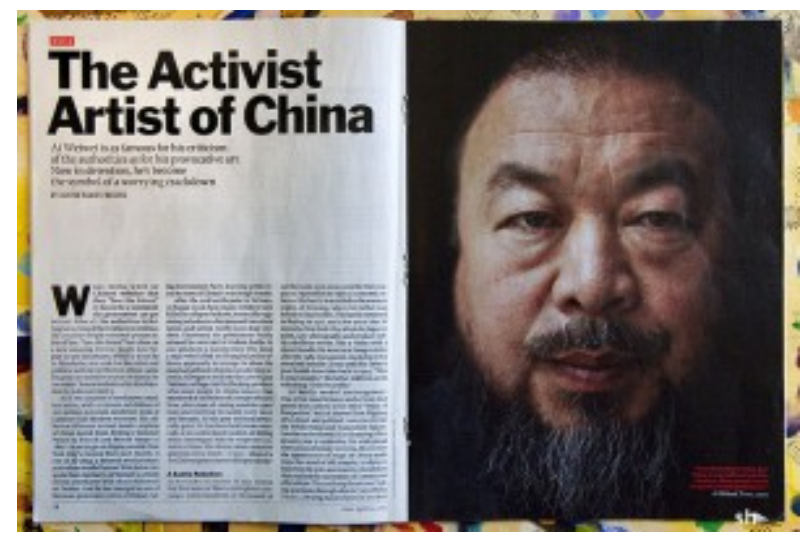

- Contain articles written by journalists, rather than researchers or specialists in a given field

- Contain articles often accompanied by photographs or other illustrations

- Contain extensive commercial advertising

- Are issued frequently (i.e., come out weekly, biweekly or monthly)

Finding popular periodical articles is no longer a challenge for most information gatherers. There are hundreds of database resources that help you locate articles that have appeared in print and digital news sources. The larger challenge is to evaluate the appropriateness and trustworthiness of the search tool you use, and to understand what you are and are not searching when you use one of them.

A few of the most useful search tools include Google News, Lexis/Nexis, Factiva, ProQuest Newsstand and the social media search tools that allow you to track news stories through the Twitter-verse and related platforms. Remember, too, that if you are just looking for information from a specific publication, going to that publication's website and searching within their archive will be the most specific route. Again, your strategy for locating information will depend on what it is you are trying to accomplish. 


\subsection{Scholarly Periodicals (aka "Journals")}

\section{Characteristics that help you identify a periodical as scholarly:}

- Often contain lengthy articles (five to fifty pages)

- Generally confine the subject matter to a single, very specific aspect of a subject area (e.g., music theory, European political science, film studies, language development)

- Contain articles with footnotes or cited reference pages. The cited references allow the reader to consult

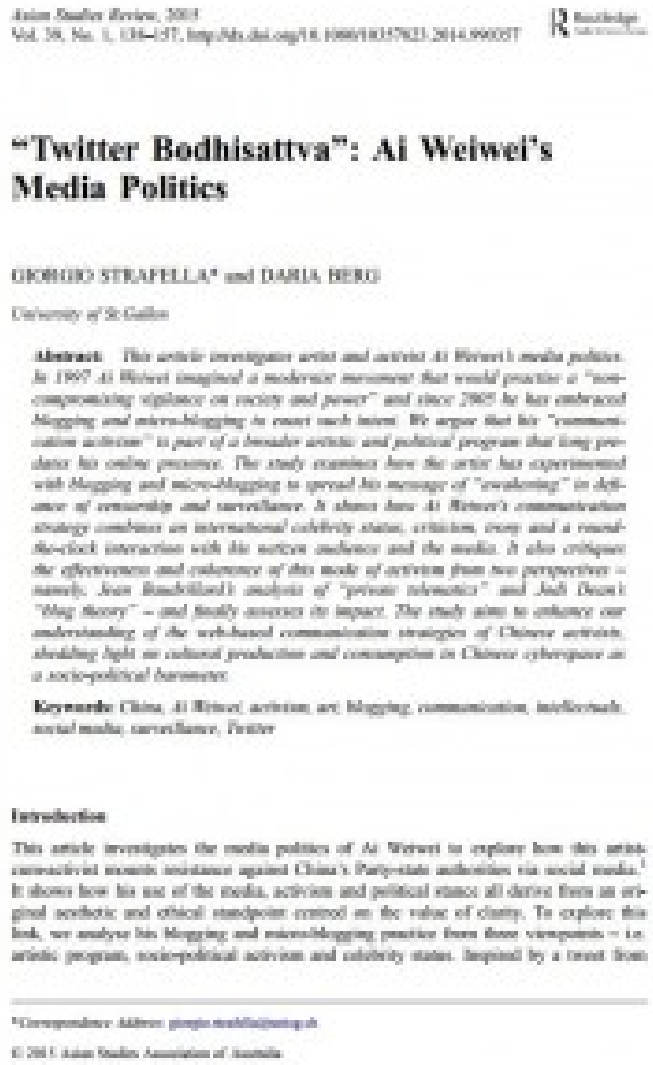

the same material that the author used in

- Are intended for an academic or scholarly audience

- Use technical or specialized vocabulary

- Publish articles written by academics, specialists or researchers in the field (as opposed to articles written by journalists reporting on or synthesizing research)

- Often publish reviews of the literature 
- Often include articles with charts or tables: news photos and other types of graphics are not often used, save in the case of articles on visual subjects, such as art, design or architecture

- Are often produced under the editorial supervision of a professional association (e.g., Journal of the American Medical Association) or by a scholarly press (e.g., Elsevier, Pergamon)

- Contain little or no advertising

- Are issued less frequently than popular or trade periodicals

Again, hundreds of databases help the searcher locate articles in scholarly periodicals. A few of the most valuable include Academic Search Premier, Google Scholar, JSTOR, and Web of Science. Also, an individual scholar may provide links to the articles s/he has produced on a personal or institutional website, and the journals themselves may offer a searchable archive, although there is almost always a charge involved in getting access to a specific article from the journal's own archive. 


\subsection{Trade Periodicals}

\section{Characteristics that can identify a periodical as Trade:}

- Geared towards very specific audiences, usually managers or administrators in business, finance, and

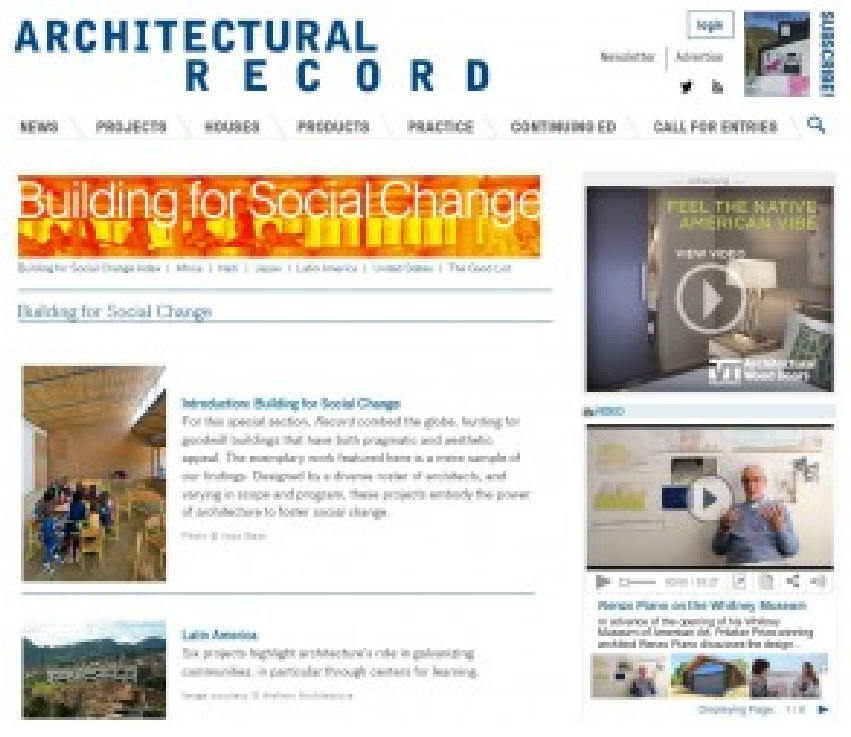

- Issued weekly or monthly to take advantage of fast-breaking changes in products or technology

- Often contain regular columns of news and commentary, as well as lengthier articles about current issues and trends of interest to people in the field

- May be written by specialists or journalists. Examples of better known trade periodicals include Beverage Industry, U.S. Banker, Progressive Farmer, Museums Journal, and Aviation Week \& Space Technology

Articles in trade periodicals may be a bit more difficult to find since many of these publications are not indexed by the tools found in library collections. However, some databases that can be helpful include Business Source Premier, Lexis/Nexis and ProQuest Newsstand.

Of course, the websites of the industry associations themselves may offer archives of their trade periodical with a searchable database of past articles. This is obviously a first-stop for any searcher trying to locate trade periodical articles. 


\subsection{Grey Areas}

There are always grey areas with respect to pinning down what is a popular, scholarly or trade periodical. Titles like Harpers, Atlantic Monthly, Parabola, and Science contain sophisticated writing, footnoted articles, and authors that hold advanced degrees. At the same time, they display advertisements; have regular columns, photos, and brief articles; and are published by large media conglomerates.

If you are concerned about whether the article you want to use falls within a particular category, look for a bibliography, or lack of one, at the end of the article. Also, look for a brief biography of the author, either at the beginning of the article, or at the end of the publication, for information about the author's education and/ or institutional affiliation. Most scholarly publications will identify the department and college, university or research lab where the author works.

You can also look at the masthead of the publication for the name of the editor or the members of the editorial board to see if you recognize the "perspective" of those responsible for publishing the material. You might also check the reference tool Ulrich's Periodical Directory which indicates the type of magazine. Academic Search Premiere provides icons next to each entry that indicates which type of periodical it is (and you can filter for information from specific types of publications.)

If you still have questions about what type of publication you have selected, talk with a reference librarian or your instructor.

Understanding the type of periodical in which information appeared can help you determine whether the material is appropriate for your message and your audience. Trade periodicals typically represent a point of view which you will need to decode; scholarly periodicals publish articles that will require some "translation" for a general audience; popular periodicals reflect the "hot" topics of the day but are usually superficial in their treatment of the subject. All of these categorizations help you become an astute information evaluator. 


\section{Lesson 13. Information Resources: Public Records}

\section{KEY CONCEPTS}

- Public records are created by public-sector institutions funded by public monies.

- Public sector institutions generate abundant information about themselves and their activities.

- Public sector institutions collect, generate and/or make available information about many other organizations, institutions and individuals in the private sector.

- Information from public sector institutions is deemed publicly available by law in most circumstances, and the people who work for those institutions are public servants obligated to provide information to those who request it.

\section{LEARNING OUTCOMES}

After completing this lesson you will be able to:

- understand the information-generation patterns of public-sector institutions.

- apply appropriate methods and tools in locating public records of all sorts.

- think critically and creatively about agencies or government sectors likely to generate certain kinds of information.

- evaluate the information found in public records.

\section{Overview}

- Did the truck driver that caused the 10 car pile-up have a clean driving record?

- Has he been convicted of drunk driving in the past?

- Are there any issues with the company that he works for?

- Who is the owner of the car with license plate $\mathrm{XXX}^{* * *}$ that was part of the pile-up?

- What about the truck - have there been any recalls of that vehicle that might indicate safety problems?

- How many multi-car accidents are there in a year?

- What's the incident level for this stretch of the highway where it happened?

- What about the hospital where the victims were taken - have there been any complaints or issues with their emergency room? 
Every one of these questions can be answered with information found in public records generated by public sector institutions. These are the kinds of questions that might be asked, and need to be answered, depending on the coverage a journalist might undertake.

In the strategic communications context, there is a need to do due diligence on new clients. For example, if a chain of nursing homes wants your agency to help them with a new advertising campaign you would want to check public records to discover if there have been any issues with regulators you should be aware of. Has the chain of nursing homes been fined for safety violations? Have the health providers been sanctioned or have any of them lost their licenses? If the chain is a publicly-held company, what is the financial health of the company — can they pay your fee? Public records can help background an issue for the public relations professional helping a client deal with crisis communications.

Minnesota defines public records as "all data collected, created, received, maintained or disseminated by any government entity regardless of its physical form, storage media or conditions of use.”

As you can imagine, the types of data collected by any individual agency in the conducting of its public work is overwhelming to think about. The challenge for researchers when using public records to fulfill information tasks is locating the likely local / state / federal agencies that would oversee or conduct business related to the topic being covered. 


\subsection{Public Records and Information Contributors}

While the actual "public records" are, by definition, those documents and materials generated by public sector institutions, the other contributors of information have important roles to play in helping you understand and use public records. Here are some key facts to understand about public records and information contributors:

- Public-sector institutions that generate public records include:

- municipal and county governments

- state government

- federal government

- international agencies

- Private-sector institutions generate much of the information that becomes a matter of public record once it is submitted to public-sector institutions. For instance, non-profit organizations must submit financial information to the IRS, which then becomes publicly available. Private-sector institutions such as businesses that sell stock to shareholders must submit financial information to the Securities and Exchange Commission (a public-sector government agency) which then becomes public.

- Scholarly sources generate information that becomes a matter of public record once submitted to public-sector agencies. For example, if a scholar is conducting research that is funded by a grant from a national agency (the National Institutes of Health, the Department of Transportation, etc.), the scholar and his/her institution must file information about how that money is being allocated, and that report becomes a public record. Public universities must reveal information about their financial circumstances to legislatures and other agencies that oversee those institutions and again, that information is considered public.

- Journalistic sources gather huge amounts of information from public records and publish that information or prepare news reports, analyses, documentaries or databases based on what they collect. They often provide easier-to-use interfaces for searching public records than the agencies that generate the information.

- Informal sources are the subject of huge amounts of public record data. Every person leaves a public record trail that we will explore in more detail as we move forward. 


\subsection{Nature of Public Record Information}

Public-sector institutions are primarily responsible for gathering public-record information from other sources and for generating public-record information themselves. Each piece of information collected or produced by a publicsector institution has either a public or a private character. By definition, some information must be public. The clearest example is laws. Obviously, laws enacted by legislatures, signed by executives and interpreted by courts cannot be obeyed unless they are made public.

Conversely, some information has little or no significant public character. For example, public clinics treat patients who have no way to pay their own medical bills, but these patients' medical records are considered private even though they receive care at public expense. In this case, privacy laws trump public records access requirements.

Although you cannot find the health records of individuals, that medical information is aggregated into data and statistics that monitor the state of public health at all levels of government. In each local community, contagious diseases and causes of death are recorded, tabulated and analyzed. Thus you have access to government-produced documentation about public health matters in the community, the state and the nation even though individual medical records are private.

Since it is impossible to commit to memory all the sources of governmental information, you have to learn how governments operate, how they produce information, and what portion of the information is available in public records, documents and publications.

In addition to general background on governmental operations, it is useful to maintain a file of material that is specific to your local area. Such a file should include organization charts of municipal and county governments; state government organization charts; the state versions of the Freedom of Information Act, open meetings and privacy laws; and contact information or web browser bookmarks for the public sector institutions you deal with most often. 


\subsection{Types of Public Records}

As we've already discussed, institutions generate information for a wide variety of purposes, and these types of public records generally fall into some identifiable categories.

\section{Vital statistics}

Governments at all levels generate statistics to administer government programs, allocate government funding, and communicate with the public. For example, the federal census of population is one of the most well-known examples of government statistics, but there are thousands of other sources of government-generated statistics on almost any topic imaginable. Cities, counties and states generate statistics that reflect births, deaths, property ownership, tax payments, communicable diseases being reported, voter registration rolls, military service, and many other aspects of life in those communities.

\section{Evaluation reports}

The federal Government Accountability Office and individual state auditors' offices do countless investigations on the efficiency and effectiveness of government programs. They issue reports that would be otherwise prohibitively expensive for news organizations and political parties or candidates to undertake. These reports are usually designed to be "neutral" in their approach, seeking to simply provide accurate oversight and evaluation of sometimes very expensive government activities.

\section{Laws and regulations}

As we've mentioned, individuals and organizations cannot comply with laws and regulations if they don't know what those statutes say. The process of legislating and rule-making is generally open to public scrutiny and the final or end result of the process is the publication of the laws and regulations that have been written, passed by the legislative branch and signed into law by the executive branch or enacted by the regulatory agency. Records about compliance with said laws and regulations are also public. So, for instance, the records collected by the Pollution Control Agency about a company's compliance (or non-compliance) with regulations about chemical discharges into the local rivers and lakes are a matter of public record.

\section{Court proceedings}

One of the reasons that the U.S. legal system is generally respected at home and abroad is that courts conduct their business under public scrutiny. If an individual or an institution is brought before a judge, with very few exceptions, that court appearance and any subsequent civil or criminal charges are a matter of public record. Unless specifically sealed by a judge, the names of all witnesses, descriptions of all evidence and transcripts of all proceedings are part of the public documentation of court activities.

\section{Criminal justice records}

Again, the local, state and federal agencies responsible for policing society do their work under the public's 
watchful eye. Arrest records are public - individuals do not disappear into the jail or prison system in the middle of the night with no record of why or where they were taken. Jail logs must be made accessible to the public by local and county officials. Logs of calls for police service are available as well. If a squad car is dispatched to a particular address because of a call for help, that is a matter of public record. When certain types of convicted criminals are released back into the community (sex offenders, for instance), there are public records about their living arrangements and the type of supervision they are under.

\section{Political campaign finance records}

While there have been several significant Supreme Court rulings in the last several years that have damaged the transparency of public record information about where campaign funds originate, cities/counties, states and the federal government still gather information about political donations to candidates for public office and make those records available to the public. The Federal Elections Commission, for instance, generates enormous databases of campaign contribution information that can be searched in many different ways.

\section{Institutional financial information}

For-profit and non-profit institutions in the private sector and all public-sector institutions generate information about their financial activities. Again, the U.S. system of commerce is considered a model for the world because of the transparency of these institutions' financial doings. Government agencies such as the Internal Revenue Service or the Securities and Exchange Commission and independent agencies such as the Federal Deposit Insurance Corporation oversee the financial records of thousands of institutions and organizations and in most cases, these are public records.

\section{Licenses}

One of the ways that governments generate revenue is by issuing licenses. Almost every kind of enterprise or profession requires a license. The list of licenses required in the state of Minnesota gives you a sense of how wide ranging they are: http://mn.gov/elicense/ 


\subsection{Public Records about Individuals}

Let's look at some of the types of records that are generated about you that are, by federal, state and local law, considered "public" - that is, anyone can have access to these records with a simple request to the appropriate authority. These records are collected and maintained by public-sector institutions such as government agencies or licensing boards.

- When you are born, there is a birth certificate registered.

- If you have a license to drive or hunt; own a gun or a pet; operate a boat or airplane; sell liquor or dispense prescription drugs; operate a restaurant or beauty parlor; work as a health-care provider or interior designer; or any of hundreds of other types of licensed activities, you generate a public record.

- If you served in the military, there is a record of your military service and discharge.

- When you are married the marriage license becomes a public record.

- When you have or adopt children, their births and school registrations are recorded.

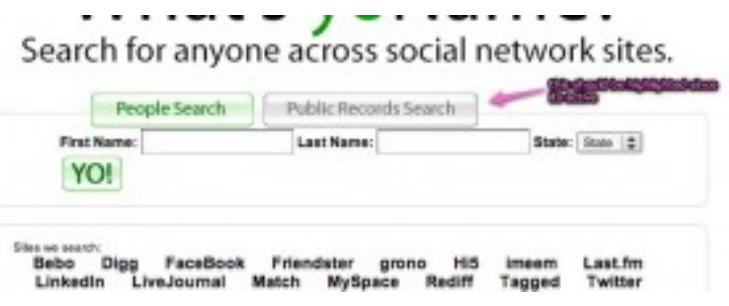

- If you register to vote, there is a record in the state voter registration files, along with a record

Brandon Titus - CC BY-NC-ND 2.0 of whether or not you voted in previous elections.

- If you give money to a political candidate, there is a record of the amount you gave and who received the campaign contribution.

- If you divorce, there is a public record of the terms of settlement.

- If you own property, there are records with a description of the property and how much you pay in property taxes.

- If you are arrested, there is an arrest record and if you spend time in jail there is a log of your stay there.

- If you go bankrupt, there is a court bankruptcy filing that details the financial arrangements to which you and your debtors have agreed.

- If you go to civil or criminal court for any reason, as defendant or plaintiff, there is a court record.

- If you get injured working for a public agency your worker's compensation claim is public. 
- When you die, there is a record of the death. If you failed to leave a will, the probate court records about the dispersal of your earthly goods are public.

All of this means that public records are extremely valuable information sources about individuals. News professionals need to conduct background checks on people in the news. Strategic communications professionals need to conduct research about their clients to see if they can pay the bills or if they have image or licensing problems. We will discuss some of the search tools to help locate public record information later in this lesson. 


\subsection{Public Records Laws}

Communicators should familiarize themselves with the federal and state laws that govern access to public records in their communities. Public records laws help ensure that citizens (and communicators) have access to the workings of the government. There are three aspects of public records laws: what records you can request, requirements that government conduct their business openly, and that citizens can see what has been recorded about them in public records.

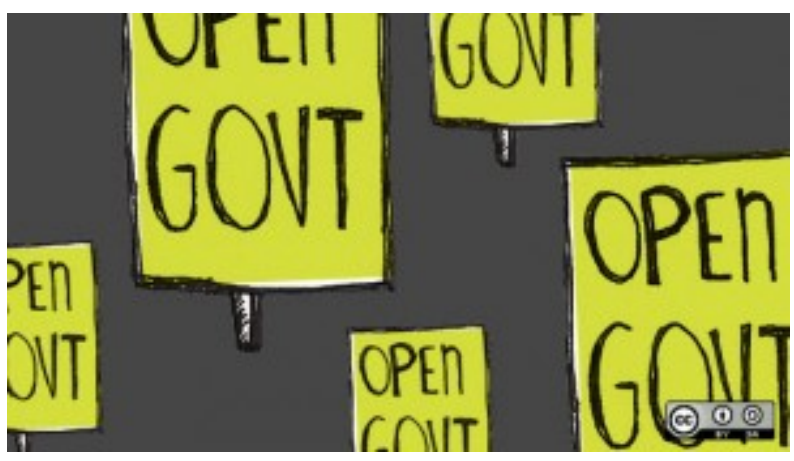

OpenSource.com: CC BY-SA 2.0 


\subsection{What You Can Request}

At the federal level, the Freedom of Information Act (FOIA), passed in 1966 and amended multiple times over the years, ensures that individuals may have access to information generated by all executive branch departments, agencies and offices of the U.S. federal government. The law does not cover information generated by Congress or by the federal judiciary, however.

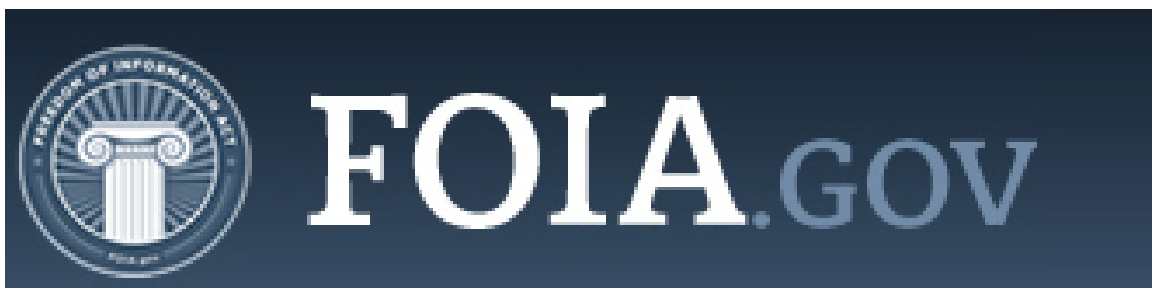

However, some provisions of the USA Patriot Act passed shortly after the terrorist attacks on the U.S. in 2001 and reauthorized in 2011 reversed some rights afforded by the FOIA so it may not be possible to get some things that once were available under the original law, depending on circumstances that are particular to your information search.

Requests for information under FOIA provisions must be specific enough that the agency can identify what the information seeker is requesting. The FOIA identifies nine exemptions designed to safeguard national security, trade secrets, law-enforcement investigations, foreign-policy actions, and privacy rights of government officials, along with geological information about the location of oil wells! All states have their own versions of the FOIA that spell out access to state government records.

So, for example, under FOIA statutes, you cannot ask for the personal health records of the current Chief of Staff of the U.S. Army. As an official in the executive branch of the U.S. government (Department of Defense), his personal health records are protected by one of the FOIA exemptions for privacy rights of government officials. But under FOIA statutes, you can request the name, service number, rank, dates of service, awards and decorations, city/town and state of the last known address for any veteran who served in the U.S. military, including the Chief of Staff. If a veteran is deceased, you can also get the place of birth, geographical location of death and the place of burial. All of this information about that individual is available to anyone who requests it and releasing it to requesters is not considered a violation of the veteran's or the veteran's family's privacy. 


\subsection{Open Meetings}

Another federal law, the Government in the Sunshine Act, provides for open meetings of any federal executive branch commission, committee or other "collegial" body. Among the agencies covered are the Securities and Exchange Commission, the Federal Communications Commission and the Federal Trade Commission. Agencies are expected to announce scheduled meetings one week in advance and to publish meeting agendas so that interested persons may attend. All states have their own versions of open meetings laws, as well. Again, provisions of the 2001 USA Patriot Act limited aspects of the Government in the Sunshine Act to restrict access to some government meetings. 


\subsection{Privacy and Public Records}

Federal, state and local agencies ARE aware of privacy concerns, however. The privacy issue is governed by the federal Privacy Act, passed in 1974 and amended multiple times since. The Privacy Act is intended to give individuals some control over the personal information that is collected by the executive branch agencies of the federal government. The act guarantees three rights: the right of individuals to see files about themselves, to correct any wrong information and the right of individuals to sue the government for permitting others to see information about them without their permission. Most states also have a version of the Privacy Act that covers state records about individuals. Again though, the USA Patriot Act now severely limits citizen rights under the Privacy Act.

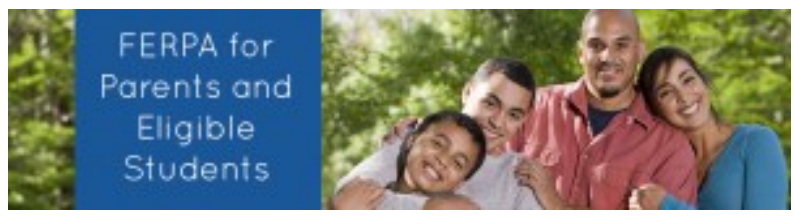

So, for instance, you can request to see the records that the U.S. Department of Education has about you as part of its National Student Loan Data System. However, you could NOT request access to another person's data in that same system without legal authority of some type (usually not something a communications professional would have).

Your ability to collect information from public agencies is affected by these laws, along with a large number of other statutes and regulations governing electronic information gathering, "hacking," credit-reporting services, electronic fund transfers, and a growing number of "homeland security” orders, laws, decrees and regulations. 


\subsection{Court Records and Legal Information}

As we've mentioned, court records are public documents. If you remember your grade school civics class lessons, you will recall that there are three bodies that can issue laws and regulations.

1. Legislatures create statutory law by passing bills that become law when signed by the executive.

2. Administrative agencies create administrative law, consisting of rules and regulations issued by each agency (for example, the Environmental Protection Agency at the federal level issues regulations concerning disposal of hazardous wastes).

3. The judicial branch of government issues case law, which is found in the court decisions written by judges or justices of the court system.

Sometimes you may have to find an actual legal decision or regulation for your message. Sometimes you may be able to suffice with an interpretation or "brief" of that statute or regulation as prepared by experts whose job is to comment on the law. In any case, there are certain characteristics of legal and court record information that you must be familiar with before attempting to search for a specific topic or case.

Federal statutory, administrative and case law applies to every state jurisdiction, court and agency in the country. These laws are collected, organized and made accessible through a well-established system of legal indexes, finding tools called "reporters" and databases.

Within the federal court system, there are three levels of courts performing different functions and writing different kinds of laws. These three levels are the trial level, the intermediate appellate level and the final appellate level. Each level generates information that is collected and made accessible through a series of indexes, reporters and databases.

In addition, the Supreme Court began issuing rulings digitally minutes after the decisions were announced starting with the 1990 session. Each of these tools will help you locate the decisions of the Court with the verbatim wording of the Court's opinion, along with the facts of the case, the names of the lawyers who argued the case before the Court, other legal decisions that were referred to by the justices in reaching their decisions, and any dissenting or minority opinions.

Courts at the state level also write decisions that affect state legal activities. Decisions of state courts are collected in a series of state reporters, many of which are published by the West Publishing Company. Each state has at least one official high-court reporter; some states have separate reporters for the appellate courts; and a few states have reporters for the trial courts.

Two online database services provide extensive access to all of the types of information we've mentioned in this section, and to the hundreds of legal periodicals and law journals that provide commentary on legal decisionmaking.

Westlaw and LexisNexis are the premiere resources for online access to the actual texts of decisions, regulations, 
statutes and legal documents. In addition, they provide indexing and in many cases full texts of the articles that are published in journals and magazines by legal scholars, lawyers, law students and commentators about all aspects of law and legal decision making.

A good website for locating legal information is FindLaw, which helps locate the websites of courts at all levels, along with many other legal resources.

Once you understand the relationship between government organizations and the legal research sources that correspond to each area, finding the actual court opinions at any level should be fairly straightforward. However, doing legal research is not for the novice information searcher.

All law libraries have legal reference librarians who can help you locate the actual legal opinions that often serve as the subjects of news, commentary and social furor. Most media organizations have a legal counsel who helps professionals make day-to-day decisions about the legality of certain kinds of messages and activities.

The legal information search tools mentioned here are really for the communicator who has to understand the atmosphere in which certain public-policy decisions are being made and who has to be able to independently locate and interpret information that the public might need to make informed decisions. 


\subsection{Locating Public Records Information}

There is no master index of public records available online, on the web or in print. However, there are a number of fee-based services that provide access to public records electronically, and a number of websites provide links to some of the free public records sites you might tap.

Accurint ${ }^{\circledR}$ is a LexisNexis service that provides one-stop shopping for public records and is widely used in news libraries. AutoTrackXP is a ChoicePoint company that combines public records with consumer profile information. SearchSystems.net and NETRonline are two web-based sites that provide links to free public records databases.

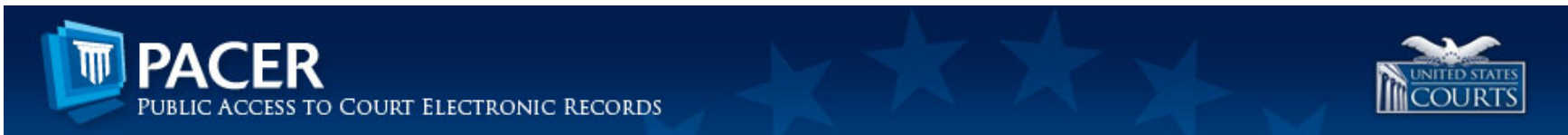

Most U.S. county, state and federal jurisdictions now provide digital services to search for court records. Again, SearchSystems.net and NETRonline provide links to the databases of court records that are available in any county and state jurisdiction. PACER (Public Access to Court Electronic Records) (http://www.pacer.gov/) provides access to records from federal appellate, district and bankruptcy courts.

Specific alert or filter services also help you monitor the institutions that generate public records, including those from USA.gov and StateNet.com

Because the staff in the offices and agencies of the U.S. federal government are concerned about maintaining their credibility, the government has developed a tool that allows you to verify that a social media site purporting to be from a government agency or official is legitimate. Produced by USA.gov, the U.S. Digital Registry site allows you to verify accounts managed by federal agencies, elected officials, heads of agencies or members of the President's Cabinet.

Recall also the tools and resources we discussed in Lesson 12 that help you locate publications from the institutions that generate public record information. 


\subsection{Evaluating Public Record Information}

While the government / public sector is sometimes considered one of the most credible of the information contributors because it is beholden to the public for its operation (and overseen by the "watchdog" media) the information generated is not entirely without an agenda. Communications from the agency charged with overseeing environmental quality will have a vested interest in presenting the information with an eye to supporting the environment and may not present all sides of the situation.

As with anything that is done with human input there is a likelihood of error in public record information. Delays in the entry of information into databases, misspellings or misinterpretation of information from hand-written documents, can jeopardize the integrity of the public records found in a search (or not able to be found because of errors.) The mantra with searching public records is, “Just because you don't find something does not necessarily mean there is nothing there.” As with any piece of information that is critical to your message, second-sourcing or using what you have found as a first step in further investigation is important. 


\section{Lesson 14. Information Resources: Data and Statistics}

\section{KEY CONCEPTS}

- Data and statistics are collected by different types of information contributors for different sorts of purposes.

- Communicators must be able to identify likely gatherers of data and know how to access and analyze the data.

- Big Data is a term being used for the massive amounts of information gathered about audience behavior, spending and media use as well as other huge collections of data.

- Statistics are generated from collections of data and are used to answer questions such as "how much" or "how many."

- Audience data sets comprise a large amount of material essential to communicators.

- Numeracy skills, as with information literacy skills, are essential to communicators when evaluating statistics.

- It is important to avoid the problems with statistical interpretation that can lead to misstatements about the significance of data.

\section{LEARNING OUTCOMES}

\section{After completing this lesson you'll be able to:}

- understand how and why different types of information contributors collect data or generate and publish statistics.

- understand when and how data and statistics can aid in the creation of messages.

- identify some of the audience data sources useful for messages.

- understand and apply basic numeracy skills.

- evaluate the statistical interpretation of data to assess their validity.

\section{Overview}

What do we mean by data? There are many different definitions, but a typical one refers to data as facts or information used to calculate, analyze or plan something and used as a basis for reasoning, discussion or processing. Many times, a computer is involved when the term data is used, but that isn't a necessary condition for the term's use.

In many cases, the data sets most useful for a communicator require statistical analysis. While most 
communicators are more comfortable working with words than with numbers, it is incumbent upon you to be sure your statistical evaluation skills are sharp enough to perform the basic types of analyses of data and to know when you need to defer to an expert.

"Data journalism" has been an important development over the past two decades as the potential to analyze large sets of data to find and tell stories has changed the tools of reporting. The ability to analyze crime data to find trends or to map the impact of crime in different parts of a city lets journalists initiate investigations without waiting for some agency or association to provide data.

For strategic communicators, the questions that can be answered about consumers, or the analysis that independent examination of data can provide about industry issues can help them provide more thorough, targeted and credible messages. 


\subsection{Big Data}

It is difficult to talk about communicators' use of data without quickly hearing the term "big data." According to Wikipedia, "Big data usually includes data sets with sizes beyond the ability of commonly used software tools to capture, curate, manage, and process the data within a tolerable elapsed time...”

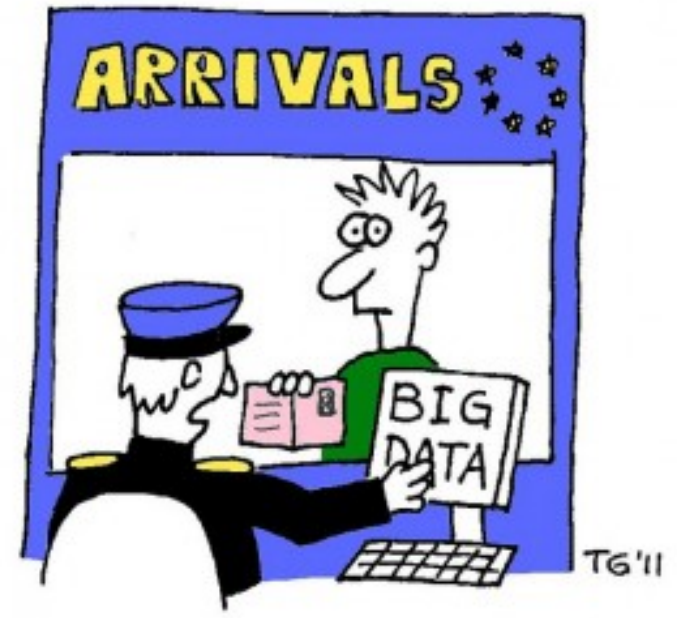

"Your recent Amazon purchases, Tweet score and location history makes you $23.5 \%$ welcome here."

Thierry Gregorius - Big Data - CC BY 2.0

communications purposes.
Any organization with a web and mobile site presence has the capacity to gather mind-boggling amounts of data about the second-by-second activities taking place on those platforms. The challenge is to figure out what to do with all of that data and how to use that information in a reasonable way to improve the work communications professionals are doing.

Private-sector institutions such as Google, Facebook and Amazon are collecting "big data" about everything their customers and users are doing, saying, sharing, buying, liking and more. These "big data" practices are the subject of considerable attention and concern as they have the potential to create an individual profile of anyone who uses a site for any purpose whatsoever, many times without that person's knowledge or consent. This is an ongoing area of legal and ethical debate and communicators need to stay current on the most recent rules and regulations about use of "big data" for

Let's look at each of the contributors of data to understand what they create, how it gets used and how they make their data available for your uses. 


\subsection{Public-Sector Institutions' Data}

Public sector institutional sources gather, generate and use data for a wide number of purposes. Government agencies collect data about the economic health of the nation or the community; the production of goods and services; the health of the food supply. As we learned from recent news reports, one particular U.S. federal government agency has been (mostly illegally) collecting data on billions of phone calls, texts and email messages coming in and going out of the country.

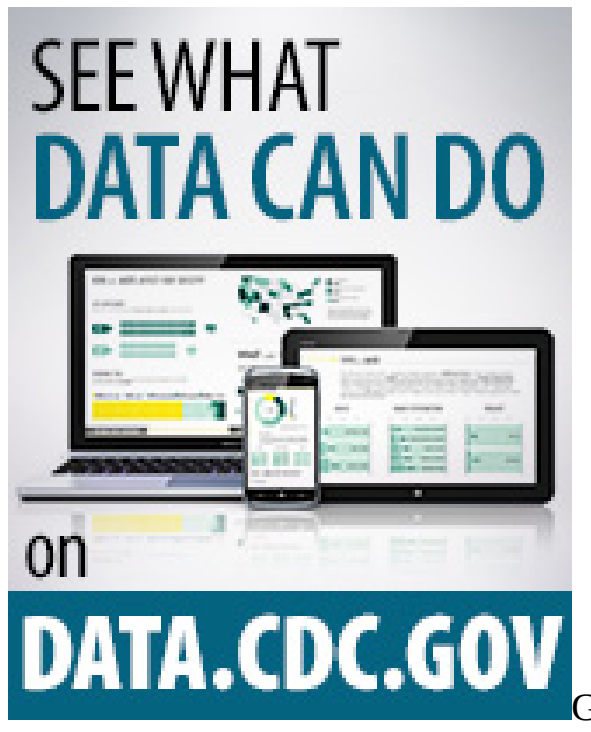

Government agencies at all levels collect data about individuals, organizations, and activities in order to allocate funds, administer justice and legislate/regulate. One of the key "information functions" of the U.S. federal government is to collect and produce statistics about the population (the decennial Census of Population), business, labor, trade, agriculture, education, crime, defense and myriad other topics.

State governments generate data about the same sorts of topics as they relate to a particular state's interests. For instance, a state that depends on growing corn for much of its economic prosperity will collect and generate different types of data than one that depends on mining iron ore or coal. These data will be collected and generated for economic purposes, for the purpose of regulation/legislation, and for a variety of other purposes that meet the state's need for information. These data are also generally accessible to the public, including communicators, because they are generated at public expense.

Local governments at the city and county level also collect and generate data. Again, much of this material is necessary for the smooth functioning of the government agencies themselves, but the data are also available to the public.

Let's look at some of the specific types of data you can find.

\section{- Local and municipal governments}


- may subject institutions to inspections by the county food-service inspection agency or related public safety watchdogs

- issue contracts for service from for-profit vendors; if the company you are profiling does business with the local government, the terms of that work are available

- rent city facilities to for-profit or non-profit institutions; is the institution you are profiling paying its bills in a timely way?

- issue warrants for arrest and keep track of calls for service; if the institution or individual you are profiling has had run-ins with the law, you can request those records

This is just a sampling of the types of records you might want to search at the local or municipal level. In almost all instances, these government entities now have websites where individuals (not just communicators) can request public records and conduct searches.

\section{- State governments}

- require for-profit and non-profit institutions to file articles of incorporation which provide extensive background about the finances and top managers of the organization. Such records are searchable through the Secretary of State for that state

- require many institutions or individuals to carry a license to conduct business. This "permission" to do business affects business people from the ice-cream vendor on the street corner to the local styling salon to the hospital serving thousands of patients every year. Every state now has a website(s) where licensing information is managed.

- collect state taxes from for-profit institutions; some of the information about tax revenue generated from these types of institutions are a matter of public record; the state Department of Revenue will be the place to search

- maintain regulatory oversight records about the compliance or non-compliance of institutions; if the company you are profiling is required to adhere to regulations about environmental protection, for instance, you can search for those oversight records. The state Environmental Protection Agency or Pollution Control Agency would have searchable records

Again, this is just a tiny fraction of the material that is available by searching the appropriate public agency databases for data about the organizations or individuals you are profiling.

\section{- Federal government}

- requires that publicly held companies (that is, companies that sell stock to the public) file quarterly and annual reports on their financial condition; the reports include the names of corporate officers along with their salaries, bonuses and certain fringe benefits. Additional content of these reports includes information on new products and services; acquisition, sales, divestiture or merger plans; major lawsuits in which the company was engaged; and 
government actions or regulations that affect business; these reports are available through the the Securities and Exchange Commission

- requires that non-profit organizations file financial information (called an IRS 990) with the Internal Revenue Service in order to maintain their non-profit status; the IRS 990 includes detailed information about the organization's mission, programs and how it is raising and spending its money; non-profits include everything from the local cemetery to the Howard Hughes Medical Institution and these IRS 990 reports can be searched using a tool called GuideStar

- requires for-profit companies with international business activities to file extensive information about their trade agreements with foreign governments, their import and export activities and related materials; the International Trade Administration (a part of the U.S. Department of Commerce) publishes vast information about U.S. exporters and their economic impacts; if the for-profit institution you are profiling is selling commodities overseas, you will want to search some of these federal agency websites

- collects and publishes extensive statistical information about every conceivable activity; the most useful tool to identify statistics and the agencies that generate them is FedStats.

As we've said many times, these are just a small fraction of the types of data that are gathered by public-sector institutions. 


\subsection{Private-Sector Institutions' Data}

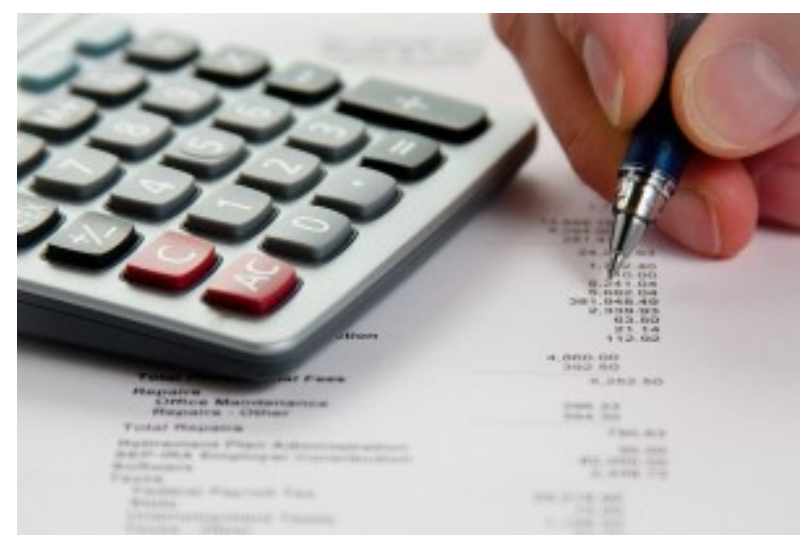

Dave Dugdale - Analyzing Financial Data - CC BY-SA 2.0
Private-sector institutions gather, generate and use data about their customers, their businesses and industries, their financial circumstances and many other practices central to their success. Businesses, advocacy groups, think tanks, and many other private-sector institutions generate data to bolster their positions, lobby for change, defend their actions and communicate with the public. Many times, institutions will take data from a source such as the federal government (census data, for instance) and "massage" it for their own purposes by reinterpreting the figures, adding analysis or selectively choosing the "evidence" that supports a position or point of view.

Many of these institutions have vested interests in providing you with a particular set of facts or pointing you in a specific direction for your information strategy. They all want to "set the agenda" in their subject areas and control the parameters of public discourse. For this reason, they will go to great lengths to provide some types of data and withhold other types. Your job as a communications professional is to understand how to dissect the data you collect and how to seek material that eludes you.

For our purposes here, you simply need to recognize that there are a large number of firms that collect data on consumer behavior, audience characteristics, media use, and related activities and sell that information to media organizations, among many others. Strategic communicators, especially, rely on these syndicated research services for the data they provide to help understand audiences. 


\subsection{Sources of Audience Data}

Media organizations may conduct their own surveys or audience analyses for the purpose of understanding more about the types of content their readers/viewers want to see, or for managerial decisions about where to launch a new publication. Marketing and advertising firms may conduct a focus group to learn more about customer usage and opinions about a product or service. The results of a poll conducted by a PR firm might be used as part of a public relations campaign to persuade policymakers to make a certain decision that positively affects a client's interests. We will discuss finding and using poll or survey information in Lesson 15.

In addition to their own internal surveys, media organizations use a number of tools to locate information about the audience characteristics we have been discussing.

Two major external sources for audience information are the syndicated services GfK MRI and Experian Simmons. Each company conducts more than 20,000 personal interviews annually in which they ask participants to record their product-purchase habits, their media-use habits and their demographic characteristics.

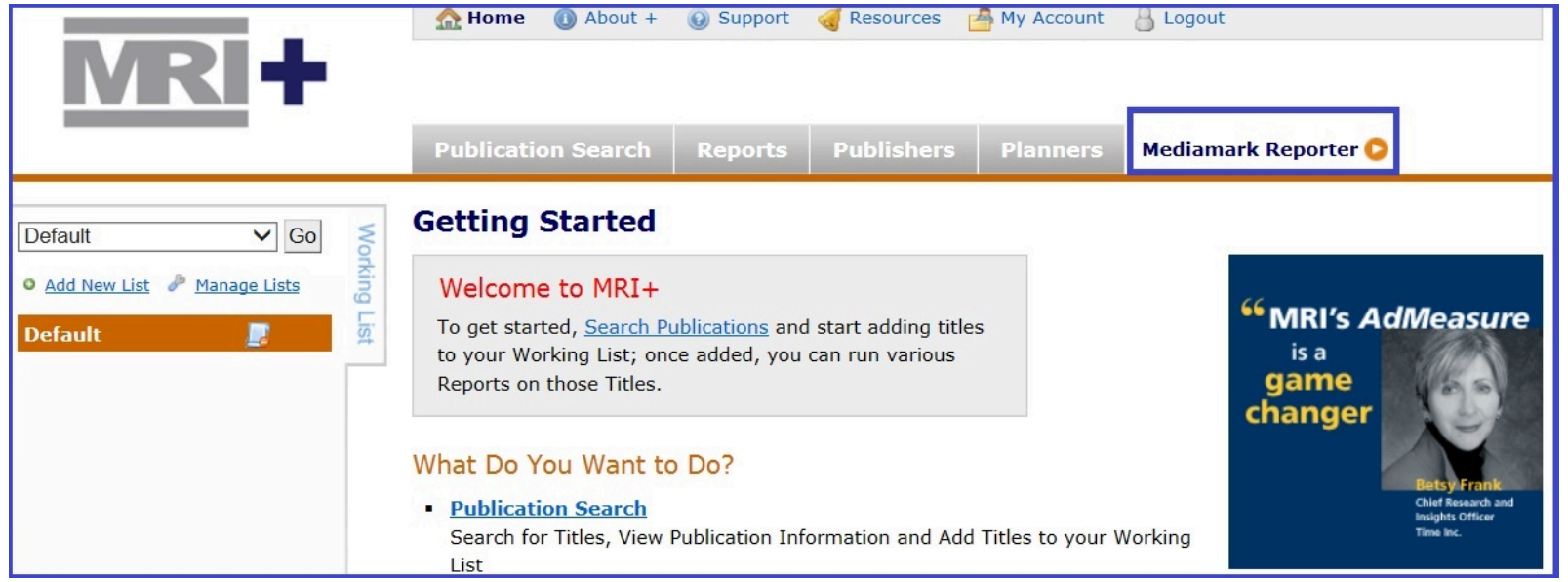

http://www.mriplus.com

These services compile information into massive data sets, published in electronic form. The reports are used by magazines, television, radio, digital and other media, leading national advertisers and hundreds of advertising agencies to help determine what kinds of people purchase which kinds of products and use which types of media to learn about trends, styles, new products and events.

Let's look at one of these tools to help define the types of audience data you can locate. The GfK MRI company site explains their product as follows:

Below is a quick listing of what the Survey of the American Consumer ${ }^{\mathrm{TM}}$ measures.

\section{Demographics, Lifestyles \& Attitudes}

- Age, Sex, Occupation, Income 
- Home Ownership

- Children in Household

- Business Responsibilities

- Personal \& Business Travel

- Public Activities

- Leisure Activities

- Consumer Attitudes

- Political Outlook

- 1,100+ Psychographic Questions

\section{Product and Brand Usage}

- Usage Data for 6,000 Brands in 550 Categories

- Groceries \& Household items

- Personal \& Health Care Products

- Tobacco, Candy, Snacks

- Cars, Vans, Trucks \& Motorcycles

- Financial Products \& Activities

- Household Furnishings \& Appliances

- Apparel \& Accessories

- Consumer Electronics

\section{Media Usage}

- Magazines

- Television

- Newspapers

- National Newspapers 
- Radio

- Internet

- Yellow Pages

- Mobile \& Smart Phones

- Outdoor

- E-Readers $^{1}$

You can see from this list that the GfK MRI company is collecting and analyzing an enormous amount of data about audience characteristics, product use and media use. A communicator can answer many of the audiencespecific questions using one of these types of tools.

For example, if you need to know how to reach people who use mopeds or motor scooters, who shop in health food specialty stores, who live in the Northeast, who are between the ages of 25 and 34, who own a smart phone and who watch "The Tonight Show Starring Jimmy Fallon" on TV, these tools will help you identify them and understand how best to reach them with messages.

Gfk MRI data are available in the University library under MRI - Media Mark Reporter 


\subsection{Broadcast Audience Data}

Likewise, broadcast audience data are available from the research service that collects and compiles ratings services. Nielsen collects information about television (broadcast, cable, computer and mobile) and radio audiences. The ratings information is used by a wide segment of mass communication professionals, not just advertisers.

The ratings volumes and reports generated by Nielsen include a wealth of data about the geographic markets surveyed, the demographic characteristics of the households and individuals surveyed, including:

- the time of day when people watch television or listen to the radio.

- the types of programs that attract the largest audiences.

- the time spent by different types of people using broadcast media.

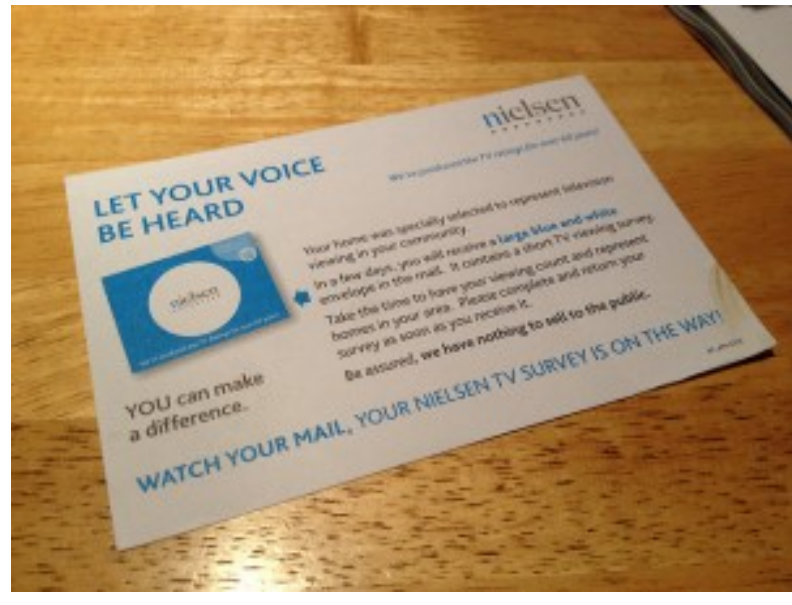

Michael Styne - CC BY-SA 2.0

- the device the person was using to watch or listen.

While it is not necessary for every communicator to learn to decode the data in the ratings volumes, it is important to understand how this information is used.

Ratings information determines the advertising rates charged by TV and radio stations, helps communicators understand something about the characteristics of media consumers, and gives a snapshot of the types of media programming that are popular or influential among audiences.

The Internet has become an important advertising medium and Nielsen, along with a number of new companies, provide "ratings" services for web and mobile advertising. These companies track usage of web and mobile sites based on things such as the number of unique visitors to a site on an hourly, daily, weekly or monthly basis, and they also can provide basic information about how users move around at a particular web or mobile site.

Many digital sites ask users to provide additional information about themselves, such as demographic information (income, family profiles, spending habits), and media professionals can combine that data with the tracking of site visits to provide advertisers with a powerful form of tailored audience measurement for this medium. 


\subsection{Media Analysis Data}

A great many services reveal to advertising professionals where ad dollars are spent. By analyzing where competitors and previous campaign professionals have allocated their budget, the communications professional can infer a lot about the intended audience for those messages.

Media analysis is a data-intensive aspect of work in strategic communications involving decisions about:

- how to set an ad budget.

- how to determine competitors’ ad spending.

- how best to reach the target audience with specific ad purchases of time or space.

- how to locate sponsors and the most effective means for communicating your client’s message.

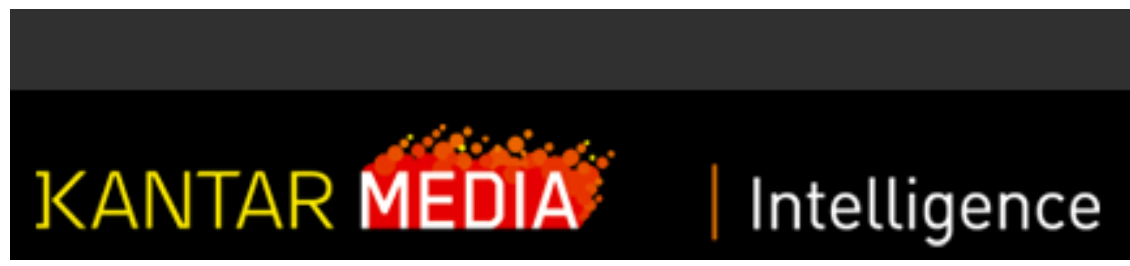

http://www.kantarmedia.com/

One important set of data tools to help with this task are those available from Kantar Media Intelligence. Their many publications report advertising expenditures in 18 major media (Ad\$pender ${ }^{\mathrm{TM}}$ ); competitive multi-media expenditure and occurrence information for 19 media, with a national and local market view of the advertising marketplace, including Branded Entertainment (Stradegy ${ }^{\mathrm{TM}}$ ); and in-depth online advertising intelligence on millions of brands across thousands of web sites within the U.S. and Canada (Evaliant ${ }^{\mathrm{TM}}$ )

For instance, you could learn how much Proctor \& Gamble spent on advertising for all its products in any year, or how much they spent on advertising for just their Head \& Shoulders ${ }^{\circledR}$ shampoo brand, and how those ad dollars were apportioned among the different types of media (mostly magazine and network TV ads, it turns out). The allocation of those dollars tells you something about who the P\&G advertisers thought their audience would be.

You could also learn the total number of ad pages and total dollars spent in specific magazine titles (how much does Cosmopolitan magazine bring in from P\&G product ads each year?) or the amount of money spent on advertising for particular categories of products, such as personal care products.

Using these media analysis data tools provides an insight into which audiences are receiving what types of messages through which media. If you are trying to define the best audience for your ad campaign, you want to see what competitors have done with their decision process about audience. You can think of this as a sort of competitive analysis process. 


\subsection{Audience Analytics Data}

Analytics are being used by all types of communications professionals as a way to learn more about the nature of the audience. An ever-changing suite of services, tools, companies and providers allow message creators to track how audiences are interacting with content online, on mobile devices, on social networks and in other ways. Google Analytics, Chartbeat, Adobe Digital Marketing Suite, Signalnoi.se, and Salesforce Marketing Cloud are just a few of the players in the audience analytics field.

A PR professional might partner with a real-time sentiment marketing firm to understand what consumers are saying through social media. For example, when several Golden Globe Awards actresses walked the red carpet with slicked-back hairdos, social media Tweeters reacted as they watched. Some of those commenters almost immediately received a Tweet from L'Oreal Paris showing them how to achieve the same look at home, and offering coupons. The real-time sentiment marketing firm Poptip (working on behalf of L'Oreal) was looking for hairdo chatter, analyzing which conversations were appropriate for the response (ignoring Tweets from males about how hot an actress was, for instance) and sending a message that reflected the client's perspective and product to the right audience at the right moment.

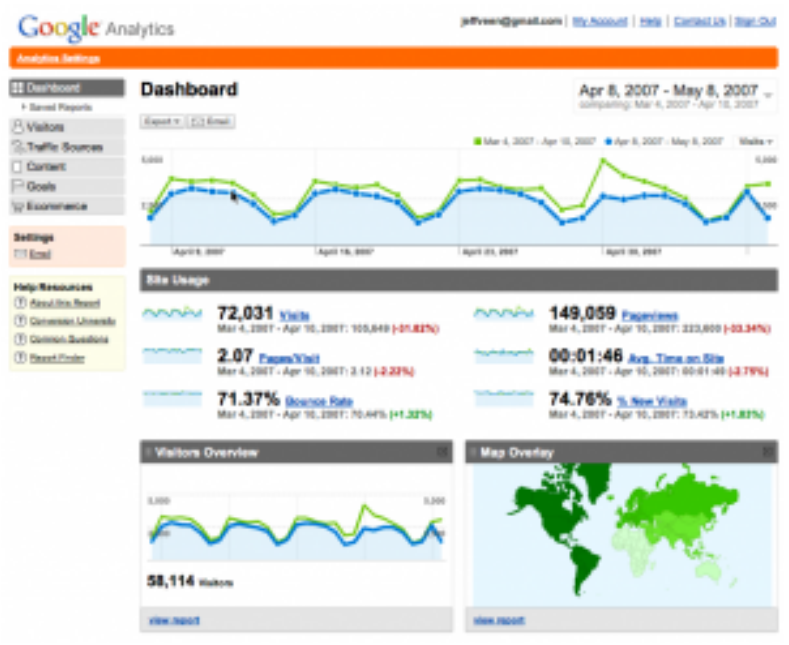

Jeffrey Veen - Google Analytics Redesign - CC BY-NC-SA
An advertising professional might look at Google Analytics for evidence of how well a client's web page is reaching the target audience before deciding how to position the next set of promotional messages. The report from Google Analytics will tell the ad professional how much traffic the website is getting, where that traffic is coming from and how visitors behave on the site. The ad professional can also monitor mobile app traffic and social media activities around that client's brand. All of this information would help inform the ad professional about possible strategies for the next campaign the client wants to launch.

A news editor might use a service such as Signaloi.se to see how stories about a particular topic have trended on social media (Facebook, Twitter, etc.) with the audience in the past before deciding how to direct her reporters' follow-up work on that issue. Or the news ad sales team may use the information from a service such as Chartbeat to show potential advertisers data about the news site's audience and how effective their ads would be in reaching that audience if they placed an ad on the website.

Many news organizations are building their own "dashboards" that allow them to track audience behavior on their websites and social platforms in real time. The dashboard helps journalists understand where a story's traffic is coming from, how it is being shared, whether readers are interacting with related content on the site, how much attention the story is getting, etc. 
For example, The New York Times has created a tool it calls the Package Mapper. It assesses data directly from the NYT web site logs to create a network diagram that shows editors how readers are navigating through a package of related stories and features in real time. During the 2014 winter Olympics in Sochi, Russia, most of the Times' stories were generated by their sports reporters and were published in the sports section of the newspaper and website. However, one afternoon social media exploded with commentary about a Times article (produced by a metro reporter not assigned to the Olympics) that described an incident where the Russians blocked a shipment of Chobani yogurt from reaching American athletes. The Package Mapper immediately detected the social media interest in the yogurt story and editors were able to make an appropriate link in the sports section to the yogurt story so sports section readers could find it.

Understanding how to use the burgeoning suite of message and audience analytics data tools is becoming a basic expectation for communicators entering the profession. You would be well-served to familiarize yourself with the most important tools in the specific area of communications work in which you are interested and learn the basics of how those tools are used in that field. 


\subsection{Data from Media Kits}

Another important source of information about audiences is the media kit produced by media outlets that are seeking ad dollars. Primarily used by advertisers who need to decide whether to place an ad in that publication, on that website or on that tablet edition, the media kit can also be a good source of information about the audience for a freelancer or journalist who needs to understand how to pitch an article or please an editor (the "gatekeeper" audience discussed in previous lessons).

For example, a major magazine publisher such as Conde Nast produces media kits for all of its titles. For Vogue magazine, there are media kits for the print, web and tablet

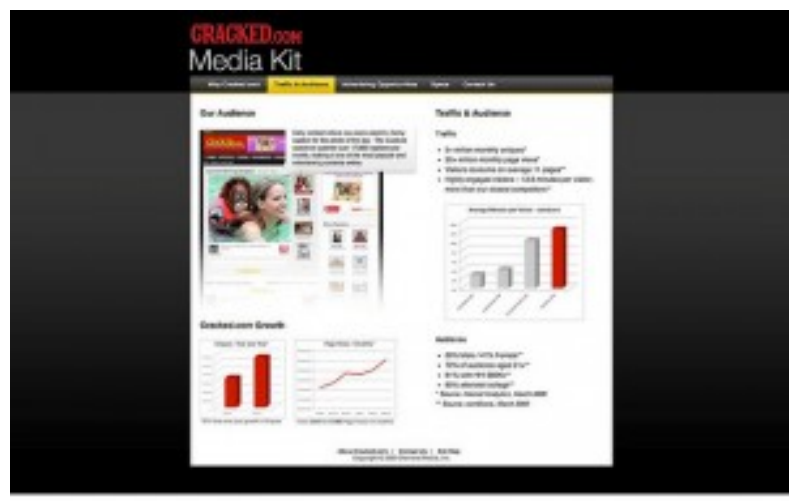
apermanentwreck - CC BY-SA 2.0 version of the title.

The Vogue media kit shows that for the print version of the magazine, the audience data look like this:

- Median age 37.8

- Household income $\$ 58,612$

- Female/Male $88 \%$ / 12\%

- Any college 65\%

- Employed FT/PT 65\%

The Vogue media kit shows that for the web version of the magazine, the audience data look like this:

- Median age 39.7

- Household income $\$ 89,838$

- Female/Male 64\% / 36\%

- Any college $82 \%$

- Employed FT/PT 73\%

Tablet audience data are available for advertisers who inquire. But just looking at the difference between audiences for the print and web version of the magazine provides some interesting insights.

- The web audience has a significantly higher income, meaning the advertisers of high-priced items might want to focus their budget on web ads rather than buying an ad page in the print edition.

- The percentage of male audience members is higher for the web version than for the print version. If 
you are placing ads for a gender-neutral product, you have a better chance of finding male audience members via the web version.

- A journalist might get an idea for a story that looks at whether men feel uncomfortable subscribing to or buying a title such as Vogue on the newsstand but are much more likely to view the content online based on the media kit insight about a higher percentage of male audience members for the web version of the magazine than for the print edition.

Another portion of the media kit lays out the editorial philosophy of the publication:

“The foundation of Vogue's leadership and authority is the brand's unique role as a cultural barometer for a global audience.

Vogue places fashion in the context of culture and the world we live in — how we dress, live and socialize; what we eat, listen to and watch; who leads and inspires us. Vogue immerses itself in fashion, always leading readers to what will happen next. Thought-provoking, relevant and always influential, Vogue defines the culture of fashion.”

If you are a freelancer hoping to pitch an idea for an article in Vogue, you need to understand how the magazine editors define their editorial focus and their audience's interests. In this case, you would need to recognize that your pitch for a story idea must incorporate a "global” perspective and take a cultural approach to the topic in order to meet the audience's expectations. This portion of the media kit also provides biographical information about the top editors. You would certainly want to understand as much as possible about these "gatekeeper" audience members as possible before preparing your story pitch letter and proposal. 


\subsection{Consumer Data from Private-Sector Sources}

In addition to the syndicated research services, individual businesses are gathering a breath-taking amount of information about their own, and sometimes their competitors', customers. Private-sector businesses have become major players in gathering and mining data about their customers. If you are reporting about a business or a trend or if you are doing strategic communications for one of these organizations, you will almost certainly want to ask about their customer data practices.

Here is one example: a major discount retailer used information willingly provided by customers from its "Baby Registry” and sales information from its customer loyalty programs (you sign up for special deals and notices in exchange for allowing the company to monitor your purchases) to identify a "profile" of female customers who were in their second trimester of pregnancy. When the retailer's research staff crawled through millions of customer records, it became clear there there were about 25 products that, when purchased together, allowed them to assign shoppers a “pregnancy prediction” score.

Let's say there is a 23-year-old shopper who bought, in March, a large jar of cocoa-butter lotion, a purse roomy enough to double as a diaper bag, zinc and magnesium supplements and a bright blue rug. According to the retailer's interpretation of those data, there is an 87 percent change that shopper was pregnant with a delivery date in late August. Based on that information, the retailer could then send a coupon for related products and services or target advertising messages to her based on her "pregnancy score.” If you were doing advertising for this retailer, you can imagine how valuable this information could be. You can also imagine how disturbed many of the retailer's customers would be to know they are being so profiled.

Such "profiling" is being done by companies based on every single thing we do in our virtual and "real" lives. Communications professionals are among those who are using such data to better reach us with information when, when and how we want it.

Here is another description of this "social profiling" from an article by Joseph Turow that appeared in The Atlantic magazine

Consider a fictional middle class family of two parents with three children who eat out a lot in fast-food restaurants. After a while the parents receive a continual flow of fast-food restaurant coupons. Data suggest the parents, let's call them Larry and Rhonda, will consistently spend far more than the coupons'value. Additional statistical evaluations of parents' activities and discussions online and off may suggest that Larry and Rhonda and their children tend toward being overweight. The data, in turn, results in a small torrent of messages by marketers and publishers seeking to exploit these weight issues to increase attention or sales. Videos about dealing with overweight children, produced by a new type of company called content farms, begin to show up on parenting websites Rhonda frequents. When Larry goes online, he routinely receives articles about how fitness chains emphasize weight loss around the holidays. Ads for fitness firms and diet pills typically show up on the pages with those articles. One of Larry and Rhonda's sons, who is 15 years old, is happy to find a text message on his phone that invites him to use a discount at an ice cream chain not too far from his house. One of their daughters, by contrast, is mortified when she receives texts inviting her 
to a diet program and an ad on her Facebook page inviting her to a clothing store for hip, oversized women. What's more, people keep sending her Twitter messages about weight loss. In the meantime, both Larry and Rhonda are getting ads from check-cashing services and payday-loan companies. And Larry notices sourly on auto sites he visits that the main articles on the home page and the ads throughout feature entry-level and used models.

His bitterness only becomes more acute when he describes to his boss the down-market Web he has been seeing lately. Quite surprised, she tells him she has been to the same auto sites recently and has just the opposite impression: many of the articles are about the latest German cars, and one home-page ad even offered her a gift for test-driving one at a dealer near her home.

This scenario of individual and household profiling and media customization is quite possible today. Websites, advertisers, and a panoply of other companies are continuously assessing the activities, intentions, and backgrounds of virtually everyone online; even our social relationships and comments are being carefully and continuously analyzed. In broader and broader ways, computer-generated conclusions about who we are affect the media content - the streams of commercial messages, discount offers, information, news, and entertainment - each of us confronts.

This excerpt describes both the types of data that are being collected by private-sector institutions, and the practice of targeting specific types of messages based on what those data say about us. In fact, one popular online travel site that offers one-stop shopping for airline tickets, hotels and rental cars was exposed for showing searchers using a Mac computer pricier hotel options than those using more "down-market” models of computers. One of the pieces of data collected by online sites is the type of equipment the searcher is using to gain access. The assumption in this case was that if a user owned a Mac computer, they had deeper pockets and would be less likely to continue to search for less-expensive accommodations. Since the travel sites earn a "cut” of every reservation booked, they have an incentive to steer wealthier users away from the cheapest options.

Here is another example. We all are familiar with this scenario: we go to Google and do a search for information about, say, the best brand of athletic shoes for playing tennis. For many days after conducting that search, every other website we visit is suddenly showing us ads for athletic shoes. How does that happen? Is it a massive coincidence? Of course not. Google, and many other similar search sites, collects data about every action we take on its site. It then turns around and sells that data to advertisers, or offers to place ads on behalf of advertisers, when we do anything else or go anywhere else online.

Of course, many of us are now spending most of our online time using mobile devices (smartphone, tablets, "phablets" [phone-tablet hybrids]) rather than traditional computers. Services are now springing up to ensure that advertising messages delivered to mobile devices through individual tracking are as effectively targeted as they have been through websites on desktop and laptop computers. Again, these companies are tracking individual behavior on mobile devices, triangulating the data traces (“cookies") we leave via those devices with those we leave on our desktop or laptop computer, and then making sure the targeted ads reach us via every device we use.

Especially for communications professionals, understanding these data practices of public- and private-sector institutions is a major obligation of doing their work. Strategic communicators need to know how to scrape, evaluate and use such data to effectively create and target ads and PR messages for their clients. Journalists need 
to understand how readers/viewers/listeners are moving through their news sites to better generate content that will attract news users. 


\subsection{Data from Scholarly Sources}

Scholars collect and report on data as part of their work as new knowledge creators. Physical scientists collect data from the innermost reaches of quantum space to the outermost reaches of the universe. Social scientists gather huge datasets about individuals, communities, governments and businesses as they try to understand how society works. Humanists gather data about languages or codes of writing, architectural developments, music, and other topics related to human beings' creativity. Scholars also generate data when they report on their research work.

The scientific method is designed to generate publicly-verifiable results. Scholars are supposed to do their work under conditions that are reproducible by others. Scholars also try to minimize factors that affect the accuracy and interpretation of their results. Hence, they try to conduct their work under controlled circumstances as much as possible.

This is sometimes easier for physical scientists than for social or policy scientists, however. Physical scientists can do their work in the laboratory and/or with multiple observations of the phenomena they're studying. Social scientists do much of their work in the social environment and are studying complex human behavior, thereby making control harder to achieve. Nonetheless, all reputable scholars strive to be precise in their methods and careful in their interpretation of research findings.

As much as scholars want to achieve this perfection of the scientific method, they are, in the end, human beings. The data they generate must be scrutinized and used with caution, just as with any other source of information. Critical thinking experts M. Neil Browne and Stuart Keeley suggest that you keep a number of factors in mind when you are considering using scholarly research data as a source of information. These include:

- Research varies in quality, and because the research process is so complex and subject to so many external influences, even well-trained scholars sometimes make mistakes. Just because something was published in a peer-reviewed journal does not mean it is not flawed in other important ways. This is why it is important to try to interview several scholars about the findings of a particular study in order to understand the reputation of that work.

- Research reports often contradict one another. Thus, single research studies presented out of the context of the body of work in that area often present misleading conclusions. You should look for studies that have been repeated by more than one researcher or group of researchers.

- Research data do not "prove" conclusions. All someone can do with a set of data is say it does or does not "support" a particular conclusion. Scholars must always interpret the meaning of their findings, and all findings can be interpreted in more than one way. Thus, when you see the statement, "research findings show...," you should translate that statement into "researchers interpret their findings to show..."

- Despite best intentions, scholarly work is not neutral and value-free. Scholars, just like the rest of us, have emotional investments in particular ideas and ways of understanding the world. Regardless of how 
objective a piece of scholarship may appear, subjective elements are always involved. Therefore, you must always try to put an individual scholarly finding or piece of evidence into the larger context of what we think we know about that topic, and try to understand the full set of influences on that scholar's work.

- A scholar's work may be mischaracterized by another scholar who is citing or using that original piece of evidence in a new study. Do not rely on someone else's characterization of another person's data. Look at the original piece of scholarship yourself and make sure you understand what that particular scholar said he or she found.

- Research findings change over time. What we once thought we knew is no longer true, or has been superseded by more recent scholarship. As with so many other sources of information you will use for your messages, be sure you have the most recent findings in front of you.

- Some studies are done using artificial circumstances because trying to do the study in the "real" world would be impractical, unethical or otherwise not feasible. For instance, many studies about the effects of media messages on children involve exposing kids to messages with particular characteristics (violence, pro-social behavior, etc.) and then studying how the children interact with one another or with dolls or toys in a laboratory setting. How do we know that this artificial setting isn’t affecting the outcome?

- Other studies are conducted with research subjects chosen because of their easy availability rather than their appropriateness for the study. For example, an advertising scholar may use a classroom full of freshmen advertising students to study the effects of several different commercials for house paint (some using humor, some using a more rational appeal, etc.). How many of the freshmen in the room are actually in the market for house paint (in other words, how many of them are in the target audience for that product)? You need to ask whether the scholarly study you are thinking of using is flawed by the artificiality of the research setting and/or the selection of research subjects.

- As we've already said, many scholars do work that is funded by outside sources such as research grants or contracts from large companies or government agencies with an interest in the outcome of the work. This does not, of course, automatically mean that their findings are biased. However, it is not uncommon for drug companies, for instance, to require a scholar funded with one of their grants to seek permission from the company before submitting any findings to academic journals for peer review. Understandably, the drug companies are unlikely to give permission for studies that are not favorable to their products or treatment regimens. As a communicator considering using any type of scholarly research findings, you need to know how the work was funded, and by whom. You also need to ask the author(s) what restrictions they might have been working under as a result of that funding source.

As Browne and Keeley advise, you should approach any scholarly study with the skills of a critical thinker. Just because you are not an expert in the subject area, you are not relieved from the responsibility to make sure you get your facts right and your interpretations verified. 


\subsection{Data from Journalistic Sources}

Journalistic sources are generating huge sets of data with their minute-by-minute updating of news and information through their publications, websites and mobile platforms. Both the words and pictures of the stories themselves along with all of the "meta-data" about those stories (when and with what equipment a photo was taken, what part of a website a story was published on, how many versions of the story were created before it was published, etc.) are funneled into databases through the work that journalists are doing each day.

Also, journalists make other contributors' data sets accessible and understandable. For example, when the Centers for Disease Control and Prevention issues a data set about the frequency and location of incidences of a particular illness, those data are used by journalists to write a story and put the data into context. School "report cards" are another kind of data, generated by public-sector institutions that journalists will take and make more accessible. Compare, for example, the school report card data from by the Oregon Department of Education and the interface the Portland Oregonian published.

Journalists gather data generated by all the other information contributors as part of the reporting and interpretation work. For example, a news organization might gather public-sector data about the drunk driving convictions in the state and cross-reference those data with the airplane licensing data to see how many people who have been convicted for driving while intoxicated also have a license to fly a plane. When one news organization did this, it discovered an alarming amount of overlap, including several individuals who were licensed to fly commercial aircraft for the hometown-based major airline!

Journalists are also becoming expert at using large data sets to develop info-graphics or data visualizations to help make the data more understandable to the audience. For example, maps are always popular with readers/viewers. There are several easy-to-use interactive visualization tools that help journalists build interesting info-graphics for their digital sites from data they have gathered. Journalists have used data sets from a variety of contributors (but mostly public records) to create maps such as:

- bikeshare rides in Boston

- pedestrian injuries in San Francisco

- green roofs in Chicago

- rat sightings in New York City

- tsunami sirens in Honolulu

- dangerous dogs in Austin

So one source of data from journalistic sources is all of the news reports, investigative accounts and other types of interpretive work that journalists do with other organizations' data. Using any of the search databases 
that incorporate news content to locate these types of reports will uncover such journalistic work. Most news organizations will highlight these types of reports on their own websites as well.

Web analytics from publishing platforms comprise the other type of data generated by journalistic sources. Every news organization with a digital platform for disseminated content uses the "back-end" system of that platform to gather second-by-second information about how that platform is being used, and by whom. As an individual news consumer moves through the site, there is a data trace of each click, every ad that is opened, each link that is followed, how long the reader stayed on the site, whether the user shared that information through a social networking site, and similar actions.

News organizations are learning how to use these data to fine tune their content. For example, if a news editor sees that a particular story on the site is getting a lot of clicks and shares, the editor might move that story to the homepage or send a Tweet to followers with the link to that story to generate more views. The advertising sales staff for those news organizations refer to the user data when trying to convince an advertiser to buy an ad on the news website.

While some traditionalists bemoan the use of these types of data to make news judgments, the reality is that it is now commonplace to do so, and any news organization that isn't using these "back-end” data is missing a chance to improve the reach of their news content. 


\subsection{Data about Journalistic Audience}

Public relations professionals need to understand how to best place their news releases and other types of strategic communications messages with their journalist audiences. There are a number of tools and resources that help PR professionals identify the best targets.

For example, a service called MuckRack provides information to help strategic communicators pitch their stories or news releases to the most appropriate journalists covering a topic or a beat, to get alerts when a journalist Tweets or links to materials related to the PR specialist's topic, to track how journalists are sharing the content generated by the PR specialist, and to create media lists of successful contacts and notes about what has worked in the past.

The PR specialist can do a search for journalists writing about industry YYY or bloggers who follow company ZZZ. Clients want to know if their PR efforts are effective. MuckRack can track the news releases generated by the

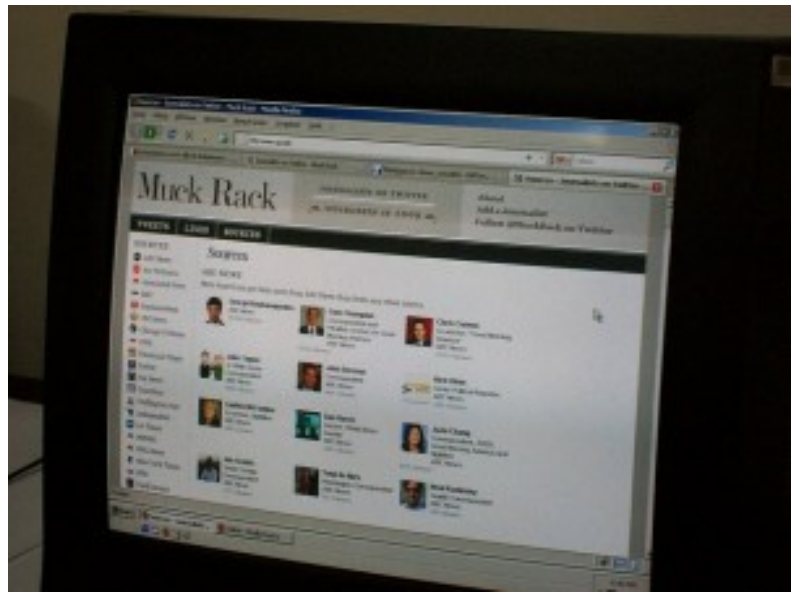

Telomiova.org - Introducing Muck Rack - CC BY-NC-SA 2.0 PR specialist to see how and where they have appeared.

For the busy PR professional, having this sort of tailored tracking service is invaluable. 


\subsection{Data from Informal Sources}

For the most part, data from informal sources is gathered by the other contributors. Informal sources create data about themselves through every activity they undertake. Aggregated information about online site users, individualized data about customers or readers, personal information about social networking site participants, and much more information about “average folks” is being vacuumed up through all of the methods we've outlined.

Conducting a poll is another way to think about gathering data from informal sources. If the group you want to learn something about is the general population, then a poll might be the best way to gather that data. We will discuss polls in much more detail in Lesson 15. 


\subsection{Numeracy Skills}

Communications professionals generally think of themselves as "word nerds" rather than number wizards. For that reason, many communicators suffer from "innumeracy," the numerical equivalent to illiteracy. As we said at the start of this lesson, because we are so awash in number-based claims and information, it is crucial that ALL communicators have basic skills in interpreting and evaluating numerical data. But certain types of tasks within mass communication demand more than simple familiarity.

\section{Journalists’ Uses of Numeracy Skills}

- Those who are interested in data-based reporting have a special responsibility to make sure their number skills are top notch. There are entire texts and courses devoted to teaching journalists how to use number-based information and computer programs for analysis of data in news.

- Journalists who cover science and medicine also have need for high-level skill in interpreting data based on statistical claims and evidence. Journalists who cover politics and economics are also required to interpret and evaluate the hundreds of studies, reports, and documents the agencies of government continually provide. Something as seemingly straightforward as a city budget or the monthly federal unemployment statistics are actually fraught with many potential traps for communicators with innumeracy problems.

- Politicians and economists like to point to the certainty of one set of numbers or another. The problem is that many of these precise numbers and reports are precisely wrong, and our understanding of politics and economics remains imprecise at best. Journalists can protect themselves by asking for all of the numbers from a report or study, and making their own judgments about whether they are appropriate for drawing the conclusions the experts have drawn.

\section{Strategic Communicators' Uses of Numeracy Skills}

- Advertising professionals use data in claims about product effectiveness, rates of satisfaction with a product or service, product comparisons, and many other types of assertions. It is easy to fall into misleading use of numbers in ad copy. Be sure that you can substantiate any number-based claims, as the various advertising self-regulatory bodies require this. Also, ask how the provider of the figures came up with those numbers-what do they mean?

For example, an advertiser of an electric juice extractor once claimed that the juicer "extracts 26 percent more juice" but failed to say what the comparison was. It turned out that the extractor provided 26 percent more juice than if someone used an old-fashioned hand juicer. But the relevant comparison would have stated how the advertised product compared with other electric juicers.

- Advertising professionals also use number-based information in evaluating audience characteristics and the characteristics of specific media vehicles through which a message reaches the audience. An entire 
area of advertising work called media planning and media buying is heavily number-based. These professionals need to know how to read tables of numbers, how to calculate reach and frequencies, cost-per-thousands, and many other figures. This requires nothing more than simple arithmetic and high school math, but those who seek to do this type of work must be comfortable with numbers. 


\subsection{Applied Statistics}

Most communicators need to master nothing more complicated than a few principles of applied statistics in order to overcome their innumeracy.

Applied statistics are not to be feared. They are based on basic, simple, fourth-grade arithmetic - addition, subtraction, multiplication and division. Mathematicians will tell you that algebra and calculus provide the support for the assumptions and techniques of statistics, but applied statistics do not require computation beyond basic arithmetic.

It is important for communicators to brush up on their basic mathematical terminology in order to be able to interpret the data they find in many reports, studies, documents, and other types of information resources. The following are a few commonly confused terms:

\begin{tabular}{|c|c|}
\hline percent & $\begin{array}{l}\text { a standard way of expressing a fraction, where the } \\
\text { denominator (the bottom number) equals } 100 \text {; so } 1 / 4 \\
\text { equals } 25 \text { percent ( } 4 \text { X } 25=100), 1 / 3 \text { equals } 33 \\
\text { percent ( } 3 \text { X } 33=99 \text { rounded to } 100), 1 / 5 \text { equals } 20 \\
\text { percent ( } 5 \text { X } 20=100) \text {, and so forth }\end{array}$ \\
\hline percent change & $\begin{array}{l}\text { a way to express a relationship between an “old" } \\
\text { number and a "change” or a "new" number and a } \\
\text { "change;" for example, last year's budget is } \$ 500,000 \\
\text { and the current budget is } \$ 600,000 \text {. The "change" is } \\
\$ 100,000 \text {. To express this as a percent change from last } \\
\text { year to this, you have to divide the "change” by the } \\
\text { "old” number, or } \$ 100,000 \text { / } \$ 500,000=0.2=20 \\
\text { percent. The new budget is therefore } 20 \text { percent higher } \\
\text { than the previous year’s budget. To figure what percent } \\
\text { of spending in the current budget is "new" you have to } \\
\text { divide the "change" by the higher "new" figure, or } \\
\$ 100,000 \text { / } \$ 600,000=0.1666 . . .=16.7 \text { percent }\end{array}$ \\
\hline percentage point & $\begin{array}{l}\text { a way to compare two numbers that are already } \\
\text { expressed as percents; for example, the March } \\
\text { unemployment figure is } 5 \text { percent, the April } \\
\text { unemployment figure is } 6 \text { percent, and the change is } 1 \\
\text { percentage point. The percent change is } 1 \text { (the change) } \\
\text { divided by } 5 \text { (the old number) or } 20 \text { percent }\end{array}$ \\
\hline mean & the arithmetic average of a set of values \\
\hline median & $\begin{array}{l}\text { the middle value in a group, where values have been } \\
\text { ranked from top to bottom }\end{array}$ \\
\hline
\end{tabular}


Let's look at the important differences between a mean and a median. The mean is the arithmetic average of a set of values. To compute a mean, you simply add up the values and divide by the number of values.

For example, let's say that among 100 workers at a company, 95 make $\$ 30,000$ and 5 make $\$ 300,000$ a year. The mean salary is therefore (95 times 30,000) plus (5 times 300,000) divided by 100 OR 4,350,000 divided by 100 OR $\$ 43,500$. This simple arithmetic average provides information about the average salary for workers at the company. But does it accurately describe salaries at this company?

If you answered no or not always, then you understand how important it is to evaluate how a figure is arrived at. A better way to portray salaries for this company is to use the median figure rather than the mean.

The median is the middle value in a group, where values have been ranked from top to bottom. A median figure is more likely to smooth out very wide differences between the highest and lowest values in the group.

For example, the middle value in our group of 100 salaries in our imaginary company ranked from top to bottom is the average of the salary of the 50th and 51st highest paid people. In this case, the median is therefore $\$ 30,000$. The median figure clearly tells you more accurately about the salaries for the majority of people in the company.

In most cases, it is necessary to understand how both figures were arrived at and what some of the reasons might be for significant differences between the mean and the median. 


\subsection{Using Statistical Data}

We have no intention to turn this lesson into a mini-seminar on statistics, but you need to apply some fundamental skills when making decisions about using numbers, data and statistics in your messages.

There are some basic types of statistical interpretation problems to look out for:

\section{Everything is going up}

More people are employed, more people are getting certain diseases, etc.. This type of statistic is usually right, but also meaningless, because the total number of people is also going up all the time. A more useful statistic is the RATE or PROPORTION of the population that is affected by something or doing something. A front page news report with the headline "Playing in pain" trumpeted the alarming "statistic" that more than 3.5 million children under the age of 15 required medical treatment for sports injuries, and said that total had quadrupled since 1995 when it was 775,000. But the article failed to point out that the overall number of children under the age of 15 participating in sports had also increased over that same time period. A much more accurate way to report the injury statistic would have been to compare the rate of injuries per 1,000 children under the age of 15 playing sports across the two time periods. Using absolute numbers in comparisons across time is almost never an accurate way to interpret a statistic.

\section{Best foot forward}

Statistics that use the number that best supports a case. This is the figure that is chosen by the person making the argument. Someone may choose the worst year of a recession and compare current economic conditions to that worst year in order to make the current climate look good. Or someone may choose to use the mean family income figure to distort what's typical when the median figure might more accurately reflect whether incomes have risen or fallen.

\section{“Gee-whiz" or half-truth}

Use of statistics where the number tells just part of the story. If the overall unemployment figure is not dramatic enough to make the point, then the person providing the number focuses on the unemployment rate for teens, or for specific industrial states, or some other smaller or unrepresentative group. Groups that are trying to influence public debate are notorious for these types of "half-truth" statistics.

\section{Anecdote}

The one-in-a-million exception that supposedly proves the rule. It is always crucial for you to ask how many instances or people are represented by the statistic.

\section{Everyone is average}

Use of statistics that tend to characterize individuals by group characteristics. For example, many argue that women can't be soldiers or firefighters because the average man can lift more weight than the average woman. But people are individuals, not averages, and many women can and do lift more than many men.

\section{Coincidence}


When is something actually related to something else, and when is it just a coincidence? The corollary is that just because two things are correlated doesn't mean that one thing CAUSED the other. For instance, a study may invite us to infer a causal connection with the following title: "Bottled Water Linked to Healthier Babies.” Without further investigation, this study should be rejected. Why? Affluent parents are more likely both to drink bottled water and to have healthy children; they have the stability and wherewithal to offer good food, clothing, shelter, health care and amenities. Families that own cappuccino makers are more likely to have healthy babies for the same reason, but we wouldn't give a second thought to a "study" that was titled "Cappuccino Linked to Healthier Babies.”

\section{Suspect calculation}

Determining just how the statistics are arrived at requires careful attention. Playing with the numbers can get a company into trouble as seen in this case between Proctor \& Gamble and Pfizer. P\&G claimed in their advertising that 4 out of 5 dentists recommended Crest oral rinse to their patients. As reported on the Trademark Blog, March 7, 2006, "Proctor \& Gamble sent the Crest product to 344 dentists who were asked to use the product for one week. The dentists were paid $\$ 75$ to participate in a survey. 269 dentists participated in a phone survey where they were asked 'Based on your experience using this oral rinse, which of the following statements best describes your most likely recommendation of this oral rinse to your patients?' According to the complaint, P\&G arrived at the 4 out of 5 number by combining those who responded that they 'would recommend' the product with those who responded that they 'would recommend only if their patients asked about it.' Pfizer alleges that this hypothetical recommendation does not constitute proper substantiation that health professionals recommend the product in their actual practice."

In sum, communicators are confronted with much information that is based on numbers, statistics, and numerical claims. It is no longer acceptable to simply rely on a source's interpretation of those numbers. You have to be able to independently evaluate and critique this material, on deadline, and with confidence. It is a skill that is as basic as knowing how to ask a good interview question or run a tape recorder. Take whatever steps you require to get your numbers skills in shape, and keep them sharp. 


\subsection{Evaluating Data}

An important strategy in evaluating data is to find out as much as possible about where the data were obtained. Avoid estimates that appear too precise to be true, use common sense when presented with numbers that appear counterintuitive, and maintain skepticism with claims that could just as easily be based on coincidence.

- A good starting question to ask about any statistical data claim is, "How do you know that?" Is the person or organization providing the data just telling you something they "know" or have "found to be true?” Or can they provide studies, experiments, documentation of the claim? And even if someone says, "I’ve done a study,” you should ask, "What kind? What were the possible flaws in the study?” An honest researcher will always report the limitations of his or her data and recognize that a single study rarely proves anything.

- Another good question is, ”How sure are you about your data?” There are many obstacles to gathering certain types of information. How certain can we be about the number of people in the U.S. who shoplift, carry the AIDS virus, are homeless, commit white-collar crimes or drink more than three beers a day? People are unwilling to provide truthful information for certain purposes, many things go undocumented and there are physical barriers to accurate observation of many types of activities.

As this lesson has demonstrated, communicators have many opportunities to generate and use data from both inside their own media organizations and from other organizations. The evaluation skills we discussed in Lesson 10 should be applied to data sets as rigorously as they are to the content of interviews or the claims of clients. Asking where the data originated, how they were collected, what the original purpose or use for the data was, and all of the other information evaluation questions will help you avoid making a mistake or misinterpreting what you find.

In some cases, you will find yourself in over your head with a particular data set. The best strategy then is to seek out the help of a data expert, either inside your own organization or from a reputable outside organization (academic center, statistical consulting firm, polling organization, etc.). Your request for help from those experts, however, will be much better informed if you have at least a basic familiarity with how data are gathered and used. 


\subsection{Endnotes}

Browne, M. N. and Keeley, S. (2015). Asking the Right Questions. 11th ed. Upper Saddle River, NJ: Prentice-Hall.

Duhigg, Charles (2012, February 16). How Companies Learn Your Secrets. New York Times Magazine at http://www.nytimes.com/2012/02/19/magazine/shopping-habits.html?pagewanted=all\&_r=0, captured August 16, 2017.

Robinson, J. G. (2014, May 28). Watching the audience move: A New York Times tool is helping direct traffic from story to story. Nieman Journalism Lab at http://www.niemanlab.org/2014/05/watching-the-audience-move-a-new-york-timestool-is-helping-direct-traffic-from-story-to-story/, captured August 16, 2017.

Rosman, K. and Dwoskin, E. (2014, March 23). Marketers Want to Know What You Really Mean Online. Wall Street Journal at http://online.wsj.com/news/articles/SB10001424052702303369904579423402132106512, captured August 16, 2017.

Turow, J. (2012, February 7). A Guide to the Digital Advertising Industry That's Watching Your Every Click. The Atlantic at http://www.theatlantic.com/technology/archive/2012/02/a-guide-to-the-digital-advertising-industry-thatswatching-your-every-click/252667/, captured July 14, 2014. 


\section{Lesson 15. Information Resources: Polls and Surveys}

\section{KEY CONCEPTS}

- Communicators rely on information generated through polls and surveys for a wide variety of message tasks.

- Media organizations may conduct their own polls or use polls conducted by others.

- Evaluating information generated by a poll or survey requires special skills and strategies.

\section{LEARNING OUTCOMES}

After completing this lesson you will be able to:

- understand how and when information from a poll or survey may meet an information need.

- demonstrate a rudimentary understanding of how to construct a poll or survey questionnaire.

- understand how to evaluate the information generated by a poll or survey.

\section{Overview}

No matter what type of message you are working on, sooner or later you are likely to confront information that was generated through the use of a poll or survey. Communicators and media organizations conduct their own polls and rely on poll data supplied by many other sources. Messages may contain information that was generated with the use of a poll, and communicators use survey data to understand more about their audiences and the media to reach them. 


\subsection{Surveys and Information Contributors}

We've discussed the possible contributors to an information strategy in many previous lessons. Surveys are conducted and used by all sorts of people for many different purposes. Let's look at a few examples

- Public-sector institutions such as local government offices may conduct surveys of the citizenry to understand public attitudes towards the police department or to gather information about public use of the park system. State government agencies may conduct surveys to gauge support for a proposed piece of legislation or new regulation. Federal government agencies conduct hundreds of surveys, with the U.S. Census of Population being the most familiar. Because these institutions are in the public sector, much of the information they generate is considered a public record, and hence the results of such surveys may be accessible to those who ask.

- Private-sector institutions such as businesses, political parties, trade associations, non-profit organizations and related entities conduct surveys of their members, customers, adherents, etc. Much of the survey work these private-sector institutions do is considered proprietary, meaning that it is a part of the institution's internal activities and hence will not be shared with outsiders. However, some privatesector institutions make their survey work accessible when they are trying to influence stakeholders, such as legislators or funders, and communicators should always ask if the private-sector institution they are reporting on or for whom they are creating messages has survey data to share.

- Scholars, especially in the social sciences, rely heavily on survey data for their work in knowledge creation. The findings from survey data generated by scholars are published in articles, books, conference papers and on scholarly websites.

- Journalistic organizations conduct their own surveys on all sorts of topics and subscribe to the survey findings generated by institutions such as Gallup, Harris or Roper. Some news organizations have their own survey research units that are called into duty around election time.

- Informal sources are generally not going to be generating survey data themselves, but you might occasionally find an individual who can talk about responding to a survey or who knows that a survey was conducted, which would lead you to the appropriate contributor that did the survey.

The bottom line is that all five contributors to the information strategy process may be generating survey findings and as an astute communications professional, you can locate, evaluate and use these findings in your message when appropriate. 


\subsection{Survey Definition}

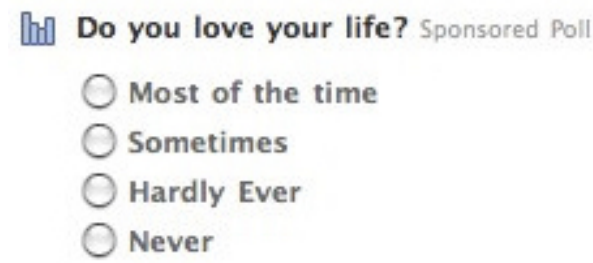

Tyler Neu - CC BY-NC-ND 2.0

We've been using the terms polls and surveys interchangeably, and that reflects the ambiguity about which term to use. The term "poll” generally refers to a measure of public opinion, while the term "survey" has a more scholarly connotation. For our purposes, we will use the term survey to encompass all types. To be clear, we will use the following definition:

Surveys measure a number of variables for a sample of a population at one point in time

Each of the italicized terms has a specific meaning in this definition:

Variable: something that can be measured and which varies. Opinions, attitudes, intentions, demographic characteristics and similar items constitute the variables in a survey.

Sample: a small group selected to represent the larger group that the survey researcher wants to learn about. Unless the researchers are going to conduct a census (talk to every member of the group in question), they must draw a sample.

Population: the broad group of people with something in common that the researchers want to learn something about. For example, a reporter investigating the popularity of Facebook may define the population for her survey as 18-24 year-olds who have an account on Facebook. For a study to inform the creators of an advertising campaign for Toyota, researchers may want to look at the population of everyone who purchased a new Toyota in the last year in the state of Colorado. In other words, the population can be defined in any way that makes sense given who the researchers want to study for a particular purpose.

One point in time: the survey's "snapshot" of one particular moment. Because surveys measure things that vary, the results of any one survey are good only for that one point in time. We could ask you your opinion about a controversial issue today and you might tell us how you truly feel about it. But something could happen tomorrow in your personal world or the world at large that could utterly change your opinion about that same topic. For this reason, surveys cannot be used to predict anything - it is scientifically invalid for someone to use the results of any poll or survey to predict the outcome of any activity whatsoever. Despite the fact that you will run across 
reports all the time that appear to be predicting the outcome of an election or the likelihood of one thing or another based on survey results, there is absolutely no validity in those predictions. 


\subsection{How are Surveys Used?}

\section{Results \\ Is it the responsibility of school districts to educate parents about gang activity online?}

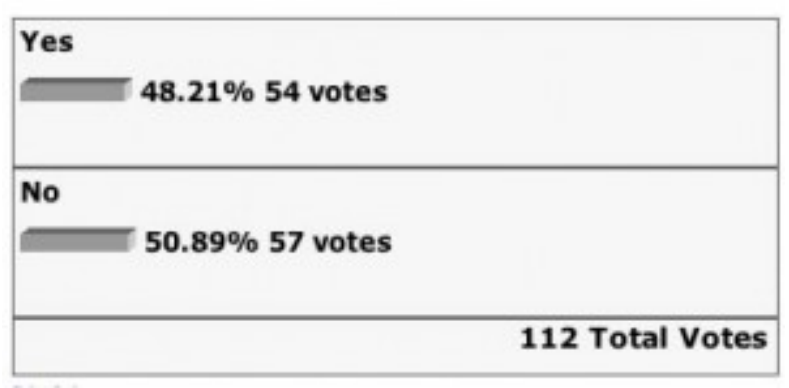

Wesley Fryer - CC BY-SA 2.0

Media professionals use information from surveys to meet many types of information needs.

- Public opinion surveys may comprise the grist for news stories, particularly around election season.

- Surveys conducted by academics or research organizations may become the topic of news stories when those specialists share their results with the public.

- Market researchers and advertisers rely heavily on syndicated research services such as GfK MRI or Experian Simmons that do extensive polling to learn about consumers and their media and product purchase habits.

- Public relations professionals monitor the attitudes and opinions of the stakeholders towards their client or company in order to influence how those stakeholders feel or behave.

- Media company researchers use surveys they conduct themselves to understand more about the audiences for their product — news organizations want to understand who is reading/viewing/listening (and who isn't) in order to grow their circulation or viewer/listenership; magazine publishers want to know whether they should invest in a new design or start a sister publication (e.g. Vogue and Teen Vogue).

As we've said, sometimes communicators rely on surveys done by “outside” companies, organizations or polling firms and sometimes they use surveys conducted by their own media organization.

The point here is not to turn you into survey researchers. There will be people in your media organization who are trained to conduct surveys, or your organization will hire firms that do so. But that doesn't exactly let you off the hook. You still need to become good consumers of survey research in order to use that type of information 
as communicators. You need to be able to explain the results of a survey in ways that are clear, valid, and not misleading. And you need to be able to use those survey results as a way to learn more about your audience. 


\subsection{Searching for Survey Data}

Many polling organizations have been conducting studies on public opinion for decades. Companies such as Gallup, Roper, Harris and the National Opinion Research Center have archives of their studies going back, in some cases, to the 1930's. Their Web sites provide access to summaries of current studies and, for subscribers, the complete information about each poll they conduct.

In addition, the Web site PollingReport.com provides free information about hundreds of national polls and opinion surveys as they are released by the major polling organizations. The tools American Public Opinion Index and Polling the Nations help you locate surveys conducted by many other domestic and foreign organizations as well.

Whether you are contemplating using the results from someone else's survey or one conducted by your own media organization, there are several things you want to be sure you understand. Survey sampling details, question wording/ordering and interview techniques used by the surveyors are all important. 


\subsection{Survey Sample Types: Non-Probability}

You must be very careful to evaluate the sampling techniques employed in any survey you are contemplating using. There are many types of samples, and some are more reliable than others. The two types of survey samples are non-probability samples and probability samples.

\section{NON-PROBABILITY SAMPLES}

Non-probability sampling methods include all those in which respondents are selected without randomness. Nonprobability sampling is generally cheaper and easier to do than probability sampling. However, a survey that uses a non-probability sample generally has no value to a communicator interested in revealing information about a particular population.

\section{Types of Non-Probability Samples}

\section{Available or “convenience” sample}

- Interviewers choose respondents who are readily accessible

- Using people passing by a street corner

- There is no way to determine who the respondents represent

- Results of the survey are not generalizable to any larger group

- a convenience sample conducted at a mall in an upscale neighborhood will not yield results that can be represented as the opinions of "typical” consumers for a particular product

\section{Volunteer sample}

- Interviewees choose to volunteer for the sample

- Using students who volunteer to complete a survey

- Posting a questionnaire on a popular website or social media platform and inviting responses

- Using a "call-in” survey on a TV or radio show

- People who volunteer for things usually have different characteristics from those of the general population (more education, higher intelligence, greater need for approval). This makes them unrepresentative of a larger group

- Impossible to generalize from these results to any larger group 


\section{Quota sample}

- Interviewers choose respondents based on prearranged categories of sample characteristics

- Setting out to interview 50 men and 50 women for a survey and considering the survey completed when those numbers have been reached

- Does not allow the pollster to measure the representativeness of any larger group

\section{Purposive sample}

- Interviewers select respondents from subgroups in the population in question because these subgroups have specific characteristics or qualities of interest

- At a grocery store interviewing only those people who say they eat yogurt and not administering the survey to any others

- Results can reveal the opinions of a specific subset, but cannot be representative of any larger group 


\subsection{Survey Sample Types: Probability}

Probability sampling methods, while more difficult, costly, and time-consuming, allow the survey researcher a much better chance of accurately choosing representative respondents. In fact, it is the only method that makes it possible to estimate the amount of error that the sample will produce.

The term "random sample" (referring to a sample that is constructed using probability sampling methods) can be confusing. "Random” does not mean haphazard. Instead, a random sample is set up systematically so that every member of the population being studied has an equal and non-zero chance of being included in the sample.

There are variations of random samples including:

- simple random sample

- stratified random sample

- disproportionate random sample

The key for your purposes is to recognize that a random sample based on a probability sampling method results in findings that are likely to be generalizable to the larger group, although several other factors, such as the wording of questions, must also be considered.

Even the most carefully selected random sample will never provide a perfect representation of the population being studied, however. There will always be some degree of error. That is called sampling error, the yardstick that measures the potential for variation between the survey responses and what the entire population might have answered if everyone had been questioned.

For instance, a poll might indicate that 41 percent of the adults polled had a positive opinion of your client company, while 43 percent had a negative opinion, and the rest don't have an opinion. The stated sampling error is plus or minus 4 percent. That means that those who feel positively may be as many as 45 percent or as few as 37 percent (41 plus 4 or 41 minus 4 percent). Those who feel negatively may be as many as 47 percent or as few as 39 percent. In other words, you can't draw any conclusions about the audience for your PR campaign for that client except to say that the opinions are evenly divided between the two camps. 


\subsection{Sample Size}

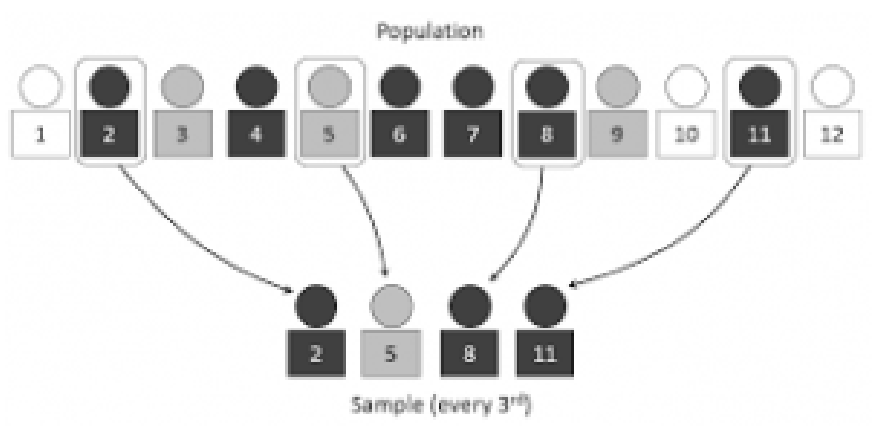

Dan Kernler - Systematic Sampling - CC BY-SA 4.0

percent) so that a larger sample size is not justified.

It is important for you to look for a stated sampling error in the results of any survey you may be contemplating using. Also, when a stratified random sample or a disproportionate random sample is used, the results may include an analysis of sub-samples, or responses from smaller groups within the larger sample. The margin of error for sub-sample results will always be larger than for the total sample, thereby requiring even more careful scrutiny to determine if differences in responses are real. For example, if a survey of 250 people shows results by region (Midwest, South, East and West), you should be cautious of these results. When the sample is divided in this way, recognize that only about 62 people represent each region in the sample - almost never a large enough sample to be truly representative of a particular region.
Several things determine the sampling error in a random-sample survey. One major factor is the size of the sample. A general rule is that the larger the sample, the smaller the sampling error. After a certain level, however, any increase in the sample size results in such a small decrease in the sampling error that it is not worth the effort to increase the size of the sample any further. This is why most major polling organizations use a random sample of between 1,200 and 1,500 respondents. That size sample results in a sufficiently small sampling error (between 2.4 to 3.4

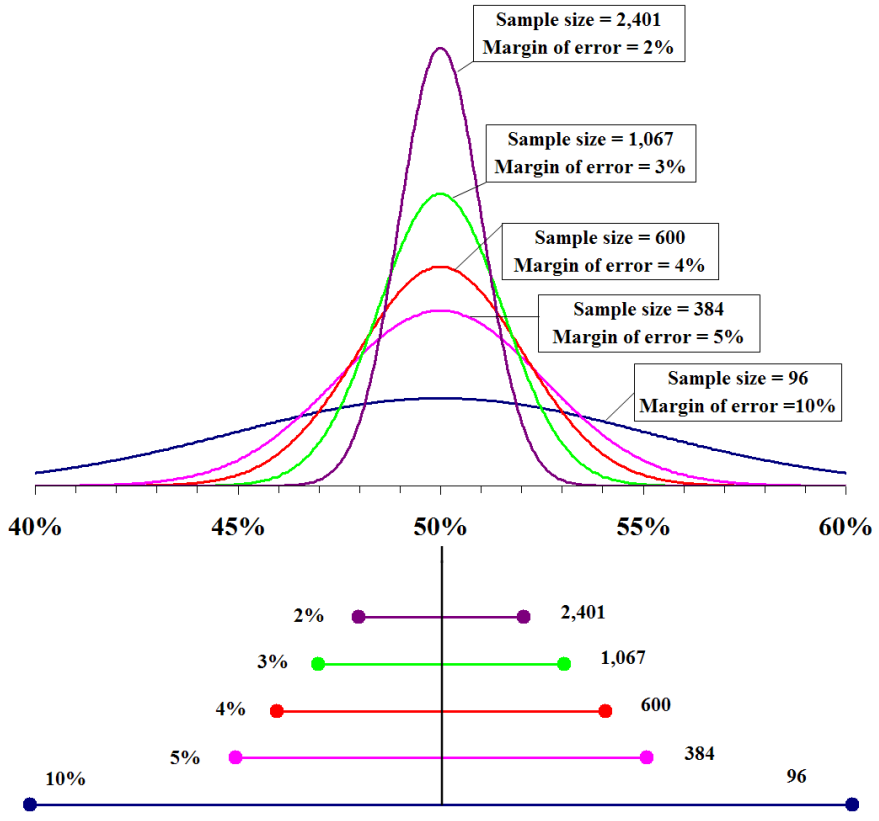

Image by Fadethree: Public Domain

Another factor determining sampling error is the level of confidence used with the analysis of the results. The level of confidence refers to the odds that the results of a specific survey are within the estimated sampling error range. In other words, if the survey were repeated, the researchers are 90 percent (or 95 or 99 percent) confident that they would get the same results within the same range of error. Again, confidence level increases as the size of the sample in a probability sample increases.

When you are evaluating the results from a poll that used a random-sample method, you should look for the statement of the sampling error and the level of confidence. If you see these figures, you can be sure the results 
are based on a probability sampling method. A common goal is to look for a poll with a sampling error of no more than plus or minus 5 percent at the 95 percent confidence level. If you are evaluating a poll with those kinds of figures, the data are likely to be more credible than those from a poll with higher sampling error and lower confidence levels. 


\subsection{Wording of Survey Questions}

The wording of questions is a major area of concern in constructing a questionnaire or evaluating someone else's survey. Question bias, clarity, length and construction can cause crucial differences in results from surveys. Closed-ended questions are the norm for most survey questionnaires.

- Questions should be clear, using everyday language and avoiding jargon.

- Questions should be short, thereby reducing the likelihood of being misunderstood, especially in telephone interviews.

- Questions should not ask more than one thing. An example of a double-barreled question might be: “This product is mild and gets out stubborn stains. Do you agree or disagree?” The respondent might agree with the first part of the statement, but disagree with the second.

- Questions should avoid biased words or terms. An example might be: "Where did you hear the news about the president's new tax program?” The word "hear" biases against an answer such as "I read about it online.” Instead ask, "Where did you learn the news...." There are even more insidious examples of bias in questions, a result of the survey sponsor's having an interest in seeing the survey produce a certain set of answers. Think about the difference between asking about "pro-choice" or "pro-life" opinions. Questions can be written to signal the respondent about exactly what the interviewer wishes to get as the "right" answer.

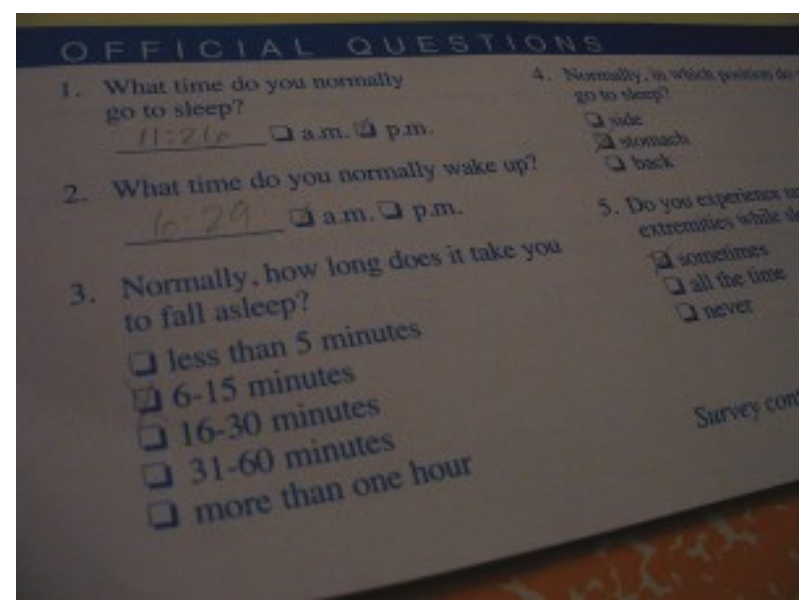

piratejohnny - Sleep survey - CC BY-NC-ND 2.0

- Questions should avoid leading the respondents' answers. For example, asking the question "Like most Americans, do you support the government's war on terror?” leads the respondent to think that if he or she answers "no," they are in an un-American group! Another example might be: "Do you believe, along with many others of good faith, that abortion is murder?” The leading question tells the respondent what the expected answer is.

- Questions should avoid asking for unusually detailed or difficult information. A detailed question might be: “Over the past 30 days, how many hours have you spent watching TV?” Most respondents would not be able to answer that question without considerable calculation. A simpler way of gathering the same information would be to ask, “About how many hours a day do you spend watching TV?”

- Questions should avoid embarrassing the respondent whenever possible. It is difficult to judge which 
kinds of questions will be embarrassing to every person, but some questions will embarrass almost everyone. For instance, questions about level of income are usually perceived as intrusive. In fact, many survey researchers put those questions at the very end of the questionnaire so that if the respondent is offended by the question, the rest of the interview is not spoiled.

- Questions should not assume knowledge on the part of the respondent. Many surveys include "filter questions" which help the interviewer decide whether that part of the questionnaire is pertinent to the respondent. For instance, the questionnaire might ask: "Have you purchased something online in the past month?” If the respondent says "no," then the questions that deal with the online purchase experience are best not answered by that respondent.

- Questions should avoid abbreviations, acronyms, foreign phrases or slang. Respondents are less likely to be confused when simple, familiar language is used. Also, certain slang phrases may connote some kind of bias on the part of the interviewer, which will influence the respondent.

- Questions should be specific about the time span that is implied. For instance, a question may ask about the respondent's approval or disapproval of a \$20 billion program for road and bridge improvement. Unless the question specifies the number of years over which the money will be spent, the respondent has no way to evaluate the program's impact and the answer given will be meaningless.

- Where appropriate, questions should attempt to gauge the intensity of feeling the respondent has about a topic. For instance, a question may ask for the respondent's preference for one product over another. Some respondents may not feel particularly intense about their preference for either, but just to be polite, they will give an answer. If an intensity question were included ("How strong is your preference for Product A?”), those who were less intense could indicate their ambivalence.

- Questions should avoid using a forced response strategy. Respondents should have the option to say "I don’t know” or "I don't have enough information to answer” to avoid the problem of respondents giving an answer, any answer, just to be polite. (Wimmer \& Dominick, 113-120) 


\subsection{Question Order in Surveys}

The order in which questions appear in the questionnaire can also affect the reliability of the results. Questions should be grouped together by topic and within topic to avoid confusion. The first few questions in a questionnaire are crucial in preventing termination of the interview and in relaxing the respondent. Questions asking personal characteristics (age, education level, income level) should come in the last section. Topic questions that are likely to be objectionable (asking about touchy subjects such as sexuality, religious beliefs or illegal behavior) should be placed just before the personal items at the end of the questionnaire.

Furthermore, try to evaluate how the order of the questions might have affected respondents' tendency to answer. For instance, a poll might ask about how much trust respondents have in the federal government. If the question is asked as a stand-alone question without any preceding "set-up” questions, you are likely to get a response that reflects Americans' general dislike of big bureaucracies.

However, if the question about trust in government is preceded by questions asking about trust in a number of programs that Americans generally support (Social Security, Medicare, environmental protection, programs to support wounded military veterans), the question about trust in the government as a whole would reflect a very different response. Respondents would have been reminded about the things that the federal government does that are generally supported, and hence their answer about trust in the government would be different than it would be by asking that one question in isolation. 


\subsection{Survey Interview Types}

Conducting a survey is a form of interviewing. However, the difference between a survey and a more traditional interview is that the "interviewees," or respondents in a survey, are generally anonymous and the results of the survey do not include individual identification of the "interviewees." Survey interviews represent an aggregation of information rather than a personalized accounting of the topic.

There are several methods used to gather survey data:

- face-to-face interview

- telephone interview

- self-administered (by mail or online) interview

Each has its advantages and disadvantages, and each poses evaluation problems for communicators who may wish to use the information from a survey as a way to help define an audience. 


\subsection{Face-to-Face}

Trained interviewers meet individually with the survey respondents and ask them the survey questions in person

\section{- Advantages:}

- longer and more complex questions can be accommodated

- questions that require the respondent to react to visual images can be asked

\section{Disadvantages:}

- labor costs for interviewer training is high

- transportation costs for interviewers’ travel to and from the respondents' locations are very high

- respondents are less and less likely to allow strangers into their homes so the completion rate is low

Evaluating face-to-face survey data: The following questions are important guides to determining the quality of the firm doing the survey and to the reliability of the information gathered by the survey:

- How were the interviewers selected?

- Were the interviewers chosen to avoid the bias of race, age, sex or other social factors that might limit respondents' comfort level in participating?

- How was the work of each interviewer checked?

- What instructions did the interviewers receive regarding the selection of respondents? 


\subsection{Telephone}

Trained interviewers call potential respondents on the telephone, often through random / automated dialing, and ask them a set of survey questions.

- Advantages:

- lower cost than face-to-face

- non-response rate is relatively low because interviewers can keep calling back until the respondent is home

- interviewers can collect a large amount of data in a short time.

\section{- Disadvantages:}

- some portions of the population do not have access to a telephone

- increasing numbers use a mobile phone

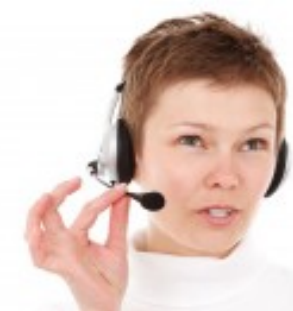
exclusively and FCC rules say that automated dialing to mobile phones is illegal

- many respondents are suspicious of telephone interviews, consider them a sales pitch

- long or complicated questions are inappropriate over the phone

- increasing numbers of people have put themselves on federal "do not call” lists that prohibit researchers from calling

\section{Evaluating telephone interview survey data:}

- Were the questionnaire and individual questions appropriately brief?

- Were the telephone banks staffed in a central location? (Telephone interviewers who work from home are subject to less supervision, obviously)

- What instructions were the interviewers given about who in the household they should interview? 


\subsection{Self-Administered}

A survey questionnaire is mailed to each member in the sample or is posted online, and respondents choose to fill it out and return it.

- Advantages:

- least expensive method because it takes fewer personnel to administer

- able to cover a wide geographic area

- allows anonymity to the respondents (which encourages candid responses)

- requires a less skilled staff to administer

\section{Disadvantages:}

- response rate is usually very low because respondents forget to respond, throw it out or delete it, ignore the request or fail to complete the questionnaire

- no way to know who filled out the questionnaire unless one of the questions specifically asks for that information. (For instance, a questionnaire intended for a corporate executive might be filled out by his or her secretary.)

- results may be skewed because only those people who were really interested in the topic of the survey took the time to fill out the questionnaire which introduces bias into the results.

- big issue with polls on a web page - if the population for a survey is only those people who visit a particular web page, then the people with an interest in that web page (and in the topic of the particular survey) will be overrepresented. Typically, these types of polls are conducted more for fun or to prompt reader interaction, but they are not at all scientific.

\section{Evaluating self-administered survey data:}

- What was the response rate? (The lower the response, the less reliable the results)

- Were follow-up questionnaires sent to those who failed to respond the first time?

- How self-explanatory were the instructions to the respondents?

- The self-administered questionnaire obviously does not allow the respondent to ask questions of the poll-takers, so clear instructions to the respondent are crucial. 


\subsection{Interpreting Survey Data}

Communicators are faced with a formidable task in evaluating and interpreting information generated from polls and surveys. In order to avoid some of the common pitfalls and mistakes that are possible when using survey data, you must ask important questions about how the survey was conducted, how the respondents were selected to participate, and how questions were worded and ordered.

Evaluating the results of a survey involves both statistical analysis and interpretive skill. The person who conducts and analyzes the survey data has great sway in determining how the data get interpreted. It is up to you to carefully critique any information based on a survey and apply stringent standards of evaluation. When you are considering using survey information, you should have the answers to the following questions:

1. Who sponsored or paid for this survey, and who conducted it? Serious bias can enter into a survey design if the sponsoring agency or the firm conducting the survey has a particular ax to grind.

2. Who was interviewed? What population was sampled?

3. How were people selected for the interviews? In other words, was it a probability or a non-probability sample? If a non-probability sample was used, the results cannot be generalized to a larger population.

4. How many people were interviewed? What was the size of the sample? Were the results categorized into specific sub-samples or subgroups and if so, what was the size of those smaller groups?

5. If a probability sample was used, what was the range of sampling error and the level of confidence for the total sample? What were those figures for any sub-samples?

6. How were the interviews conducted? Were they telephone, face-to-face or self-administered (mail or online) interviews? Were the interviewers trained personnel or volunteers? Were they supervised or working on their own?

7. What were the actual questions that were asked? What kind of response choices did respondents have (open-ended responses; pre-set choices). Experts know that when you ask questions about something that is potentially awkward or embarrassing, people over-report socially desirable behavior and under-report behavior that is considered antisocial. If the survey asks about topics such as sexuality or illegal behavior such as drug use, the results must be interpreted and reported upon with a great deal of caution.

8. What was the wording of questions? Were there biased, loaded, double-barreled, leading or ambiguous questions? Even individual words can influence results. Did the question ask about taxes or revenues? Welfare or assistance to the poor? Universal health insurance or managed health care?

9. When were the interviews conducted? The results of a survey are good only for the time at which the questions were asked. Surveys do not have any predictive value and cannot and should not be used to predict anything. For instance, a survey may ask respondents about their preferences for one candidate over another 
during a three-day polling window just before an election and the results may show that candidate A has a wide margin of support over candidate B. But some last-minute revelation about candidate A may change the atmospherics around the election, influencing the outcome and making the poll data irrelevant. Outside events always hold the potential to affect results of any survey. That is why surveys should never be used to predict anything. The results are good for just one point in time. 


\subsection{Cautions for Careful Communicators}

Media professionals should be aware of the pitfalls that come with using information generated by a survey. There are a number of legitimate critiques of the way media organizations use (or mis-use) survey data. They include:

- particularly around political elections, news organizations use opinion surveys to track only the horserace aspect of the race, crowding out more analytical and in-depth reporting about the substance of candidates' positions on the issues.

- news reports about survey results may actually affect public opinion or behavior; there are a number of documented instances where the use of a particular technique called an "exit poll” (asking people who they voted for as they leave the polling place) has resulted in a news organization declaring a victor in a national election before the polls have closed across the country, resulting in people waiting in line at the polling place leaving before casting their vote.

- marketing firms may interpret the results of a survey about consumer preferences in a way that suppresses innovation; how many people would have answered "yes" to the question about whether they wanted a camera in their mobile phone before such a thing became common place?

- advertisers use survey data in the actual content of the ads in a way that may be misleading or confusing; for example, an ad may say that " 2 out of 3 dentists recommend" a type of baking-soda toothpaste for healthier teeth and gums; the advertiser may have the survey results to substantiate that claim, but what the ad doesn't say is that the dentists also recommended flouride toothpaste, dental floss, and mouthwashes; and furthermore, the pollsters only interviewed 100 dentists.

In sum, the information generated by surveys conducted by the contributors to an information strategy can be enormously helpful to communicators. It is your responsibility to understand the appropriate uses, and limits, of these types of sources. 


\subsection{Endnotes}

Wimmer, R. D. and Dominick, J. (1983). Mass Media Research: An Introduction. Belmont, CA: Wadsworth. 


\section{Lesson 16. Message Tasks: Applying What You've Learned}

\section{KEY CONCEPTS}

- Communicators can follow an orderly process when approaching a new information task or message assignment.

- Communicators apply key skills to their information strategies, including searching, interviewing, evaluating information and managing and synthesizing what is located.

- Relevant information may be located from a variety of contributors and appear in a large number of forms.

\section{LEARNING OUTCOMES}

After completing this lesson you will be able to:

- apply the information strategy process to a variety of information and message tasks.

- assess the strengths and weaknesses of an information strategy as it has been applied to a particular type of information or message task. 


\subsection{Putting It All Together}

Over the course of the semester we've examined the steps a communications professional must take when trying to tackle a new information task or message assignment.

These steps, by of way review,

\section{THE INFORMATION STRATEGY MODEL}

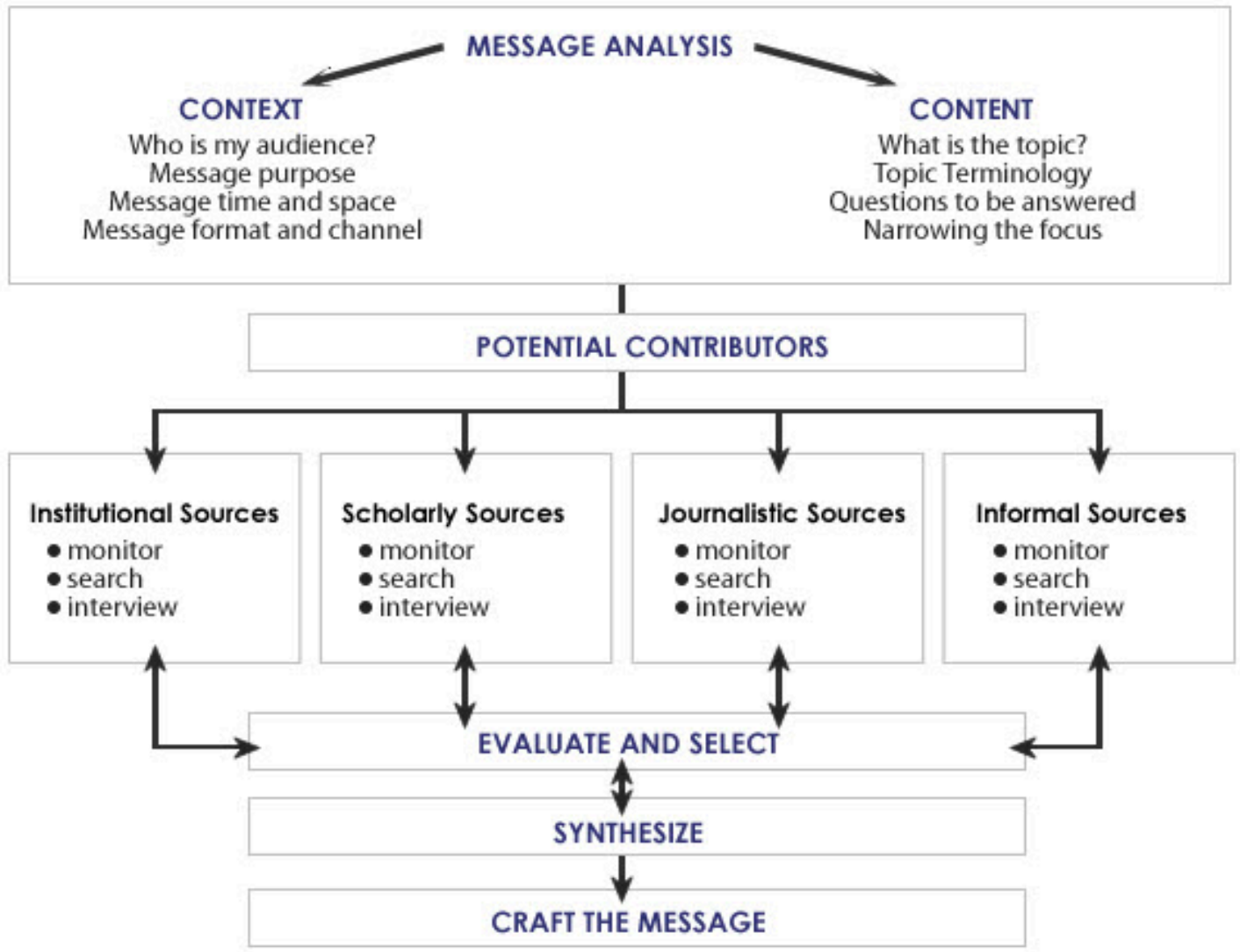

- clarify the parameters of the message assignment.

- identify potential audiences.

- generate ideas and bring focus to the topic.

- understand the variety of potential contributors of information.

- appreciate the ethical and legal considerations required. 
These first steps of the process will help you generate a set of questions or information "tasks" that you will need to perform in order to create the required communication message. Thinking about the potential contributors that could provide information to complete those tasks or answer the questions will get you started on the information strategy process. Knowing the ethical expectations and how to craft a message that meets legal standards will help guide you as you find and select information to use.

We've also discussed the key skills researchers must hone to be efficient and strategic in their information strategy tasks. These skills are:

- Searching: understanding how and where to locate both traditional repositories and databases of material and more esoteric or specialized resources, and constructing an effective search "equation" with appropriate keywords and utilizing search fields.

- Interviewing: finding and "vetting" people from a variety of contributor types who might have information, insights, or perspectives on whatever you are searching and developing the techniques to best engage and elicit helpful responses from them.

- Evaluating: knowing how to detect bias, misinformation, or unsubstantiated information you might find through searching or interviewing.

- Managing and Synthesizing: developing techniques for keeping track of the information you locate, methods for synthesizing key points or ideas to generate new insights, and criteria for selecting (or discarding) the information you find.

Finally, we've discussed the forms in which information appears. We've looked at the tools, techniques and special requirements for understanding and using information from:

- data and statistics

- polls and surveys

- public records

- periodical publications

Now it is time to apply all of these skills and use the suite of resources for specific kinds of information requirements. Here's how to apply all of these skills and resources. The following scenarios will step through the thinking process and track the information seeking path.

An information strategy is used throughout the message generation process. Here are the various stages at which communication researchers will need to locate information to complete the required tasks:

- Initial idea generation or project focusing

- Understanding the intended audience / who they are, what they do, where they are, how to reach them

- Understanding an unfamiliar topic 
- Finding information from various types of contributors using different information gathering skills

- Understanding what the information means and how to organize and synthesize it for your message task In this lesson we will work through several specific communication task scenarios and detail the thought processes and research strategy used when:

- analyzing the message needs

- clarifying the audience to address

- generating ideas and focusing on angles of a topic

- finding information on the topic / angle from a variety of types of contributors

- synthesizing and selecting material that was found 


\subsection{Freelance Magazine Scenario}

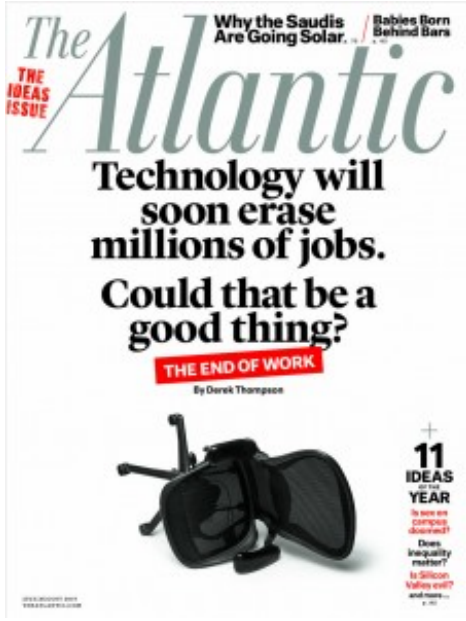

FREELANCE MAGAZINE SCENARIO: You are a freelance reporter and you've been interested in the use of drones, particularly as the market is growing for non-combat use of "unmanned aerial vehicles." You have a good contact at the Atlantic Monthly magazine and think you might be able to pitch a story to them.

Your task: what should you pitch, and how would you research the topic? 


\subsection{Journalism: Clarify Message Task}

You've identified the Atlantic as the magazine you want to target.

Questions to ask:

- How long are Atlantic articles?

- How much are freelancers paid?

- How do I submit a proposal?

- To whom should I submit a proposal?

Your questions are all about what a writer needs to know to sell their article. The Writer's Market is a reference work that all freelance writers should have. There is a fee but it is well worth having the "bible" for freelance writers. Here is the page about the Atlantic Monthly. Does it answer all your questions? Does it raise any new questions? (ie: What is a "kill fee” and why would you care?) 


\subsection{Journalism: Identify Audience}

You need to learn about both the "gatekeeper" audience (the editor to whom you want to pitch your story) and the magazine's target audience (the main concern of the editor.) Answering these questions will help clarify the orientation of the article you will pitch.

\section{Questions to clarify audience:}

- Which editor would actually read the pitch and decide? What can I learn about them?

Sometimes it is hard to know when the submission just goes to a general "pitch" box. But you can find the names by going to the magazine website. Find on the homepage where the key personnel are listed (hint: in this case it is referred to as the Masthead.) Links are provided to the editors' pages; in some cases they have a little biographical information. If they don't, it is worth checking on LinkedIn or Facebook to get a sense of their interests through posting (and it’s a good strategy to "like” or “connect” with them - people like to help out people who like them.)

- Who is the audience for the magazine? What would they be interested in? Are they highly educated?

A magazine's media kit is compiled to provide advertisers and media buyer information about the audience it would reach if they placed an ad in that magazine. Every magazine site will have a button called "media kit" or "advertise" that will give valuable demographic and psychographic information about the audience for that publication. Here is The Atlantic's media kit. 


\subsection{Journalism: Narrow Focus / Brainstorm Ideas}

Your broad topic of interest is "drones" - but what angle on this should you take? Given your knowledge of the Atlantic's audience, how do you start to zero in on potential ways to focus the topic?

\section{Questions to clarify topic focus:}

- What, if anything, has the Atlantic already written about drones?

Search the Atlantic's website. Scanning through the articles retrieved (what is a good search strategy?) will give you some ideas of things they have covered - and help you find some different angles.

- What are some of the angles on the topic of drones that others are writing about?

Do a quick check on Google News - scanning the headlines might give you insights on a new angle. And you'd want to stay up to speed on the topic, so set several Google Alerts on different aspects of the topic (drones and legislation, drones and public safety, drones and shopping)

- What are people saying about drones? What are their issues or concerns?

Social media sites are a great way to see new and emerging topics of discussion or concern. Go to Facebook and see if there is an interest group - and who is talking about it. Follow a Twitter hashtag (like \#drone or \#dronesforgood) 


\subsection{Journalism: Locate Information from Sources}

After brainstorming angles and understanding the interests of the Atlantic audience, you decide the use of drones for delivery services would be an interesting focus. As commercial firms from Amazon to local breweries and drug stores explore drone delivery, the regulatory or safety concerns this raises would be great topic for Atlantic readers.

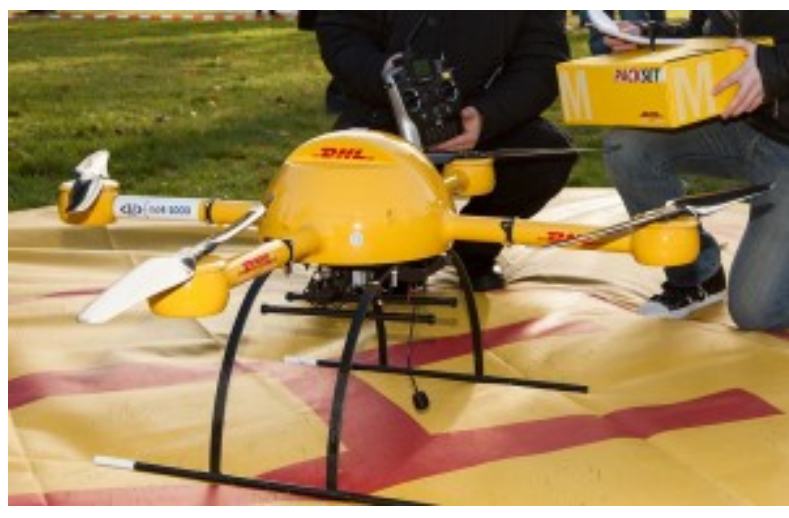

Frankhöffner - Package copter microdrones - CC BY-SA
Now you need information. You develop a set of questions that could be answered with information from a variety of potential contributors. There are many ways to do this kind of brainstorming and if you have a very specific question, thinking through what kind of agency or organization would be likely to have information or data or expertise on that specific question is the logical first step.

For example, if you want to know what the outlook is for the drone industry, you might want to find a public sector agency that generates industry outlooks and see what they have published. Check the government search engine

USA.gov for drone manufacturing and you get a report published by the Congressional Research Service on UAS manufacturing trends.

But if your specific question is "how many accidents have there been from the use of drones?" it would be logical to think about which agency is likely to track that sort of information. At the national level it would be the Federal Aviation Administration. You do a search on drone accidents at faa.gov and the second item looks perfect: A Summary of Unmanned Aircraft Accident / Incident Data. Sadly, on further examination, you see that it doesn't pass the recency or relevance tests of evidence. But you have identified the likely agency for this kind of information - so it might be time to pick up the phone and make a call to see if you can locate someone who knows about those types of records and ask for the most recent version of the report.

At the beginning stages of the information strategy, sometimes you are better off with imagining the kinds of information that different contributors could offer - and the sort of questions they can answer. Here's how that brainstorming might look for this particular topic:

Public Sector Institutions: government agencies could provide answers to questions about drones and unmanned aerial vehicles (UAVs) related to:

- Economy: Bureau of Labor Statistics, Department of Commerce: census of business and manufacturing, specific financial information about companies in the drone business, employment outlook for the industry

- Safety: Federal Aviation Administration, Department of Transportation, Homeland Security: concerns about usage, creative uses of drones (for traffic regulation or monitoring road conditions) 
- Regulation: Department of Justice, State Legislatures: laws regulating use can be handed down at different levels of government

- Technology: National Technical Information Service: technical reports

A good strategy for finding public sector sources that might have information to gather or experts to interview is to look through the directory of government agencies.

Private-Sector Institutions: You've decided your angle is the regulation of drones for commercial use. Clearly, you would want to identify some commercial enterprises that would be affected. Researching the background of this angle provides stories about a drug store in San Francisco, a brewery in Minnesota, and the mega-online store Amazon as having used, or wanting to use, drones to deliver products. Going to the corporate sites for QuiQui, Lakemaid Beer, and Amazon would provide answers to questions about their use of drones - and more importantly, the names of people you might want to interview.

On the non-profit side, talking to people in advocacy groups or organizations with concerns about the use of commercial drones can help fill in questions about the different perspectives on the issue that should be considered. These are often good places to check for backgrounders or "white papers" on the topics of most interest to those associations.

Do a search in Google for drones and association - look at their websites to see issues they cover. For a more authoritative source on associations, check the Associations Unlimited database (found on the UMN library website.)

Scholarly: Conducting a search for scholarly articles in the Business Source Premier database using the search equation ("drone aircraft" OR “unmanned aerial vehicles") NOT war, you locate a number of relevant articles. One that appeared in Computer Law and Security Review is titled "Drones: Regulatory challenges to an incipient industry,” and the abstract of the article sounds like it is a good fit for your needs. A challenge with using scholarly sources can be deciphering the specialist language they use in their writings. For journalists, it can be better to find sources to interview - scholars will speak more conversationally than they will write. In the Lesson on Interviewing we talked about sources for locating scholars to interview. In this case, you would read the article and then contact the author, David Wright, for an interview.

Journalistic: News articles are essential sources for other journalists - not only to find out what has been covered but also to see the types of sources that have been used. You'll want to search one of the news archives services such as Google News (if you only want recent stories) or LexisNexis for broader coverage. In this case, however, you also find that journalists themselves are interesting sources of information because many of them want to use drones in their news work. So, journalistic sources are not only fodder for background and places to cull for good sources to find, they are also sources themselves. You might want to contact the Professional Society of Drone Journalists http://www.dronejournalism.org/

Informal Sources: If you are writing about how drones for commercial or non-military use are being regulated, you'd want to find some "just folks" to represent the impact of regulation. You'll need to brainstorm the kinds of people you would want to hear from: people who use drones for fun, those concerned about drones flying over their neighborhood, people who have been injured by a drone, people who can't wait to have their latest purchase from Amazon dropped on their doorstep. Locating informal sources might mean finding specific people who have 
posted on social media sites (look for tweets or pages related to drones) or it might be posting a "call” for comment on these sites and seeing what kinds of response you get. Reading the comments on articles you found through journalistic sources might lead you to interesting informal sources to interview.

Search tip: A term like “drone” has multiple related terms and different ways different disciplines will refer to the term. Take care when searching to try different versions (drone, UAV, UAS, Unmanned Aerial Vehicle...)

As you can see from this scenario, there are many steps and hundreds of information sources that could help with this message task. We are just scratching the surface of what you would actually need to do to prepare this type of story pitch to the editors of The Atlantic. 


\subsection{Crisis Communications Scenario}

You work as a Communications Manager for the American Wind Energy Association (AWEA), the trade group that represents the country's wind energy industry. An article appears in the Journal of Raptor Research that reports on the results of a study by the U.S. Fish and Wildlife Service. The study found that wind energy facilities have killed at least 85 golden and bald eagles between 1997 and 2012_and that eagle fatalities possibly may be much higher. The study also indicated that eagle deaths have increased dramatically in recent years as the nation has turned increasingly to wind farms as a source of renewable, low-pollution energy, with nearly 80 percent of the fatalities occurring between 2008 and 2012 alone.

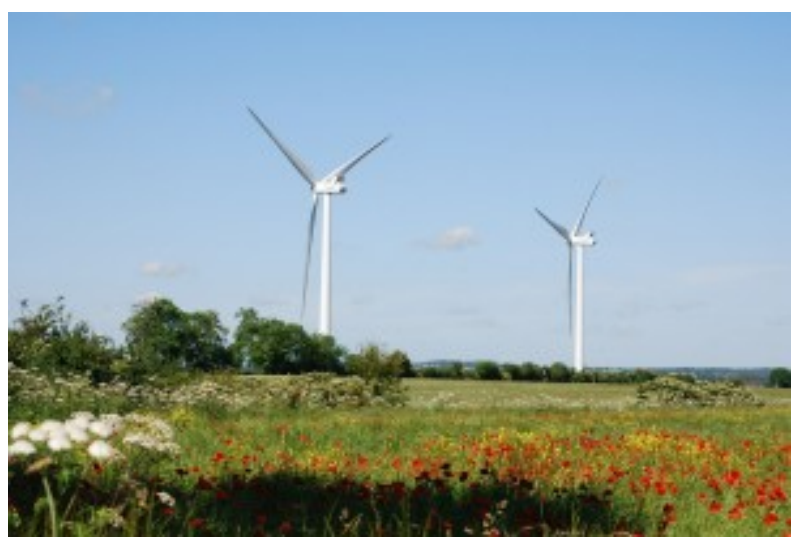

Your Executive Director (ED) asks you to prepare the Association's response to the questions and requests for comment that are certainly going to be pouring in as the results of the study start to gain public awareness. You need to get up to speed quickly on the topic of bird mortality due to wind energy facilities. Let's look at how you would prepare to respond to this "crisis."

stevebidmead - Wind Turbines - CCO 


\subsection{PR: Clarify Message Task}

Your discussion with the Executive Director would include seeking the answers to these questions:

- Does the ED want to issue a statement to the media on behalf of the AWEA?

- If yes, should that be in the form of a news release, a news conference, a streaming web conference, something else?

- Does the ED want to consider posting something on the AWEA's website as part of the response?

- If yes, you need to determine "best practices" for how to do this effectively.

- Does the ED want to provide "talking points" to the industry members of the AWEA so they know how to respond if they get questions? How should those "talking points" be distributed most effectively?

- Similarly, should the AWEA communicate with other stakeholders with an interest in the work of the AWEA? What form would that take? 


\subsection{PR: Identify Audience}

Once you clarify the types of messages and the communications strategy your ED wants you to pursue, you need to determine the audiences who will be targeted. This leads to another set of questions:

- Which media outlets should we target with our news releases/news conference/web conference messages? Are we trying to reach media organizations that produce news and information for the general public or for specialist audiences? Who are those specialist audiences?

- What will our industry members need to have in the "talking points" material we create for them? We need to anticipate their information needs since our mission is to help association members be effective advocates for the wind power industry as well as succeed in their individual business endeavors.

- Who are the other stakeholders we might target with our response? Our partner organizations and associations at the state and national level? Regulators at the state and national level who govern our industry? Bird enthusiasts who oppose wind turbines? Environmentalists who care about both renewable energy AND wildlife protection? Researchers inside and outside the government who study bird mortality and wind power?

- Once we know which stakeholder audiences we want to address, how can we best reach them with our messages? 


\subsection{PR: Narrow Focus / Brainstorm Ideas}

Based on your discussions with the ED, you start to brainstorm some of the ways you might address the message task. Again, you identify some questions that can help you focus on the right angle.

- Aside from this one study, what do we know about bird mortality caused by wind energy facilities and who has studied the issue?

- What else kills birds and how does that compare with avian deaths from wind turbines?

- What are our member industries doing right now, if anything, to reduce bird mortality?

- How does energy production using other methods affect wildlife and how does that compare with wind energy production?

- What regulations are in place that our industry members must follow to protect birds? How are we doing with compliance? 


\subsection{PR: Locate Information from Sources}

Here is just a tiny sample of the information contributors you could tap and the information they might provide to help you focus your messages.

\section{Public-sector Institutions}

The Department of the Interior, U.S. Fish and Wildlife Service Wind Energy Guidelines provide detailed specifications for the way wind energy facilities must operate, including ways to reduce bird and other animal mortality. You might suggest posting a link to these guidelines on the AWEA's website and include some narrative about the ways your members are complying with the regulations. You might also include this document and some of the data about compliance to your association members as part of their "talking points" material. This document could also be shared as part of a news conference or in any statement your ED might issue to the media.

\section{Private-sector Institutions}

The National Academy of Sciences, a widely-respected, private-sector, non-profit organization, conducted a study about other causes of bird mortality in addition to those caused by the wind power industry. It appears from this study that bird mortality from other causes is much greater than bird deaths from wind power facilities. You might, once again, consider posting a link to this study on the AWEA's website, compose some narrative that summarizes the findings of the study and make sure any public statements or "talking points" include the results. At the same time, you need to be sure that you don’t minimize the concern for bird mortality rates caused by wind power.

The National Wind Coordinating Collaborative is a private-sector, non-profit organization with partners from the wind industry, science and environmental organizations, and wildlife management agencies. They did a study of wind-wildlife interactions that summarized a huge amount of scientific and scholarly data and produced a fact sheet that outlines how the wind power industry and environmentalists are responding to the issue. This document would clearly be part of your information package.

\section{Scholarly Sources}

Conducting a search in Google Scholar using the search statement "bird mortality from wind energy" uncovers hundreds of scholarly studies done in the U.S. and around the world. The general consensus appears to say that there is a clear link between wind turbines and bird mortality, but there are lots of caveats in the findings.

One article in the scholarly journal Biological Conservation shows that bird mortality is greater with a type of wind turbine that is being phased out (lattice vs. monopole); that taller monopole turbines may pose more risk of raptor bird mortality than shorter monopole turbines because raptors fly at a higher elevation than song birds (the usual victims of wind turbines), but that the blades on taller monopole turbines turn at a slower rate than the blades on shorter turbines so those risks may offset one another. Again, the data from studies such as this one would need to be summarized and included in any messages you generate.

\section{Journalistic Sources}


A search for journalistic coverage of this issue turns up thousands of news stories, including recent reports about offshore wind farms that pose fewer risks to birds than land-based turbines. Many news stories have been written about opposition to wind farms because of concerns about wildlife mortality, and there is state and local-level opposition as well as national-level concern. At the same time, editorials supporting wind energy as an alternative to the more harmful effects of other types of energy production have appeared in a number of newspapers in communities where the issue is of particular concern. This might suggest a list of news organizations you would want to target for your news releases since you know they have written about the issue and are open to a nuanced approach to the problem. You could also create a Google Alert on the topic so you would be notified whenever a new news story appears.

\section{Informal Sources}

You would want to monitor social media chatter about the most recent raptor mortality/wind power study and pay attention to those individuals and groups who seem to be most influential or have the largest followings. You could create a set of alerts on the most popular social media sites to be notified whenever there are new postings. You could then decide whether or not to respond based on the type of information in the postings or the likely impact of the messages. Additionally, you might suggest that the AWEA reach out to the most vocal individual opponents of wind energy (you would be able to generate a list of their names from the news stories you found) and incorporate their perspectives and concerns into your responses where appropriate. 


\subsection{PR: Synthesize the Information}

The information you locate from a variety of contributors appears to show that there is definitely a problem with bird mortality and wind energy. At the same time, the wind power industry, private-sector institutions, publicsector institutions and scholars are working on ways to lessen the impact. Also, the potential danger to animal life from wind-power appears to pale in comparison to the danger posed to ALL life from other forms of energy generation (climate change due to rising CO2 levels, strip coal mining, fracking, oil pipeline construction through wildlife habitat, deep water oil drilling, etc.).

You would want to be sure that your message strategy does not minimize the harm to birds, but also points out the efforts being taken by the industry to address the problems with newer technologies, additional precautions, changes in turbine sitings (offshore rather than on land), compliance with existing and emerging regulations and related initiatives.

The message strategy you might propose to your Executive Director would include recommendations to include these types of arguments, with plenty of links and references to the information and evidence you have located, in any public comments, website content, news releases, "talking points" documents, and related messages to address the immediate "crisis" and to address longer-term communication needs for the association. 


\subsection{New Advertising Pitch Scenario}

Let's say that you are working on a new business pitch for a possible advertising client. A new business pitch is the presentation and supporting documentation that an agency prepares to show to a prospective client in an effort to win that advertiser's business.

\section{UNITED}

The company whose advertising account you would like to win is United Airlines. The airline currently works with McGarryBowen advertising agency but since the merger with Continental Airlines, the company is considering other options for their advertising business.

The agency for which you work has not had a commercial airline account in the past so the first task in your preparation of the new business pitch is to get up to speed quickly on the passenger airline industry.

\section{Questions to pose:}

- What is the overall economic health of the passenger/commercial airline industry?

- Who are the main players - the airline companies, the aircraft manufacturers, the regulators, the workers' unions, the customers, the other stakeholders? What perspective or position does each player take on the industry?

- What does airline advertising look like? Who is advertising, where do the ads appear, what do the ads say, how effective are the ads?

- What restrictions and regulations, if any, govern advertising for this industry?

- Who comprises the largest and most lucrative group of airline travelers? In other words, who are airlines trying to reach with their ads? 


\subsection{Advertising: Locate Information from Sources}

Depending on the questions you need to answer, there is a vast array of potential sources of information. Following is a sampling of the contributors that would have relevant information and the kinds of information you could find.

\section{Private-sector institutional sources:}

- associations that are important for that industry (Airlines for America, Airline Passenger Experience Association, etc.)

- trade journals that discuss the most recent news and trends for that field (Aviation Week, etc.)

- financial records that detail the industry's economic health from the company itself and from financial analysts who monitor the industry

- unions that represent the workers in that field (Airline Pilots Association, Association of Professional Flight Attendants, Transport Workers Union, etc.)

- demographic data that describe the customers for that industry's products/services and the audiences for its ads

- syndicated research service reports about airline advertising

\section{Public-sector institutional sources:}

- court records that document the interactions the company and competitors in the industry have had with the U.S. justice system

- government records that document regulation of the industry (Federal Aviation Administration reports, Occupational Safety and Health Administration reports, etc.)

- government records that provide insight into the financial health of the industry (Bureau of Transportation Statistics reports)

- government records about consumer complaints about the industry (Aviation Consumer Protection agency reports which are housed in the U.S. Department of Transportation)

\section{Scholarly sources:}

- experts who can speak authoritatively about the commercial airline industry

- experts who can speak about the effectiveness of advertising in that industry 


\section{Journalistic sources:}

- news operations that write about the industry or are published in towns where key companies in that industry operate

\section{Informal sources:}

- social media pages where people talk about that industry and its products/services

Once you have a good understanding of the industry overall and the types of advertising that are typical for companies in that sector, you can start to search for specific information about United Airlines, the company for which you are preparing the new business pitch.

\section{Again, you would identify a number of important questions to answer:}

- How does United stack up against its competitors?

- Is the company financially sound?

- Does the company have a "unique selling proposition”?

- Who are United's current customers and what do customers think about United?

- What do relevant workers' groups think about United? (pilots, flight attendants, baggage handlers, air traffic controllers, aircraft manufacturers, etc.)

- What have United's ads looked like in the past? To whom were they targeted? Where did the ads appear? Were they effective?

- How much has United spent on advertising in the past?

- Who should we propose that the airline target with their advertising? Business travelers, families, retirees, customers currently flying with other airlines or those who are traveling by other means, etc.?

\section{A tiny sample of what you could find:}

\section{Private-sector institutional sources}

- United's own demographic data about customers

- United's corporate information

- McGarryBowen’s advertising work for United

- Google Finance’s compilation of public-sector and private-sector data about the company

- Customer ratings for United produced by other organizations 
330 Information Strategies for Communicators

- Syndicated research services reports about ad spending for United; this would tell you where United ads are currently appearing and would help you identify the audiences that are currently being targeted with the advertising

\section{Public-sector institutional sources}

- Securities and Exchange Commission annual reports for United

- Air Travel Consumer Reports from the U.S. Department of Transportation

\section{Scholarly sources}

- scholars who have studied the company specifically

- scholarly studies about airline customer satisfaction that include United’s rankings

\section{Journalistic sources}

- news stories about United in general

- business journalism reports about United as a company and an investment

- journalistic reports about United’s advertising

\section{Informal sources}

- United's social media accounts

- Other social media accounts that discuss United

- FlyerTalk and related blog posts about United

After reviewing the information you have found, you have learned that United is doing well financially but their customer satisfaction ratings are at the bottom of the heap and their current advertising campaign, which resurrected the 30-year-old slogan "Fly the Friendly Skies," has been widely ridiculed as ineffective and downright misleading. Especially after the airline's horrendous treatment of a passenger forcibly removed from a United flight in spring 2017, the company has a major PR problem. The company has simmering labor problems with its workforce (dissatisfied pilots, flight attendants, airplane mechanics, etc.) and a public image problem as a large, impersonal corporate behemoth after its merger with Continental. 


\subsection{Advertising: Synthesize the Information}

Synthesizing all of this information, you would want to focus your brainstorming about a possible new advertising direction on a recommendation that the company reposition itself away from the claim about customer satisfaction because it cannot live up to that promise, especially after the fiascos of customer mistreatment in 2017. You and your advertising colleagues would want to identify other possible unique selling propositions on which the company could actually deliver (more non-stop routes to popular destinations, newer aircraft, more hubs, etc.) and be sure that any advertising claims could be clearly demonstrated and backed-up by the reality of the company's performance.

Furthermore, you would want to examine in more detail the specifics of different audiences for the advertising - what appeals would work better with business customers vs. leisure travelers, etc.? If you find that the airline could have better results by targeting a subset of its customers with its new advertising rather than producing a general audience ad campaign, that is where you would focus your news business pitch.

The new business pitch to United's decision-makers presents an opportunity for you and your advertising agency colleagues to demonstrate your command of the facts about the airline industry overall and the relative position of United Airlines within that industry. It also provides an opportunity for you to generate creative and effective suggestions for ways the company could improve its advertising and its public image. 


\subsection{So What and Who Cares?}

All of the scenarios and examples we've provided here are intended to give you concrete insights into the way the information strategy process works for real-life communications message tasks. Internalizing the process will prepare you for the work you will do in the rest of your coursework and your career in journalism or strategic communication. 


\section{Change Log}

\section{August 16, 2017}

- Fixed links throughout the textbook

- 8.3 - E\&P Yearbook now called the E\&P Newspaper Data Book

- 8.11 - Star Tribune website is in upper LEFT hand corner now

- 8.13 - SEO link is now dated 2016

- 14.7 - Radian6 is now Salesforce Social Studio

- 14.18 - Fixed spacing in notes

- 16.13, 16.14 and 16.15 - updated text in light of United Airlines’ recent PR problems

- 10.6 - added some brief material that touches on the topic of "fake news."

\section{October 8, 2018}

- Upgraded to Pressbooks version 4.9.8, hosted through Unizin 